Overcoming Central Nervous System-barriers by the development of hybrid

structured systems for nose-to-brain drug delivery using clean technologies

Vanessa Santos Silva Gonçalves

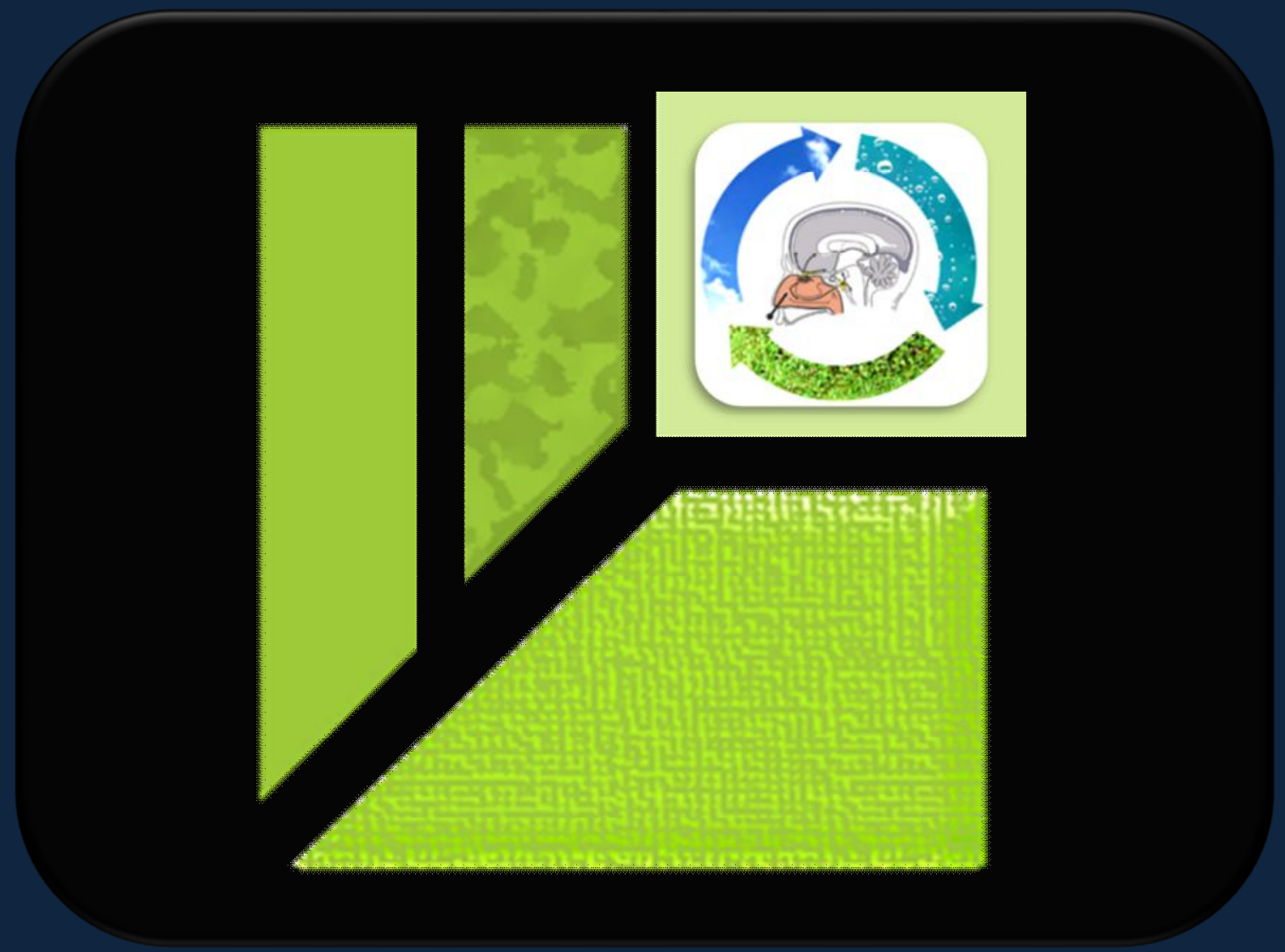

Dissertation presented to obtain the Ph.D. degree in Engineering and Technology Sciences, Pharmaceutical Technology

Instituto de Tecnologia Química e Biológica António Xavier | Universidade Nova de Lisboa

Oeiras,

September, 2016

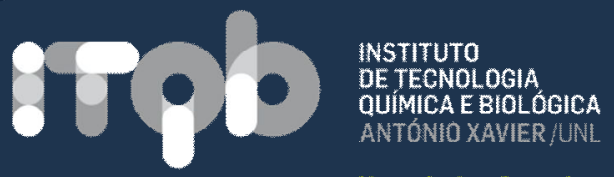

Knowledge Creation

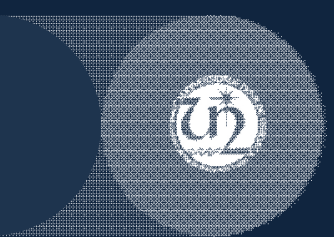





\section{Overcoming Central Nervous System-barriers by the development of hybrid structured systems for nose-to- brain drug delivery using clean technologies}

Vanessa Santos Silva Gonçalves

Dissertation presented to obtain the Ph.D. degree in Engineering and Technology Sciences, Pharmaceutical Technology

Instituto de Tecnologia Química e Biológica António Xavier | Universidade Nova de Lisboa

Oeiras, September, 2016 



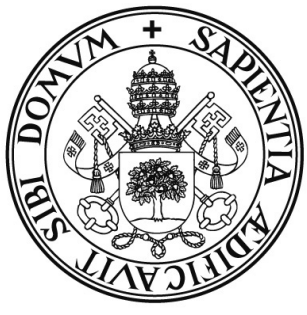

\section{Universidad deValladolid}

ESCUELA DE INGENIERÍAS INDUSTRIALES

DEPARTAMENTO DE INGENIERÍA QUÍMICA Y TECNOLOGÍA DEL MEDIO AMBIENTE

\section{TESIS DOCTORAL:}

\section{OVERCOMING CENTRAL NERVOUS SYSTEM- BARRIERS BY THE DEVELOPMENT OF HYBRID STRUCTURED SYSTEMS FOR NOSE-TO-BRAIN DRUG DELIVERY USING CLEAN TECHNOLOGIES}

Presentada por Vanessa Santos Silva Gonçalves para optar al grado de

Doctora en Ingeniería química y ambiental por la Universidad de Valladolid 

International Ph.D. degree - Co-tutorship between Universidade Nova de Lisboa and Universidad de Valladolid

Title

Overcoming Central Nervous System-barriers by the development of hybrid structured systems for nose-to-brain drug delivery using clean technologies

- Dissertation presented to obtain the Ph.D. degree in Engineering and Technology Sciences - Pharmaceutical Technology (Instituto de Tecnologia Química e Biológica António Xavier - Universidade Nova de Lisboa); Supervisor: Dr. Catarina Duarte; CoSupervisor: Dr. Ana Matias

- Dissertation presented to obtain the Ph.D. degree in Chemical and Environmental Engineering (Universidad de Valladolid); Supervisor: Dr. Soraya Rodriguez-Rojo

\section{Author}

Vanessa Santos Silva Gonçalves

Nutraceuticals and Delivery Laboratory

Instituto de Tecnologia Química e Biológica António Xavier

Universidade Nova de Lisboa / Instituto de Biologia Experimental e Tecnológica

Av. da República

Estação Agronómica Nacional

2780-157 Oeiras, Portugal

High Pressure Processes group

Departamento de Ingeniería Química y Tecnología del Medio Ambiente

Escuela de Ingenierías Industriales - Sede Mergelina

Universidad de Valladolid

Valladolid 47011, Spain 


\section{Cover Image}

Design by Vanessa Santos Silva Gonçalves

First Edition, August 2016

Copyright (C) 2016 by Vanessa S. S. Gonçalves

All rights reserved

Printed in Portugal 
I declare that the work presented in this thesis, except where otherwise stated, is based on my own research. The work was mainly performed in the Nutraceuticals and Delivery laboratory of Instituto de Tecnologia Química e Biológica António Xavier (ITQB), Universidade Nova de Lisboa / Instituto de Biologia Experimental e Biológica (iBET) between April 2012 and May 2016, and supervised by Doctor Catarina Duarte (ITQB-UNL/iBET), Doctor Ana Matias (ITQB-UNL/iBET) and Doctor Soraya Rodríguez-Rojo (UVa).

Part of the results was attained during visiting periods to High Pressure Processes group, Departamento de Ingeniería Química y Tecnología del Medio Ambiente, Universidad de Valladolid, Spain, and to the Thermal Separation Processes, Hamburg University of Technology, Hamburg, Germany.

Financial support was provided by Fundação para a Ciência e a Tecnologia through the doctoral fellowship SFRH/BD/77350/2011.

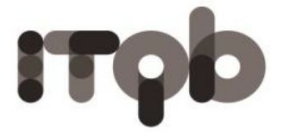

INSTITUTO

DE TECNOLOGIA ANTÓNIO XAVIER/UNL

Knowledge Creation

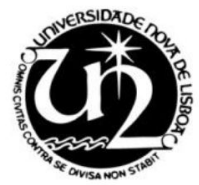

Instituto de Biologia

Experimental e Tecnológica
Fundação para a Ciência e a Tecnologia
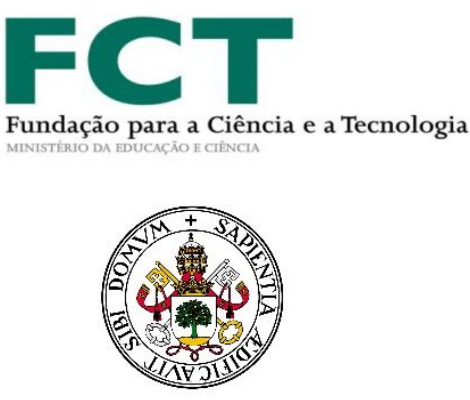

Universidad deValladolid 

Ao meu pai e à minha mãe...

"Our parents love us because we are their children and this is an unalterable fact, so that we feel more safe with them than with anyone else. In times of success this may seem unimportant, but in times of failure it affords a consolation and a security not to be found elsewhere."

\section{Bertrand Russell}





\section{Acknowledgments}

"Coming together is a beginning; keeping together is progress; working together is success."

\section{Henry Ford}

Às minhas orientadoras, Doutora Catarina Duarte, Doutora Ana Matias e Doutora Soraya Rodriguez-Rojo, por todo o apoio e orientação cientifica, pelos conhecimentos transmitidos e por me terem ensinado a ser "cientista". Obrigada Catarina, por ter acreditado em mim e nesta tese, por todos os conselhos científicos (e pessoais...) e por todos os momentos bons e maus que passamos juntas. Sim, porque também se aprende algo nos momentos menos bons, e a sua garra e perseverança são um exemplo a seguir!! Obrigada Ana, por me teres entregue este teu projeto $\mathrm{N} 2 \mathrm{~B}$, por teres estado presente mesmo quando tinhas mil e uma coisas ao mesmo tempo e pela ajuda na recta final com as minhas amigas "células". Obrigada Soraya, pela orientadora que foste para todos nós em 2012 (na antiga unidade piloto), pelos conhecimentos e conselhos que proporcionaste!!! A tua presença foi, sem dúvida, um excelente motor de arranque para esta tese!!! Obrigada também pela "mãe" que foste para mim em 2014, sempre pronta a ajudar, por me teres integrado tão bem na vida e cultura "vallisoletana"!! Não me esqueço, por exemplo, de me teres ido buscar para o almoço dos Reyes para que não estivesse sozinha nessa data tão especial para vocês!!

A todos os meus colegas de doutoramento e comparsas de aulas no ITQB, foram sem duvida um primeiro suporte para o que aí vinha...muitas noitadas, pizzas no instituto e neurónios queimados enquanto tentávamos escrever e apresentar 
trabalhados cujos temas não dominávamos de todo!!! Aprendemos desde cedo a evitar o "streetlight effect" ;)

Aos meus colegas de laboratório que se tornaram amigos para a vida...

Cátia, Agostinho e Daniel...a minha "piloto", dos momentos que mais tenho saudades!! Vanessa...Cátia Vanessa (private joke!!) Começámos juntas, ajoelhadas a esfregar o chão da "piloto" (e a "roubar" sonasol) e vamos acabar isto praticamente juntas cada uma com o seu canudo!! Obrigada por todos os conselhos que me deste, a partilha de experiências profissionais e pessoais! Obrigada por seres quem és, pela pessoa sensata e de coração cheio sempre pronta a ajudar os outros!! Um agradecimento enorme ao Agostinho que me aturou (e eu a ele) desde o primeiro dia de aluna "supercrítica"... um palhacito autentico que animava aquele pedaço de laboratório com as suas cantorias e devaneios, mas atenção, palhacito de coração cheio que estava lá sempre para ajudar no que fosse preciso (os "fittings", as fugas, as sondas, a falta de força para lidar com equipamentos de alta pressão).. És um filho de uma grande "patite"! Ao palhacito numero dois, Daniel Deo Deo, um especial obrigada por me teres apresentado o nosso amigo em comum PGSS :P A todos os bons momentos que passámos juntos, quer no laboratório, quer nas festas dentro e fora do ITQB, "tanto beto, tanto beto"!...até nos maus momentos, com os stresses no laboratório, conseguias sempre fazer sorrir as pessoas com esse teu jeitinho alentejano. Saca! Ao Victor e Rut que chegaram e animaram aquela piloto uma vez mais, un besito especial! (:) “Victorino, los cafés"!!!

Agradeço também a ti, Sara, por todo o apoio que me deste enquanto la estiveste, foste a primeira pessoa a falar comigo nos corredores do ITQB, sempre bemdisposta e com algum conselho a dar! À Joana, um muito obrigada pela paciência ao ensinar-me a "mexer nas células", ao muito trabalho e dedicação que sempre depositaste nos desafios que te dava, aos copos de vinho, gargalhadas e sorrisos que partilhamos! À Ana Nunes, a eterna menina do cabelo apanhado, a "faz tudo" 
do laboratório, um muito obrigada pela paciência que tiveste ao ensinar-me o belo do ORAC ou outros "be-a-bás" científicos! À Teresa, um agradecimento especial por todas as dicas "celulares", trocas de conhecimento, apoio e amizade! Agradeço ainda à Liliana, ao Mário, à Inês, à "Maia”, à Maria João, Luis e restantes nutracêuticos pela presença, ajuda e conhecimentos trocados!

A todos mis colegas y amigos de Valladolid... “¿Qué pasará, qué misterio habrá?”... Han sido muchos los momentos inolvidables que he pasado ahí. ¡Vos echo de menos desde que he salido de Valladolid! iMe han acariñado desde el primero día, han sido 9 meses de fiesta, de amistad, y claro, trabajo y de entreayuda en el laboratorio!!! Gyuri... thank you for being always present...Not only during work: quercetin nightmares, coffee time (your favorite), conferences with stressful oral presentations, HPLC pump's thieves, etc, etc..but also after work, always presenting us with good hungarian food (out of date chocolates and chorizos), good dance moves (without t-shirt) and, most importantly, your true friendship! Like I once said, it was a pleasure to meet you!! Joaninha e Ricardo, obrigada por me fazerem sentir um pouco mais perto de casa quando as saudades apertavam, pelos muitos almoços, lanches, jantares, passeios, festas, etc, que partilhámos juntos! iA Gian Luca y Sergio, por todos los momentos juntos y todas las risas que me han sacado! A Marta, por toda la amistad y conocimiento que me ha dado. A Reinald, que ha sido mi primero (y muy bueno) koala. A todos los otros: Rut, Ana Moño, Álvaro Sastre y Cabeza, Alberto, Victor, Núria, Yoana, Célia, Gerardo, María, Maria José (la "otra"), Sandra, LuisMi y Miriam... iMuchas Gracias por tantos y tantos momentos juntos: vinos merinos, santa válvula, fiestas, tapas, ...! Por fin, de una forma especial quiero agradecer a Prof. Maria Jose Cocero por toda la dedicación y ayuda que siempre ha tenido comigo. 
I would like to acknowledge Dr. Irina Smirnova, head of Thermal Separation Processes group, Hamburg University of Technology (Hamburg, Germany) for the possibility to carry out research collaboration in her group. I would specially like to thank Dr. Pavel Gurikov for all the knowledge, kindness, advices and support provided during the development of aerogel microparticles.

A todos os meus amigos, de longa data e mais recentes, agradeço o facto de preencherem a minha vida e de me terem ajudado a não me tornar um rato de laboratório sem qualquer vida social!

Ao Ricardo...o meu aliado, amigo, namorado, companheiro... por me teres acompanhado desde o primeiro dia do doutoramento. Por teres compreendido os meus momentos menos bons, por teres sido o meu "saco de pancada"... por teres compreendido as minhas ausências, quer físicas quer mentais...por me apoiares nos momentos bons e maus, por teres suportado as minhas deslocações e esperado sempre por mim! Obrigada por seres quem és e por estares ao meu lado!

Aos meus pais... mesmo sem perceber bem o que fiz durante estes mais que quatros anos, estiveram sempre lápara me apoiar...e é tão bom ver o orgulho nos vossos rostos sempre que contava um pouquinho das minhas vitórias pessoais! Obrigada por terem dedicado a vossa vida a mim! 
President

Thesis Supervisors

Thesis Examiners to be defined

Dra Catarina Maria Martins Duarte, Scientific Researcher at Instituto Tecnologia Química e Biológica António Xavier, Universidade Nova Lisboa, Portugal

Dra Soraya Rodriguez-Rojo, Scientific Researcher at Grupo de Investigación en Procesos a Alta Presión, Departamento de Ingeniería Química y Tecnología del Medio Ambiente, Universidad de Valladolid, Spain.

Dra Concepción Domingo Pascual, Scientific Researcher at CSIC, Dept. Estado Sólido / Supercritical Fluids, Instituto de Ciencia de Materiales de Barcelona, Spain.

Dr António J. L. das Neves Almeida, Cathedratic Professor at Tecnologia Farmacêutica, Faculdade de Farmácia, Universidade de Lisboa, Portugal.

Dr Manuel Nunes da Ponte, Cathedratic Professor at Faculdade de Ciências e Tecnologia, Universidade Nova de Lisboa, Portugal.

Dr Carlos A García-González, Scientific Researcher at Farmácia e Tecnoloxía Farmacéutica, Facultade de Farmácia, Universidade de Santiago de Compostela, Spain. 



\section{Contents}

Overcoming Central Nervous Systembarriers by the development of hybrid structured systems for nose-to-brain drug delivery using clean technologies 



\section{Abstract}

The effective delivery of therapeutics into the brain is challenging since drugs or drug delivery systems (DDS) candidates are not able to cross the blood-brain barrier (BBB), making the development of new drugs alone not enough to ensure progresses in Central Nervous System (CNS) drug therapy. Due to several problems related with other routes of brain drug administration, the interest has increased towards exploring the possibility of intranasal administration. The nose-to-brain transport and the therapeutic viability of this route have been investigated for rapid and effective transport of drugs to CNS, but the development of nasal drug products for brain targeting is still faced with many challenges. Nasal to brain delivery requires solid-based particulate formulations capable to provide drug deposition in the olfactory region and prolonged residence time with high local drug concentration. Face to this, core-shell or layered solid particles that combine different carrier materials could be considered an attractive alternative to single carriers, which still present limitations. There are several conventional techniques to produce hybrid delivery systems, however, these have many post-processing steps, are time-consuming and use organic solvents.

The goal of this dissertation was to use Supercritical fluid (SCF)-based precipitation and drying technologies to produce hybrid particulate structures with improved features for efficient nose-to brain drug administration.

Particles from gas saturated solutions (PGSS ${ }^{\circledR}$ ) technique, a precipitation method that avoids completely the use of organic solvents, was explored in this thesis to prepare novel hybrid particles such as Glyceryl monoolate (GMO): glycerolipid structured lipid particles and Gelucire $43 / 01^{\mathrm{TM}}$ core- polyethylene glycol (PEG) 4000 shell particles. Structured lipid particles developed in this thesis presented increased storage stability, higher encapsulation efficiency and fast release of model drug (ketoprofen) with higher drug permeation through a mucous- 
membrane model (Strat-MR membrane impregnated with mucin) in comparison with single glycerolipid particles. Another PGSS ${ }^{\circledR}$ application was the precipitation from a $\mathrm{CO}_{2}$-saturated $\mathrm{O} / \mathrm{W}$ emulsion with ketoprofen, constituted by Gelucire $43 / 01^{\mathrm{TM}}$ as the discontinuous phase and an aqueous solution containing PEG 4000 as continuous phase, that led to the development of novel hybrid particles constituted by lipid multicores involved by the polymeric shell. Fundamental research was essential to be performed before each PGSS ${ }^{\circledR}$-precipitation work. The production and application of hybrid biopolymer aerogels as carriers for noseto-brain delivery of drugs was also explored and investigated in this thesis. Low methoxyl pectin and $\mathrm{k}$-carrageenan were co-gelled with alginate and further dried with supercritical- $\mathrm{CO}_{2}$, yielding spherical mesoporous microparticles with high specific surface area and mucoadhesive properties. Drugs with different polarities were successfully loaded in amorphous state, presenting a fast release from the polysaccharide matrix.

The purpose of this thesis was not only to show the versatility of SCF technology in the development of hybrid particles but also to preliminary evaluate their application as effective DDS for nose-to-brain administration. Thus, structured lipid particles and aerogel formulations were evaluated in terms of cytotoxicity and drug permeation using RPMI 2650 as human nasal epithelial cell line model. None of the solid formulations showed cytotoxicity, whereas aerogel microparticles exhibited the highest permeation-enhancing effect compared to the pure model drug, which can be attributed to the mucoadhesive characteristics of the carrier materials, being this the most interesting formulation for nasal drug delivery.

The data presented throughout these chapters clearly show that the endless combination of polymers and/or lipids using SCF methodologies allows the development of new delivery systems for more efficient and sustainable nose-tobrain delivery of drugs. Due to the promising data and innovative results obtained in this dissertation, it is possible that the sustainable technologies used allied with 
the hybrid approach could play an especial role as pharmaceutical technology alternatives in the future. 


\section{Publications, Oral and Poster presentations}

\section{Publications in peer reviewed journals (5)}

- RPMI article - accepted major revision

- Vanessa Gonçalves, Joana Poejo, Ana Matias, Soraya Rodriguez-Rojo, Maria Jose Cocero, Catarina Duarte: Using different natural origin carriers for development of epigallocatechin gallate (EGCG) solid formulations with improved antioxidant activity by PGSS-drying. RSC Advances (2016); 6(72):67599-67609 DOI:10.1039/C6RA13499H

- Vanessa Gonçalves, Pavel Gurikov, Joana Poejo, Ana Matias, Stefan Heinrich, Catarina Duarte, Irina Smirnova: Alginate-based hybrid aerogel microparticles for mucosal drug delivery. European Journal of Pharmaceutics and Biopharmaceutics (2016); 107:160-170. DOI: 10.1016/j.ejpb.2016.07.003

- Vanessa Gonçalves, Ana Matias, Soraya Rodriguez-Rojo, Isabel Nogueira, Catarina Duarte: Supercritical fluid precipitation of ketoprofen in novel structured lipid carriers for enhanced mucosal delivery - A comparison with solid lipid particles. International Journal of Pharmaceutics (2015); 495(1):302-311. DOI:10.1016/j.ijpharm.2015.08.026

- Vanessa Gonçalves, Soraya Rodriguez-Rojo, Esther de paz, Cristina Mato, Angel Martin, Maria Jose Cocero: Production of water soluble quercetin formulations by pressurized ethyl acetate-in-water emulsion technique using natural origin surfactants. Food Hydrocolloids (2015); 51:295-304. DOI:10.1016/j.foodhyd.2015.05.006

- Vanessa Gonçalves, Soraya Rodríguez-Rojo, Ana Matias, Ana Nunes, Isabel Nogueira, Daniela Nunes, Elvira Fortunato, António Alves de Matos, María José Cocero, Catarina Duarte: Development of multicore hybrid particles for drug 
delivery through the precipitation of $\mathrm{CO}_{2}$ saturated emulsions. International Journal of Pharmaceutics (2015); 478(1):9-18.

DOI:10.1016/j.ijpharm.2014.11.003

Book chapters (1)

- Vanessa Gonçalves, Catarina Duarte: Development of Hybrid Structured Particles Prepared through PGSS ${ }^{\circledR}$ Process. Supercritical Fluid Nanotechnology: Advances and Applications in Composites and Hybrid Nanomaterials (2015); Edited by Concepcion Domingo Pascual, Pascale Subra-Paternault, chapter 7, Pan Stanford, ISBN: 9789814613408

Oral presentations in international scientific conferences (5)

- Vanessa Gonçalves, Liliana Rodrigues, Joana Poejo, Pavel Gurikov, Ana Matias, Irina Smirnova, Catarina Duarte: Novel alginate-chitosan aerogel fibers for potential wound healing applications,. 8th International Conference and Exhibition on Pharmaceutics \& Novel Drug Delivery Systems, Madrid, Spain; 2016

- Vanessa Gonçalves, Soraya Rodriguez-Rojo, Joana Poejo, Ana Matias, Catarina Duarte, Maria José Cocero: Development of epigallocatechin gallate (egcg) solid formulations by PGSS-drying. ECCE 10 + ECAB 3 + EPIC5, Nice, France; 2015

- Vanessa Gonçalves, Soraya Rodríguez-Rojo, Ángel Martín, Maria José Cocero: Development of water soluble formulations of quercetin by high pressure emulsion technique. XXII International Conference on Bioencapsulation, Bratislava, Slovakia; 2014

- Vanessa Gonçalves, Joana Poejo, Ana Matias, Isabel Nogueira, Catarina Duarte: Encapsulation and precipitation of aqueous natural hydroxytyrosol-rich 
concentrate into a solid lipid matrix through PGSS ${ }^{\circledR}$. 14th European Meeting on Supercritical Fluids, Marseille, France; 2014

- Vanessa Gonçalves, Ana Matias, Isabel Nogueira, Catarina Duarte: Production of Mucoadhesive Hybrid Lipid-Based Drug Delivery Systems Containing Glyceryl Monooleate Through Supercritical Fluid Precipitation Technology. 6th International Symposium on High Pressure Processes Technology, Belgrade, Serbia; 2013

Poster presentations in international scientific conferences (9)

- Vanessa Gonçalves, Pavel Gurikov, Joana Poejo, Ana Matias, Hélder Vila-Real, Catarina Duarte, Irina Smirnova: Alginate-based hybrid aerogel microparticles as new drug delivery systems. 10th World Meeting on Pharmaceutics, Biopharmaceutics and Pharmaceutical Technology, Glasgow, Scotland; 2016

- Vanessa Gonçalves, Esther Paz, Daniel Deodato, Oscar Benito Roman, Soraya Rodriguez-Rojo, Teresa Moreno, Ana Matias, Angel Martin, Hayley Every, Marisa Sanz, Catarina Duarte, Maria Jose Cocero: Grape marc polyphenols encapsulation in natural origin carriers by high pressure and supercritical fluid techniques, ProSCiba 2016, Viña del Mar, Chile; 2016

- Vanessa Gonçalves, Pavel Gurikov, Joana Poejo, Ana A. Matias, Catarina M.M. Duarte, Irina Smirnova: Alginate-based hybrid aerogel microparticles as new carriers for drug delivery. AAPS Annual Meeting 2015, Orlando, EUA; 2015

- Vanessa Gonçalves, Victoria Saprina, Joana Poejo, Liliana Rodrigues, Pavel Gurikov, Ana Matias, Natalia Menshutina, Irina Smirnova, Catarina Duarte: Alginate-chitosan aerogel fibers with antimicrobial properties for potential wound healing applications. IX Internacional Forum on Advances in Pharmaceutical Technology - CISDEM, Santiago de Compostela, Spain; 2015 
- Víctor Martín, Vanessa Gonçalves, Soraya Rodriguez-Rojo, María José Cocero, Catarina Duarte: Copper Loaded Lipid Microparticles by PGSS. The 11th International Symposium on Supercritical Fluids, Seoul, Korea; 2015

- Teresa Moreno, Ana Matias, Ana Alvarez, Esther de Paz, Vanessa Gonçalves, Daniel Deodato, Yolanda Gil, Rut Romero, Oscar Benito, Soraya Rodriguez-Rojo, Angel Martin, Rafael Mato, Catarina Duarte, A Guadarrama, Hayley Every, Maria Jose Cocero: Extraction and formulation intensification processes for natural actives of wine. Primo simposio internazionale sulla valorizzazione dei sottoprodotti vitivinicoli per il settore alimentare, Pavia, Italy; 2015

- Teresa Moreno, Ana Alvarez, Esther de Paz, Vanessa Goncalves, Soraya RodriguezRojo, Angel Martin, Rafael Mato, Maria Jose Cocero: Extraction and formulation intensification processes for natural actives of wine. Hungarian National Conference on Supercritical Fluids, Budapest, Hungary; 2015

- Vanessa Gonçalves, Soraya Rodríguez-Rojo, Ana Matias, Catarina Duarte, Maria Jose Cocero: Supercritical antisolvent precipitation of hybrid carriers for intranasal drug delivery. 14th European Meeting on Supercritical Fluids, Marseille, France; 2014

- Vanessa Gonçalves, Ana Matias, Isabel Nogueira, Daniel Deodato-Lopes, Catarina Duarte: Development of Hybrid Particles for Mucosal Drug Delivery through Green Precipitation Technology. 9th World Meeting on Pharmaceutics, Biopharmaceutics and Pharmaceutical Technology, Lisbon, Portugal; 2014 
Thesis Layout

\section{Chapter 1 - Introduction}

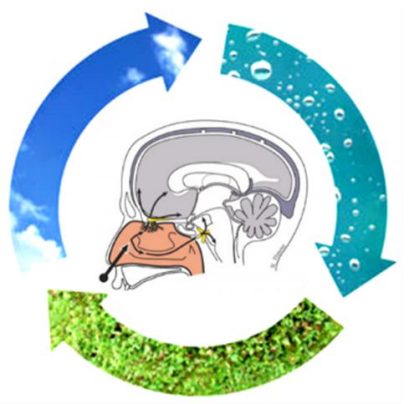

Overview of the state of the art, background and general concepts which fall within the thesis' scope.

Chapter 2 - Part I: Glycerolipids-Based Particles Produced by PGSS ${ }^{\circledR}$

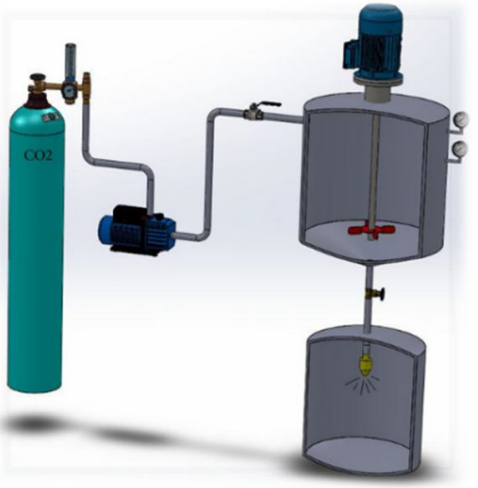

Production of solid lipid particles by PGSS $^{\circledR}$ technique with evaluation of process parameters effect on the size and morphology of the precipitated solid lipid particles.

Chapter 2 - Part II: Development of structured lipid carrier systems containing glyceryl monooleate through PGSS ${ }^{\circledR}$

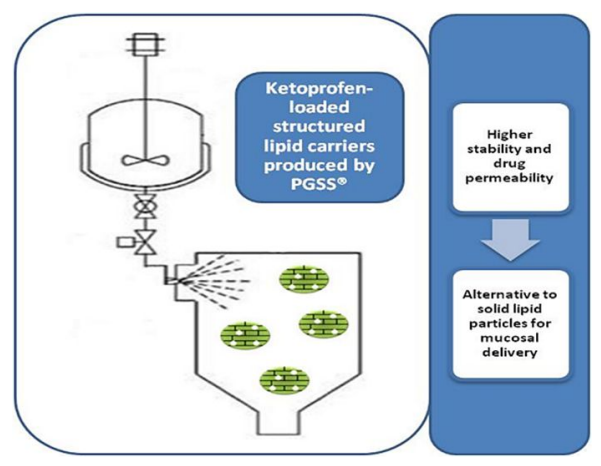

Structured solid lipid carriers composed of glyceryl monooleate and solid glycerolipids, were produced by PGSS ${ }^{\circledR}$ for the first time. 
Chapter 3 - Development of multicore hybrid particles for drug delivery through the precipitation of $\mathrm{CO}_{2}$ saturated emulsions

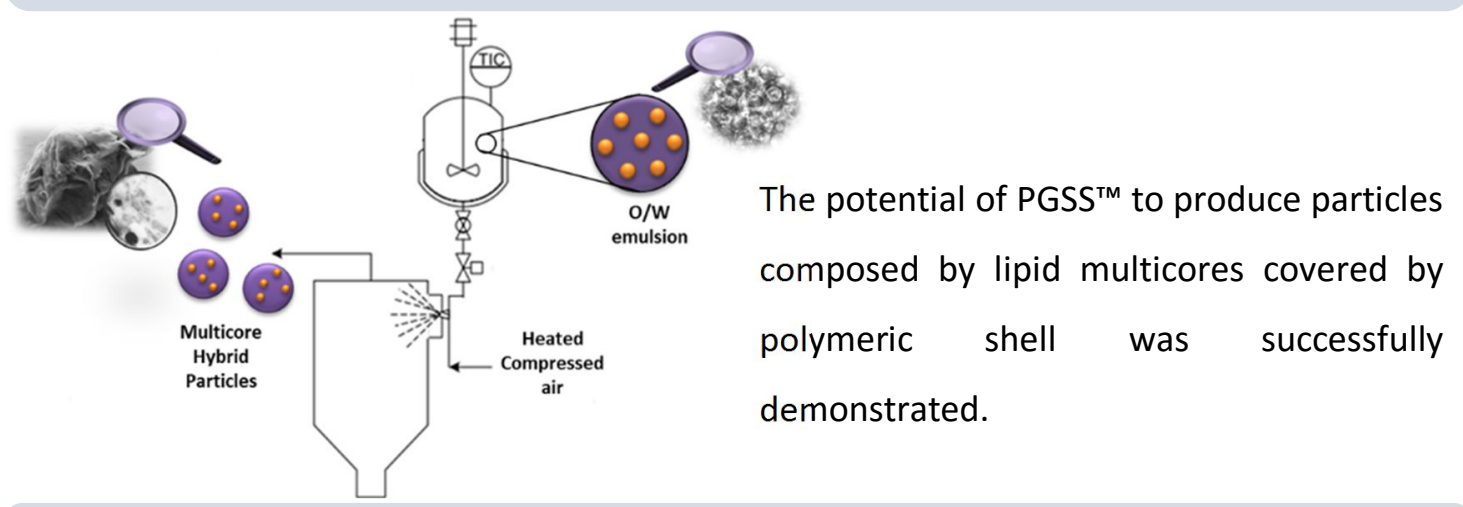

Chapter 4 - Alginate-based hybrid aerogel microparticles

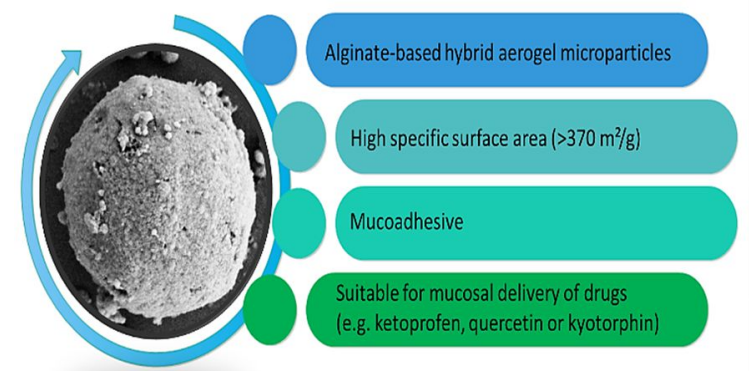

Alginate-based hybrid aerogels in the form of microparticles were investigated in this work as carriers for mucosal administration of drugs.

\section{Chapter 5 - Application of RPMI 2650 as a cell model to evaluate} solid formulations for intranasal delivery of drugs

Human nasal epithelial cell line RPMI 2650 Air-Liquid interface culture

Drug-loaded microparticles

808080

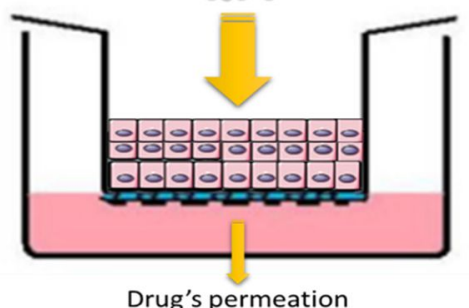

Investigation of RPMI 2650 cell line as an effective alternative to animal tissues for solid drug-loaded formulations cytotoxicity and permeation studies 
Chapter 6 - Concluding Remarks \& Outlook

The key achievements and conclusions are highlighted herein. Possible challenges and perspectives for future research are also presented. 



\section{Thesis Guidelines}

This Ph.D. thesis is divided into six chapters. Chapter 1 introduces the context and motivation at the start of this PhD project, general concepts on the barriers between the blood and central nervous system and nose-to-brain delivery of drugs, as well as a revision of the state of the art focusing on the use of hybrid particles and supercritical fluid technology. This chapter contains essential information for understanding the subsequent chapters enclosed in this thesis and contains sections already published in a book chapter.

This dissertation focus on designing hybrid particles for nose-to-brain delivery through two different approaches: the first makes use of supercritical fluid precipitation-based technique, namely PGSS ${ }^{\circledR}$, for the preparation of microparticles (Chapter 2 and 3), while the second takes advantage of supercritical carbon dioxide ethanol drying capacity for the preparation of hybrid aerogel microparticles (Chapter 4). In Chapter 5 is described the further development of RPMI 2650 nasal cell line as a valid tool to mimic human nasal mucosa, using it subsequently to evaluate the hybrid microparticles produced in previous chapters as efficient drug delivery systems for nose-to-brain administration. Ultimately, in Chapter 6, the main conclusions are reported and discussed in an integrated way. Some perspectives for future research are also presented.

Taking into consideration that this is a published article-based Ph.D. thesis, each chapter (from Chapter 2 - Part II to Chapter 5) includes an introduction that reviews the state of the art, contains the materials and methods section, presents and discusses the results, revealing the key conclusions of that particular work. Moreover, this thesis does not contain general list of figures and/or symbols since figure captions, symbols or abbreviations are carefully identified and described in each chapter. The sequence of chapters provides the reader with a view of the steps required during pharmaceutical development of drug delivery systems: from fundamental studies necessary to perform before the production of particles to the 
particles' development and further in vitro evaluation of its efficiency as nose-tobrain drug delivery systems. 


\section{Chapter 1}

\section{Introduction}

1. Barriers between the blood and the central nervous system ...........3

2. Nasal delivery of drugs to the brain........................................................ 6

2.1. Nasal anatomy .............................................................. 6

2.2. Pathways and mechanisms ................................................... 8

2.3. Nose-to-brain drug delivery ............................................ 10

2.4. Strategies to enhance intranasal delivery of drugs to the brain formulation of compounds ................................................................. 11

3. Hybrid particles - An emergent formulation approach ................... 17

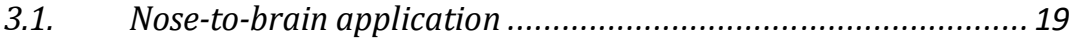

3.2. Characterization of hybrid particles...................................... 20

4. Supercritical fluid technology applied to the production of hybrid drug delivery systems........................................................................... 25

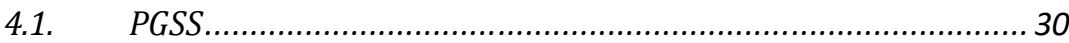

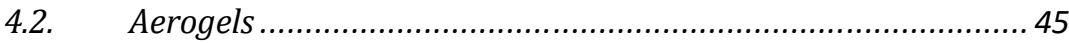

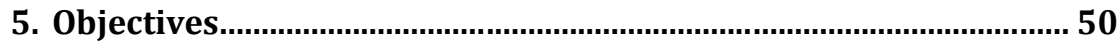

6. Thesis outline.................................................................................... 51

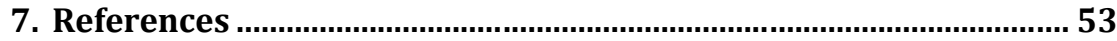


Sections 3 and 4 contain parts of the author's publication: Gonçalves, V.S.S., Duarte, C.M.M. (2015) Development of Hybrid Structured Particles Prepared through PGSS ${ }^{\circledR}$ Process. In: Pascual, C.D., Subra-Paternault, P. (Eds.), Supercritical Fluid Nanotechnology: Advances and Applications in Composites and Hybrid Nanomaterials. Pan Stanford. 


\section{Barriers between the blood and the central nervous system}

Despite intense research efforts, the delivery of active pharmaceutical ingredients (APIs) to the central nervous system (CNS) and cerebrospinal fluid (CSF) remains one of the major challenges tackled by the pharmaceutical industry ${ }^{1-3}$. Therefore, the treatment of neurological diseases (brain tumors, neurodegeneration, infectious diseases) is being compromised due to drugs' difficulty in crossing the blood-brain barrier (BBB), which is localized at the level of the endothelial cells and separates brain interstitial fluid (ISF) from blood, and the blood-cerebrospinal fluid barrier (BCSFB), which separates CSF from the choroid plexus interstitial fluid (CP ISF) ${ }^{3-8}$. In fact, when the delivery of exogenous molecules for treatment into the CNS is desired, these barriers prevent $98 \%$ of small-molecules and an even greater percentage of large molecules from reaching their intended targets, especially polar substances such as peptides or proteins ${ }^{2}$.

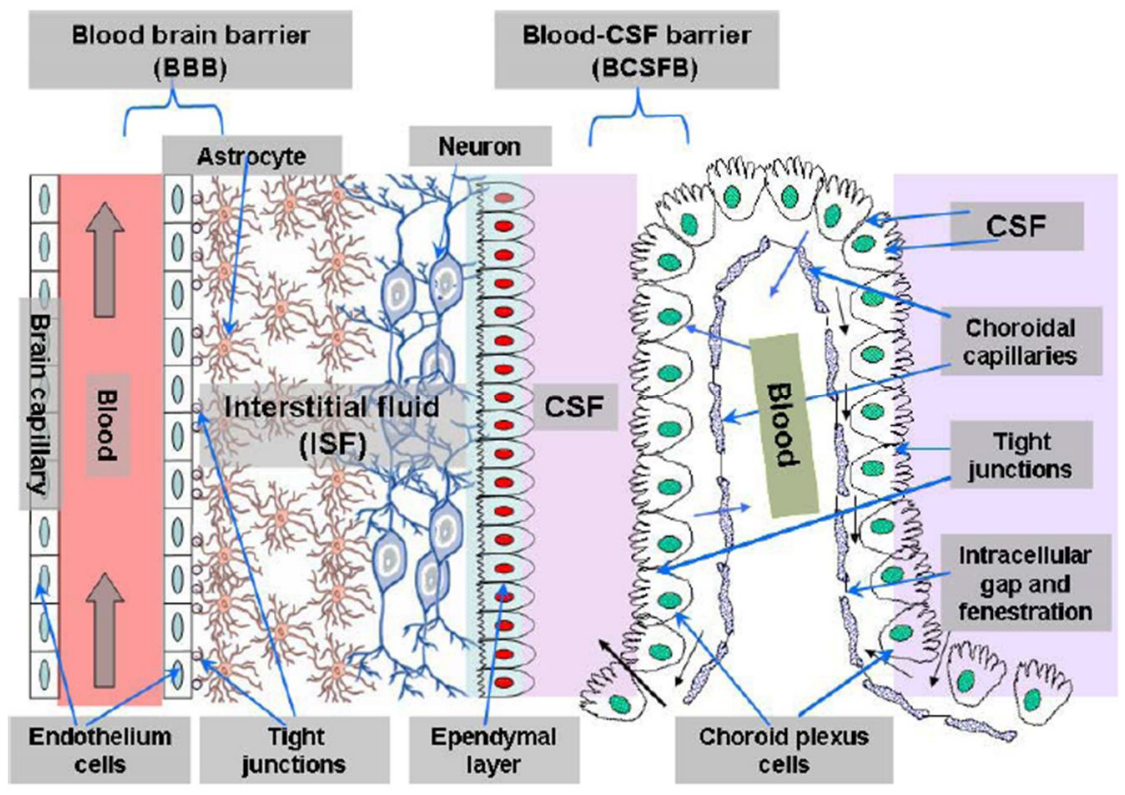

Figure 1| Overview of the two main barriers in the CNS. BBB - Blood-brain barrier; BCSFB - bloodcerebrospinal fluid barrier; ISF - interstitial fluid; CSF - cerebrospinal fluid. ${ }^{3}$ 
In figure 1 it is possible to observe an overview of the BBB and BCSFB structural composition. Blood-brain barrier separates the blood flowing through the circulatory system from the brain interstitial fluid and neurons, being composed of microvascular endothelium cells, basement membrane and neuroglial structures such as astrocytes, pericytes and microglia ${ }^{2,3}$. The monolayer of microvascular endothelial cells lines and the intraluminal space of brain capillaries are packed close together, forming tight junctions composed by transmembrane proteins, being an effective block to aqueous diffusion between the cells ${ }^{9,10}$. Since the bloodbrain barrier acts as a shield by protecting the brain from polar harmful substances in order to maintain the brain homeostasis, the endothelial cells of the cerebral capillaries must maintain a high level of expression of transporters for essential nutrients and metabolites (glucose or aminoacids) in order to facilitate their entry into the brain ${ }^{2,10}$. The presence of specific drug efflux transport systems that actively remove APIs and macromolecules form endothelial cells also limit the efficacy of neuronal treatment ${ }^{11}$. Moreover, besides the structural integrity of the $\mathrm{BBB}$, it is present an enzymatic surveillance system that is capable to metabolize drugs or other compounds that overcome the structural barrier ${ }^{9}$. The bloodcerebrospinal fluid barrier is the second important feature of the CNS, considered more 'leaky' than BBB, and being formed by two components. The first component separates the blood from the CSF and is formed by the choroid plexus, a complex neuroendocrine structure where the CSF is made, providing passive and active transport and perhaps even hormonal activity for the $\mathrm{CSF}^{3}$. The other component of this barrier separates the CSF from the brain extracellular fluid and neurons, being formed by arachnoid membrane, the cells of which are lined by tight junctions ${ }^{2}$.

Despite their physiological functions, these vital barriers prevent an efficient delivery of API's to the CNS and even if they can get into the cerebral compartment, their half- life is limited by fluid turnover, efflux transporters or metabolism. Thus, 
several strategies can be applied to enhance drug transport across brain barriers ${ }^{10}$. Regarding non-invasive options, one well explored approach to improve delivery of drugs to the brain is the attachment of a substance that does cross the BBB to a drug that doesn't cross it. The production of the so called "Trojan horses" use antibodies, recombinant proteins, non-viral gene medicines or RNA-interference drugs able to target receptor-mediated transport systems in capillaries ${ }^{2}$. This approach requires different mechanisms for brain uptake such as adsorptive endocytosis and receptor-mediated transcytosis ${ }^{1,9}$. Other alternative is the production of lipophilic pro-drugs able to penetrate into the brain where they are metabolized into their active forms or the coating of drug loaded nanoparticles with materials in which apolipoproteins from the blood adsorb, promoting higher absorption across the BBB ${ }^{5,12}$. The inhibition of drug efflux transporters present in BBB (e.g. P-glycoprotein) is another strategy to overcome this barrier, by means of using low concentration pluronic copolymers, for instance ${ }^{5,11}$. Regarding invasive methods to delivery drugs to CNS, the osmotic disruption/shrinking of the BBB by the intracarotid administration of hypertonic solutions or the opening of BBB's tight junctions via receptor- mediated mechanisms are some examples. Nevertheless, this transient opening can be considered unsafe and may possibly damage neurons due to exogenous components entering the brain ${ }^{9,13}$. Other alternative is the direct introduction of drugs into the CNS by intracerebro-ventricular or intraparenchymal injections, however being risky and experience since it requires surgical expertise and hospitalization ${ }^{13}$. A non-invasive option that is being increasingly studied during last years is the intranasal delivery of drugs, which will be deeply focused in the next section. 


\section{Nasal delivery of drugs to the brain}

Intranasal administration of drugs is a viable option for local and systemic delivery of drugs ${ }^{14}$. Moreover, numerous animal and human studies have shown that following nasal administration, API's are also transported directly from the nasal mucosa to the CNS via olfactory epithelium or trigeminal nerve system, bypassing the brain barriers ${ }^{2,5,15,16}$. Thus, intranasal administration could be a noninvasive and essentially painless rout for delivery of large molecules, such as insulin-like growth factor-1, nerve growth factor, basic fibroblast growth factor, vasoactive intestinal peptide and $\beta$-interferon ${ }^{6,13}$. Nevertheless, the amount of polar drugs that actually reach the brain could be less than one percent of the drug administered owing to poor capacity of penetration through nasal mucosa, the enzymatic degradation, limited absorption area and rapid mucociliary clearance in the nose ${ }^{6,17,18}$. Thus, it is still necessary to increase drug's transport across this pathway and this could be achieved through pharmaceutical technology strategies.

\subsection{Nasal anatomy}

The nasal cavity is divided into two by the nasal midline septum with each half opening at the face via nostrils and extending posteriorly to the oral cavity through the nasopharynx ${ }^{16,19}$ (Figure 2). 


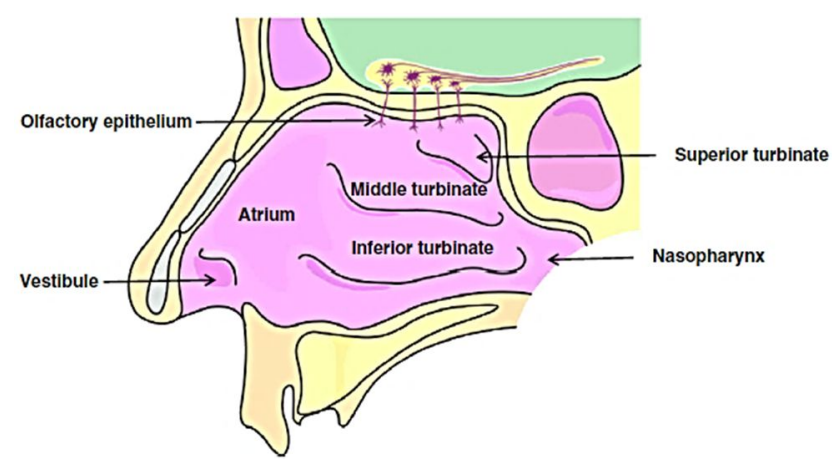

Figure 2| Representation of the different areas of the nasal cavity. Drug deposition following intranasal administration mainly occurs in the respiratory zone around the inferior turbinate. Partial obstruction by the turbinates prevents in part the deposition on the olfactory epithelium and on the nasopharynx ${ }^{20}$.

Each cavity consists of anterior and posterior vestibules, respiratory region (containing the superior, the middle and the inferior turbinates) and olfactory region situated at the top. The atrium is an intermediate region between vestibule and respiratory region. The nasal cavity has a surface area around $155 \mathrm{~cm}^{2}$, being 12-14 cm long with a volume of each nasal cavity of $13 \mathrm{~mL}^{21}$.

There are four types of nasal epithelia in nasal cavity, namely, respiratory, olfactory, squamous (vestibule) and transitional (atrium), being the first two the most important sites of absorption for APIs administered intranasally ${ }^{19}$. The respiratory region is composed by pseudostratified epithelium formed by ciliated and nonciliated columnar cells, mucus-containing goblet cells and basal cells. Goblet cells produce a complex mixture of materials composed of approximately $95 \%$ water, $2 \%$ mucin, $1 \%$ salt, $1 \%$ of other proteins and less than $1 \%$ of lipids, that form the mucus layer ${ }^{21}$. Ciliated cells, by the beating cilia at a mean pace of $6-10 \mathrm{~mm} / \mathrm{min}$, facilitate the transport of mucus towards the nasopharynx in order to be swallowed (mucociliary clearance mechanism), while basal cells, which are poorly differentiated, act as stem cells to replace other epithelial cells ${ }^{2,14}$. The olfactory epithelium covers only $3 \%$ of the total nasal cavity area, being composed by 
olfactory neural cells, supporting cells and basal cells ${ }^{21}$. The olfactory neural cells, or axons, are elongated bipolar neurons that have cell bodies located at various depths within the epithelium, with one end in the nasal olfactory epithelium and the other end extending to the olfactory bulb. Supporting cells are covered with microvilli and basal cells are capable to differentiate to become new receptor cells 22.

The nasal cavity plays an important role to filter, warm and humidify the inhaled air before it reaches the lower airways. Any inhaled exogenous material is trapped by the hair of the nasal vestibule or by the mucus layer covering the respiratory area of the nasal cavity ${ }^{20,21}$.

\subsection{Pathways and mechanisms}

The mechanisms of intranasal delivery of drugs to CNS remain to be fully elucidated. Recent evidence proposes that nerves that connect the brain and spinal cold to the nasal passages, as well as the vasculature, lymphatic system and CSF are involved in the molecules' transport to the CNS after adsorption from nasal mucosa ${ }^{9}$. Several drug transport pathways have been suggested, namely: the systemic pathway where the drug is adsorbed through the nasal cavity straight into the blood circulation where it can go through BBB into the brain or cross the more 'leaky' barrier of the choroid plexus into the CSF and subsequently penetrate BCSFB; or through both the olfactory and trigeminal pathway which nerves innervate the nasal cavity, providing a direct connection with the CNS (Figure 3) 7,8,13 


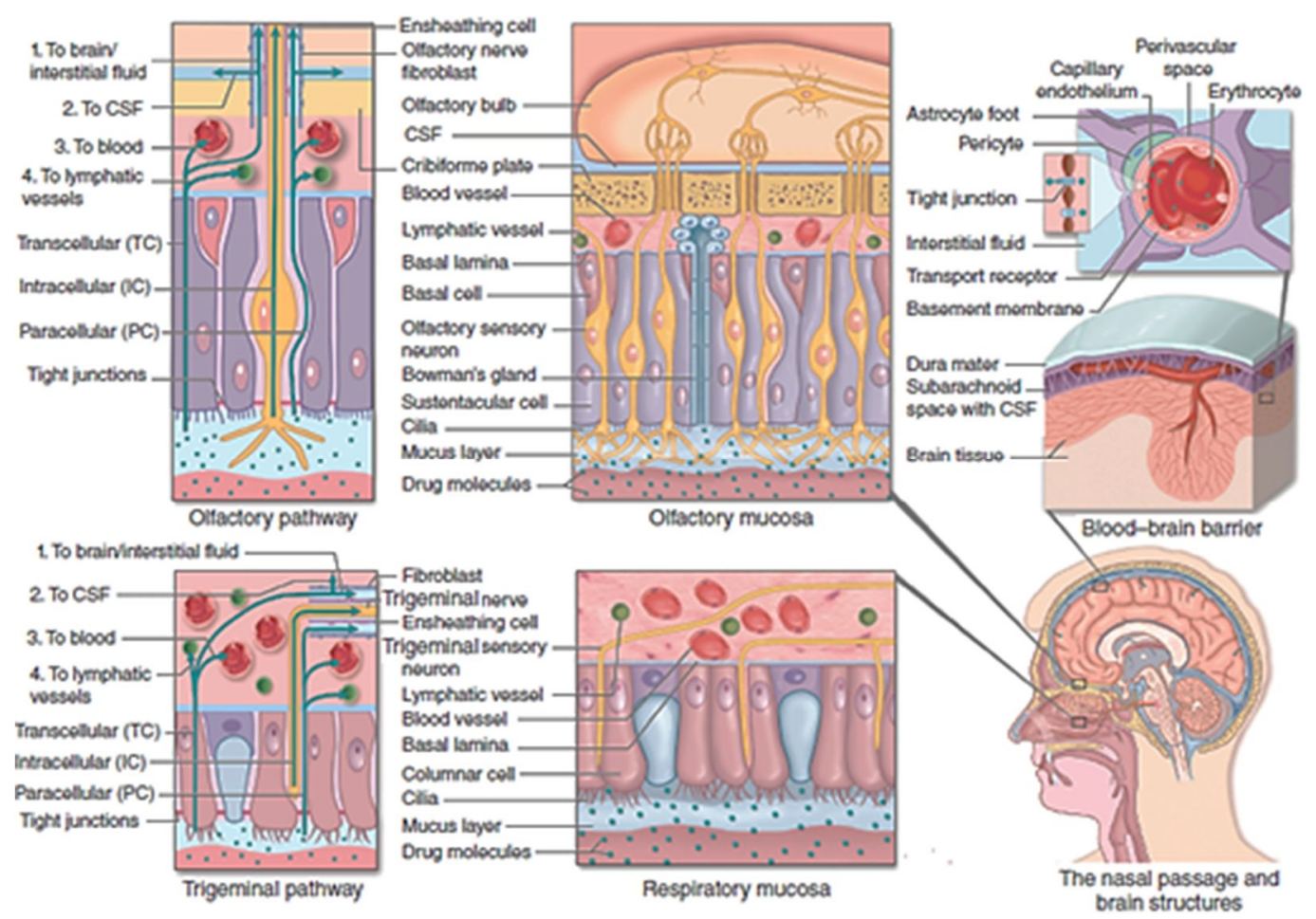

Figure 3| The potential transport routes for substances into the brain from the blood across the blood-brain barrier and along the olfactory and the trigeminal pathways ${ }^{2}$

\subsubsection{Olfactory pathway}

Olfactory pathway begins in the upper nasal passages, where olfactory sensory neurons extend from the mucus layer of the olfactory epithelium, through the lamina propria and cribiform plate, and into the CSF-filled subarachnoid space of the cranial cavity. The projections of the olfactory nerve extend from the olfactory bulbs toward several brain regions via the olfactory tract, including piriformcortex, amygdala, and hypothalamus ${ }^{10,23}$. When a drug reaches the olfactory mucosa, it can reaches the brain through transcellular, paracellular or olfactory nerve pathways ${ }^{18}$. The transcellular pathway, especially across the sustentacular cells, is performed most likely by receptor-mediated endocytosis, fluid phase endocytosis, or passive diffusion while in olfactory nerve pathway the APIs are taken up into the 
neurons by endocytotic or pinocytotic mechanisms and transported by intracellular axonal transport to the olfactory bulb ${ }^{18,21}$. Axonal transport is very slow since drugs could take from several hours to 4 days to reach the olfactory bulb and other brain areas ${ }^{13}$. The paracellular pathway is done through tight junctions between the sustentacular cells and olfactory neurons; this pathway presents fast kinetics, taking just $30 \mathrm{~min}$ (or even less, in some cases) from the drug's administration until it reaches the olfactory bulb ${ }^{13}$.

\subsubsection{Trigeminal pathway}

The trigeminal nerve, or the fifth (V) cranial nerve, is the largest of the twelve cranial nerves and its distribution and nasal passage innervation are well understood ${ }^{19}$. In addition to the olfactory pathway, transport to the CNS can also take place via a trigeminal nerve pathway, along the peripheral ophthalmic branch (V1) of trigeminal nerves located at the respiratory region. Collaterals from the trigeminal nerve also reach the olfactory bulb. The trigeminal nerve endings do not penetrate the mucosal surface and so, substances must cross the mucosa and might travel along the trigeminal axons through paracellular channel mechanisms similar to those described for the olfactory nerve. The trigeminal pathways would allow for the transport of molecules to both caudal and rostral brain regions, such as cerebellum and brainstem ${ }^{13,23}$.

\section{3. $\quad$ Nose-to-brain drug delivery}

Despite the fact that drugs can enter rapidly the brain tissue after intranasal administration, only a small percentage successfully reaches CNS. Nevertheless, if a highly potent API is administered, such as Glial Cell Derived Neurotrophic Factor (GDNF), the low dose could still achieve therapeutic concentration in the brain. Successful nose-to-brain (N2B) delivery has been confirmed for several pharmaceutics, including chemotherapeutics, peptides, proteins (e.g. insulin), 
siRNAs, viral gene vectors, non-viral gene vectors, and even cells ${ }^{7,23}$. However, in order to guarantee the viability of N2B delivery approach, it is necessary to know the physicochemical properties of the drug and its suitability for this route of administration ${ }^{14}$. The drug is required to pass through mucus layer and epithelial membrane before reaching the brain. Small and uncharged molecules cross easily this layer while large and charged compounds find it more difficult to pass. And even if drugs enter the systemic circulation after intranasal delivery, we need to know if APIs exhibit satisfactory passive or active transport across the tight junction barriers of the BBB, in order to get through it. Thus, physicochemical characteristics of drugs are extremely important and can influence its bioavailability and rate of transport during N2B delivery, namely its molecular weight (MW), lipophilicity, dissociation constant, partition coefficient or solubility ${ }^{24}$. It was observed in some studies that drugs' nasal absorption increases with an increase in lipophilicity or partition coefficient of APIs ${ }^{21}$. In general, lipophilic drugs take the transcellular route, while hydrophilic compounds could take the transcellular or paracellular route. Nevertheless, high molecular weight (above $1 \mathrm{kDa}$ ) could be a limiting factor for paracellular passage through the tight junctions whereas for drugs with a MW below $300 \mathrm{Da}$, nasal absorption is rapid and hardly influenced by the other physicochemical properties. For drugs with MW between $300 \mathrm{Da}$ and 1 kDa (great majority of active principles), liposolubility is an important property for resorption, since it influences passive diffusion across the epithelium ${ }^{20}$.

2.4. Strategies to enhance intranasal delivery of drugs to the brain formulation of compounds

Considerable research is still desirable in the field of N2B delivery of drugs to CNS. Inadequate appreciation of the inherent challenges imposed by the complex nasal anatomy and physiology may also have slowed progress in this field. With increased notion of these hurdles, new nasal delivery devices have been produced allowing 
more targeted delivery to the sites innervated by the cranial nerves that offer direct pathways from the nose to the brain ${ }^{2}$. Researchers investigated several methods for the enhancement of APIs permeation through the nasal mucosa applying complementary strategies in order to increase the final bioavailability of N2B administered drugs. The administration of the drug with enzyme inhibitors or absorption promoters, or even the chemical change of the initial molecule to produce a prodrug are an examples of these approaches. One attractive solution is also the formulation of the drugs into solid or liquid drug delivery systems ${ }^{20}$. In figure 4 is represented the percentage of each kind of N2B drug-loaded formulation present in literature.

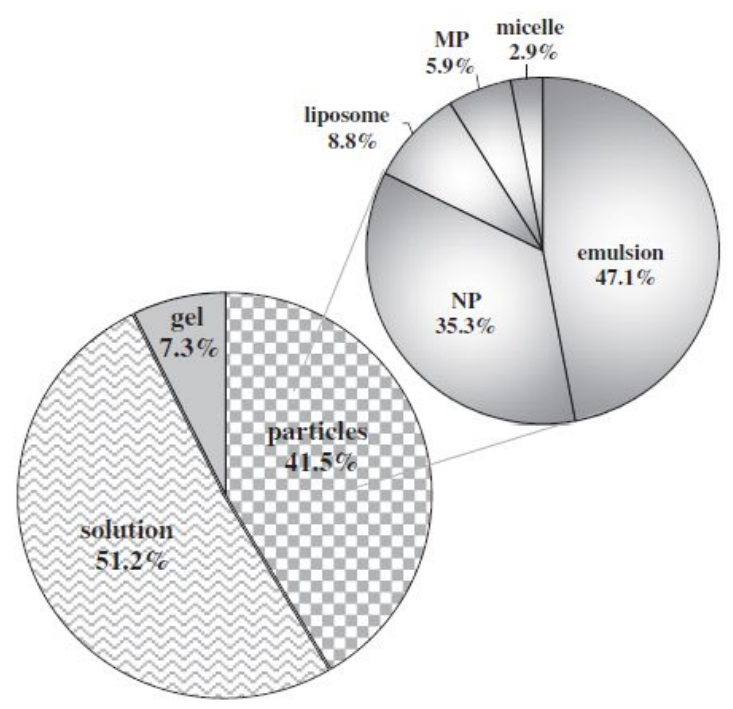

Figure 4| Type of the formulations and relative number of publications that applied specific formulation type. The inset shows the relative number of publications that applied a specific subtype of particles. NP-nanoparticles.MP-microparticles 25 .

It is possible to verify that more than half of the formulations were in solution state, while the gel-based formulations were less common. Particle-based formulations were frequently used for drug delivery and targeting to the brain via the nasal route in which the emulsions and nanoparticles were more commonly applied, as 
compared to the other types of particulate delivery systems ${ }^{25}$. The encapsulation of drugs into particles increase their protection from degradation and enhance their transport across the mucosal barrier ${ }^{6}$. Powder formulations seem to be cleared somewhat slower, possibly due to the time it takes for the powder to dissolve ${ }^{2}$. Moreover, compared with solutions, powder formulations can facilitate the administration of larger amounts of drugs, resulting in higher APIs concentration on nasal mucosa, which can saturate its enzymatic degradation and consequently increase drug's bioavailability ${ }^{26}$.

Besides the physical state of the formulation, also the correct choice of carrier materials used is crucial for efficient nasal drug delivery. For instance, the use of mucoadhesive excipients can prolong the contact time of drugs with the nasal mucosa enhancing their permeation ${ }^{8}$. On the other hand, the use of enzymatic inhibitors, solubilization agents or absorption enhancers can effectively increase the bioavailability of intranasally administered drugs ${ }^{20,24}$. The further surface engineering of solid formulations is also an excellent approach to increase the interaction of the drug delivery systems with the biological mucosa ${ }^{21}$.

\subsubsection{Mucoadhesive formulations}

Mucociliary clearance is one of the greatest obstacles to nasal administration of drug loaded formulations, since it can reduce the time of contact between the mucosa and the dosage form. As mentioned above, the use of mucoadhesive formulations is known to be one of the biggest strategies to increase drug's bioavailability after intranasal administration ${ }^{24}$. This strategy has two objectives, to increase contact time between the formulation and the nasal mucosa, and to slow down mucociliary drainage ${ }^{14,17}$. The term mucoadhesion is defined as the attachment of syntetic/biological material to mucus for an extended period of time 27. The process of mucoadhesion subsequent nasal administration refers to the interaction between the formulation and the mucus secreted by the goblet cells ${ }^{26}$. 
This process starts with an intimate contact between the mucoadhesive carrier material and the nasal mucosa due to proper wetting and swelling of the formulation. Then it occurs the penetration of the swelled carrier into the tissue crevices, with interpenetration between the mucoadhesive formulation chains and those of the mucus ${ }^{16,26}$. Thus, the mucoadhesion process probably results from a combination of several mechanisms and theories ${ }^{27}$, which are summarized in Table

1.

Table 1| Theories and mechanisms of mucoadhesion (adapted from ${ }^{16,28}$ )

\begin{tabular}{|c|c|c|}
\hline Theory & Mechanism & Comments \\
\hline Electronic & $\begin{array}{l}\text { Attractive electrostatic forces } \\
\text { between glycoprotein mucin } \\
\text { network and the mucoadhesive } \\
\text { material }\end{array}$ & $\begin{array}{c}\text { Electrons transfer occurs between the two } \\
\text { forming a double layer of electric charge at } \\
\text { the surface }\end{array}$ \\
\hline Wetting & $\begin{array}{l}\text { Ability of mucoadhesive polymer to } \\
\text { spread and develop intimate } \\
\text { contact with the mucous } \\
\text { membrane }\end{array}$ & $\begin{array}{l}\text { Spreading coefficient of carriers must be } \\
\text { positive; contact angle between carriers and } \\
\text { nasal cells must be near to zero }\end{array}$ \\
\hline Adsorption & $\begin{array}{l}\text { Surface force resulting in chemical } \\
\text { bonding }\end{array}$ & $\begin{array}{c}\text { Strong primary force: covalent bonds. Weak } \\
\text { secondary forces: hydrogen bonds and van } \\
\text { der Waal's forces }\end{array}$ \\
\hline Diffusion & $\begin{array}{l}\text { Physical entanglement of mucin } \\
\text { strands and flexible carrier chains }\end{array}$ & $\begin{array}{l}\text { For maximum diffusion and best adhesive } \\
\text { strength, solubility parameters of the } \\
\text { mucoadhesive carrier and the mucus } \\
\text { glycoproteins must be similar }\end{array}$ \\
\hline Mechanical & $\begin{array}{l}\text { Adhesion arises from an } \\
\text { interlocking of liquid adhesive into } \\
\text { irregularities on the rough surface }\end{array}$ & $\begin{array}{c}\text { Rough surfaces provide an increased surface } \\
\text { area available for interaction along with an } \\
\text { enhanced viscoelastic and plastic dissipation } \\
\text { of energy during joint failure }\end{array}$ \\
\hline Fracture & $\begin{array}{l}\text { Analyses the maximum tensile } \\
\text { stress developed during } \\
\text { attachment of the transmucosal } \\
\text { DDS from the mucosal surface }\end{array}$ & $\begin{array}{l}\text { Does not require physical entanglement of } \\
\text { mucoadhesive carrier chains and mucous } \\
\text { strands }\end{array}$ \\
\hline
\end{tabular}

When applied to nasal mucosa, it is necessary that the mucoadhesive compounds have the capacity to spread well on the nasal mucosa in order to interact with it, being also important the flowability and wettability in the case of solid formulations ${ }^{26}$. There are a lot of mucoadhesive polymers reported in the literature, which are summarized in figure 5 . 


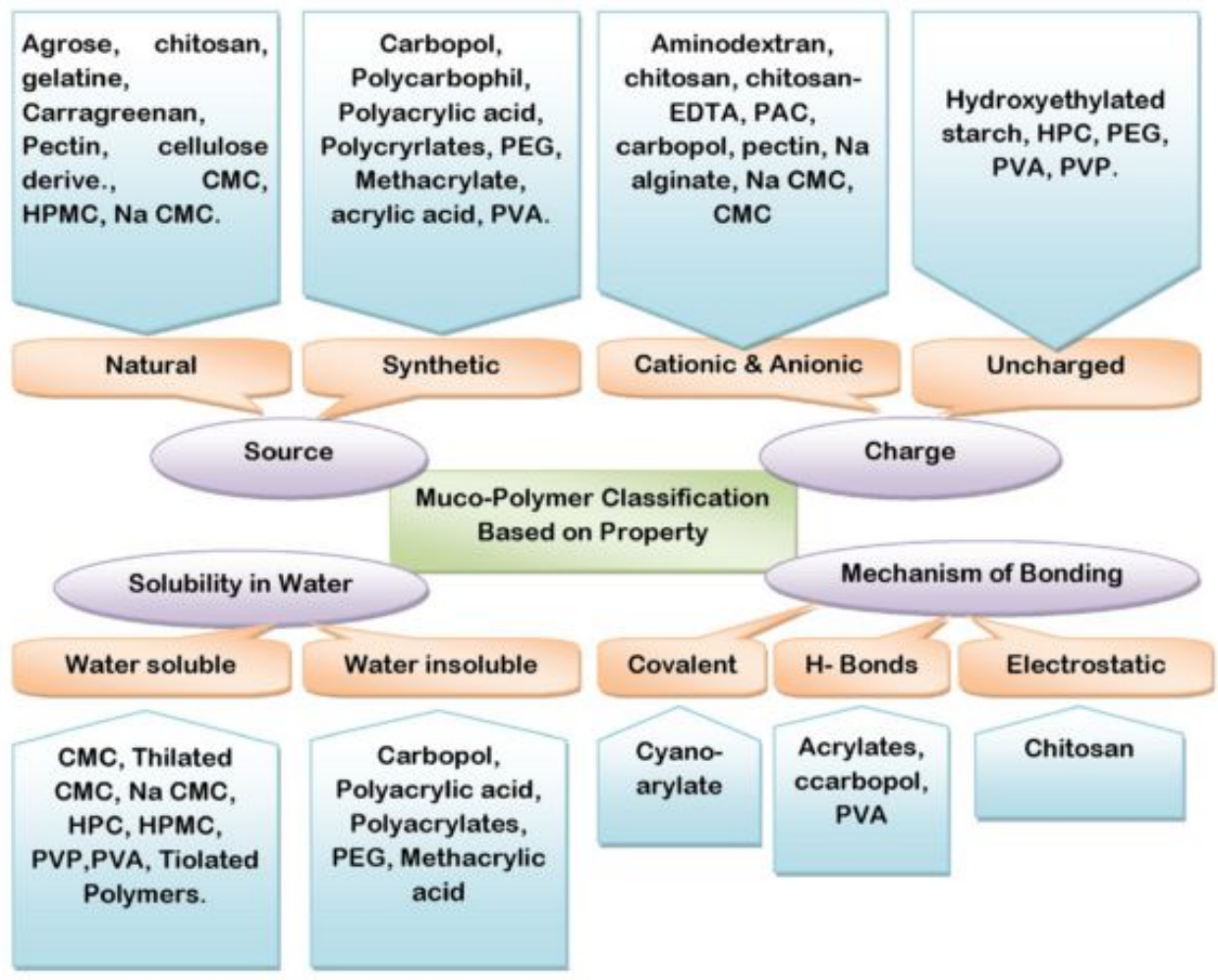

Figure 5| An overview of mucoadhesive carrier materials classifications based on their source, charge, solubility and mechanism of bonding. CMC-Carboxymethylcellulose; HPMCHydroxypropylmethylcellulose; Na CMC-Sodium carboxymethylcellulose; PEG-Polyethylene glycol; PVA-Poly (vinyl alcohol); EDTA-Ethylenediaminetetraacetic acid; PAC-Polyalkylcyanoacrylate; HPCHydroxypropylcellulose; PVP-Poly(vinyl pyrrolidone) ${ }^{27}$.

Some of these polymers' mucoadhesive strength is listed in Table 2. 
Chapter 1

Table 2| Mucoadhesive property of different carrier materials (adapted from ${ }^{29}$ )

\begin{tabular}{cc}
\hline Polymer & Mucoadhesive strength \\
\hline Sodium Carboxymethylcellulose & Excellent \\
Carbopol & Excellent \\
Polycarbophil & Excellent \\
Sodium alginate & Excellent \\
Hydroxypropylmethylcellulose & Excellent \\
Gelatin & Very good \\
Pectin & Good \\
Chitosan & Good \\
Hydroxypropylcellulose & Good \\
\hline
\end{tabular}

There are several proposed methods for the quantification and evaluation of mucoadhesive properties of pharmaceutical formulations ${ }^{29-32}$. Nevertheless, there is the need to refine and adapt these tests to nasal delivery, because most of these assays were developed towards application to oral administration of drugs ${ }^{32}$. Table 3 presents a comparison among several features of some mucoadhesive assays.

Table 3| Comparison of different assays for mucoadhesion evaluation (adapted from ${ }^{32}$ )

\begin{tabular}{|c|c|c|c|c|c|}
\hline \multicolumn{2}{|c|}{$\begin{array}{l}\text { Methods for measuring } \\
\text { mucoadhesion }\end{array}$} & $\begin{array}{c}\text { Insight on } \\
\text { mucoadhesion } \\
\text { mechanism }\end{array}$ & $\begin{array}{l}\text { In vivo } \\
\text { relevance }\end{array}$ & Feasibility & Cost \\
\hline \multirow{5}{*}{$\begin{array}{l}\text { Indirect } \\
\text { methods }\end{array}$} & Mucin particle method & Low & Low & High & Low \\
\hline & $\begin{array}{l}\text { Microgravimetric } \\
\text { methods }\end{array}$ & Medium & Low & Medium & Medium \\
\hline & Atomic force microscopy & High & Low & Low & High \\
\hline & Optical techniques & Medium & Low/Medium & Medium & High \\
\hline & Particle tracking methods & High & Medium & High & Medium \\
\hline \multirow{4}{*}{$\begin{array}{l}\text { Direct } \\
\text { methods }\end{array}$} & Cytoadhesion methods & Medium & Medium & Medium & Medium \\
\hline & Ex vivo methods & Low & Medium & Medium & Medium \\
\hline & In vivo administration & Low & High & Medium & Medium \\
\hline & In vivo imaging & Low & High & Low & High \\
\hline
\end{tabular}


The methods presented here are divided in indirect methods, where mucoadhesion is inferred from the balance between contributing and detrimental interactions among pharmaceutical formulations and components of mucosa, or direct methods, in which mucoadhesion is measured in vivo or in close proximity to what happens in vivo ${ }^{32}$. For instance, mucin particle method (indirect assay) was one of the first methods developed for mucoadhesion studies. It measures the mucin adsorbed into pharmaceutical formulations on simple mixture in aqueous solution and incubation during a predefined amount of time. The degree of adsorption of carriers/mucin can be determined by the variations in size, $\zeta$ potential or electrophoretic mobility of formed complexes. The interaction of mucin in solution with pharmaceutical carriers could be also assessed by measuring the transmittance of the dispersion after an adequate incubation time ${ }^{30-32}$. An example of direct method for assessing mucoadhesion is the cytoadhesion technique, which is conducted using epithelial cell monolayers of the mucosal tissue of interest. These studies evaluate in particular cytoadhesion and are done by incubating fluorescently labeled particles with cell culture; the degree of adhesion can therefore be evaluated qualitatively by fluorescent microscopy ${ }^{32}$.

Each method has its own benefits and drawbacks and so, the behavior of pharmaceutical formulations within mucus would be better explain using several methods simultaneously.

\section{Hybrid particles - An emergent formulation approach}

The development of new drugs alone is not sufficient to ensure progress in drug therapy. The development of suitable carrier systems is fundamental to overcome barriers to drug's usefulness. During the last years, pharmaceutical technology has progressed towards the production of more complex drug delivery structures in order to fulfil four key design aspects: stability, encapsulation efficiency, controlled 
release and biocompatibility. Therefore, instead of using just one carrier, hybrid particles composed of two or more classes of materials, such as polymers, lipids, silica, and metal among others, are being developed so as to combine several functionalities in a single delivery system ${ }^{33-36}$. The most common strategy is to combine the enhanced cellular uptake features of highly biocompatible lipids with the structural integrity and improved stability in biological fluids of biodegradable polymeric matrices, in order to overcome the weakness of a material using the strength of another. These robust structured systems are capable to incorporate drugs with distinct polarities and have already been applied as vaccine adjuvants, for cancer targeting and delivery of nucleic acids ${ }^{33,35}$. Although Solid Lipid Particles have been considered as an attractive delivery system, it is well-known that they have some limitations such as low drug loading capacity and drug leakage during storage mostly due to their almost perfect lipid crystal matrix ${ }^{37,38}$. The most common strategy to overcome this bottleneck is to prepare hybrid structures, namely incorporate liquid lipids into the solid matrix of lipid particles in order to enable the formation of imperfections in the crystal lattice structure. The resulting delivery systems, referred to as structured lipid carriers, present higher drug entrapment capacity and have been widely used for pharmaceutical and cosmetic applications (Figure 6) ${ }^{39,40}$.
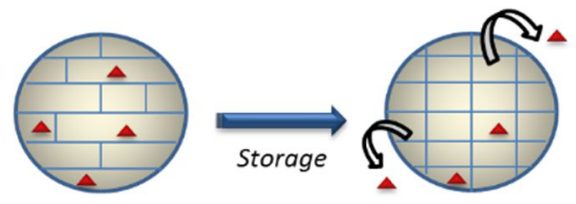

Drug expulsion

Solid lipid particles
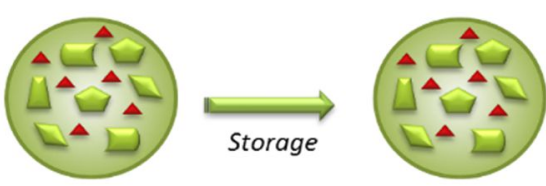

Structured lipid carriers

Figure 6| Formation of a perfect crystal lattice in solid lipid particles and a crystal structure with imperfections in structured lipid carriers. 
The methods to produce hybrid particles can be divided into two major approaches, namely the top-down and the bottom-up techniques ${ }^{35,41}$. The top-down technique consists of starting with a bulk material and through the reduction of its size, obtaining the hybrid particles, whereas the bottom-up method starts with very small structural units to form larger structures. In both approaches, there are still many drawbacks to overcome, in particular the difficulties in controlling the morphology, structure and size, the difficulty and cost of the purification step and the use of organic solvents ${ }^{42}$.

\subsection{Nose-to-brain application}

The application of hybrid approach for nose-to-brain delivery of drugs started in 2000 and until the start of this PhD thesis, more than 20 publications regarding this topic have been published, herein presented in Figure $7^{6,43-62}$.

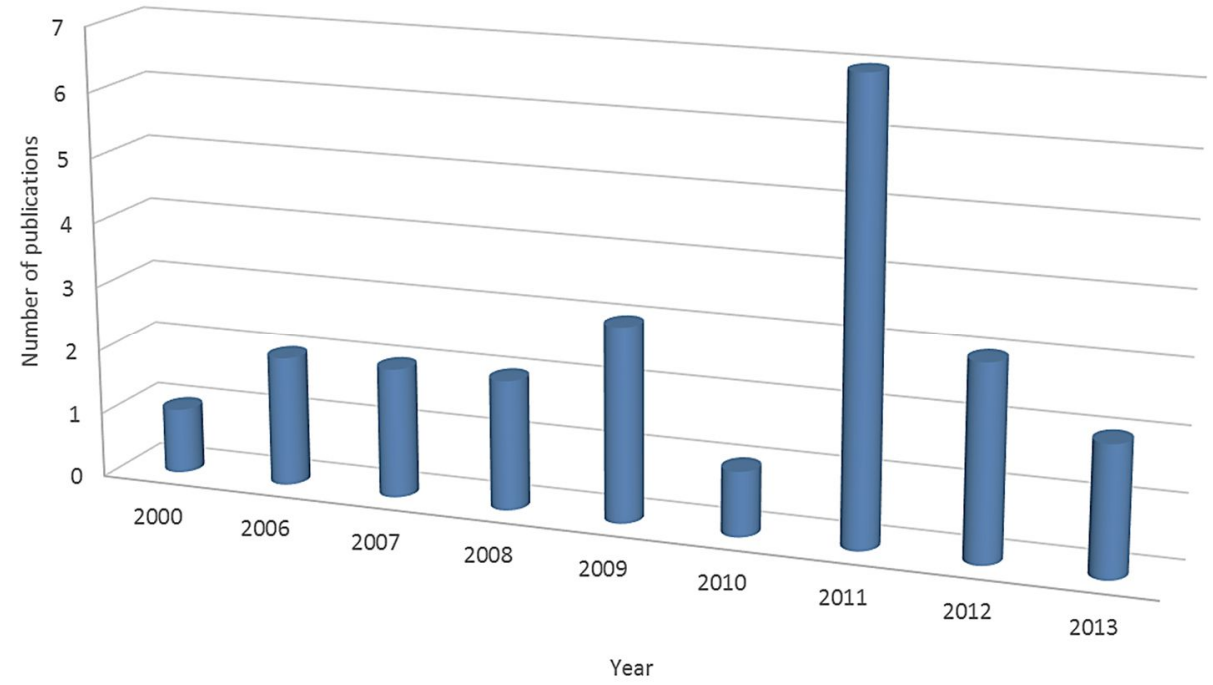

Figure 7| Number of publications regarding the development of nose-to-brain hybrid particles Keywords used here were: (nasal or intranasal or nose) AND (brain) AND (Particles or Drug Delivery Systems or Hybrid). Google Academics, Science Direct and Scopus were the main reference sources ${ }^{6,43-62}$. 
The vast majority of hybrid particles were produced through techniques in which is required the use of organic solvents, such as emulsion polymerization technique, emulsion/solvent evaporation method, nanoprecipitation technique or thin-film hydration method. Thus, more sustainable options are required for the development and production of hybrid particle for N2B delivery of drugs.

\subsection{Characterization of hybrid particles}

The complexity of hybrid structures lead to analytical challenges for their characterization, being essential the use of multidisciplinary studies for the evaluation of the physicochemical, textural, size and morphological features of the particles ${ }^{63}$. Several methods for the characterization of structured particles are summarized in Table 4.

Table 4| Methods applied for the characterization of structured particles

\begin{tabular}{cc}
\hline Parameter & Method of characterization \\
\hline Size & SEM; TEM; AFM; DLS; LD; NTA; MFI; Flow Cytometry; \\
Morphology & SEM; TEM; AFM; FIB; CLSM; \\
Surface charge & LDE \\
Textural characterization & AFM; BET method; Mercury porosimetry \\
Thermal Behavior & DSC, TGA; XRD \\
Composition & DSC; XRD; Raman, NIR; FTIR, NMR, XPS; EDS; ToF-SIMS
\end{tabular}

SEM-Scanning electron microscopy; TEM-Transmission electron microscopy; AFM-Atomic Force Microscopy; DLSDynamic light scattering; LD-Laser diffraction; NTA-Nanoparticle tracking analysis; MFI-Microflow imaging; FIBFocused-ion-beam; CLSM-Confocal laser scanning microscopy; LDE- Lase doppler electrophoresis; BET-BrunauerEmmett-Teller method; DSC-Differential scanning calorimetry; TGA-Thermogravimetric analysis; XRD-X-ray diffraction; NIR-Near-infrared; FTIR-Fourier transform infrared; NMR-Nuclear magnetic resonance; XPS-X-ray photoelectron spectroscopy; EDS-Energy-dispersive X-ray spectrometer; ToF-SIMS-Time-of-Flight Secondary lon Mass Spectrometry 


\subsubsection{Size, Morphology and Surface charge}

Particle size and morphology are two of the most important characteristics that affect the general performance and stability of drug delivery systems. Advanced microscopic techniques like atomic force, scanning electron and transmission electron are widely used to analyze size and morphology of particles. By using AFM technique, it is also possible to acquire three-dimensional surface profiles with spatial resolution up to $0.1 \mu \mathrm{m}$. The microscope uses a cantilever with a tip, acting as probe, at its end to scan the entire specimen surface. Since no vacuum is applied during the analysis, it is possible to directly examine samples containing solvents ${ }^{64}$. SEM is capable to provide an accurate assessment of the three-dimensional morphology, size and surface of particles with a spatial resolution of $5-10 \mathrm{~nm}$. However, since it has limited throughput, it is challenging to obtain particle size distribution. Moreover, it is usually necessary to previously coat the samples with electrically conducting elements, such as gold or palladium, which can damage the structure of fragile particles. Nevertheless, SEM remains the technique of choice for the evaluation of the shape of particles and is the best analytical method for the characterization of non-spherical particles ${ }^{63,65}$. Scanning electron microscopes could be equipped with a focused-ion-beam that offers the possibility of dissect and probe the interior of particles to verify their porosity ${ }^{66}$. Another electron microscopy, TEM, offers a two-dimensional picture of the particles, since a beam of electrons is transmitted through the sample. Although the resolution of this technique is better than of SEM, the sample preparation could be a complex procedure. Besides the determination of size and morphology, TEM is also a useful technique to differentiate the core-shell structure of a particle by staining the sample with uranyl acetate, osmium tetraoxide, or phosphotungstic acid for better imaging contrast. This procedure allows the observation of the lipid layer which is negatively stained ${ }^{36}$. Another strategy that can be applied to verify the core-shell structure of a hybrid particle is by using conventional fluorescence microscopy 
allied with confocal laser scanning microscopy and staining the components of the particles with distinct fluorescent dyes ${ }^{67}$.

Dynamic light scattering, also known as Photon correlation spectroscopy (PCS) is a reliable technique and the most used to analyze particle size and particle size distribution. DLS measures the fluctuation of the intensity of the scattered light caused by the Brownian motion of particles. The size that is measured is the hydrodynamic diameter, and so is related to a sphere with the same translational diffusion coefficient as the sample. Since DLS assumes spherical shape for particles, additional care must be taken when measuring the size of non-spherical samples due to the lower precision of the technique in this case. Besides that, DLS is not a suitable technique for multimodal particle size distribution and has a limit of size detection around $\leq 10 \mu \mathrm{m}{ }^{65,68,69}$. On the other hand, laser diffraction is a technique that covers a broad size range $(40 \mathrm{~nm}$ to $2000 \mu \mathrm{m})$, which is based on the dependence of diffraction angle on the particle radius ${ }^{68}$. Another alternative for measuring particle size is the nanoparticle tracking analysis method which is based on fluorescence microscopy and automatic imaging analysis. Although NTA provides high resolution when analyzing multimodal samples, it requires sample dilution in order to prevent an observation field very crowded ${ }^{69,70}$. A recent study showed that microflow imaging and Flow cytometry are also additional methods for determination of the non-spherical particle size ${ }^{65}$.

When particles are in contact with a solvent there are two liquid layers surrounding them, the weakly bound outer layer and the strongly bound inner layer. Zeta potential is measured at the boundary of the outer layer by laser Doppler electrophoresis, and is a parameter that greatly influences the stability of particles. A stable particle has a zeta potential more positive than $+30 \mathrm{mV}$ or more negative than $-30 \mathrm{mV}$, due to electrostatic repulsion. However, care must be taken while performing this analysis, since zeta potential value is greatly influenced by the ionic 
strength and $\mathrm{pH}$ of the medium, and may change depending on the solvent used 68,69 .

\subsubsection{Textural characterization}

The surface area of a particle is another important feature of solid materials applied for pharmaceutical purposes since it influences the load and dissolution rate of active compounds. AFM is a technique applied to determine the surface area and textural characteristics of particles, that could be complemented by physical gas adsorption methods. In the Brunauer-Emmett-Teller method, nitrogen is adsorbed at low temperatures on the surface of particles, and then desorbed at room temperature. The isotherms of adsorption and desorption not only can provide the surface area, but also provide information regarding the porosity of the materials, such as pore size and pore size distribution. Mercury porosimetry is another alternative method to get information regarding porosity, pore volume, pore size distribution and density ${ }^{63}$.

\subsubsection{Thermal behavior}

In order to evaluate the stability and thermal transitions of particles, calorimetric and thermogravimetric techniques are usually applied. Differential scanning calorimetry is one of the most used techniques to monitor thermochemical events, giving important insight about melting, recrystallization, sublimation, glass and polymorphic transitions or even information about decomposition of the materials. In this technique, both sample and reference are at the same temperature, being measured the heat exchanges occurring during structural alterations of materials. DSC is the technique most used to determine the glass transition temperature of non-crystalline and semi-crystalline polymers, as well as the melting point of crystalline materials. The determination of melting point of particles is very useful to estimate the purity, degree of crystallinity and particle size of the samples 
analyzed. Especially in the case of lipids, the degree of crystallinity and the modification of its lattice structure influence not only the amount of active compound that is incorporated but also its release rate ${ }^{71}$. However, the cause of a thermal event is not revealed directly by DSC, such knowledge could be achieved with complementary methods like X-ray diffraction or thermogravimetric analysis $63,68,72$. TGA is a technique that measures the weight loss of a sample as a function of temperature, being particularly suitable for the quantitative determination of the volatile content of a solid material as well as for the evaluation of its thermal stability. It is also possible to identify the volatile compound by coupling the TGA apparatus with a gas-phase Infra-red analyzer ${ }^{63}$.

\subsubsection{Composition}

Since hybrid particles are constituted by two or more compounds, it is important to study the final composition of the particles, as well as understand the way the materials are arranged. This could be performed by performing DSC, XRD, vibrational spectroscopy such as Raman, Near-infrared or Fourier transform infrared and nuclear magnetic resonance ${ }^{34,63,68,73}$. If the particles are intended for the encapsulation of active compounds, these techniques could be also useful to study the drug-matrix interaction and their spatial distribution.

Elemental analysis of the surface of the particles could be important in some cases, and could be performed either by X-ray photoelectron spectroscopy, by coupling a scanning electron microscope with energy-dispersive X-ray spectrometer, or by performing Time-of-Flight Secondary lon Mass Spectrometry ${ }^{34,63,74}$. 


\section{Supercritical fluid technology applied to the production of hybrid drug delivery systems}

The demand for new products with singular features and design of new environmentally friendly and sustainable technologies is shifting the technological processes towards high pressure. High pressure provides completely new products with special characteristics. Pharmaceutical companies are urged to develop new processes in order to reduce the use of volatile organic solvents as well as residues in the finished product ${ }^{75}$. The environmental benefits of using compressed fluids, such as supercritical fluids (SCFs), in industrial processes showed their potential of replacing the far more environmentally damaging conventional techniques, since their emergence in the early $1990 \mathrm{~s}^{42,76}$. A supercritical fluid is any substance that reaches the supercritical region when heated and pressurized above its critical pressure and temperature; the critical point represents the end of the vaporization curve in the PT phase diagram ${ }^{75}$. These types of fluids often have liquid-like densities and, therefore, solvating characteristics that are similar to those of liquids, but, at the same time, they present gas-like mass transfer properties, with similar viscosity and diffusivity values and an almost zero surface tension ${ }^{42,77}$. The most widely used $\mathrm{SCF}$ is $\mathrm{CO}_{2}$, which is nontoxic, noncarcinogenic, nonflammable, cheap, widely available and easy recyclable ${ }^{76,78}$. The supercritical region of this "green solvent" can be achieved at moderate pressures and temperatures $(\mathrm{Tc}=304.1 \mathrm{~K}$, $\mathrm{Pc}=7.4 \mathrm{MPa})^{78}$, as can be seen in figure 8 . 


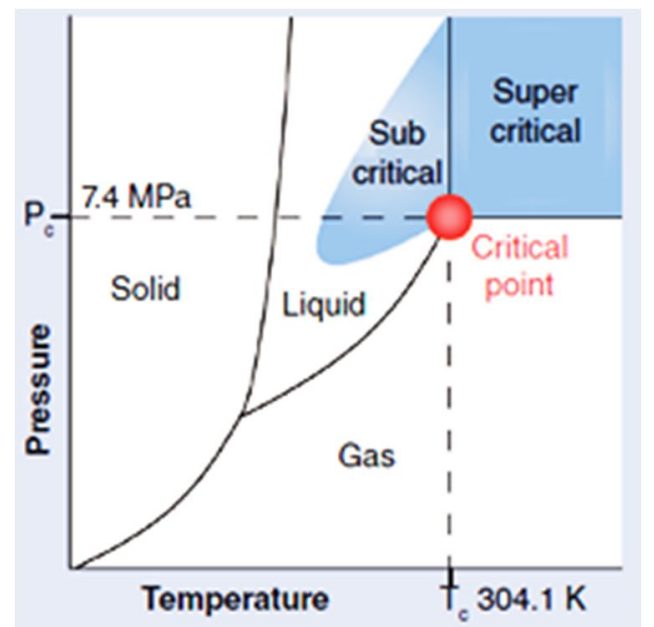

Figure 8| Pressure versus temperature phase diagram of $\mathrm{CO}_{2}$ indicating the critical point and the suband super-critical regions 42

While working with $\mathrm{sc}-\mathrm{CO}_{2}$ it is possible to carry out the process at near-ambient temperatures ${ }^{79}$. Moreover, supercritical carbon dioxide also provides an inert medium, without the presence of oxygen and without the need for the application of high shear forces, which makes them particularly suitable for the processing of thermally, chemically or physically labile materials, such as biological compounds, chemical entities and pharmaceuticals ${ }^{42,79}$. Furthermore, the use of supercritical carbon dioxide eliminates or reduces the use of toxic organic solvents in the process, being the separation of the supercritical fluid from the product easily accomplished by depressurization. Thus, at the end of the process, the high solubility of most organic solvents in supercritical $\mathrm{CO}_{2}$ allows obtaining solvent-free products ${ }^{79,80}$. Other advantage of supercritical fluid-based methodologies is the reduced complexity of the processes with reduction of number of steps with improved understanding and control ${ }^{75}$.For these reasons, SCF have been applied in several pharmaceutical fields, namely, particle and crystal engineering, formation of complexes with cyclodextrins, coating, foaming, tissue engineering, extrusion, sterilization or solvent removal, among others ${ }^{75}$. 
Several precipitation processes based on supercritical fluids and with applicability in the pharmaceutical industry have been developed. These precipitation technologies can be classified according to the role of the supercritical fluid in the process: solvent, anti-solvent, co-solvent or solute, or even propellent gas ${ }^{79}$. In order to select the most appropriate SCF-based precipitation technique it is essential to perform phase behavior studies, that is, to study the materials' phase behavior in pure $\mathrm{CO}_{2}$. One way to achieve this is to perform these studies using high pressure phase analyzers with windows that allow the visualization of the interior 42. If a known quantity of material is placed inside the high pressure equipment at a certain $\mathrm{P}$ and $\mathrm{T}$ followed by the addition of known quantities of $\mathrm{CO}_{2}$, it would result in three distinct situations: the dissolution of the solid in $\mathrm{CO}_{2}$ (SCF as solvent); the swelling of $\mathrm{CO}_{2}$ inside the solid (SCF as solute); or neither situation (SCF as cosolvent or anti-solvent). In the two first cases it would be possible to process the compound with pure $\mathrm{CO}_{2}$, whereas in the latter case it would be necessary further solubility studies with pressurized mixtures of organic solvent $/ \mathrm{CO}_{2}{ }^{42}$. Depending on the behavior of $\mathrm{CO}_{2}$, the most appropriate process among SCF-based precipitation techniques is chosen for the production of compounds' particles (Figure 9). The most common used techniques are the Rapid expansion of supercritical solutions (RESS), Supercritical antisolvent (SAS) and Particles from gas saturated solutions (PGSS). 


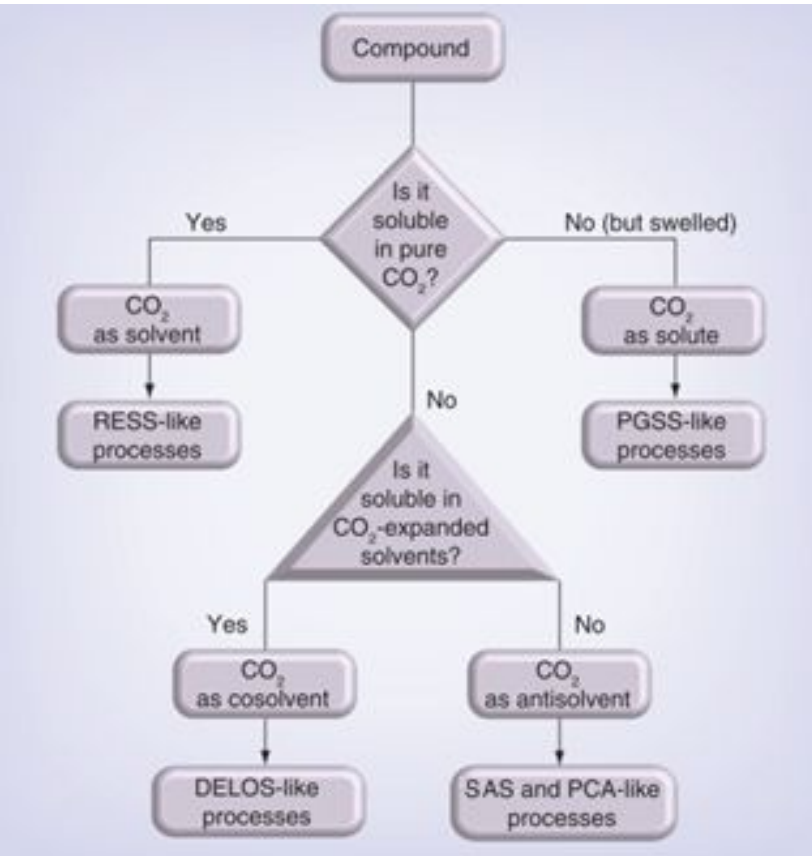

Figure 9| Selecting the most appropriate compressed fluid-based process for micro- or nanoprecipitation of a given compound ${ }^{42}$. DELOS-Depressurization of an expanded liquid organic solution; SAS-Supercritical antisolvent; PCA-Precipitation with a compressed antisolvent; PGSS-Particles from a gas saturated solutions; RESS-Rapid expansion of supercritical solutions.

In RESS process fine particles are formed from different compounds which are soluble in supercritical $\mathrm{CO}_{2}$. A solid is dissolved in a pressurized supercritical fluid and the solution is rapidly expanded to some lower pressure level through a heated nozzle, which causes the solid to precipitate and the formation of fine particles ${ }^{76,81}$. These particles are completely dry, solvent free, and they do not need further processing. However, this technique has some drawbacks such as the difficulty in scaling-up, the possible particles aggregation and nozzle blockage, the relatively high temperature, extremely high gas consumption and, overall, the poor solubility of most APIs in supercritical $\mathrm{CO}_{2}{ }^{75}$. On the other hand, the application of $\mathrm{CO}_{2}$ as anti-solvent is an alternative recrystallization technique for processing solids that are insoluble in SCFs. The solute is first dissolved in an organic solvent, then the 
system is pressurized with $\mathrm{CO}_{2}$ that is put in contact with the solution ${ }^{75}$. This method exploits the ability of $\mathrm{CO}_{2}$ to dissolve in organic solvent, lowering the solvent power of the liquid for the compounds in solution, thus causing the solids to precipitate ${ }^{76}$. In SAS method, $\mathrm{sc}-\mathrm{CO}_{2}$ is first pumped inside the high-pressure vessel until the system reaches the chosen pressure and temperature, then, the organic solution is sprayed through a nozzle into the SCF bulk leading the formation of the particles that are collected on a filter at the bottom of the vessel ${ }^{75,81}$. The major drawback of this technique is the possible residual solvent present in the particles produced ${ }^{76}$. Regarding PGSS, briefly, it consists in dissolving sc- $\mathrm{CO}_{2}$ as a solute in the bulk of melted materials and the subsequent quick expansion of this gas saturated solution through a nozzle, causing the atomization of the melt material, with complete evaporation of the gas and the formation of particles ${ }^{77,82}$. PGSS method is going to be more detailed in the next section of this chapter.

As already mentioned, besides the precipitation techniques, supercritical fluids can be applied in other fields of pharmaceutical industry. Supercritical drying method consists in the solvent removal by SCF, which exploits the great diffusivity of the compressed $\mathrm{CO}_{2}$ as well as the easy evaporation of organic solvent into the supercritical phase ${ }^{75}$. The efficacy of the drying process is function of the solid/solvent and the solvent/SCF affinity ${ }^{81}$. Supercritical drying can advantageously be applied to produce aerogels, where the organic solvent, e.g., ethanol, is removed from the gel by supercritical carbon dioxide. Moreover, APIs can be further loaded in this aerogel structures through supercritical impregnation 81. The specific properties of small $\mathrm{sc}-\mathrm{CO}_{2}$ molecules allow a high and fast penetration into the cores of solid porous materials. Aerogels are a promising field for pharmaceutical applications and thus, this topic will be further detailed in one of the following sections in this chapter. 
Chapter 1

\subsection{PGSS}

The PGSS ${ }^{\circledR}$ technique was patented by Weidner and co-workers ${ }^{83}$ and it is considered one of the most attractive $\mathrm{CO}_{2}$ based micronization processes because as it do not relies on the solvent strength of $\mathrm{CO}_{2}$, it employs relatively low operating pressures and can totally eliminate the need for organic solvents ${ }^{84}$. The major advantages of this process, in comparison with other supercritical-based precipitation methods, is the low intake of carbon dioxide, the possibility to process thermolabile substances, and also the fact that the compound to be micronized do not need to be soluble in $\mathrm{CO}_{2}$, being PGSS ${ }^{\circledR}$ already in operation at large scale ${ }^{42,81,85-}$ ${ }^{87}$. A schematic diagram of a typical PGSS ${ }^{\circledR}$ process is presented in Figure 10.

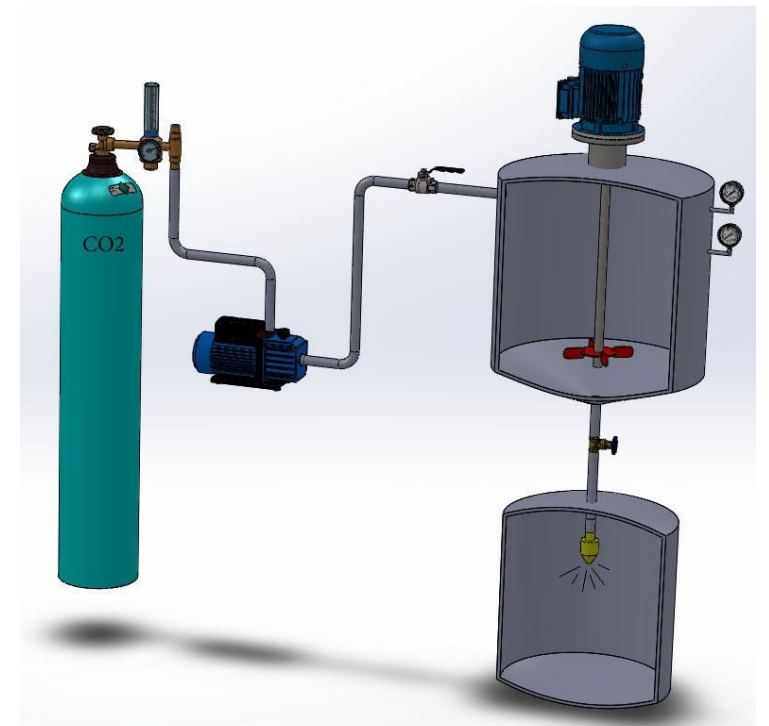

Figure 10| Particles from Gas Saturated Solution (PGSS ${ }^{\circledR}$ ) technique.

Briefly, the process consists in dissolving the compressed gas into the molten material in a stirred high pressure reactor until saturation is reached. The gassaturated solution formed which can typically contain between $5-50 \mathrm{wt}$. \% of the compressed gas is then expanded through a nozzle to ambient pressure, causing 
the release of $\mathrm{CO}_{2}$ with large cooling effect due to the energy consumption, ultimately leading to the precipitation of the compounds $41,77,86,88$.

The morphology, size and apparent density of the produced particles may depend on several parameters such as the structure and viscosity of the compounds to be precipitated, the operating conditions, and even the geometry of the equipment used to perform the PGSS ${ }^{\circledR}$ process ${ }^{76,89,90}$. Generally, the average particle size decreases when using higher pressures, and thus higher carbon dioxide content, lower temperature values, and smaller nozzle diameters, being the particles more spherical as higher temperatures are used ${ }^{77,85,91-93}$. Thus, the prior thermodynamic knowledge of the solubility of $\mathrm{CO}_{2}$ in the molten materials, as well as the determination of the solid-liquid transition of a compound in the presence of carbon dioxide is of extremely importance for the development of the experimental $\operatorname{plan}^{76,94}$.

PGSS $^{\circledR}$ process has already been applied for the micronization of polymers, fats, waxes, resins, natural products and active pharmaceutical ingredients ${ }^{76,86,94}$. This technique is especially suited for processing polymers and fats in which $\mathrm{CO}_{2}$ has a large solubility and moreover it has a melting point depression effect allowing to spray matrices that under classical conditions can hardly be sprayed or can even not be sprayed at all ${ }^{86}$. The extent of melting point depression experimented by each substance depends on the amount of $\mathrm{CO}_{2}$ that solubilizes into the substance and is caused by molecular interactions between dissolved $\mathrm{CO}_{2}$ and the substance of interest ${ }^{75}$ Determination of solid-liquid transitions in pressurized systems is essentially as it gives information on the pressure needed to melt the substance to be micronized and form a liquid phase at a given temperature ${ }^{95,96}$.

First PGSS ${ }^{\circledR}$ reported application was for the generation of powders from Polyethylene glycols (PEGs) ${ }^{97}$. PEG is a widely used hydrophilic polymer due to its biocompatibility and non-toxicity; it is used as a carrier material in the development of pharmaceutical and cosmetic formulations and has been employed by different 
authors as a model substance in order to obtain a better knowledge of this technique

The main limitation pointed to the $\mathrm{PGSS}^{\circledR}$ process is that the solute has to be melted, which can be problematic for heat sensitive materials ${ }^{80}$. Nevertheless, it is still possible to produce particles from compounds that are not melted during the PGSS $^{\circledR}$ process, like the case of some API's, by incorporating these compounds in liquefied polymers or lipids, and further atomize this suspension ${ }^{76,98}$. This was the strategy used by Critical Pharmaceuticals Ltd (Nottingham, UK) for the development of a single shot tetanus vaccine ${ }^{99}$. In order to improve the PGSS ${ }^{\circledR}$ method, several variants appeared as specific requirements for the production of particles $^{94}$.

\subsubsection{Hybrid Particles produced by PGSS}

PGSS $^{\circledR}$ is also a suitable technique for the production of well-controlled hybrid composite particles ${ }^{100}$. The reduction of the melting and glass transition temperature, due to the dissolution of $\mathrm{CO}_{2}$ in the compounds, makes possible the mixing of sensitive materials at low temperatures without the occurrence of unwanted reactions. Moreover, reducing the viscosity and surface tension enables the blend and the atomization of mixed compounds previously immiscible with one another, being possible the generation of particles with singular properties. It could be even possible to take advantage of the plasticizer effect of some carriers on other compounds to enhance the effect of $\mathrm{CO}_{2}$ on the physical properties of the mixture. This strategy is already used by Critical Pharmaceuticals Ltd (Nottingham, UK) with the so-called CriticalMix process. The developed formulations comprise mixtures of polymers that are able to provide a variety of release profiles. Despite the emergence of some variants of this process, PGSS ${ }^{\circledR}$ remains a method capable of generating particles with morphologies and compositions that have never been before achieved in just one step of production. 
The preparation of hybrid particles through $\mathrm{PGSS}^{\circledR}$ started in 2003 and since then , more than 20 publications regarding this topic have been published until the start of this PhD work, herein presented in Figure $11^{82,101-120,74,121,122}$.

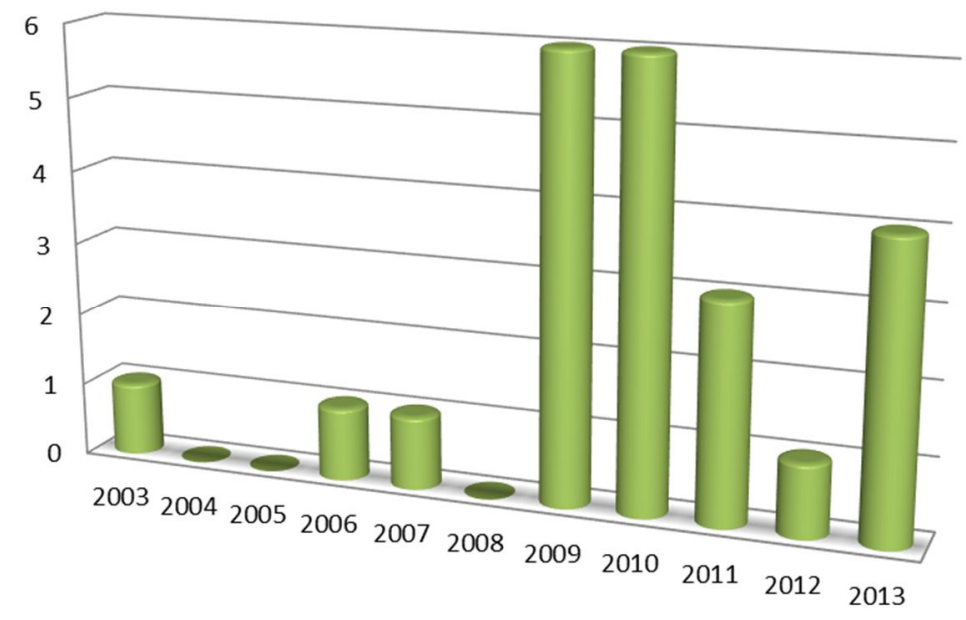

Figure 11| Number of publications regarding the production of hybrid particles through PGSS ${ }^{\circledR}$.

Keywords used here were: (PGSS ${ }^{\circledR}$ or Particles from Gas Saturated Solutions or Saturated Solutions) AND (Hybrid or Structured) AND (Particles or Drug Delivery Systems). Google Academics, Science Direct and Web of Knowledge were the main reference sources.

There was an increased number of publications concerning the production of hybrid particles from saturated solutions between 2009 and 2010. During 2011 and 2012 the number of publications reduced, but increased again throughout 2013. By analyzing the composition of the hybrid particles produced to date and published in the literature, it is possible to see that the majority is composed by a mixture of lipids or by a mixture of lipids and polymers (Figure 12). 


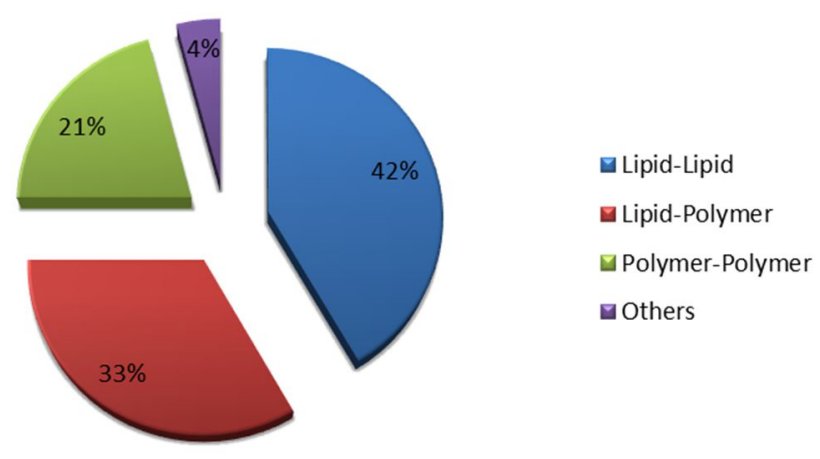

Figure 12| Types of hybrid particles produced through PGSS ${ }^{\circledR}$ thus far reported in the literature. Keywords used here were: (PGSS ${ }^{\circledR}$ or Particles from Gas Saturated Solutions or Saturated Solutions) AND (Hybrid or Structured) AND (Lipid or Polymer) AND (Particles or Drug Delivery Systems). Google Academics, Science Direct and Web of Knowledge were the main reference sources.

This tendency is in agreement with what has been said in this chapter, that is, the production of structured lipid carriers (composed of solid and liquid lipids) and lipidpolymer particles are two major strategies in pharmaceutical technology to develop drug delivery systems more robust, stable and efficient.

\subsubsection{Lipid-Lipid system}

Elvassore and co-authors ${ }^{101}$ started to develop hybrid lipid particles in 2003 , by producing a carrier composed of triestearin and phospatidylcholine. The authors were able to produce particles with $22 \mu \mathrm{m}$ using low temperature values. After 10 years, São Pedro et $\left.a\right|^{102,103}$ used the same carrier system with the purpose of encapsulating curcumin, a natural curcuminoid with biomedical applications, through the variant Gas-Assisted Melting Atomisation (GAMA), developed by Salmaso and co-authors ${ }^{111}$, where air streams are present in the atomiser and in the precipitation vessel, to facilitate the atomisation process and prevent the formation of agglomerated particles. The presence of phosphatidylcholine not only 
prevented the formation of a perfect crystal lattice of tristearin, thus enhancing the drug load capacity of this carrier, but also caused a depression in its melting point. The authors verified that using dimethyl sulfoxide (DMSO), with the purpose of improving the dispersion of the active compound in the lipid matrix, causes the aggregation of the particles. Furthermore, the encapsulation efficiency of curcumin decreased by increasing the amount of this bioactive compound in the initial mixture, probably due to a phase separation in the mixing vessel and the resulting presence of curcumin residues inside this chamber at the end of the experiment. Nevertheless, its structure was preserved during the PGSS ${ }^{\circledR}$ process.

Choosing hybrid materials as drug delivery systems is an increasingly used strategy for the enhancement of drug's solubility. By using Gelucire $50 / 13^{\text {tw }}$ (Stearoyl polyoxyl-32 glycerides) and Precirol ${ }^{\text {tm }}$ ATO 5 (Glyceryl distearate) as carriers, with a mass ratio of 1:1, Sampaio de Sousa and co-authors ${ }^{104,105}$ were able to increase the solubility of trans-chalcone both in gastric and intestinal fluid. The particles obtained with this new lipid formulation had a slightly broader size distribution with an average size of $6.7 \mu \mathrm{m}$. Since both carrier matrices have glycerides in their composition, the authors had difficulty distinguishing them through Attenuated total reflection Fourier transform infrared spectroscopy (ATR-FTIR), due their overlapping infra-red spectra. This demonstrates the challenge in characterising drug delivery systems composed by similar matrices. Nevertheless, ATR-FTIR analyses showed an effective mixing between the carriers and the active compound.

Semenzato and co-authors ${ }^{106,123}$ developed lipid nanoparticles composed of epidermal lipids with great potential to act as cosmetic ingredient in dermatological products. The authors precipitated binary mixtures of ceramide, cholesterol and fatty acids through $\mathrm{PGSS}^{\circledast}$, producing bigger particles while working at higher temperature, being the effect of pressure almost irrelevant. Interestingly, the lipid nature had also an effect in the final size of the particles, that is, larger particles 
were produced when ceramide and cholesterol, that have higher molecular weight (MW), were present in major quantities. The solid lipid nanoparticles were further incorporated into cream-gel systems, revealing that they were appropriate for emulsion formulation through a cold process.

García-González and co-authors ${ }^{82,107}$ developed a structured matrix composed of two lipids at equal mass ratio, Glyceryl Monostearate and Cutina ${ }^{\text {tw }}$ HR (Hydrogenated Castor Oil, waxy triglyceride), with supercritical silanized nanoparticulate titanium dioxide (TiO2), suitable to deliver both hydrophilic and hydrophobic drugs. The aim of the authors was to produce hybrid particles that could be used not only as sunscreens with UV-radiation protection properties free of organic absorbers, but also as lipid formulations for the treatment of skin diseases. The purpose of using a mixture of lipids to produce a matrix was again to achieve a crystal structure with more imperfections, thus, with higher drug load capacity. Moreover, the use of lipid compounds reduces the risk of $\mathrm{TiO}_{2}$ nanoparticles toxicity. The authors verified that the hydrophobic drug used in this study, ketoprofen, was encapsulated with a higher efficiency into the lipophilic particles in comparison to the hydrophilic drugs used, namely caffeine or glutathione. The low encapsulation efficiency of caffeine was not only due to its high solubility in $\mathrm{scCO}_{2}$ and further precipitation inside the mixing vessel throughout depressurisation but also due to its low solubility in the lipid carriers used. In order to increase the dissolution of caffeine in the lipophilic matrix, the authors added water to the initial mixture allowing the formation of an emulsion. The precipitation of the emulsion has led to the formation of particles with higher amount of active compound and the presence of water led to the formation of the nonstoichiometric caffeine hydrate, which was quickly dissolved during the release profile assay. The strategy to add water to the system in order to increase the solubility of hydrophilic molecules in lipophilic compounds could not be used for glutathione, since this drug rapidly oxidizes in aqueous solutions. Despite the high 
solubility of ketoprofen in $\mathrm{scCO}_{2}$, the drug was encapsulated with high efficiency due to its hydrophobic nature and high compatibility with the lipid matrices. This hybrid system was further studied by Argemí and co-authors ${ }^{108}$ concluding that the carrier provided a sustained release of ketoprofen for at least $24 \mathrm{~h}$, being suitable for topical administration of active compounds, since it avoids the skin irritation that sometimes occurs with burst releases. Moreover, the hybrid structure prevented the degradation of ketoprofen by light.

Magnetic nanoparticles (MNPs) are promising carriers for biomedical applications not only as contrast agents but also as drug delivery systems, mostly due to the possibility of moving them to the target site through the use of an external magnetic field. However, it is necessary to encapsulate these particles in biocompatible materials to enable them to be administrated into the human body. Vezzù and co-authors 109 successfully encapsulated MNPs into mixtures of triestearin and phosphatidylcholine by the variant GAMA, increasing their biocompatibility for further diagnostic and therapeutic applications. The nanoparticles produced had bi- and trimodal size distributions, yielding smaller particles when the mixture of lipids was used, probably due to the surfactant effect of phosphatidylcholine. The authors have also verified that the encapsulation efficiency of the MNPs was independent of the type of lipids used, increasing with the concentration of magnetite in the initial mixture. The lipid particles produced containing magnetite presented themselves as a viable alternative to polymeric matrices. 
Table 5| Hybrid lipid particles produced through PGSS ${ }^{\circledR}$.

\begin{tabular}{|c|c|c|}
\hline Carrier & Active compound & References \\
\hline Triestearin and Phospatidylcholine & Curcumin & 101-103 \\
\hline Gelucire $50 / 13^{m m}$ and Precirol ${ }^{\mathrm{rm}}$ ATO 5 & Trans-chalcone & 104,105 \\
\hline Ceramide, Fatty acids, Cholesterol & - & 106 \\
\hline $\begin{array}{l}\text { Glyceryl Monostearate and Cutina }{ }^{\mathrm{Tm}} \\
\text { HR }\end{array}$ & $\begin{array}{c}\mathrm{TiO}_{2} \text { and caffeine, glutathione or } \\
\text { ketoprofen }\end{array}$ & $82,107,108$ \\
\hline Triestearin and Phosphatidylcholine & Magnetic nanoparticles & 109 \\
\hline
\end{tabular}

\subsubsection{Lipid-Polymer system}

$\mathrm{PGSS}^{\circledast}$ technique can also be applied for the production of protein-loaded hybrid particles, since it does not need the use of organic solvents and therefore maintains the structure and functions of these compounds. During preliminary studies, Salmaso and co-authors ${ }^{111}$ were able to encapsulate up to $80 \%$ of insulin in a mixture of lipid carriers, namely tristearin and phosphatidylcholine, with and without the incorporation of PEG 5000, through the use of the variant GAMA. The authors used DMSO to obtain homogeneous protein/carrier mixtures and thus were able to prevent protein precipitation and segregation during the mixing step. Should be noticed that DMSO is highly miscible with $\mathrm{CO}_{2}$ and, consequently, it was removed from the final particles during the depressurization. The carrier composition was found to play a significant role in the protein release profile, as the formulation with PEG showed a burst and faster release of insulin, while the formulation without the polymer showed a slowly release. Also, the formulation containing the hydrophilic polymer was more stable to sedimentation in aqueous media, since PEG prevented lipid particle aggregation. In any case the activity of the protein was maintained. Further studies were performed by the authors ${ }^{112}$ in order to investigate the pharmacokinetic and pharmacodynamic in vivo performance of the drug delivery systems developed, by using insulin and recombinant human growth hormone (rh-GH) as model proteins. Once again, the 
combination of tristearin, phosphatidylcholine and PEG 5000, in the presence of DMSO and $\mathrm{SCCO}_{2}$, enabled a low melting homogenous dispersion. Small amounts of PEG were used so as to avoid the burst release of proteins which could compromise the therapeutic purpose of the drug delivery system. As to improve the atomization step and consequently obtain a homogeneous distribution of particle size, the authors not only slightly decreased the temperature of the process in comparison to the preliminary studies, increasing the $\mathrm{CO}_{2}$ dissolved in the lipid mixture, but also equipped the plant with a peristaltic pump that supports the mixture's atomization. However, the encapsulation efficiency of the proteins was unexpectedly low. The authors explained this outcome owing to partial precipitation of the compounds in the mixing vessel or to interactions between the proteins and the lipid compounds of the mixture. Nevertheless, the proteins formulated in particles were released in a typical diffusive mechanism for four days with preservation of their biological structure and activity. Furthermore, during the experiments using appropriate mouse models, the authors verified that the hybrid formulation enhanced the oral bioavailability of the proteins due to their protection from enzymatic degradation in the stomach.

Some bioactive compounds need to be functionalized with PEG molecules in order to increase their stability and hydrophilic properties. Vezzù and co-authors ${ }^{113}$ used the same hybrid carrier previously described, composed by triestearin and phosphatidylcholine, to incorporate the model protein Ribonuclease A (RNAse) functionalized with PEG 5000, so as to develop a drug delivery system with improved therapeutic performance. The authors concluded that the temperature of the process had influence not only in the final size of the particles produced but also in the yield of the method, that is, both parameters increased with increasing temperature values. Furthermore, pressure increase during the PGSS ${ }^{\circledR}$ experiments led to the formation of smaller particles up to a certain pressure value, thereafter the particle size was increased when using higher pressures. The addition of DMSO 
to the mixture of compounds, so as to facilitate the dispersion of the protein in the carrier matrix, led also to the precipitation of smaller particles. However, while using high amounts of DMSO, the authors observed the formation of large aggregates due to the incomplete solvent extraction by $\mathrm{CO}_{2}$. Despite the fact that the product yield obtained with PEGylated RNAse was very low, its encapsulation efficiency was considerably higher than the encapsulation of the native protein. Moreover, the enzymatic activity of functionalized RNAse was strongly preserved, leading the authors to conclude that the PEGylation prevented the tight interaction between the protein and the carrier compounds, preserving the protein activity. Lastly, the hybrid formulation developed allowed a slow release of PEGylated protein. Nunes et al ${ }^{114}$ explored the supercritical fluid precipitation technology to prepare lipid-polymer hybrid drug delivery systems. The authors developed structured spherical particles comprising PEG 4000 and Gelucire 43/01 (Hard fat), with different mass ratios. Differential Scanning Calorimetry and Transmission Electron Microscopy analyses suggested a possible organization of the materials with the formation of a core-shell structure. Rodriguez-Rojo and co-authors ${ }^{115}$ proceeded with the characterization of these particles by confocal microscopy using a hydrophilic fluorescent dye, concluding that their shell was constituted by PEG 4000. Moreover, the authors produced flufenamic acid-loaded particles, whose release profile also suggested the presence of the hydrophilic polymer in the shell. Nunes et al ${ }^{114}$ also developed a hybrid system in order to increase the bioavailability of quercetin, an essential micronutrient present in vegetables and fruits, which has low oral bioavailability. By using Glyceryl Monostearate blended with Hydroxypropyl- $\beta$-Cyclodextrin, it was possible to produce porous particles with increased quercetin intestinal transport, and thus, with high bioavailability. Almeida et $a^{116}$ reported that this new drug delivery system was capable not only to increase the solubility of quercetin in the intestinal fluid, but also to enhance the antioxidant activity of the flavonoid. 
With the purpose of producing pulmonary microparticles, Vijayaraghavan et al ${ }^{117,124}$ have studied whether it would be possible to process Polyethylenoglycols with fatty acids through PGSS ${ }^{\circledR}$. The authors studied the thermodynamic behavior of free PEGs, with different molecular weights, mixed with stearic, palmitic or myristic acid. They verified that fatty acids with low melting temperature $(T \mathrm{~m})$, namely palmitic and myristic acid, were capable to act as plasticizing agents and to reduce the $T_{\mathrm{m}}$ of PEG, making these blends suitable to be processed by $\mathrm{PGSS}^{\circledR}$. By analysing the precipitated particles, it was possible to conclude that myristic acid produced the smaller particles with the best control of particle size when mixed with PEG, resulting in a higher process yield in comparison with other fatty acids. The authors believe that this fact is due to the influence of myristic acid on the $T_{\mathrm{m}}$ and viscosity of the polymer blend being more evident when using a more viscous PEG (high mw). It is easier to break up liquefied carriers into smaller particles when using materials with lower viscosity. The morphology of these hybrid particles, instead of being spherical like in the case of processing PEG alone ${ }^{125}$, were irregularly shaped, being this event attributed to different solidification rates during the atomization process. Fraile et al ${ }^{118}$ produced systems composed of Pluronic L64 with the glycerolipid, Gelucire $43 / 01^{\mathrm{Tm}}$ or Glyceryl Monostearate, through PGSS ${ }^{\circledR}$ in order to obtain delivery systems with more controlled release of drugs. In both cases, it was added some water to the initial mixture in an attempt to get a rearrangement of the carrier materials, however this was not accomplished and only larger aggregates were formed. 
Table 6| Hybrid lipid-polymer particles produced through PGSS ${ }^{\circledR}$.

\begin{tabular}{|c|c|c|}
\hline Carrier & Active compound & References \\
\hline Tristearin, phosphatidylcholine and PEG 5000 & $\begin{array}{l}\text { Insulin, r-hGH, } \\
\text { RNAse }\end{array}$ & $111-113$ \\
\hline Gelucire $43 / 01^{m}$ and PEG 4000 & Flufenamic Acid & 114,115 \\
\hline Glyceryl Monostearate and Hydroxypropyl- $\beta$-Cyclodextrin & Quercetin & 114,116 \\
\hline Fatty acids and PEG's & - & 117 \\
\hline $\begin{array}{l}\text { Pluronic L64 and Gelucire } 43 / 01^{\mathrm{mm}} \text { or Glyceryl } \\
\text { Monostearate }\end{array}$ & Ibuprofen & 118 \\
\hline
\end{tabular}

\subsubsection{Polymer-Polymer system}

Most of the newly discovered drug candidates are poorly water soluble and therefore is important to improve their dissolution rate in order to obtain higher bioavailability of drugs. Brion et ${ }^{119}$ developed a formulation through $\mathrm{PGSS}^{\circledR}$ based on a mixture of hydrophilic polymers in order to promote the solubility and dissolution rate of a new poorly water-soluble active compound. The presence of a non-ionic surfactant, Poloxamer 407, in combination with PEG 400 and PEG 4000 allowed a more effective wetting of the particles. Moreover, the PGSS ${ }^{\circledR}$ process produced smaller particles with high porosity, which also increases the diffusion of the active compound into the dissolution medium. The authors have also studied the effect of several operating parameters on the precipitation of the hydrophilic solid dispersion, concluding that the main significant were the temperature and pressure. They have also concluded that the drug loading influenced the particle size of the final formulation, with larger particles being produced when using a high drug load. Since the active compound was not soluble in the polymeric mixture, its presence resulted in an increase in viscosity of the system and thus the production of larger particles. 
Jordan et al ${ }^{120}$ developed microparticles capable to confer sustained release of a protein for subcutaneous injections. The human growth hormone (hGH), which is a $22 \mathrm{kDa}$ protein, was processed in the dry state with the biocompatible polymers Poly Lactic-co-Glycolic Acid (PLGA) and Poly Lactic Acid (PLA) through PGSS ${ }^{\circledR}$, with an encapsulation efficiency of near $100 \%$. After testing several polymer ratios with different emulsifiers, the elected formulation was composed by PLGA and PLA with a $w / w$ ratio of $90: 10$ and Poloxamer 407, capable to produce $100 \mu m$ rounded particles with few pores. The structure and function of the protein was preserved, since the mixture of polymers used is capable of being plasticised at temperatures just above $32 \circ \mathrm{C}$ thus avoiding the degradation of the drug. Microparticles showed an initial in vitro burst of around 35\% and a sustained release for more than 14 days, revealing that some of the protein was positioned close to the surface being available to readily diffuse out of the polymeric particles. It is important to mention that hGH-loaded particles of PLGA or PLA alone did not show the features necessary for the subcutaneous administration of this protein, such as size and drug release properties. Thereafter, this long acting formulation of hGH established preclinical proof of concept in non-human primate's pharmacokinetic and pharmacodynamic studies. Currently, this vaccine is being developed at Critical Pharmaceuticals Ltd (Nottingham, UK) as a once every two-week injection and has already completed preclinical development.

Not only drugs can be present at solid state throughout PGSS ${ }^{\circledR}$ process, and Casettari and co-authors ${ }^{74}$ have proved that by developing a new biodegradable and mucoadhesive formulation composed by PLGA, MPEG and Chitosan. Both polymers were plasticized in $\mathrm{scCO}_{2}$ and thus were used as the liquefied matrix where the polysaccharide was mixed and dispersed as a dry powder. Therefore, this suspension was further precipitated by PGSS ${ }^{\circledR}$, producing microparticles (<100 $\left.\mu \mathrm{m}\right)$ under very mild conditions. Like already seen in other studies, the presence of mPEG led to an increase in particle size with the formation of more rounded and 
smooth particles. The presence of chitosan on the surface of the particles conferred mucoadhesive properties to this formulation, which was confirmed through an in vitro assay.

In order to process highly viscous polymers, like PLA, into small particles, it is often necessary to use high temperatures or volatile organic solvents to facilitate their handling. Kelly et $a l^{121}$ reported an alternative method to overcome this problem. By using a $\mathrm{sCCO}_{2}$ assisted mixing of PLA with PEG 6000, a polymer with lower viscosity, they developed a new formulation with properties of both carriers. Lowering the PLA viscosity by the addition of PEG, allied to the plasticizing effect of $\mathrm{CO}_{2}$ in the polymers matrix, allowed the processability of these carriers at temperature as low as $40^{\circ} \mathrm{C}$ by $\mathrm{PGSS}^{\circledR}$. The fine white particles obtained were bigger, more spherical and smoother as the content of PEG increased. To explain this, the authors hypothesized that, since the solubility of $\mathrm{CO}_{2}$ is lower in PEG than in PLA, the incorporation of PEG in the polymeric mixture would lead to less gas loss, during depressurization, resulting in smoother and more spherical particles. Fraile $e$ t $a l^{118}$ showed that $\mathrm{PGSS}^{\circledR}$ is a well suited technique to formulate waterinsoluble drugs with distinct features by simply varying the carrier materials. By formulating Ibuprofen with Pluronic F127 and L64, it was possible to increase by 5 fold the dissolution of the drug in simulated gastric fluid, in comparison with the pure unprocessed drug. Apparently, these polymers are capable to form micelles in aqueous solutions and thus stabilize the drug in their hydrophobic cavities leading to increased drug solubility. 
Table 7| Hybrid polymeric particles produced through PGSS ${ }^{\circledR}$.

\begin{tabular}{|c|c|c|}
\hline Carrier & Active compound & References \\
\hline Poloxamer 407, PEG 400 and PEG 4000 & YNS3107 & 119 \\
\hline PLGA and PLA & hGH & 120 \\
\hline PLGA, mPEG and Chitosan & - & 74 \\
\hline PLA and PEG 6000 & - & 121 \\
\hline Pluronic F127 and L64 & Ibuprofen & 118 \\
\hline
\end{tabular}

\subsubsection{Final remarks}

The increasing number of publications regarding the production of hybrid particles through PGSS ${ }^{\circledR}$ evidences that it is a promising method for the preparation of these singular structures. PGSS ${ }^{\circledR}$ could be implemented in several industries due to its high batch-to-batch reproducibility and high purity and sterility of compounds produced, being feasible even at economical level. This environmentally friendly method has already a simple and reproducible scale up process, being in compliance with the regulatory demands of the current Good Manufacture Practices (GMP) for the production of particles from single carriers ${ }^{126}$. Nevertheless, it is still necessary the acquirement of thermodynamic and mass transfer knowledge of ternary and multinary systems, that is, a detailed understanding of all the process parameters that affect the characteristics of the final hybrid particles produced. With a critical evaluation of these aspects, PGSS ${ }^{\circledR}$ could become a predictable, consistent and widespread method for the production of structured particles at industrial level.

\subsection{Aerogels}

Since its discovered by Steven Kistler in 1930s, aerogels have been gaining a great deal of attention in the fields of material sciences due to its unique properties ${ }^{127}$. This special class of materials possess a extremely porous and lightweight 
structure, low thermal conductivity, a large surface area and high mechanical strength, which make aerogels suitable to be employed in several fields, from thermal insulators, particle filters or active packaging until carrier materials to be used as drug delivery systems ${ }^{128,129}$. Thus, the interest of aerogels is growing, as indicated by the number of publications regarding this topic increasing each year (figure 13).

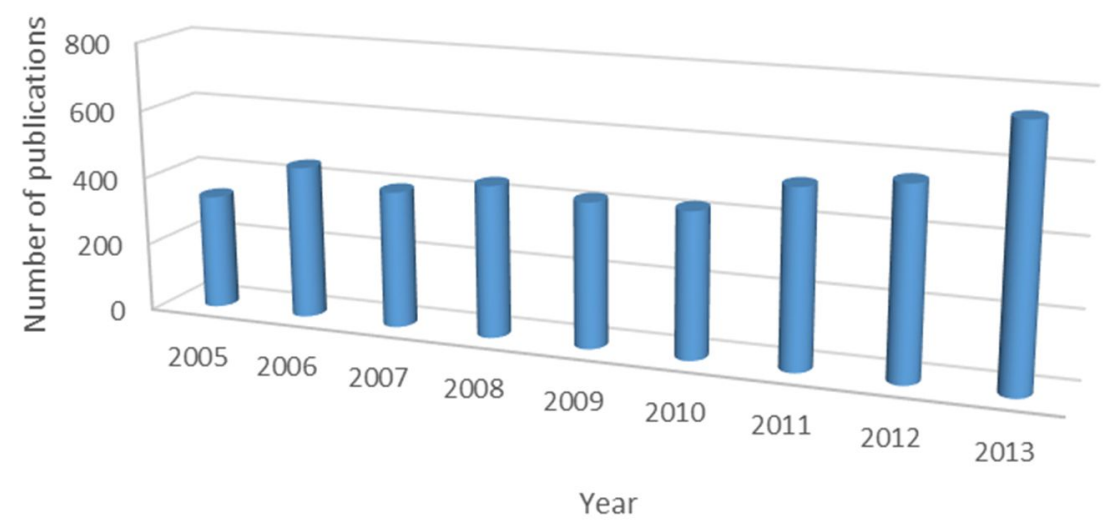

Figure 13| Number of scientific publications contributing to the subject "aerogels" by year 130

Aerogels are produced via drying of hydrogels using a suitable technique, such as air-drying, freeze-drying and supercritical drying ${ }^{128}$. However, in air-drying, capillary forces from water evaporation usually lead to structure collapse (xerogel), while in freeze and supercritical drying methods, minimal capillary force is applied, preserving the original structure of the gel and creating large surface areas ${ }^{129,130}$. Aerogels are classified according to their appearance (monoliths, powders or films) its different microstructure (microporous, mesoporous, mixed porous) or by defining their composition (inorganic or organic). Inorganic silica aerogels are prepared in a similar way as the polysaccharide-based organic aerogels. The first step consists in the formation of a hydrogel from an aqueous starting solution triggered through chemical nature (chemical cross-linker) or physical nature $(\mathrm{pH}$, temperature as cross-linking promoter) ${ }^{131}$. The following step is called the 
aging/solvent exchange step and consist of replacing the water within the porous structure with an appropriate solvent which is usually an alcohol (ethanol). final step consists in drying the wet alcogel with supercritical carbon dioxide ${ }^{130}$. A simple mechanical grinding could be further used for the production of aerogel granules or powders without changing the pore and surface properties. Emulsion/gelation is another technique that can be used for the development of aerogel particles. This method involves the preparation of an emulsion by mixing the aqueous solution with a suitable oil (forming a water/oil emulsion) in the presence of surfactants, followed by the gelation of the discontinuous phase. After separation of spheres from the oil phase, supercritical drying is used to obtain the aerogel microspheres which can be either inorganic or organic ${ }^{128,131,132}$. For applications of aerogels in life sciences, biocompatibility and biodegradability are essential ${ }^{130}$. Silica aerogels, which are biocompatible but not biodegradable, usually have higher surface areas in comparison with organic aerogels. Nevertheless, polysaccharide-based organic aerogels have been proved to be safe, biodegradable, stable, non-toxic and renewable, with low costs of production due to their abundance in nature and ease of processing which are more attractive for drug delivery applications ${ }^{130,133}$. Sources of natural polysaccharides can be parts of plants (starches, pectins, celluloses, $\beta$-glucans, gum arabic, etc.) and seaweeds (carrageenans, alginates, agarose, furcellaran), animals (chitosan, hyaluronan) and fungi (scleroglucan, schizophyllan) ${ }^{134}$. Moreover, several patents and scientific articles have been already published claiming that organic aerogels could be loaded with pharmaceutical compounds and further used as drug delivery systems ${ }^{131,135}$.

\subsubsection{Incorporation of drugs into aerogels}

There are different methods to load drugs into aerogel matrices, whether before/after the sol-gel process (in situ) or directly into the prepared aerogels (ex situ)(figure 14) ${ }^{130}$. 
a)

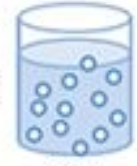

Sol

b)

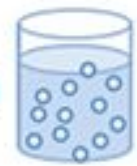

Sol

c)

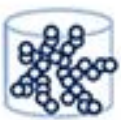

Aerogel

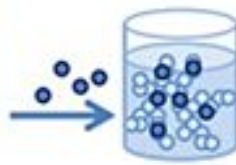

Gelation
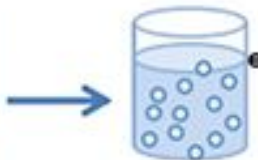

Gelation

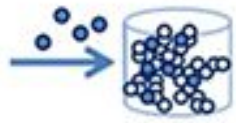

Loaded

Aerogel

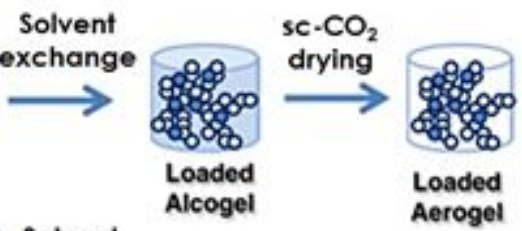

Solvent

exchange
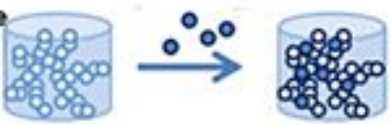

sc. $\mathrm{CO}_{2}$ drying

Loaded

Alcogel

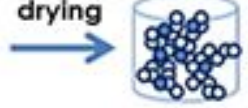

Loaded

Aerogel

Figure 14| Preparation routes of drug loaded aerogels; a) Addition of the drug during the sol-gel process (before the gelation); b) Addition of the drug after the sol-gel process (during ethanolic step); c) Addition of the drug through adsorption/precipitation in the already dried aerogel ${ }^{131}$.

The first option is to add the drug before the gelation step, which is an attractive and simple way due to its flexibility for different target compounds. With this strategy, APIs that are dissolved in the initial aqueous solution are expected to be trapped in the aerogel matrix during the gelation step and withstand the following solvent exchange and drying steps that lead to the drug loaded aerogel. The second approach is to add the drug during the ethanolic step (after solvent exchange): the alcogel is put in contact with the drug which then diffuses into the pores of the alcogel until the concentrations in the pore liquid and in the ethanolic solution become equal. Afterwards, drug-loaded alcogel is exposed to supercritical $\mathrm{CO}_{2}$ drying, in which scCO2 will act as an anti-solvent reducing the solvent power of ethanol which is present in the pores and leading to the precipitation of the drug in the pores of the alcogel. Supercritical drying will continue until all the solvent inside the pores is removed. This process is very similar to SAS process already explained in this chapter. To mention that the API should be insoluble in $\mathrm{scCO}_{2}$ in order to 
prevent it from being dragged by supercritical fluid flow ${ }^{130,131}$. The third strategy involves the supercritical drug loading of already produced aerogel. Briefly, the drug and the aerogel are placed into a high pressure cell and the system is pressurized by adding $\mathrm{CO}_{2}$; the drug will solubilize into the $\mathrm{sc}-\mathrm{CO}_{2}$, that will diffuse it into the aerogel pores. In this method, it is required that the drug has high solubility in $\mathrm{scCO}_{2}$. Thus, the loading capacity depends both on drug's solubility in $\mathrm{scCO}_{2}$ and on their affinity to the aerogel surface ${ }^{130,131,136}$.

\subsubsection{Hybrid aerogels}

Hybrid aerogel particles, like other composite materials, are always attractive due to the combination of diverse materials and their properties in one single entity, suppressing the disadvantages of one material with superior properties of another 136. Moreover, the accessibility of functional groups of some compounds, e.g., amino groups in chitosan, can promote the adsorption of chemical species with specific characteristics. For these reasons, the application of hybrid aerogels in the pharmaceutical field as drug delivery systems could be a viable choice, thus a very recent one. Several methods have been already developed to synthesize silicapolymer hybrid aerogels mainly for a wide variety of applications other than drug delivery ${ }^{131}$. The addition of a synthetic polymer to a polysaccharide-based aerogel could not only improve the mechanical properties of the aerogel, but also provide protection and promote a controlled release of the drug. First studies of chitosansilica aerogels as drug delivery systems showed 17 wt.\% gentamicin loaded within the non-cytotoxic aerogel, with improved textural properties and mechanical stability against acidic and basic solutions, which were not present in aerogels from each individual component of the hybrid material ${ }^{128}$. Sanli and co-authors developed in 2011 a novel composite of silica-poly(- ethylene glycol) aerogel and studied its potential as a ketoprofen delivery system. The authors showed that the drug release can be controlled by varying the aerogel hydrophobicity, as well as 
through varying the amount of the poly(ethylene glycol) (PEG) in the hydrogel coating. Increasing hydrophobicity was shown to decrease the release rate of ketoprofen, which was expected, since water diffusion through the aerogel pores became gradually difficult with increasing hydrophobicity ${ }^{137}$. In 2012, Alnaief and co-authors developed a novel process for coating aerogel particles with polymeric materials using a spouted bed technology ${ }^{138}$. The polymers, firstly PEG 2000 and secondly $\mathrm{pH}$ sensitive polymer Eudragit ${ }^{\circledR} \mathrm{L}$, were sprayed as an aqueous suspension or melts over the ibuprofen-loaded silica aerogels. It was shown that the polymeric coating allowed a pH controlled release of the drug. During the same year, GarciaGonzalez and co-authors developed pectin cylindrical monoliths and microspheres aerogels containing maghemite nanoparticles, with potential to be applied as magnetic targeting drug delivery vehicles ${ }^{139}$. Veronovski and co-authors prepared in 2013 alginate aerogels with multi-layers by using a multi-step sol-gel process ${ }^{140}$. Despite using only always alginate as aerogel layer, this technique could be applied with other biopolymers with distinct properties in order to produce hybrid spherical multi-layer alginate-based aerogels. The combination of two materials with high surface areas and different surface properties would be interesting for maximizing the drug loading capacity of the delivery systems. Supercritical fluid deposition and chemical vapor deposition have also been attracting increased attention as post synthesis modification techniques, though the materials prepared in these studies were not intended for use in drug delivery applications ${ }^{131,141}$.

It is obvious that there is a lot to be further explored and studied in this field which may lead to the development of superior devices for drug delivery.

\section{Objectives}

Considering the above-mentioned aspects, the aim of the present dissertation was to explore and optimize (SCF)-based precipitation and drying technologies (as 
alternatives to conventional processes) to produce hybrid structures with improved features, such as high porosity and mucoadhesion or absorption properties, for efficient nose-to brain drug administration.

To achieve this goal, this thesis explored the development of hybrid particles comprising the following steps: (1) fundamental studies, such as phase behavior studies $\left(\mathrm{CO}_{2}+\right.$ lipids or/and polymers) ; (2) development of hybrid systems (structured lipid particles, lipid core-polymeric shell particles and hybrid alginatebased aerogel particles) with further solid-state characterization (e.g. morphology, particle size distribution); (3) development of hybrid systems loaded with model drug (e.g. ketoprofen) with further physicochemical characterization (e.g. encapsulation efficiency, in vitro drug release studies and mucoadhesive properties); (4) evaluation of hybrid particles' cytotoxicity and drug permeation through RPMI 2650 nasal cell line.

The results obtained are innovative, making this dissertation an advance in the development of drug delivery systems as nose-to-brain drug formulations.

\section{Thesis outline}

This thesis is divided into six chapters, following the research work performed during the PhD project. The present chapter describes the state of the art, background and general concepts which fall within the thesis' scope.

In Chapter 2, the development of lipid particles through PGSS ${ }^{\circledR}$ is reported, being this chapter divided into two parts. Part I focuses on knowledge acquisition regarding solid-liquid transitions of glycerolipids under pressurized $\mathrm{CO}_{2}$ with further development of solid lipid particles through PGSS ${ }^{\circledR}$. The effect of several operating parameters of the supercritical fluid precipitation process on the size and morphology of the solid lipid particles produced, namely temperature, pressure, nozzle diameter, and the co-precipitation with Coenzyme Q10, were investigated. 
Following the results obtained and the know-how acquired, Part II focuses on the production of novel structured lipid particles based on a binary mixture of solid and liquid lipids (at room and body temperature) with improved features (stability under storage and drug permeation) for mucosal delivery of a model drug (ketoprofen).

With the purpose of developing core-shell particles with supercritical fluids, Chapter 3 describes the possibility of producing for the first time hybrid particles composed by lipid multicores enveloped in a polymeric layer through Particles from Gas Saturated Solutions, without using organic solvents. To achieve that, a stable $\mathrm{O} / \mathrm{W} \mathrm{CO}$-saturated emulsion, constituted by a glycerolipid as the discontinuous phase and by an aqueous solution containing an hydrophilic polymer as continuous phase, was precipitated.

With the objective of taking advantage of supercritical fluids drying capacity of ethanolic solutions, the development of alginate-based hybrid aerogels in the form of microparticles $(<50 \mu \mathrm{m})$ was investigated in this work with evaluation of mucoadhesive properties. Moreover, aerogels were further loaded with model drugs and characterized regarding drug's physical state, load and release.

As a preliminary approach, the feasibility of the hybrid particles produced within this dissertation to be used as efficient carriers for nose-to-brain delivery was assessed and presented in Chapter 5 by using RPMI 2650 nasal cell model to test cytotoxicity and drug permeability. The extent to which the administration of drugs in particulate forms differ in relation to the permeability of the same compounds applied as solutions was also studied. Furthermore, RPMI 2650 cell line was further characterized in terms of mucus production and used as an effective alternative to animal tissues for solid drug-loaded formulations cytotoxicity and absorption studies.

In Chapter 6, the principal results previously presented in the different chapters are 
summarized, and the main conclusions are withdrawn and discussed in an integrated way. Possible challenges and perspectives are also presented.

\section{References}

1 W. a. Banks, Drug Deliv. Transl. Res., 2012, 2, 152-159.

2 P. G. Djupesland, J. C. Messina and R. A. Mahmoud, Ther. Deliv., 2014, 5, 709-733.

3 S. Bhaskar, F. Tian, T. Stoeger, W. Kreyling, J. M. de la Fuente, V. Grazú, P. Borm, G. Estrada, V. Ntziachristos and D. Razansky, Part. Fibre Toxicol., 2010, 7, 3.

4 D. J. Begley, Pharmacol. Ther., 2004, 104, 29-45.

5 S. Charlton, N. S. Jones, S. S. Davis and L. Illum, Eur. J. Pharm. Sci., 2007, 30, 295-302.

6 J. Chen, C. Zhang, Q. Liu, X. Shao, C. Feng, Y. Shen, Q. Zhang and X. Jiang, J. Drug Target., 2012, 20, 174-184.

7 L. R. Hanson and W. H. Frey, BMC Neurosci., 2008, 9, S5.

8 D. Mittal, A. Ali, S. Md, S. Baboota, J. K. Sahni and J. Ali, Drug Deliv., 2014, 21, 75-86.

9 L. Biddlestone-Thorpe, N. Marchi, K. Guo, C. Ghosh, D. Janigro, K. Valerie and H. Yang, Adv. Drug Deliv. Rev., 2012, 64, 605-613.

10 B. DJ, Acta Paediatr., 2003, 92, 83-91.

11 A. V Kabanov, E. V Batrakova and D. W. Miller, Adv. Drug Deliv. Rev., 2003, 55, 151-64.

12 S. Haque, S. Md, M. Fazil, M. Kumar, J. K. Sahni, J. Ali and S. Baboota, Carbohydr. Polym., 2012, 89, 72-79.

13 F. Malerba, F. Paoletti, S. Capsoni and A. Cattaneo, Expert Opin. Drug Deliv., 2011, 8, 1277-1296.

14 H. R. Costantino, L. Illum, G. Brandt, P. H. Johnson and S. C. Quay, Int. J. Pharm., 2007, 337, 1-24.

15 L. Illum, Eur. J. Pharm. Sci., 2000, 11, 1-18.

16 T. Deshpande, R. Masareddy and A. Patil, RGUHS J. Pharm. Sci., 2012, 2, 24-37.

17 L. Illum, J. Control. Release, 2003, 87, 187-198.

18 A. Lalatsa, A. G. Schatzlein and I. F. Uchegbu, Mol. Pharm., 2014, 11, 10811093. 
19 J. J. Lochhead and R. G. Thorne, Adv. Drug Deliv. Rev., 2012, 64, 614-28.

20 S. Grassin-Delyle, A. Buenestado, E. Naline, C. Faisy, S. Blouquit-Laye, L.-J. Couderc, M. Le Guen, M. Fischler and P. Devillier, Pharmacol. Ther., 2012, 134, 366-79.

21 C. V. Pardeshi and V. S. Belgamwar, Expert Opin. Drug Deliv., 2013, 10, 957-72.

22 C. L. Graff and G. M. Pollack, J. Pharm. Sci., 2005, 94, 1187-1195.

23 A. E.-E. Aly and B. L. Waszczak, Expert Opin. Drug Deliv., 2015, 12, 19231941.

24 S. Bahadur and K. Pathak, Expert Opin. Drug Deliv., 2012, 9, 19-31.

25 L. Kozlovskaya, M. Abou-Kaoud and D. Stepensky, J. Control. Release, 2014, 189, 133-140.

26 L. Jiang, L. Gao, X. Wang, L. Tang and J. Ma, Drug Dev. Ind. Pharm., 2010, 36, 323-336.

27 S. Mansuri, P. Kesharwani, K. Jain, R. K. Tekade and N. K. Jain, React. Funct. Polym., 2016, 100, 151-172.

28 V. V Khutoryanskiy, Macromol. Biosci., 2011, 11, 748-64.

29 K. Kumar, N. Dhawan, H. Sharma, S. Vaidya and B. Vaidya, Artif. cells, nanomedicine, Biotechnol., 2014, 42, 274-83.

30 J. Grießinger, S. Dünnhaupt, B. Cattoz, P. Griffiths, S. Oh, S. B. I. Gómez, M. Wilcox, J. Pearson, M. Gumbleton, M. Abdulkarim, I. Pereira De Sousa and A. Bernkop-Schnürch, Eur. J. Pharm. Biopharm., 2015, 96, 464-476.

31 C. Woertz, M. Preis, J. Breitkreutz and P. Kleinebudde, Eur. J. Pharm. Biopharm., 2013, 85, 843-853.

32 J. das Neves, M. F. Bahia, M. M. Amiji and B. Sarmento, Expert Opin. Drug Deliv., 2011, 8, 1085-104.

33 W. S. Cheow and K. Hadinoto, Colloids Surf. B. Biointerfaces, 2011, 85, 21420.

34 B. Mandal, H. Bhattacharjee, N. Mittal, H. Sah, P. Balabathula, L. A. Thoma and G. C. Wood, Nanomedicine, 2013, 9, 474-91.

35 C. S. Morales, P. M. Valencia, A. B. Thakkar, E. Swanson and R. Langer, Front. Biosci., 2013, 15, 529-545.

36 L. Zhang, J. M. Chan, F. X. Gu, J.-W. Rhee, A. Z. Wang, A. F. RadovicMoreno, F. Alexis, R. Langer and O. C. Farokhzad, ACS Nano, 2008, 2, 1696702.

37 R. H. Müller, K. Mäder and S. Gohla, Eur. J. Pharm. Biopharm. , 2000, 50, 161-77.

38 R. H. Müller, M. Radtke and S. a Wissing, Adv. Drug Deliv. Rev., 2002, 54 Suppl 1, S131-55.

39 J. Pardeike, A. Hommoss and R. H. Müller, Int. J. Pharm., 2009, 366, 17084.

40 M. Muchow, P. Maincent and R. H. Muller, Drug Dev. Ind. Pharm., 2008, 
34, 1394-405.

41 D. Sanli, S. E. Bozbag and C. Erkey, J. Mater. Sci., 2011, 47, 2995-3025.

42 E. Elizondo, J. Veciana and N. Ventosa, Nanomedicine (Lond)., 2012, 7, 1391-408.

43 D. Betbeder, S. Spérandio, J. P. Latapie, J. de Nadai, a Etienne, J. M. Zajac and B. Francés, Pharm. Res., 2000, 17, 743-8.

44 X. Gao, W. Tao, W. Lu, Q. Zhang, Y. Zhang, X. Jiang and S. Fu, Biomaterials, 2006, 27, 3482-90.

45 Q.-Z. Zhang, L.-S. Zha, Y. Zhang, W.-M. Jiang, W. Lu, Z.-Q. Shi, X.-G. Jiang and S.-K. Fu, J. Drug Target., 2006, 14, 281-290.

46 X. Gao, J. Chen, W. Tao, J. Zhu, Q. Zhang, H. Chen and X. Jiang, Int. J. Pharm., 2007, 340, 207-15.

47 X. Gao, B. Wu, Q. Zhang, J. Chen, J. Zhu, W. Zhang, Z. Rong, H. Chen and X. Jiang, J. Control. Release, 2007, 121, 156-67.

48 A. Dalpiaz, E. Gavini, G. Colombo, P. Russo, F. Bortolotti, L. Ferraro, S. Tanganelli, A. Scatturin, E. Menegatti and P. Giunchedi, 2008, 97, 48894903.

49 X. Gao, J. Chen, J. Chen, B. Wu, H. Chen and X. Jiang, Bioconjug. Chem., 2008, 19, 2189-95.

50 F. H. Liu, Y. M. Zhao, J. Feng, Y. H. Wei and F. Z. Li, Chinese Tradit. Herb. drugs, 2009, 40, 1760-1763.

51 A. Mistry, S. Z. Glud, J. Kjems, J. Randel, K. A. Howard, S. Stolnik and L. Illum, J. Drug Target., 2009, 17, 543-52.

52 J. Shaji, A. Poddar and S. Iyer, Indian J. Pharm. Sci., 2009, 71, 715-8.

53 J. Varshosaz, S. Eskandari and M. Tabakhian, Pharm. Dev. Technol., 2010, 15, 89-96.

54 S. Eskandari, J. Varshosaz, M. Minaiyan and M. Tabbakhian, Int. J. Nanomedicine, 2011, 6, 363-71.

55 L. Liu, Y. M. Zhao and F. Z. Li, Chinese Pharm. J., 2011, 46, 203-207.

56 B. Luppi, F. Bigucci, G. Corace, A. Delucca, T. Cerchiara, M. Sorrenti, L. Catenacci, A. M. Di Pietra and V. Zecchi, Eur. J. Pharm. Sci., 2011, 44, 55965.

57 Z. Wen, Z. Yan, K. Hu, Z. Pang, X. Cheng, L. Guo, Q. Zhang, X. Jiang, L. Fang and R. Lai, J. Control. Release, 2011, 151, 131-138.

58 H. Xia, X. Gao, G. Gu, Z. Liu, N. Zeng, Q. Hu, Q. Song, L. Yao, Z. Pang, X. Jiang, J. Chen and H. Chen, Biomaterials, 2011, 32, 9888-98.

59 Q. Liu, Y. Shen, J. Chen, X. Gao, C. Feng, L. Wang, Q. Zhang and X. Jiang, Pharm. Res., 2012, 29, 546-58.

60 Y. Ruan, L. Yao, B. Zhang, S. Zhang and J. Guo, Drug Dev. Ind. Pharm., 2012, 38, 123-8.

61 G. A. Abdelbary and M. I. Tadros, Int. J. Pharm., 2013, 452, 300-310.

62 G. B. Patil and S. J. Surana, J. Biomater. Sci. Polym. Ed., 2013, 24, 1740- 
1756.

63 C. Domingo and J. Saurina, Anal. Chim. Acta, 2012, 744, 8-22.

64 J. Sitterberg, A. Ozcetin, C. Ehrhardt and U. Bakowsky, Eur. J. Pharm. Biopharm., 2010, 74, 2-13.

65 R. Mathaes, G. Winter, J. Engert and A. Besheer, Int. J. Pharm., 2013, 453, 620-9.

66 D. Heng, P. Tang, J. M. Cairney, H.-K. Chan, D. J. Cutler, R. Salama and J. Yun, Pharm. Res., 2007, 24, 1608-17.

67 A.-L. Troutier, T. Delair, C. Pichot and C. Ladavière, Langmuir, 2005, 21, 1305-13.

68 R. Parhi and P. Suresh, Curr. Drug Discov. Technol., 2012, 9, 2-16.

69 E. J. Cho, H. Holback, K. C. Liu, S. a Abouelmagd, J. Park and Y. Yeo, Mol. Pharm., 2013, 10, 2093-110.

70 H. Saveyn, B. De Baets, O. Thas, P. Hole, J. Smith and P. Van der Meeren, J. Colloid Interface Sci., 2010, 352, 593-600.

71 H. Bunjes, K. Westesen and M. H. J. Koch, Int. J. Pharm., 1996, 129, 159173.

72 H. Bunjes and T. Unruh, Adv. Drug Deliv. Rev., 2007, 59, 379-402.

73 P. Tandon, G. Förster, R. Neubert and S. Wartewig, J. Mol. Struct., 2000, 524, 201-215.

74 L. Casettari, E. Castagnino, S. Stolnik, A. Lewis, S. M. Howdle and L. Illum, Pharm. Res., 2011, 28, 1668-82.

75 I. Pasquali and R. Bettini, Int. J. Pharm., 2008, 364, 176-87.

76 Ž. Knez, E. Markočič, Z. Novak and M. K. Hrnčič, Chemie Ing. Tech., 2011, n/a-n/a.

77 A. Tabernero, E. M. Martín del Valle and M. A. Galán, Chem. Eng. Process. Process Intensif., 2012, 60, 9-25.

78 P. Girotra, S. K. Singh and K. Nagpal, Pharm. Dev. Technol., 2013, 18, 2238.

79 M. J. Cocero, Á. Martín, F. Mattea and S. Varona, J. Supercrit. Fluids, 2009, 47, 546-555.

80 A. Martín and M. J. Cocero, Adv. Drug Deliv. Rev., 2008, 60, 339-50.

81 G. Brunner, Annu. Rev. Chem. Biomol. Eng., 2010, 1, 321-42.

82 C. A. García-González, A. Argemí, A. R. Sampaio de Sousa, C. M. M. Duarte, J. Saurina and C. Domingo, J. Supercrit. Fluids, 2010, 54, 342-347.

83 WO/1995/021688, 1995.

84 N. Foster, R. Mammucari, F. Dehghani, A. Barrett, K. Bezanehtak, E. Coen, G. Combes, L. Meure, A. Ng, H. L. Regtop and A. Tandya, Ind. Eng. Chem. Res., 2003, 42, 6476-6493.

85 Ž. Knez, in Proceedings for the Sixth International Symposium for Supercritical Fluids, 2003, p. 1865.

86 E. Weidner, J. Supercrit. Fluids, 2009, 47, 556-565. 
87 J. Jung and M. Perrut, J. Supercrit. Fluids, 2001, 20, 179-219.

88 S.-D. Yeo and E. Kiran, J. Supercrit. Fluids, 2005, 34, 287-308.

89 S. Pollak, S. Kareth, a. Kilzer and M. Petermann, J. Supercrit. Fluids, 2011, 56, 299-303.

90 J. Li, H. a. Matos and E. G. de Azevedo, J. Supercrit. Fluids, 2004, 32, 275286.

91 M. Strumendo, A. Bertucco and N. Elvassore, J. Supercrit. Fluids, 2007, 41, 115-125.

92 P. Kappler, W. Leiner, M. Petermann and E. Weidner, in 6th International Symposium on supercritical fluid, Versailles, France, 2003.

93 N. Elvassore, M. Flaibani, A. Bertucco and P. Caliceti, Ind. Eng. Chem. Res., 2003, 42, 5924-5930.

94 A. V. M. Nunes and C. M. M. Duarte, Materials (Basel)., 2011, 4, 20172041.

95 Z. Knez and E. Weidner, Curr. Opin. Solid State Mater. Sci., 2003, 7, 353361.

96 Ž. Knez, M. Škerget and Z. Mandžuka, J. Supercrit. Fluids, 2010, 55, 648652.

97 E. Weidner, R. Steiner and Ž. Knez, High Press. Chem. Eng., 1996, 12, 223228.

98 J. Fages, H. Lochard, J.-J. Letourneau, M. Sauceau and E. Rodier, Powder Technol., 2004, 141, 219-226.

99 A. Baxendale, P. van Hooff, L. G. Durrant, I. Spendlove, S. M. Howdle, H. M. Woods, M. J. Whitaker, O. R. Davies, a Naylor, a L. Lewis and L. Illum, Int. J. Pharm., 2011, 413, 147-54.

100 E. Weidner, M. Petermann and Z. Knez, Curr. Opin. Solid State Mater. Sci., 2003, 7, 385-390.

101 N. Elvassore, M. Flaibani, K. Vezzù, A. Bertucco, P. Caliceti, A. Semenzato and S. Salmaso, in 6th International Symposium on supercritical fluids, Versailles, France, 2003.

102 A. São Pedro, S. Dalla Villa, P. Caliceti, S. Salmaso, E. Albuquerque and A. Bertucco, in 6th International Symposium on High Pressure Processes Technology, Belgrade, Serbia, 2013, pp. 1-7.

103 A. São Pedro, S. Dalla Villa, P. Caliceti, S. Salmaso, N. Elvassore, E. Serena, R. Fialho, S. Vieira de Melo, A. Bertucco and E. Cabral-Albuquerque, in XXI International Conference on Bioencapsulation, Berlin, Germany, 2013, pp. 252-253.

104 A. R. Sampaio de Sousa, R. Silva, F. H. Tay, A. L. Simplício, S. G. Kazarian and C. M. M. Duarte, J. Supercrit. Fluids, 2009, 48, 120-125.

105 C. M. M. Duarte, A. R. S. De Sousa, S. G. Kazarian and A. Luísa, in 11th European Meeting on Supercritical Fluids, Barcelona, 2007.

106 A. Semenzato, G. Amabile, K. Vezzù, P. Caliceti and A. Bertucco, in The 
AlChe Annual Meeting, San Francisco, U.S.A., 2006.

107 C. A. García-González, A. R. Sampaio da Sousa, A. Argemí, A. López Periago, J. Saurina, C. M. M. Duarte and C. Domingo, Int. J. Pharm., 2009, 382, 296304.

108 A. Argemí, C. Domingo, A. R. Sampaio de Sousa, C. M. M. Duarte, C. A. García-González and J. Saurina, J. Pharm. Sci., 2011, 100, 4783-4789.

109 K. Vezzù, C. Campolmi and A. Bertucco, Int. J. Chem. Eng., 2009, 2009, 1-9.

110 V. S. S. Gonçalves, A. A. Matias, I. D. Nogueira and C. M. M. Duarte, in 6th International Symposium on High Pressure Processes Technology, 2013, pp. 1-8.

111 S. Salmaso, N. Elvassore, A. Bertucco and P. Caliceti, J. Pharm. Sci., 2009, 98, 640-650.

112 S. Salmaso, S. Bersani, N. Elvassore, A. Bertucco and P. Caliceti, Int. J. Pharm., 2009, 379, 51-8.

113 K. Vezzù, D. Borin, A. Bertucco, S. Bersani, S. Salmaso and P. Caliceti, J. Supercrit. Fluids, 2010, 54, 328-334.

114 a V Nunes, S. Rodriguez-Rojo, a P. Almeida, a a Matias, D. Rego, a L. Simplicio, M. R. Bronze, M. J. Cocero and C. M. M. Duarte, J. Control. Release, 2010, 148, e11-2.

115 S. Rodriguez-Rojo, D. Rego, A. V. M. Nunes, I. D. Nogueira, M. J. Cocero and C. M. M. Duarte, in 12th European Meeting on Supercritical Fluids, Graz (Austria), 2010, p. 75.

116 A. P. C. Almeida, I. D. Nogueira, A. A. Matias and C. M. M. Duarte, in 1st Iberian Meeting on Natural Bioactives Entrapment for the Food Industry, Lisbon, Portugal, 2011, vol. 23.

117 M. Vijayaraghavan, S. Stolnik, S. M. Howdle and L. Illum, Int. J. Pharm., 2013, 441, 580-8.

118 M. Fraile, Á. Martín, D. Deodato, S. Rodriguez-Rojo, I. D. Nogueira, A. L. Simplício, M. J. Cocero and C. M. M. Duarte, J. Supercrit. Fluids, 2013, 81, 226-235.

119 M. Brion, S. Jaspart, L. Perrone, G. Piel and B. Evrard, J. Supercrit. Fluids, 2009, 51, 50-56.

120 F. Jordan, A. Naylor, C. A. Kelly, S. M. Howdle, A. Lewis and L. Illum, J. Control. Release, 2010, 141, 153-60.

121 C. A. Kelly, A. Naylor, L. Illum, K. M. Shakesheff and S. M. Howdle, Adv. Funct. Mater., 2012, 22, 1684-1691.

122 S. Pollak, M. Petermann, S. Kareth and A. Kilzer, J. Supercrit. Fluids, 2010, 53, 137-141.

123 K. Vezzù, A. Bertucco and F. P. Lucien, in 11th European Meeting on Supercritical Fluids, Barcelona, 2008, pp. 1-6.

124 M. Vijayaraghavan, S. Stolnik, S. M. Howdle and L. Illum, Int. J. Pharm., 2012, 438, 225-31. 
125 J. Hao, M. J. Whitaker, G. Serhatkulu, K. M. Shakesheff and S. M. Howdle, J. Mater. Chem., 2005, 15, 1148.

126 M. Perrut, F. Deschamps, J. Jung, F. Leboeuf and S. F.-C. France, in 10th European Meeting on Supercritical Fluids, Colmar, France, 2005.

127 S. Quraishi, M. Martins, A. A. Barros, P. Gurikov, S. P. Raman, I. Smirnova, A. R. C. Duarte and R. L. Reis, J. Supercrit. Fluids, 2015, 105, 1-8.

128 C. a. García-González, M. Alnaief and I. Smirnova, Carbohydr. Polym., 2011, 86, 1425-1438.

129 M. Ahmadi, A. Madadlou and A. A. Saboury, Food Chem., 2016, 196, 10161022.

130 J. Stergar and U. Maver, J. Sol-Gel Sci. Technol., 2016, 1-15.

131 Z. Ulker and C. Erkey, J. Control. Release, 2014, 177, 51-63.

132 C. A. García-González, M. Jin, J. Gerth, C. Alvarez-Lorenzo and I. Smirnova, Carbohydr. Polym., 2015, 117, 797-806.

133 A. Veronovski, G. Tkalec, Z. Knez and Z. Novak, Carbohydr. Polym., 2014, 113, 272-278.

134 T. Kudeva, Hamburg University of Technology, 2014.

135 T. Mehling, I. Smirnova, U. Guenther and R. H. H. Neubert, J. Non. Cryst. Solids, 2009, 355, 2472-2479.

136 P. Veres, A. M. López-Periago, I. Lázár, J. Saurina and C. Domingo, Int. J. Pharm. , 2015, 496, 360-370.

137 D. Sanli, Z. Ulker, S. Giray, C. Erkey and B. Engineering, in 13th European meeting on supercritical fluid, The Hague, Netherlands, 2011, vol. 90.

138 M. Alnaief, S. Antonyuk, C. M. Hentzschel, C. S. Leopold, S. Heinrich and I. Smirnova, Microporous Mesoporous Mater. , 2012, 160, 167-173.

139 C. a. García-González, E. Carenza, M. Zeng, I. Smirnova and A. Roig, RSC Adv., 2012, 2, 9816.

140 A. Veronovski, Ž. Knez and Z. Novak, J. Supercrit. Fluids, 2013, 79, 209-215.

141 G. Tkalec, M. Pantić, Z. Novak and Ž. Knez, J. Mater. Sci., 2015, 50, 1-12. 



\section{Chapter 2}

Solid lipid particles and structured lipid particles produced by PGSS ${ }^{\circledR}$

Part I: Glycerolipids-Based Particles Produced by PGSS ${ }^{\circledR}$

Part II: Development of structured lipid carrier systems containing glyceryl monooleate through PGSS ${ }^{\circledR}$ 


\section{Chapter 2}

\section{Part I: Glycerolipids-Based Particles Produced by PGSS $^{\circledR}$}

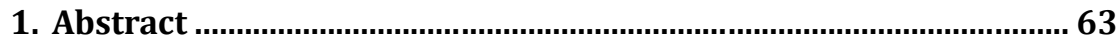

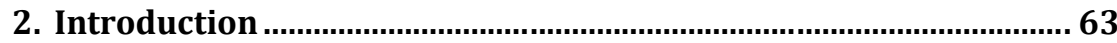

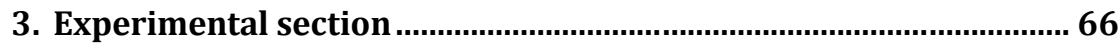

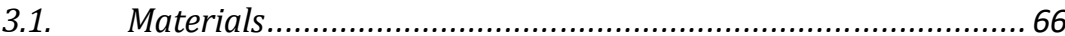

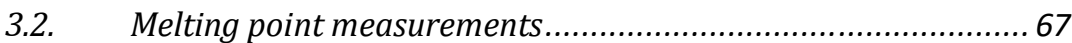

3.3. Particles from gas saturated solutions $\left(\mathrm{PGSS}^{\circledR}\right)$...........................67

3.4. Particles' characterization .................................................... 70

4. Results and discussion .................................................................... 71

4.1. Melting point measurements................................................. 71

4.2. Particles from gas saturated solutions (PGSS $₫$ ) ....................... 72

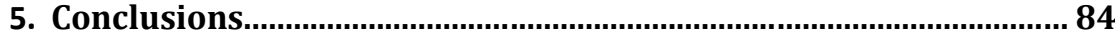

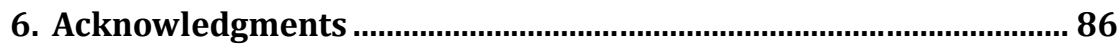

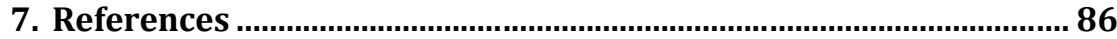


The author was involved in all the design of experiments, performed all the experimental work, except for SEM analysis performed by I.D. Nogueira, and actively contributed to the discussion and interpretation of results for the chapter. 


\section{Abstract}

For controlling size and morphology of lipid particles produced through Particles from gas saturated solutions (PGSS ${ }^{\circledR}$ ), it is essential to know the influence of the operating conditions of the method and the properties of the chosen carriers on these features. Particles of glycerolipids, namely Gelucire $43 / 01^{\mathrm{TM}}$, Gelucire $50 / 13^{\mathrm{TM}}$ and Geleol ${ }^{\mathrm{TM}}$, were produced by PGSS ${ }^{\circledR}$. The effect of several operating parameters of the supercritical fluid precipitation process on the size and morphology of the lipid particles, namely temperature, pressure, nozzle diameter, and the coprecipitation with Coenzyme Q10, were investigated. The solid lipid particles obtained were analysed by Field Emission Scanning Electron Microscopy, Laser Diffraction Analysis, Differential Scanning Calorimetry and for the Coenzyme Q10loaded particles, the quantification of the active compound was performed through Ultraviolet-visible spectrophotometry. Particles with a wide range of particle size and non-spherical morphology were obtained for all the carriers. Moreover, it was possible to verify that as the complexity of the components of the lipid matrices was increased, unique thermodynamic properties were obtained during the atomization step. For the production of particles through PGSS ${ }^{\circledR}$ with desired features it is crucial the knowledge of the thermodynamic behavior of each carrier material.

\section{Introduction}

Solid lipid particles emerged in the last two decades as an alternative to liposomes, emulsions or polymeric particles as interesting carriers for delivery of drugs. They are constituted of biodegradable and non-toxic lipids that are solid at room and body temperature ${ }^{1,2}$. Furthermore, solid lipid particles have the advantage to increase the uptake of particles by epithelial cells and are capable to promote sustained release of drugs ${ }^{3,4}$. Lipid particles have been studied for the 
administration of drugs through several routes, like parenteral, ocular, pulmonary, per os and nasal, presenting great advantages ${ }^{4-7}$. The administration of drugs using lipid carriers improves the absorption of the API due to a reduction in their enzymatic degradation and an enhanced permeation through the epithelial barrier².

Solid lipid particles can be prepared by several different methods and more recently new techniques based on supercritical fluid technology are being used as a very attractive alternative to prepare these carriers without the use of organic solvents 3,8,9. Particles from Gas Saturated Solutions, patented by Weidner and co-workers ${ }^{10}$, has proved to be a suitable technique to produce solid lipid particles capable to incorporate not only hydrophobic but also hydrophilic drugs ${ }^{11,12}$. In addition, the incorporation of $\mathrm{CO}_{2}$ in the lipid matrices enables a reduction of their melting point and viscosity, being possible to produce particles at mild processing conditions ${ }^{13}$. The particle size and morphology of the particles produced through PGSS ${ }^{\circledR}$ are largely influenced by the operating conditions such as temperature, pressure and nozzle diameter, as already reported by other authors ${ }^{14-17}$. It is recognised that size is a vital feature of the particles used in the delivery of API's as it influences almost every aspect of their functions, such as drug load capacity, route of administration, dissolution and absorption rates, flow properties, stability or uptake and clearance mechanisms ${ }^{18}$. On the other hand, morphology is also a parameter that could have a major impact on the carrier's performance, like degradation, transport or targeting, and therefore is a feature that should be studied ${ }^{19}$.

Both size and morphology of solid lipid particles depend not only on the operating conditions of the experimental methods used for their production but also on the physical and chemical properties of the chosen carrier materials. There are several types of lipids approved for use as carriers in pharmaceutical formulations, such as waxes and fatty acids, being cetyl palmitate and stearic acid an example of each, respectively. In particular, glycerolipids are a class of lipids composed by mixtures 
of different glycerides, shown in Figure 1, whose proportions and limits are defined and regulated by the PhEur and USP-NF.

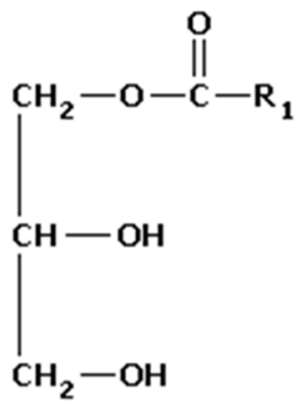

Monoglyceride<smiles>[R]C(=O)OCC(CO)OC([R4])=O</smiles>

Diglyceride<smiles></smiles>

Triglyceride

Figure 1| Different types of glycerides

Therefore, it should be taken in consideration that two lipid matrices commercially available by distinct suppliers, despite having the same nonproprietary name in accordance with pharmacopoeias, may have different properties. A minimum difference in the fractions of mono-, di- or tri- glycerides can be enough to modify the melting point or the HLB of the lipid carrier material ${ }^{20}$.

The aim of the present chapter was to produce solid lipid particles of three carriers constituted by different mixtures of glycerides, namely Gelucire $43 / 01^{\mathrm{TM}}$, Gelucire $50 / 13^{\mathrm{TM}}$ and Geleol ${ }^{\mathrm{TM}}$, by $\mathrm{PGSS}^{\circledR}$ technique. Moreover, the effect of process parameters, including temperature, pressure and nozzle diameter, on the size and morphology of the precipitated solid lipid particles were studied. The purpose of using carriers in pharmaceutical technology is the transport of drugs and hence, the increase of drug's bioavailability in the therapeutic target ${ }^{21}$. However, using another compound during the PGSS ${ }^{\circledR}$ process may also affect the final morphology and size of the solid lipid particles and thus it would be interesting to study the effect of co-precipitation with a drug ${ }^{22}$. For that purpose, Coenzyme $Q_{10}$ was 
selected in this work as a model API to be co-precipitated with the lipids in order to investigate its effect on the final size and morphology of the solid lipid particles. Coenzyme $\mathrm{Q}_{10}$, also known as ubiquinone, is a lipophilic endogenous antioxidant that has been used in the pharmaceutical field in treatment of cardiovascular and neurodegenerative diseases. However, due to its low aqueous solubility, it has reduced oral bioavailability being necessary to search for new routes of delivery (e.g. nasal) or to formulate this compound with lipid carriers to overcome this problem ${ }^{23-25}$. The thermodynamic properties of Coenzyme $Q_{10}$ in the presence of compressed $\mathrm{CO}_{2}$ are already known, being this hydrophobic drug a good candidate for precipitation through PGSS ${ }^{\circledR} 26,27$.

\section{Experimental section}

\subsection{Materials}

Gelucire $43 / 01^{\mathrm{TM}}$, Gelucire $50 / 13^{\mathrm{TM}}$ and Geleol ${ }^{\mathrm{TM}}$ were kindly supplied by Gattefossé (France). Coenzyme $Q_{10}$ (98\% purity) was purchased from Sigma Aldrich (Steinheim, Germany). $\mathrm{CO}_{2}$ (99.95 and 99.998 mol\% purity) was delivered by Air Liquide (Portugal). Dichloromethane was purchased from Fisher Scientific (Loughborough, UK). All the chemicals were used without further purification. The properties of the carrier materials are listed in Table 1.

Table 1| Properties of the carrier materials

\begin{tabular}{|c|c|c|c|}
\hline & Gelucire $43 / 01^{m}$ & Gelucire $50 / 13^{\text {Tm }}$ & Geleol $^{\text {mm }}$ \\
\hline Composition & $\begin{array}{c}\text { Mixture of } \\
\text { triglycerides, } \\
\text { diglycerides and } \\
\text { monoglycerides }\end{array}$ & $\begin{array}{l}\text { Mixtures of monoesters, } \\
\text { diesters and triesters of } \\
\text { glycerol and monoesters } \\
\text { and diesters of } \\
\text { macrogols with a mean } \\
\text { relative molecular mass } \\
\text { between } 300 \text { and } 4000\end{array}$ & $\begin{array}{l}\text { Mixture of monoacylglycerols, } \\
\text { mainly monostearoylglycerol, } \\
\text { together with variable } \\
\text { quantities of di- and } \\
\text { triacylglycerols }\end{array}$ \\
\hline HLB & 1 & 13 & 3 \\
\hline $\operatorname{Tm}(K)$ & 315 to 318 & 319 to 324 & 328 to 332 \\
\hline
\end{tabular}




\section{2. $\quad$ Melting point measurements}

The knowledge of the solid-liquid transitions of the lipids under pressurized $\mathrm{CO}_{2}$ is essential for their precipitation through PGSS ${ }^{\circledR}$ process $^{28}$. For Gelucire $43 / 01^{\mathrm{TM}}$ and Gelucire $50 / 13^{\mathrm{Tm}}$, data of their melting point depression as a result of $\mathrm{CO}_{2}$ dissolution in the lipids matrix can already be found in the literature ${ }^{29,30}$. The melting point depression of Geleol ${ }^{\mathrm{m}}$ in the presence of $\mathrm{CO}_{2}$ was measured within this work using a visual method previously described ${ }^{29}$. Briefly, the lipid was placed inside a glass $\left(1 \mathrm{~cm}^{3}\right)$, which was then inserted in a stainless steel high-pressure visual cell with an internal volume of approximately $5 \mathrm{~cm}^{3}$. After, $\mathrm{CO}_{2}$ was pumped using a Haskel pump (model 29723-71) into the cell until the desired pressure was reached. The pressure in the cell was measured with a pressure transducer Digibar II calibrated between 0 and 25MPa (accuracy: $0.15 \%$ ). The temperature was then gradually increased until it was possible to visually observe the complete melting of the lipid. The heating system was composed of a heating cable (Horst), a controller (Ero Electronic LMS) and a high accuracy thermometer (Omega HH 501 AT, $0.1 \%)$. Measurements were performed in a pressure range up to $19 \mathrm{MPa}$. In order to confirm the reproducibility of the results some points were repeated resulting in maximum deviations of $0.2 \mathrm{~K}$.

\subsection{Particles from gas saturated solutions (PGSS ${ }^{\circledR}$ )}

Solid lipid particles were produced through $\mathrm{PGSS}^{\circledR}$ process using three different lipid matrices. The schematic representation of the equipment (FAME UNIT, Separex, France) used to produce the particles is shown in Figure 2 and was previously described in the work of Rodríguez-Rojo et al. with some modifications ${ }^{31}$. 


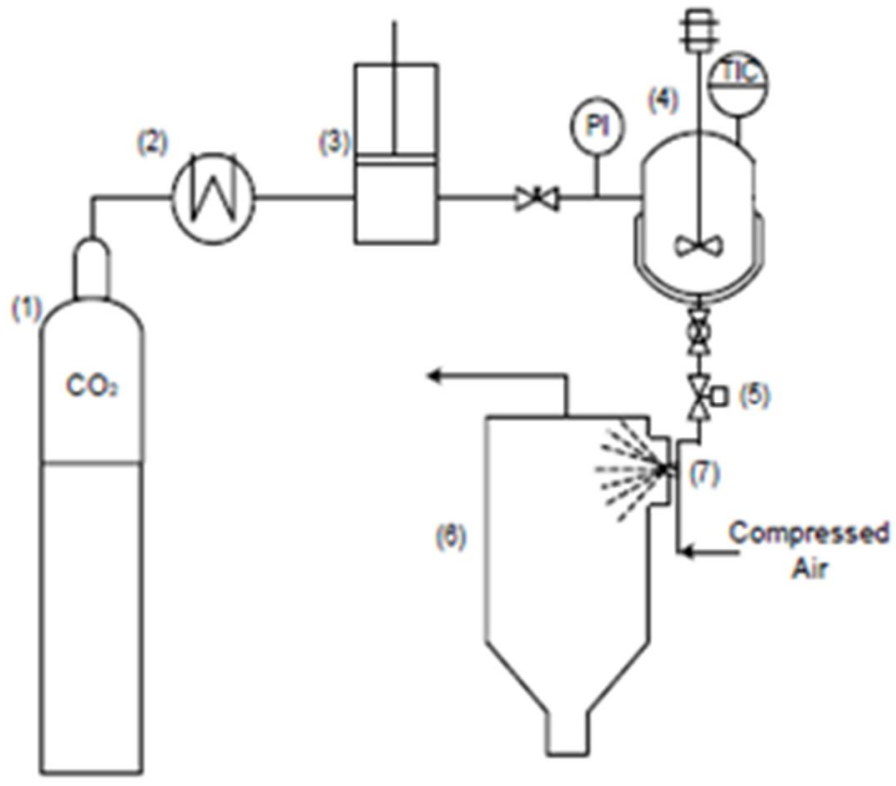

Figure 2| Experimental setup: (1) $\mathrm{CO}_{2}$ cylinder (2) cryostate (3) pneumatic piston pump (4) stirred vessel (electrically thermostated) (5) automated depressurisation valve (6) recovery vessel (7) nozzle

Carbon dioxide was fed by a pneumatic pump (29723-71, Haskel International Inc., CA, USA) to a $50 \mathrm{~cm}^{3}$ electrically thermostated high-pressure stirred vessel, containing the lipid to be processed, until the desired working pressure was reached. After 30 minutes of stirring $(150 \mathrm{rpm})$, the mixture was depressurized by an automated depressurization valve and atomized through a two-fluid nozzle $(d=250 \mu \mathrm{m})$ to a cyclone, where it was externally mixed with compressed air $(0.7$ $\mathrm{MPa}$ ). The particles were finally recovered into a collector vessel of $18 \mathrm{~L}$ at atmospheric pressure.

The operating conditions ( $\mathrm{T}$ and $\mathrm{P}$ ) were chosen according to melting point values of the lipids in the presence of $\mathrm{CO}_{2}$ and were varied in order to see their effect on the particles' size and morphology. The temperature and pressure values that previously led to smaller and more homogeneous particles were selected, and some experiments were performed with $711 \mu \mathrm{m}$ nozzle in order to study the effect 
of the nozzle diameter on the final morphology and size of the particles. The PGSS ${ }^{\circledR}$ experiments are summarized in Table 2.

Table 2| Summary of PGSS ${ }^{\circledR}$ precipitation experiments performed with glycerolipids

\begin{tabular}{|c|c|c|c|}
\hline System & Pressure (MPa) & Temperature (K) & Nozzle Diameter $(\mu \mathrm{m})$ \\
\hline Gelucire $43 / 01^{\text {tM }}$ & 9 & 311.15 & 250 \\
\hline Gelucire $43 / 01^{\mathrm{TM}}$ & 9 & 321.15 & 250 \\
\hline Gelucire $43 / 01^{\mathrm{Tm}}$ & 20 & 311.15 & 250 \\
\hline Gelucire $43 / 01^{\mathrm{TM}}$ & 20 & 321.15 & 250 \\
\hline Gelucire $43 / 01^{\mathrm{Tm}}$ & 20 & 311.15 & 711 \\
\hline Gelucire $50 / 13^{\mathrm{Tm}}$ & 9 & 313.15 & 250 \\
\hline Gelucire $50 / 13^{\text {TM }}$ & 9 & 323.15 & 250 \\
\hline Gelucire $50 / 13^{\mathrm{Tm}}$ & 20 & 313.15 & 250 \\
\hline Gelucire $50 / 13^{\text {TM }}$ & 20 & 323.15 & 250 \\
\hline Gelucire $50 / 13^{\mathrm{TM}}$ & 9 & 323.15 & 711 \\
\hline Geleol $^{\mathrm{TM}}$ & 9 & 331.15 & 250 \\
\hline Geleol $^{\mathrm{TM}}$ & 9 & 341.15 & 250 \\
\hline Geleol $^{\mathrm{Tm}}$ & 20 & 331.15 & 250 \\
\hline Geleol $^{\mathrm{TM}}$ & 20 & 341.15 & 250 \\
\hline Geleol $^{\mathrm{TM}}$ & 20 & 331.15 & 711 \\
\hline
\end{tabular}

Coenzyme $\mathrm{Q}_{10}$-loaded lipid particles were also produced by PGSS $^{\circledR}$ technique using the $250 \mu \mathrm{m}$ nozzle. Table 3 presents a summary of these experiments with the mass proportion between the active compound and the lipid carrier.

Table 3| Summary of PGSS ${ }^{\circledR}$ co-precipitation experiments performed with Coenzyme Q10 (1\% w/w) and glycerolipids; nozzle diameter $\mathrm{d}=250 \mu \mathrm{m}$

\begin{tabular}{|c|c|c|}
\hline System & Pressure (MPa) & Temperature (K) \\
\hline Gelucire $43 / 01^{\mathrm{TM}}+$ Coenzyme Q10 & 20 & 311.15 \\
\hline Gelucire $50 / 13^{\mathrm{TM}}+$ Coenzyme Q10 & 9 & 323.15 \\
\hline Geleol $^{\mathrm{mM}}+$ Coenzyme Q10 & 20 & 331.15 \\
\hline
\end{tabular}




\subsection{Particles' characterization}

Morphology was analyzed visually by FE-SEM (JEOL 7001F) at 10-15kV. Before analysis, particles were covered with approximately $300 \AA$ of a gold-platinum film with a sputter-coater in argon atmosphere (Polaron). Particle size and particle size distribution (PSD) were determined by Laser Diffraction (Malvern Mastersizer 2000). Particles were dispersed in distilled water and measurement was carried out after a gentle rotation of the particles suspension container in order to obtain an even dispersion of the particles. In this work, particle size measurements are reported as volume distribution and defined as the d0.5 (maximum particle diameter below which $50 \%$ of the sample volume exists - also known as the median particle size by volume). Each diameter value reported is the average of three suspensions of particles. The span value is also reported, that is, the ratio between d0.5 and (d0.9- d0.1); span values near to 1 represent narrow PSD. Differential Scanning Calorimetry measurements were carried out on a DSC TA instruments Q200 (module MDSC) with the aim of studying the thermal behavior of the particles and pure compounds. The samples were placed in an aluminium pan and sealed; the probes were heated from 253.15 to $473.15 \mathrm{~K}$ at a rate of $10 \mathrm{~K} / \mathrm{min}$ under nitrogen atmosphere. The quantification of coenzyme Q10 loaded inside the lipid particles was determined by Ultraviolet-visible spectrophotometry. A certain amount of particles was dissolved in dichloromethane; the absorbance of the resulting solutions was analysed at $275 \mathrm{~nm}$ in a UV-Visible Spectrophotometer (Genesys10uv spectrometer; Thermo Spectronic, New York, USA). Each analysis was made in triplicate. 


\section{Results and discussion}

\subsection{Melting point measurements}

Geleol $^{\mathrm{TM}}$ is one of the commercial presentations of Glycerol Monostearate 40-55 (PhEur), being this lipid carrier constituted by a mixture of mono-, di- and triglycerides. Since each commercial presentation has different proportions of these compounds, it is expected that Geleol ${ }^{\mathrm{TM}}$ would present different melting point values when compared to other commercial presentations ${ }^{11,32}$. Hence, the melting point depression of Geleol ${ }^{\mathrm{TM}}$ in the presence of $\mathrm{CO} 2$ was studied in the scope of this work. The experimental data for solid-liquid transition of Geleol ${ }^{\mathrm{TM}}$ under compressed $\mathrm{CO}_{2}$ are presented in Table 4 and Figure 3.

Table 4| Melting points of Geleol ${ }^{\mathrm{TM}}$ in the presence of $\mathrm{CO}_{2}$

\begin{tabular}{cc}
\hline Pressure (MPa) & Temperature (K) \\
\hline 0.10 & 334.45 \\
1.25 & 333.35 \\
2.25 & 331.45 \\
3.30 & 331.15 \\
3.95 & 330.45 \\
5.05 & 329.65 \\
6.05 & 329.05 \\
6.60 & 327.75 \\
6.90 & 327.75 \\
8.60 & 325.85 \\
9.85 & 326.45 \\
10.80 & 326.15 \\
10.95 & 326.55 \\
12.35 & 327.25 \\
14.70 & 327.15 \\
16.90 & 327.65 \\
17.40 & 327.65 \\
17.80 & 328.45 \\
18.45 & 328.55 \\
19.20 & 328.55 \\
\hline
\end{tabular}

The binary system Geleol ${ }^{\mathrm{m} M} / \mathrm{CO}_{2}$ showed an initial depression in the melting point as the pressure increased due to the incorporation of $\mathrm{CO}_{2}$ into the matrix of the lipid. A maximum melting point reduction of $8.6 \mathrm{~K}$ was observed at $8.6 \mathrm{MPa}$. After 
this pressure value, the effect of the hydrostatic pressure started to prevail, leading to an increase in the melting point. This general behavior is common with not only lipid but also with polymeric substances ${ }^{22,29}$.

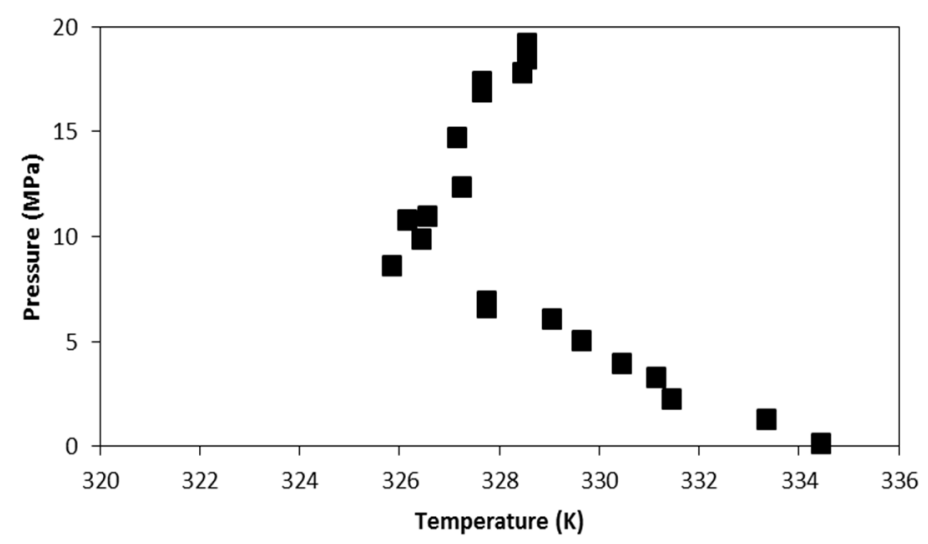

Figure 3| Melting points of Geleolm in the presence of compressed $\mathrm{CO}_{2}$

\subsection{Particles from gas saturated solutions (PGSS®)}

As mentioned above, Gelucire $43 / 01^{\mathrm{TM}}$, Gelucire $50 / 13^{\mathrm{TM}}$ and Geleol ${ }^{\mathrm{TM}}$ were precipitated through the PGSS ${ }^{\circledR}$ technique using different temperature and pressure conditions to evaluate their impact on the physical characteristics of the final particles. Operating conditions were chosen according to data for the melting point depression in the presence of $\mathrm{CO}_{2}$, in order to guarantee the liquid state of the lipids before the atomization of the mixture. Pressure and temperature were fixed and the experiments proceeded with the study of the effect of both the nozzle diameter and the co-precipitation with a model drug in the final shape and size of the lipid particles.

\subsubsection{Effect of operating pressure and temperature}

Strumendo and co-authors have studied the general behavior of a carbon dioxide super-saturated solution drop during the atomization step. They concluded that the obtained average particle size decreases when increasing the pressure in the mixing 
vessel and increases when increasing the temperature ${ }^{15}$. However, there are some exceptions to this behavior, as verified during the processing of polyethyleneglycols by PGSS $^{\circledR}$, where the pressure apparently had no influence on final particle size ${ }^{14}$. Therefore, it is extremely important to know the influence of both temperature and pressure of the PGSS ${ }^{\circledR}$ process on final particle properties of each lipid carrier before incorporation with drugs.

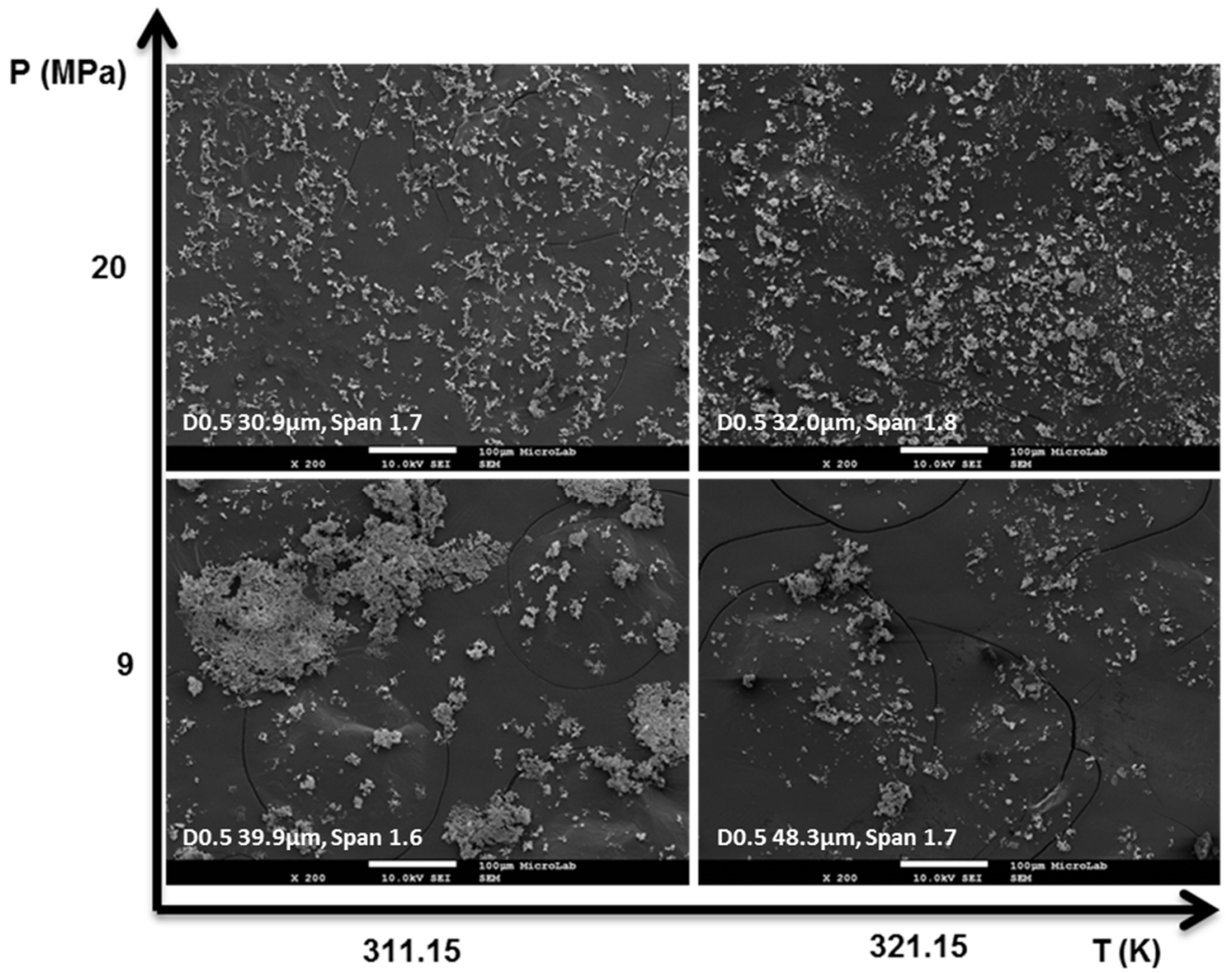

Figure 4| SEM micrographs at 200x magnification and mean particle size of Gelucire $43 / 01^{\mathrm{TM}}$ particles produced by PGSS ${ }^{\circledR}$ (nozzle diameter $d=250 \mu \mathrm{m}$ ); effect of operating conditions

As shown in figure 4, particles with a branched shape were obtained while processing Gelucire $43 / 01^{\mathrm{TM}}$ by $P G S S^{\circledR}$. This morphology is quite different from the spherical shape obtained through the use of other techniques ${ }^{33,34}$. Less 
polydisperse and smaller particles of Gelucire $43 / 01^{\mathrm{TM}}$ were obtained using the highest pressure (20MPa) and lowest temperature (311.15K), being in agreement with the general behavior of molten materials while processed by PGSS ${ }^{\circledast 15,35}$. Large aggregates with structures similar to corals were produced at the lowest pressure and lowest temperature most probably due to the higher viscosity of the lipid matrix in these conditions. Besides the fact that viscosity generally decreases as the temperature increases, the incorporation of $\mathrm{CO}_{2}$ into the lipid matrix also decreases its viscosity ${ }^{36}$. It could be expected that both low temperature and pressure values during the PGSS ${ }^{\circledast}$ process could lead to higher lipid viscosity, making it more difficult to overcome the intermolecular forces necessary to atomize the solution into smaller particles ${ }^{37}$. Particles of Gelucire $43 / 01^{\text {TM }}$ had also some tendency to adhere to the interior of the recovery vessel and some amount was not able to be collected, therefore the yield of the process was reduced.

Figure 5 presents the results obtained in experiments performed with Gelucire $50 / 13^{\mathrm{TM}}$ at different pressures and temperatures. The smaller porous particles with fewer aggregates were produced at the highest temperature (323.15K) and lowest pressure $(9 \mathrm{MPa})$ tested, in concordance with previous experiments ${ }^{31,38}$. The obtained particle morphology is quite different from that obtained with other techniques, as in the case of spray chilling, where spherical particles of Gelucire $50 / 13^{\mathrm{TM}}$ were obtained by Qi and co-authors ${ }^{39}$. 


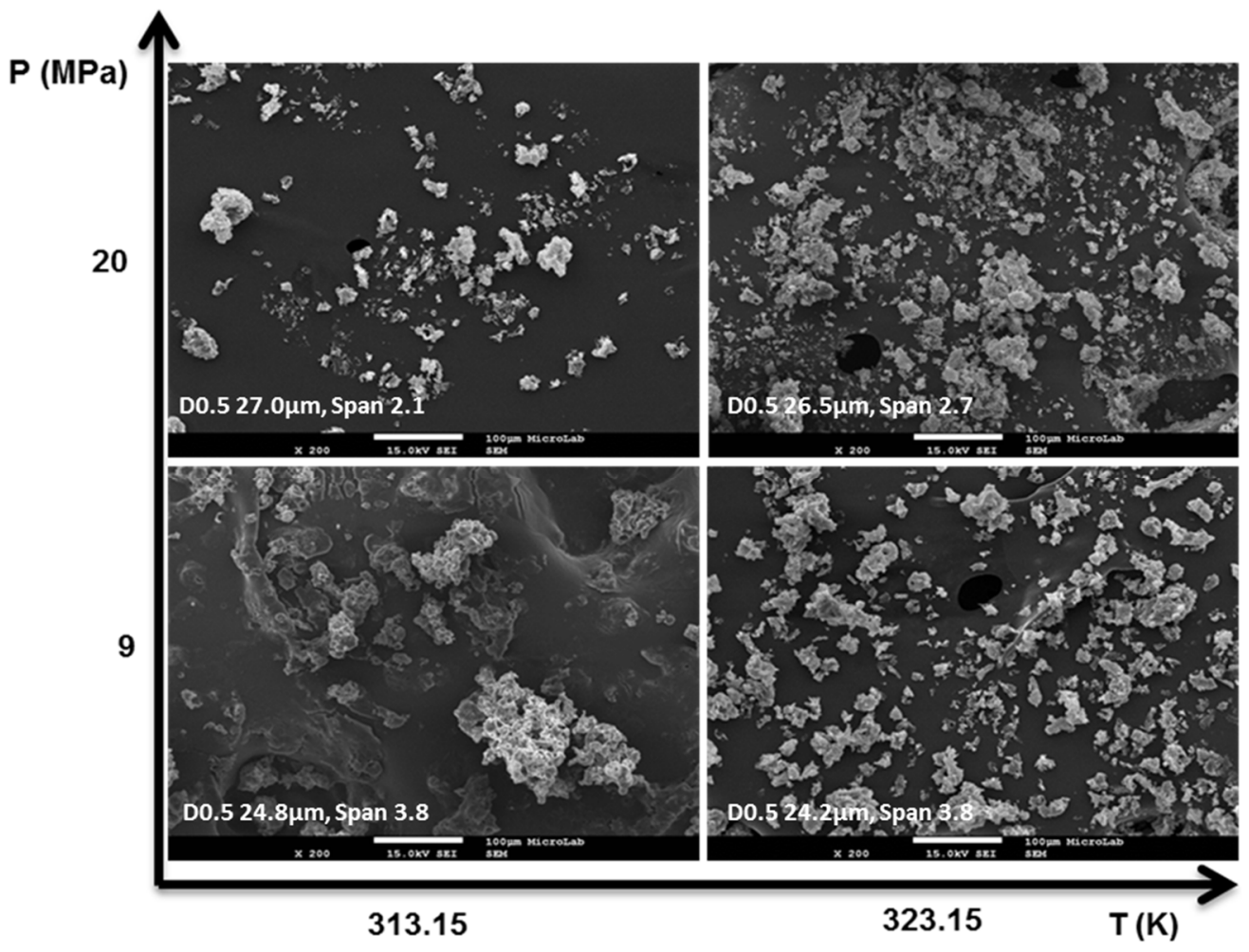

Figure 5| SEM micrographs at 200x magnification and mean particle size of Gelucire 50/13 ${ }^{\mathrm{TM}}$ particles produced by PGSS $^{\circledR}$ (nozzle diameter $d=250 \mu \mathrm{m}$ ); effect of operating conditions

Gelucire $50 / 13^{\mathrm{TM}}$ does not behave as the generality of the molten compounds when processed by PGSS ${ }^{\circledR}$ and this could be explained by its varied composition which has not only glycerides but also PEG esters of fatty acids, having each one different properties and thus distinct behaviors. The lipids and polymers that comprise Gelucire $50 / 13^{\text {TM }}$ may solidify at different rates, leading to the formation of aggregates if the solidification step does not occur sufficiently quickly after the atomization step $^{37}$. 


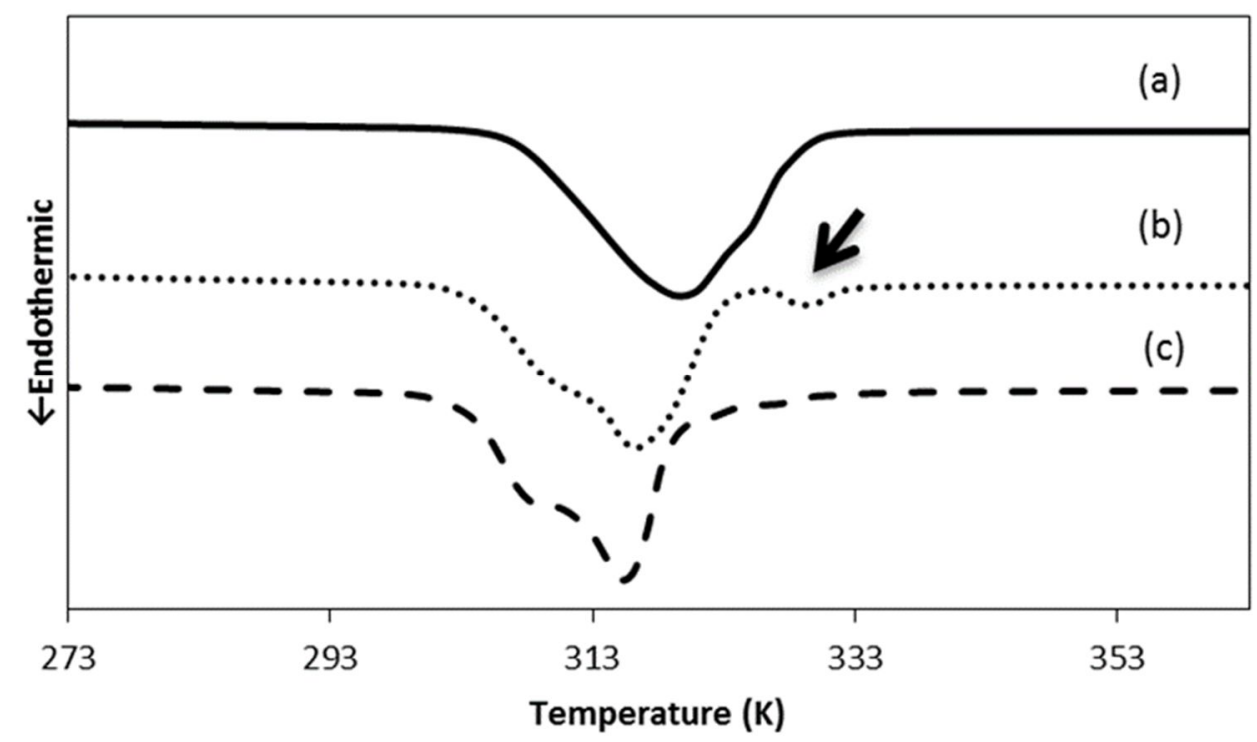

Figure 6| DSC Thermograms of (a) unprocessed Gelucire 50/13 ${ }^{\mathrm{TM}}$, Gelucire 50/13 $3^{\mathrm{TM}}$ particles processed with a nozzle of $250 \mu \mathrm{m}$ of diameter (b) at $313.15 \mathrm{~K}$ and $9 \mathrm{MPa}$, and (c) at $323.15 \mathrm{~K}$ and $9 \mathrm{MPa}$

Despite the fact that Gelucire 50/13 ${ }^{\mathrm{TM}}$ is liquefied in all operating conditions tested, we can verify through analysis of the thermogram presented in Figure 6 that the lowest temperature used (313.15K) resulted in the production of particles with two melting peaks in its thermogram (316.10K and 329.59K). The experiment performed with the same temperature and a pressure of $20 \mathrm{MPa}$ showed a similar thermogram (data not shown). It is possible that at this operating temperature, the different components of the mixture that comprises Gelucire 50/13 ${ }^{\mathrm{TM}}$, although being all liquefied, have very distinct viscosities that result in poor mixing of the molten material and the separation of the compounds.

Figure 7 presents the SEM pictures of Geleol ${ }^{\mathrm{TM}}$ particles obtained by $\mathrm{PGSS}^{\circledast}$ at different pressure and temperature conditions. It is possible to verify that, like in the general case, the smaller particles were obtained at the lowest temperature (331.15K) and highest pressure (20MPa) tested. 


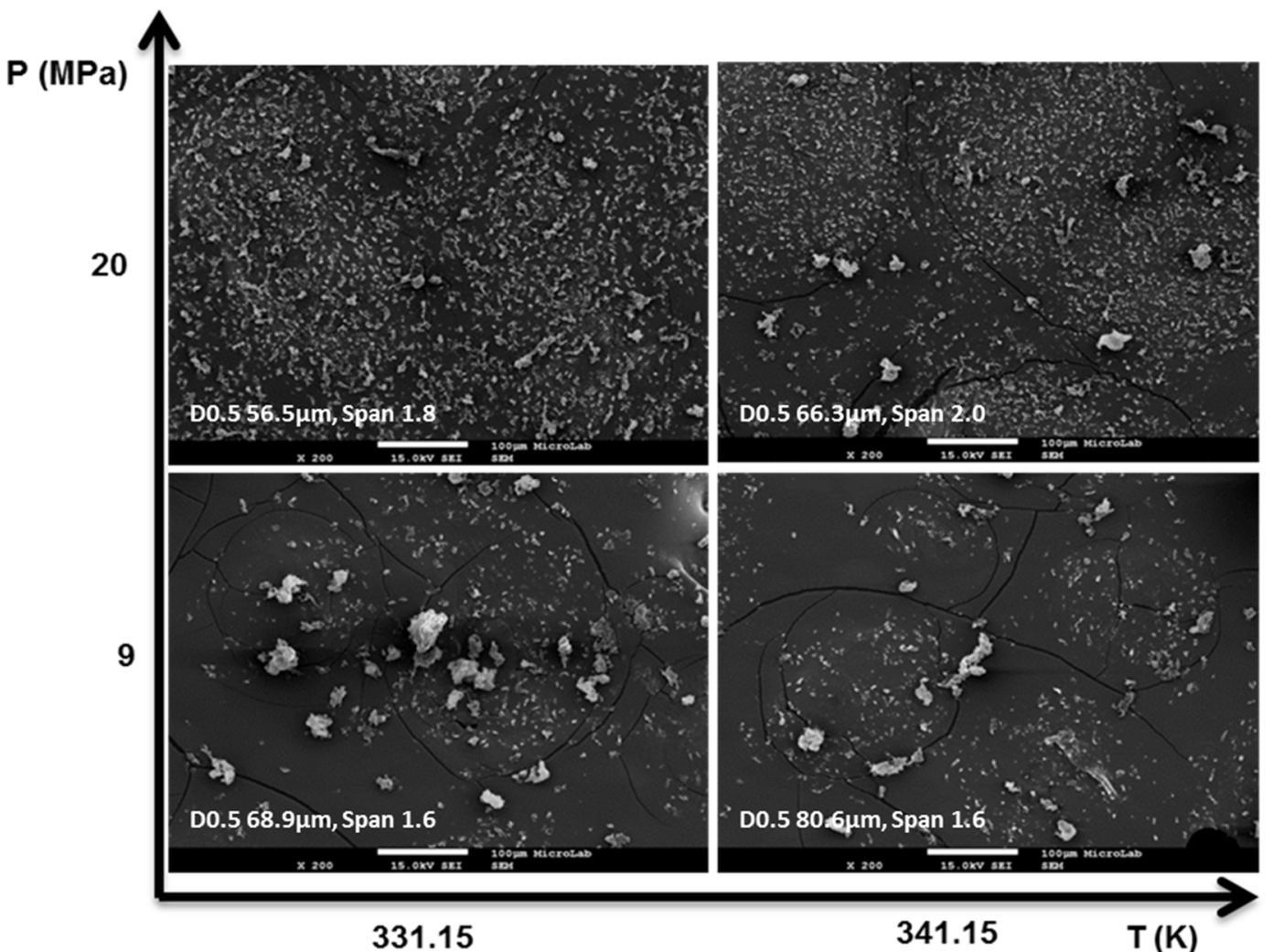

Figure 7| SEM micrographs at 200x magnification and mean particle size of Geleol ${ }^{\mathrm{TM}}$ particles produced by PGSS ${ }^{\circledR}$ (nozzle diameter $d=250 \mu \mathrm{m}$ ); effect of operating conditions

We can verify once again that the PGSS ${ }^{\circledR}$ processing at the lowest temperature and lowest pressure resulted in the formation of more aggregates. Still, the general yield of the batches prepared were higher when compared with the other two lipids tested in our study, due to the lower quantity of particles bonded to the interior of the recovery vessel. A possible explanation for this is the simplest composition of Geleol $^{\mathrm{TM}}$, which consists mainly of mono- and diglycerides, whereas Gelucire $43 / 01^{\mathrm{TM}}$ is composed mostly of triglycerides and Gelucire $50 / 13^{\mathrm{TM}}$ has also PEG esters of fatty acids in addition to the glycerides. It appears that it is easier to atomise this less complex matrix, leading to better process yields with the formation of less polydisperse particles. Furthermore, it must be noticed that the 
branched shape of the obtained particles is different from those obtained while processing Lumulse ${ }^{\mathrm{TM}}$ GMS K (HLB 3.9), another commercial presentation of Glycerol Monostearate, through PGSS ${ }^{\circledR}$. In this case the particles obtained were similar to flakes with an extremely smooth surface ${ }^{11}$.

\subsubsection{Effect of nozzle diameter}

It is known that the diameter of the nozzle used also influences the size of the particles obtained by $\mathrm{PGSS}^{\circledR}$, that is, a higher nozzle diameter produces bigger particles $^{14,35}$. In order to see the effect of this parameter, the lipids were processed by PGSS ${ }^{\circledR}$ with a nozzle with $711 \mu \mathrm{m}$ of diameter, using the conditions of temperature and pressure that led to the formation of smaller particles for the carriers alone. 

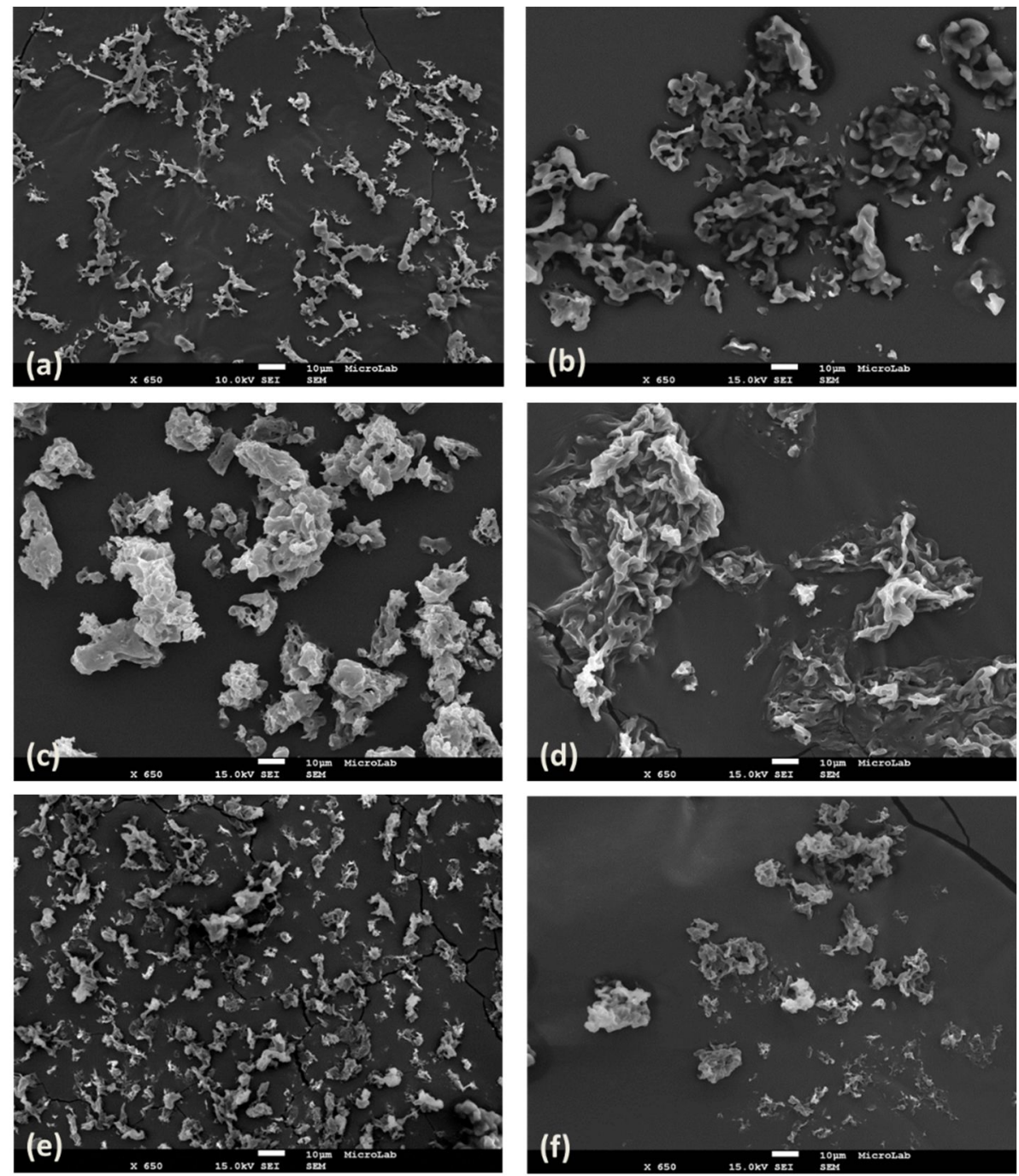

Figure 8 | SEM micrographs at $650 x$ magnification of Gelucire $43 / 01^{\mathrm{TM}}$ particles produced by $\mathrm{PGSS}^{\circledR}$ at $311.15 \mathrm{~K}$ and $20 \mathrm{MPa}$ (a) nozzle of $250 \mu \mathrm{m}$ of diameter, (b) nozzle of $711 \mu \mathrm{m}$ of diameter; of Gelucire $50 / 13^{\mathrm{TM}}$ particles produced by PGSS ${ }^{\circledR}$ at $323.15 \mathrm{~K}$ and $9 \mathrm{MPa}$ (c) nozzle of $250 \mu \mathrm{m}$ of diameter, (d) nozzle of $711 \mu \mathrm{m}$ of diameter; of Geleol ${ }^{\mathrm{TM}}$ particles produced by PGSS ${ }^{\circledast}$ at $331.15 \mathrm{~K}$ and $20 \mathrm{MPa}$ (e) nozzle of $250 \mu \mathrm{m}$ of diameter, (f) nozzle of $711 \mu \mathrm{m}$ of diameter 


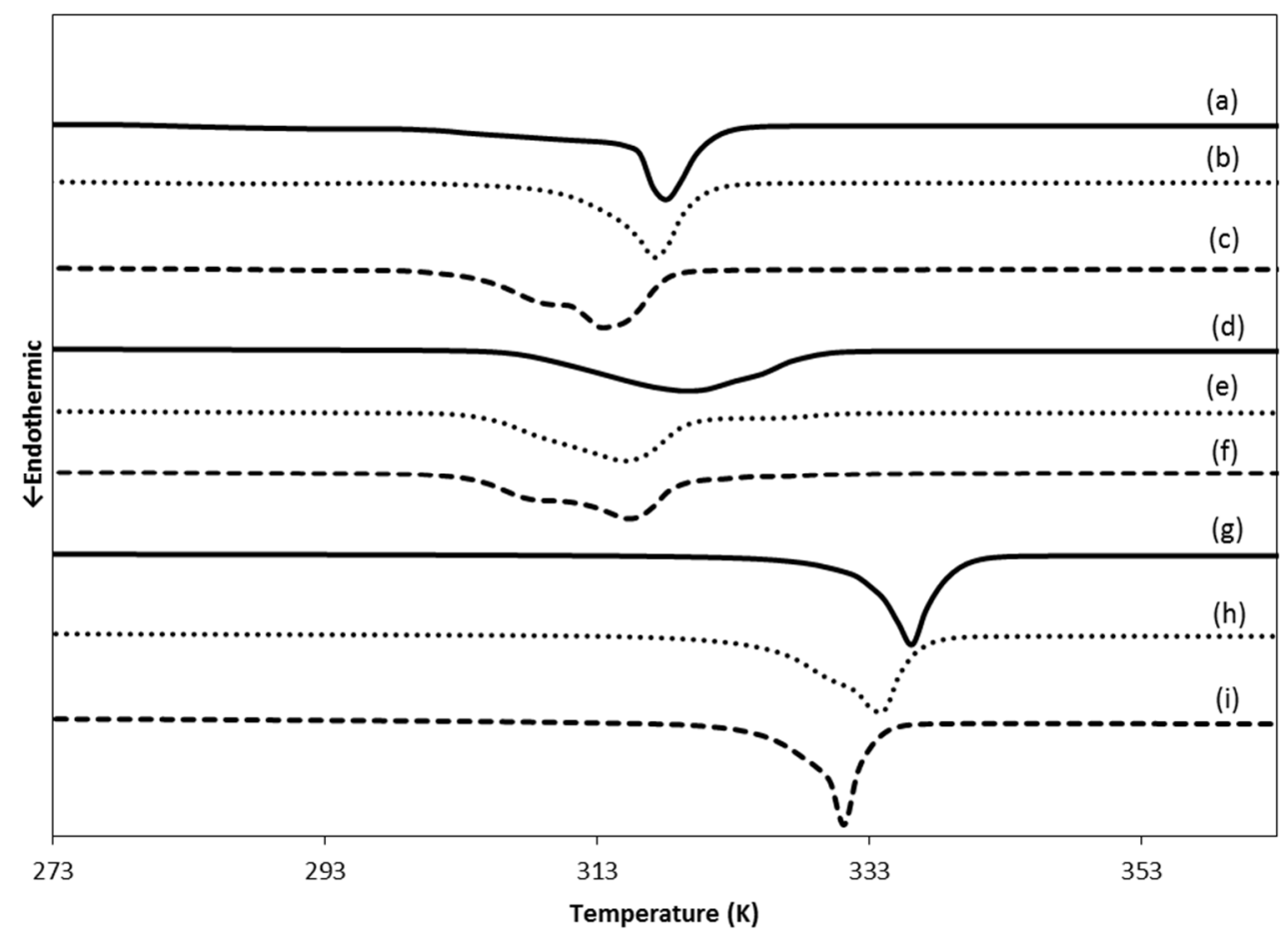

Figure $9 \mid$ DSC Thermograms of (a) unprocessed Gelucire $43 / 01^{\mathrm{TM}}$; Gelucire $43 / 01^{\mathrm{TM}}$ particles processed at $311.15 \mathrm{~K}$ and $20 \mathrm{MPa}$ with (b) a nozzle of $711 \mu \mathrm{m}$ of diameter, and with (c) a nozzle of $250 \mu \mathrm{m}$ of diameter; (d) unprocessed Gelucire 50/13 ${ }^{\mathrm{TM}}$; Gelucire 50/13 ${ }^{\mathrm{TM}}$ particles processed at $323.15 \mathrm{~K}$ and $9 \mathrm{MPa}$ with (e) a nozzle of $711 \mu \mathrm{m}$ of diameter, and with (f) a nozzle of $250 \mu \mathrm{m}$ of diameter; (g) unprocessed Geleol ${ }^{\mathrm{TM}}$; Geleol ${ }^{\mathrm{TM}}$ particles processed at 331.15K and 20MPa with (h) a nozzle of $711 \mu \mathrm{m}$ of diameter, and with (i) a nozzle of $250 \mu \mathrm{m}$ of diameter

Figure 8 and Figure 9 present the SEM pictures and the DSC thermograms obtained, respectively, for the precipitation of Gelucire $43 / 01^{\mathrm{Tm}}$, Gelucire $50 / 13^{\mathrm{TM}}$ and Geleol $^{\text {TM }}$. As expected, Gelucire $43 / 01^{\text {TM }}$ particles produced with a higher nozzle diameter were bigger $\left(d_{0.5}=268.2 \mu \mathrm{m}\right.$, span 2.4$)$ but with the same morphology as the particles obtained with a smaller nozzle diameter. By analyzing the thermograms is possible to observe that particles produced with $250 \mu \mathrm{m}$ nozzle have the lowest melting point (313.48K). This occurred because smaller particles have a larger surface area, which leads to a melting point depression attributed to the Kelvin effect described by the Thomson equation ${ }^{40,41}$. The results obtained with particles of Gelucire $50 / 13^{\mathrm{TM}}$ were once again unexpected since it did not result in 
a substantial difference in particle size but, instead, it changed the morphology of the particles. It is possible to observe that the particles obtained are less spherical with a more branched shape and high polydispersity $\left(d_{0.5}=25.1 \mu \mathrm{m}\right.$, span 7.7), having a similar melting point to that of particles obtained with the $250 \mu \mathrm{m}$ nozzle. Experiments carried out with Geleol ${ }^{\mathrm{TM}}$ resulted in the formation of larger particles with a higher incidence of aggregates $\left(d_{0.5}=90.9 \mu \mathrm{m}\right.$, span 1.7$)$, having a similar morphology as the particles produced with a smaller nozzle. As in the case of Gelucire $43 / 01^{\mathrm{TM}}$, also Geleol ${ }^{\mathrm{TM}}$ particles produced with $250 \mu \mathrm{m}$ nozzle have the lowest melting point (330.96K).

The yield of the PGSS ${ }^{\circledR}$ experiments performed with the $711 \mu \mathrm{m}$ nozzle was lower than the ones performed at the same operating temperature and pressure with the $250 \mu \mathrm{m}$ nozzle. This could be explained by the higher volume of carbon dioxide saturated solution that is atomized when using the $711 \mu \mathrm{m}$ nozzle. Thus, the droplets do not have time to solidify before hitting the expansion unit walls and therefore are not collected.

\subsubsection{Effect of co-precipitation with Coenzyme Q10}

Coenzyme $\mathrm{Q}_{10}$-loaded lipid particles, with $1 \%(\mathrm{w} / \mathrm{w})$ of drug, were produced with the nozzle of $250 \mu \mathrm{m}$ of diameter, using the conditions of temperature and pressure that led to the formation of smaller particles for the carriers alone. It is important to refer that Coenzyme $\mathrm{Q}_{10}$ was liquefied in the presence of compressed $\mathrm{CO}_{2}$ at all used temperatures. Moreover, its load in any of the lipid carriers used was confirmed to be $1 \%(\mathrm{w} / \mathrm{w})$ by the analytical method previously described. 

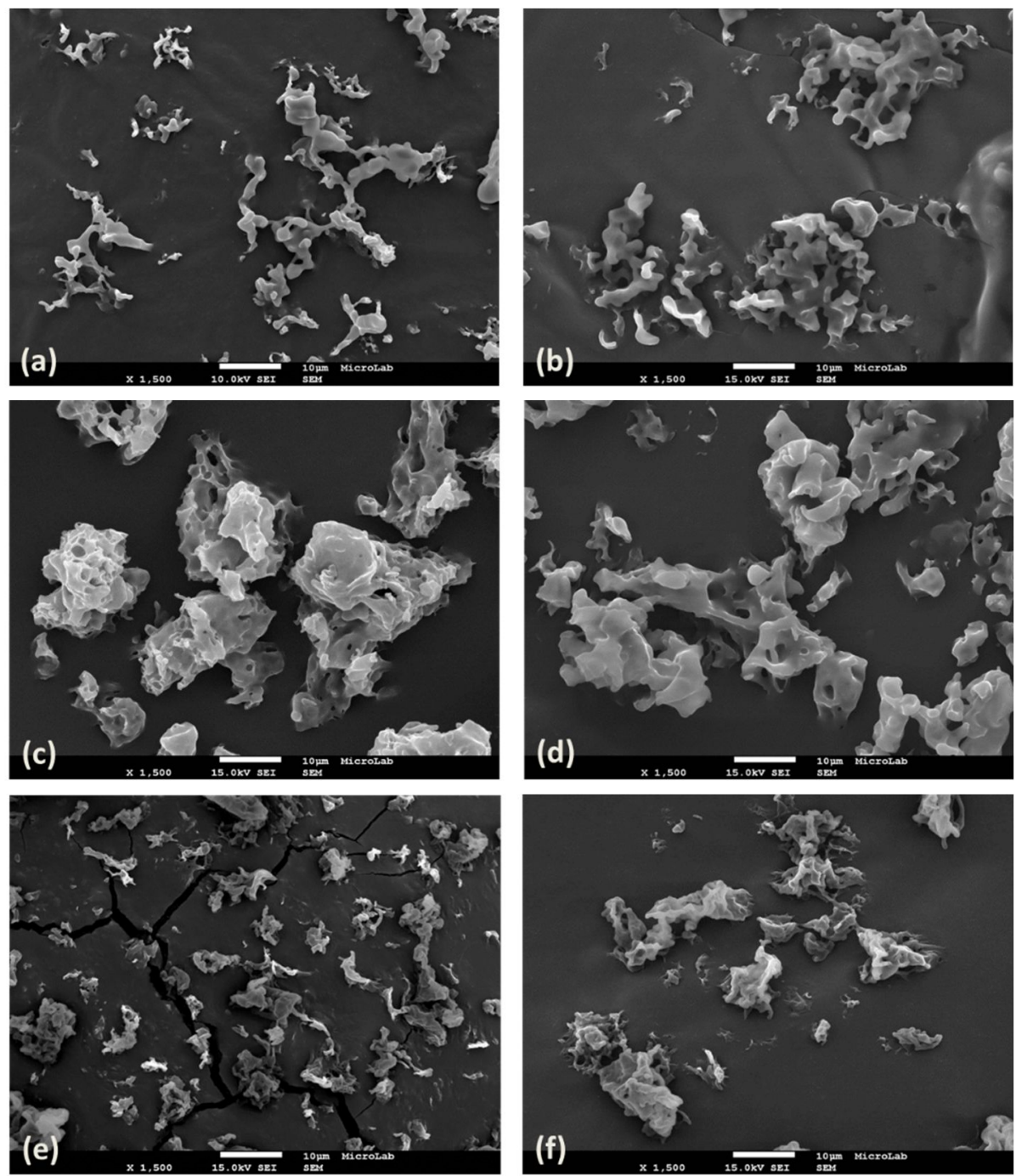

Figure 10 | SEM micrographs at $1500 x$ magnification of Gelucire $43 / 01^{\mathrm{TM}}$ particles produced by PGSS ${ }^{\circledR}$ at $311.15 \mathrm{~K}$ and $20 \mathrm{MPa}$ (a) unloaded, (b) loaded with $1 \%\left(\mathrm{w} / \mathrm{w}\right.$ ) of Coenzyme Q10; of Gelucire $50 / 13^{\mathrm{TM}}$ particles produced by PGSS ${ }^{\oplus}$ at $323.15 \mathrm{~K}$ and $9 \mathrm{MPa}$ (c) unloaded, (d) loaded with $1 \%(\mathrm{w} / \mathrm{w})$ of Coenzyme Q10; of Geleol ${ }^{\mathrm{TM}}$ particles produced by PGSS ${ }^{\circledR}$ at $331.15 \mathrm{~K}$ and 20MPa (e) unloaded, (f) loaded with $1 \%(\mathrm{w} / \mathrm{w})$ of Coenzyme Q10. 


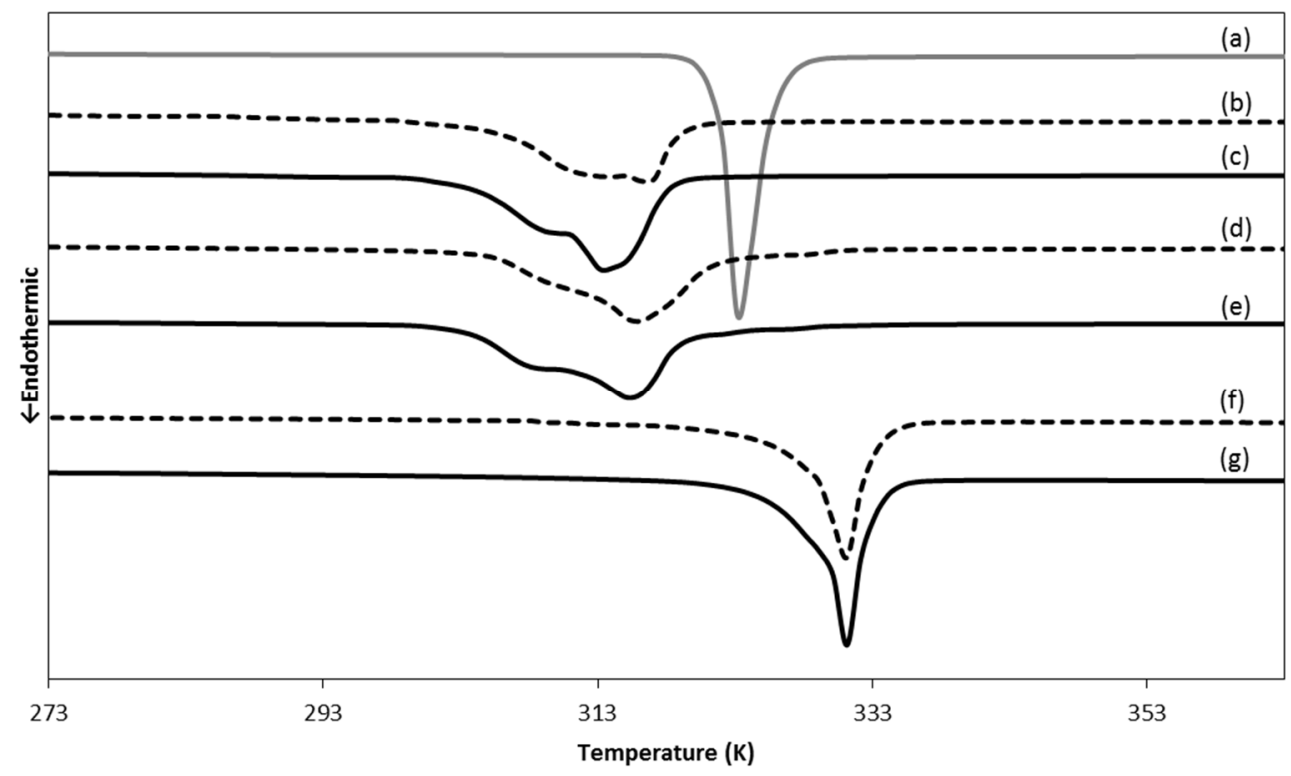

Figure 11| DSC Thermograms of (a) unprocessed Coenzyme Q10; Gelucire 43/01 ${ }^{\mathrm{TM}}$ particles processed at $311.15 \mathrm{~K}$ and $20 \mathrm{MPa}$ (b) loaded with $1 \%(\mathrm{w} / \mathrm{w})$ of Coenzyme Q10, and (c) unloaded; Gelucire $50 / 13^{\text {TM }}$ particles processed at $323.15 \mathrm{~K}$ and $9 \mathrm{MPa}$ (d) loaded with $1 \%(\mathrm{w} / \mathrm{w})$ of Coenzyme Q10, and (e) unloaded; Geleol ${ }^{\mathrm{TM}}$ particles processed at $331.15 \mathrm{~K}$ and $20 \mathrm{MPa}$ (f) loaded with $1 \%(\mathrm{w} / \mathrm{w}$ ) of Coenzyme Q10, and (g) unloaded

Figure 10 and Figure 11 present the SEM pictures and the DSC thermograms obtained, respectively, with the precipitation of the lipids with $1 \%(w / w)$ of Coenzyme Q10.

The Coenzyme Q10-loaded Gelucire 43/01 ${ }^{\mathrm{TM}}$ particles were bigger $\left(d_{0.5}=60.6 \mu \mathrm{m}\right.$, span 1.9) but with the same morphology as the unloaded particles. As predictable, the DSC thermogram of unprocessed Coenzyme Q10 shows a well-defined melting peak of $323.25 \mathrm{~K}$ which indicates a high degree of crystallinity. The thermogram of Coenzyme Q10-loaded Gelucire 43/01 ${ }^{\mathrm{TM}}$ particles shows a broad melting peak (316.56K) more displaced towards the melting temperature of the unloaded particles (313.48K).

Regarding the Coenzyme Q10-Loaded Gelucire 50/13 ${ }^{\mathrm{TM}}$ particles, it is possible to observe that the particles collected were the same size as the unloaded particles 
$\left(d_{0.5}=21.2 \mu \mathrm{m}\right.$, span 2.8$)$, with a less porous structure. When analysing the DSC thermograms, is possible to verify once again the displacement of the melting peak of Coenzyme Q10-loaded particles (315.8K) towards the melting temperature of the unloaded particles (315.59K).

The co-precipitation of Geleol ${ }^{\mathrm{TM}}$ and Coenzyme Q10 led to the formation of bigger and more aggregated particles $\left(d_{0.5}=60.6 \mu m\right.$, span 1.6$)$ compared to the precipitation of Geleol ${ }^{\mathrm{TM}}$ by itself. The DSC thermogram of the loaded particles shows a similar melting peak as the melting temperature of the unloaded Geleol ${ }^{\mathrm{TM}}$ particles (331.15K), however the onset temperature of the loaded particles occurs first (328.91K).

Although Coenzyme Q10 was present at $1 \%(w / w)$, it seems enough to form a new matrix with distinct physical features, in all the lipids tested, resulting in particles with different size or different morphology compared to the unloaded-lipid particles.

\section{Conclusions}

Solid lipid particles of glycerolipids, namely Gelucire $43 / 01^{\mathrm{TM}}$, Gelucire $50 / 13^{\mathrm{TM}}$ and Geleol $^{\mathrm{TM}}$ were successfully produced by PGSS ${ }^{\circledR}$. The particles produced are suitable to be further used as carriers of active compounds in the pharmaceutical field, being Geleol ${ }^{\mathrm{TM}}$ also appropriate for formulation of nutraceuticals $11,22,29,31,33,42$. Furthermore, the effect of different parameters of the PGSS ${ }^{\circledR}$ technique on the size and morphology of the precipitated particles, including temperature, pressure, nozzle diameter, and the co-precipitation with an API were studied. In general, the particles obtained had a wide range of particle size and showed a non-spherical morphology. Since the solubility of $\mathrm{CO}_{2}$ in the lipid matrices, either in Gelucire $43 / 01^{\mathrm{TM}}$, Gelucire $50 / 13^{\mathrm{TM}}$ or in Geleol ${ }^{\mathrm{TM}}$, increases with increasing pressure and decreases with increasing temperature, it would be expected that smaller particles 
would be produced at higher pressure and lower temperature values $29,30,32$. Also, if the working temperature is close to the melting point of the lipid matrix, it would lead to shorter solid-liquid equilibrium condition time and thus less droplet coalescence and production of smaller particles ${ }^{15}$. This common behavior was observed for Gelucire $43 / 01^{\mathrm{TM}}$ and for Geleol ${ }^{\mathrm{TM}}$, both being composed of mixtures of glycerides. However, when processing Gelucire 50/13 ${ }^{\mathrm{TM}}$ by PGSS ${ }^{\circledR}$, it behaved differently, producing smaller particles at higher temperature and lower pressure values. Moreover, the particles obtained with this carrier were the more polydisperse of this study. This carrier comprises a mixture of lipid and polymeric materials with different physical characteristics which probably led to different behavior during its precipitation. When atomizing the three lipids through a nozzle with higher diameter, Gelucire $43 / 01^{\mathrm{TM}}$ and Geleo ${ }^{\mathrm{TM}}$ gave bigger particles compared to those obtained with the smaller diameter nozzle. Once again, Gelucire $50 / 13^{\mathrm{TM}}$ behaved in a different way, keeping the same size and changing the shape of the particles while processed with the $711 \mu \mathrm{m}$ nozzle. Finally, the co-precipitation of the lipids with just $1 \%(\mathrm{w} / \mathrm{w})$ of Coenzyme Q10 resulted in an increase of particle size in the case of Gelucire $43 / 01^{\mathrm{TM}}$ and Geleol ${ }^{\mathrm{TM}}$, and in a change in the particle morphology in the case of Gelucire $50 / 13^{\mathrm{Tm}}$. This API, which was liquefied in all experiments, was blended with the carriers forming a new lipid matrix with distinct behavior, leading to the production of particles with distinct size or morphology in comparison to the unloaded particles.

We can conclude from this study that a minimal change in the operating conditions of the PGSS ${ }^{\circledast}$ process can result in significant differences in the size and morphology of the final lipid particles. In particular, when the chosen carrier comprises mixtures of compounds, like lipid and polymeric materials, the resulting gas saturated solution does not follow the general behavior of the carriers while processed by $\mathrm{PGSS}^{\circledast}$. Moreover, it is always important to consider that commercial presentations of the same pharmaceutical carrier are not completely equal, and that minimal 
changes in its composition may be enough to alter the properties of the matrix and hence the size and morphology of the final particles produced by PGSS ${ }^{\circledR}$. Therefore, the knowledge of the thermodynamic behavior of each system, like the S-L data, as well as the effect of each variable of the process is indispensable for the production of particles with desired features.

\section{Acknowledgments}

This work was supported by Fundação para a Ciência e Tecnologia (FCT) through Grant No. PEst-OE/EQB/LA0004/2011. V.S.S. Gonçalves is also grateful for the financial support from SFRH/BD/77350/2011 grant from FCT. S. Rodríguez-Rojo acknowlegdes the Ministerio de Economía y Competitividad and Universidad de Valladolid for her Juan de la Cierva fellowship.

\section{References}

1 J. Pardeike, A. Hommoss and R. H. Müller, Int. J. Pharm., 2009, 366, 17084.

2 M. Muchow, P. Maincent and R. H. Muller, Drug Dev. Ind. Pharm., 2008, 34, 1394-405.

3 A. J. Almeida and E. Souto, Adv. Drug Deliv. Rev., 2007, 59, 478-90.

4 R. H. Müller, K. Mäder and S. Gohla, Eur. J. Pharm. Biopharm., 2000, 50, 161-77.

5 S. Patel, S. Chavhan, H. Soni, a K. Babbar, R. Mathur, a K. Mishra and K. Sawant, J. Drug Target., 2011, 19, 468-74.

6 J. Varshosaz, S. Eskandari and M. Tabakhian, Pharm. Dev. Technol., 2010, 15, 89-96.

7 A. S. Joshi, H. S. Patel, V. S. Belgamwar, A. Agrawal and A. R. Tekade, J. Mater. Sci. Mater. Med., 2012, 23, 2163-75.

8 R. Parhi and P. Suresh, Curr. Drug Discov. Technol., 2012, 9, 2-16.

9 C. C. Beh, R. Mammucari and N. R. Foster, Chem. Eng. J., 2012, 188, 1-14.

10 WO/1995/021688, 1995.

11 A. R. Sampaio de Sousa, A. L. Simplício, H. C. de Sousa and C. M. M. Duarte, J. Supercrit. Fluids, 2007, 43, 120-125. 
12 C. A. García-González, A. Argemí, A. R. Sampaio de Sousa, C. M. M. Duarte, J. Saurina and C. Domingo, J. Supercrit. Fluids, 2010, 54, 342-347.

13 A. V. M. Nunes and C. M. M. Duarte, Materials (Basel)., 2011, 4, 20172041.

14 Ž. Knez, in Proceedings for the Sixth International Symposium for Supercritical Fluids, 2003, p. 1865.

15 M. Strumendo, A. Bertucco and N. Elvassore, J. Supercrit. Fluids, 2007, 41, 115-125.

16 P. Kappler, W. Leiner, M. Petermann and E. Weidner, in 6th International Symposium on supercritical fluid, Versailles, France, 2003.

17 N. Elvassore, M. Flaibani, A. Bertucco and P. Caliceti, Ind. Eng. Chem. Res., 2003, 42, 5924-5930.

18 M. Dunne, I. Corrigan and Z. Ramtoola, Biomaterials, 2000, 21, 1659-68.

19 J. A. Champion, Y. K. Katare and S. Mitragotri, J. Control. Release, 2007, 121, 3-9.

20 R. Rowe, P. Sheskey and M. Quinn, Eds., Handbook of Pharmaceutical Excipients, Pharmaceutical Press and American Pharmacists Association, Sixth., 2009.

21 V. P. Torchilin, Adv. Drug Deliv. Rev., 2012, 64, 302-315.

22 M. Fraile, Á. Martín, D. Deodato, S. Rodriguez-Rojo, I. D. Nogueira, A. L. Simplício, M. J. Cocero and C. M. M. Duarte, J. Supercrit. Fluids, 2013, 81, 226-235.

23 E. H. Gokce, E. Korkmaz, S. Tuncay-Tanrıverdi, E. Dellera, G. Sandri, M. C. Bonferoni and O. Ozer, Int. J. Nanomedicine, 2012, 7, 5109-17.

24 V. Teeranachaideekul, E. B. Souto, V. B. Junyaprasert and R. H. Müller, Eur. J. Pharm. Biopharm., 2007, 67, 141-8.

25 H. Piao, M. Ouyang, D. Xia, P. Quan, W. Xiao, Y. Song and F. Cui, Int. J. Pharm. , 2011, 419, 255-9.

26 A. A. Matias, A. V. M. Nunes, T. Casimiro and C. M. M. Duarte, J. Supercrit. Fluids, 2004, 28, 201-206.

27 J. Li, M. Rodrigues, A. Paiva, H. A. Matos and E. G. De Azevedo, Fluid Phase Equilib., 2006, 241, 196-204.

28 Ž. Knez, M. Škerget and Z. Mandžuka, J. Supercrit. Fluids, 2010, 55, 648652.

29 A. R. Sampaio de Sousa, M. Calderone, E. Rodier, J. Fages and C. M. M. Duarte, J. Supercrit. Fluids, 2006, 39, 13-19.

30 A. R. Sampaio de Sousa, Development of Functional Particles using Supercritical Fluid Technology, Instituto de Tecnologia Química e Biológica, Oeiras, Portugal, Ph.D. Thes., 2007.

31 S. Rodríguez-Rojo, D. D. Lopes, a. M. R. C. Alexandre, H. Pereira, I. D. Nogueira and C. M. M. Duarte, J. Supercrit. Fluids, 2013.

32 Z. Mandžuka and Ž. Knez, J. Supercrit. Fluids, 2008, 45, 102-111. 
33 S. K. Jain and A. Gupta, AAPS PharmSciTech, 2009, 10, 1128-36.

34 S. Shimpi, B. Chauhan, K. R. Mahadik and A. Paradkar, AAPS PharmSciTech, 2004, 5, article 43.

35 J. Li, H. a. Matos and E. G. de Azevedo, J. Supercrit. Fluids, 2004, 32, 275286.

36 J. Fages, H. Lochard, J.-J. Letourneau, M. Sauceau and E. Rodier, Powder Technol., 2004, 141, 219-226.

37 M. Vijayaraghavan, S. Stolnik, S. M. Howdle and L. Illum, Int. J. Pharm., 2013, 441, 580-8.

38 D. Deodato Lopes, FCT-Universidade Nova de Lisboa (Portugal), 2012.

39 S. Qi, D. Marchaud and D. Q. M. Craig, J. phar, 2010, 99, 262-274.

40 V. Teeranachaideekul, P. Boonme, E. B. Souto, R. H. Müller and V. B. Junyaprasert, J. Control. Release, 2008, 128, 134-41.

41 B. Siekmann and K. Westesen, Colloids Surfaces B Biointerfaces, 1994, 3, 159-175.

42 A. R. Sampaio de Sousa, R. Silva, F. H. Tay, A. L. Simplício, S. G. Kazarian and C. M. M. Duarte, J. Supercrit. Fluids, 2009, 48, 120-125. 



\section{Chapter 2}

Part II: Development of structured lipid carrier systems containing glyceryl monooleate through PGSS ${ }^{\circledR}$

1. Abstract ..............................................................................................

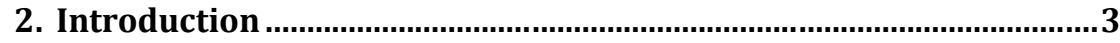

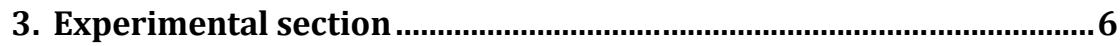

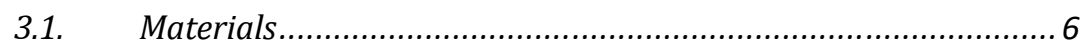

3.2. Melting point measurements.............................................. 6

3.3. Particles from gas saturated solutions $\left(\mathrm{PGSS}^{\circledR}\right)$........................ 7

3.4. Spray Chilling .................................................................... 8

3.5. Particles' characterization ..................................................... 9

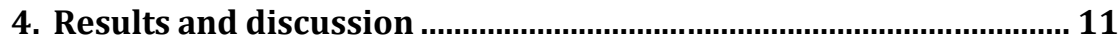

4.1. Melting point measurements............................................. 11

4.2. Development of structured lipid carriers................................ 14

4.3. Development of Gelucire 43/01 ${ }^{\text {TM}}$ :GMO structured lipid carriers loaded with ketoprofen ................................................................... 21

5. Conclusions............................................................................................ 29

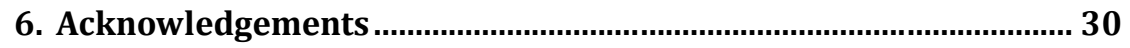

7. References ............................................................................................ 30 
Adapted from: Gonçalves, V.S.S., Matias, A.A., Rodríguez-Rojo, S., Nogueira, I.D., Duarte, C.M. (2015) Supercritical fluid precipitation of ketoprofen in novel structured lipid carriers for enhanced mucosal delivery - a comparison with solid lipid particles. International Journal of Pharmaceutics, 495(1):302-311. doi: 10.1016/j.ijpharm.2015.08.026

The author contributed to the planning and execution of all the experiments described in this chapter, except for SEM analysis performed by I.D. Nogueira. The author was also involved on the discussion and interpretation of results, as well as on the preparation of the manuscript. 


\section{Abstract}

Structured lipid carriers based on mixture of solid lipids with liquid lipids are the second generation of solid lipid particles, offering the advantage of improved drug loading capacity and higher storage stability. In this study, structured lipid carriers were successfully prepared for the first time by precipitation from gas saturated solutions. Glyceryl monooleate (GMO), a liquid glycerolipid, was selected in this work to be incorporated into three solid glycerolipids with hydrophilic-lipophilic balance (HLB) ranging from 1 to 13 , namely Gelucire $43 / 01^{\mathrm{TM}}$, Geleol ${ }^{\mathrm{TM}}$ and Gelucire $50 / 13^{\text {TM }}$. In general, microparticles with an irregular porous morphology and a wide particle size distribution were obtained. The HLB of the individual glycerolipids might be a relevant parameter to take into account during the processing of solid:liquid lipid blends. As expected, the addition of a liquid lipid into a solid lipid matrix led to increased stability of the lipid carriers, with no significant modifications in their melting enthalpy after 6 months of storage. Additionally, Gelucire 43/01 ${ }^{\mathrm{m} M}: \mathrm{GMO}$ particles were produced with different mass ratios and loaded with ketoprofen. Spray chilling was also used as a comparison technique, proving not be as efficient as $\mathrm{PGSS}^{\circledR}$ for the production of structured lipid particles. The drug loading capacity of the structured lipid carriers increased as the GMO content in the particles increased, achieving a maximum encapsulation efficiency of $97 \%$ for the 3:1 mass ratio. Moreover, structured lipid carriers presented an immediate release of ketoprofen from its matrix with higher permeation through a mucous-membrane model, while solid lipid particles present a controlled release of the drug with less permeation capacity.

\section{Introduction}

Solid lipid particles (SLP's) are carriers often used as drug delivery systems since the beginning of 1990s, being composed of lipids that are solid at body temperature ${ }^{1}$. 
Despite their excellent tolerability, controlled release and protection from degradation of drugs, they present some limitations, such as low drug loading capacity and drug leakage after storage ${ }^{2-4}$. It is known that during the production of solid lipid carriers, particularly those composed of highly pure lipids, the particles crystallize in metastable polymorphic forms of low thermodynamic stability. Usually, active compounds are incorporated in the imperfections of this crystal structure, between the fatty acid chains. Thus, the more perfect is the crystal structure formed, less drug is incorporated ${ }^{5,6}$. Moreover, during storage, the number of imperfections in this structure is reduced due to the formation of lowenergy modifications resulting in a more ordered structure, hence leading to the expulsion of the active compound ${ }^{1,7,8}$. To overcome this problem, a second generation of lipid particles whose matrix is composed of solid and liquid lipids have been developed ${ }^{1,9-11}$. This binary mixture, known as structured lipid carriers, is still solid at room and body temperature. It enables the formation of more imperfections in the crystal structure, leading to higher drug entrapment and minimum drug leakage during storage ${ }^{5}$. Furthermore, drugs are mostly soluble in liquid lipids than in solid ones, being these structured carriers attractive alternatives for transdermal and mucosal delivery of active compounds ${ }^{7,12,13}$. Glyceryl monooleate (GMO) is a polar amphiphilic waxy lipid with a HydrophilicLipophilic Balance (HLB) of 3, that has been recently used as carrier for drug delivery systems, being non-toxic, biocompatible and biodegradable ${ }^{14}$. This water insoluble surfactant is capable to form sequential lyotropic liquid crystalline structures under certain circumstances. As the temperature and water content increase, GMO enters the cubic phase region which is capable to simultaneously accommodate lipophilic, hydrophilic and amphiphilic active compounds with distinct molecular weights ${ }^{14-16}$. This highly stable and robust mesophase is insensitive to salts and solvents, being appropriate for the incorporation of sensitive molecules such as peptides ${ }^{17}$. Moreover, upon hydration, the matrix of GMO swells and earns higher 
viscosity, thus acquiring mucoadhesive properties ${ }^{15}$. This, coupled to its ability to increase the bioavailability of drugs by inhibiting the P-glycoprotein and by promoting their lymphatic transport, makes GMO an interesting alternative to polymeric carriers for the mucosal (e.g. intranasal) release of active compounds ${ }^{18,19}$. Usually, this lipid carrier is applied in aqueous formulations, however is highly desirable to work with alternative formulations (non-aqueous and solid) to promote higher chemical stability of drugs and thus lower rates of oxidation or hydrolysis ${ }^{17,20}$.

Despite the fact that supercritical fluid precipitation techniques, more precisely Particles from Gas Saturated Solutions (PGSS ${ }^{\circledR}$ ), are being increasingly applied in the production of solid lipid particles, the production of structured carriers composed of solid and liquid lipids has not yet been explored ${ }^{21-24}$. Thus, the objective of this work was to produce a novel carrier system based on a binary mixture of solid and liquid lipids, through PGSS ${ }^{\circledR}$, in order to obtain particles with improved features for mucosal (intranasal) delivery of drugs. PGSS ${ }^{\circledast}$ technique consists of dissolving $\mathrm{scCO}_{2}$ in the melted mixture of lipids, causing a depression of their viscosities and melting points, being possible to produce particles at mild processing conditions ${ }^{25}$. The expansion of this $\mathrm{CO}_{2}$-saturated solution to atmospheric pressure through a nozzle, causes the atomization and precipitation of particles with complete expansion of carbon dioxide ${ }^{26,27}$. GMO was chosen as the liquid lipid in order to confer mucoadhesive properties to lipid particles. Three different carriers constituted by mixtures of glycerides, namely Gelucire $43 / 01^{\mathrm{TM}}$ (HLB 1), Gelucire 50/13 ${ }^{\text {TM }}$ (HLB 13) and Geleol ${ }^{\text {TM }}$ (HLB 3), were used as the solid lipid matrix due to their capacity to provide controlled release of drugs ${ }^{22,28,29}$. The influence of temperature and pressure of the PGSS ${ }^{\circledR}$ process on the physical properties of the precipitated particles was investigated. Furthermore, it was studied whether or not the incorporation of a liquid lipid increases the stability of the particles during storage by verifying the melting enthalpy variation during aging 
at room temperature ${ }^{30}$. Further experiments were performed with the solid lipid Gelucire $43 / 01^{\mathrm{TM}}$, namely the production of particles with different solid lipid:liquid lipid mass ratios, the development of ketoprofen-loaded structured lipid particles and the production of structured lipid carriers by Spray Chilling, used as a comparison solvent-free technique. The particles obtained were characterized considering their size, morphological and thermal properties as well as their drug release/permeation behavior.

\section{Experimental section}

\subsection{Materials}

Gelucire $43 / 01^{\mathrm{TM}}$, Gelucire 50/13 ${ }^{\mathrm{TM}}$, Geleol ${ }^{\mathrm{TM}}$ and Peceol ${ }^{\mathrm{TM}}$ (GMO) were kindly supplied by Gattefossé (France). Ketoprofen ( $\geq 98 \%$ purity) was purchased from Sigma-Aldrich (Steinheim, Germany). CO2 (99.95 and 99.998 mol\% purity) was delivered by Air Liquide (Portugal). Ethanol (96\%) was purchased from AGA (Portugal). All the chemicals were used without further purification.

\subsection{Melting point measurements}

The melting point depression of the lipid carriers in the presence of compressed $\mathrm{CO}_{2}$ was determined within this work using a visual method previously described ${ }^{31}$. Briefly, the mixture of lipids was placed inside a glass $\left(1 \mathrm{~cm}^{3}\right)$, which was then inserted in a stainless steel high-pressure visual cell with an internal volume of approximately $5 \mathrm{~cm}^{3}$. After, $\mathrm{CO}_{2}$ was pumped using a Haskel pump (model 2972371) into the cell until the desired pressure was reached. The pressure in the cell was measured with a pressure transducer Digibar II calibrated between 0 and $25 \mathrm{MPa}$ (accuracy: $0.15 \%$ ). The temperature was then gradually increased until it was possible to visually observe the complete melting of mixture of lipids. The heating 
system was composed of a heating cable (Horst), a controller (Ero Electronic LMS) and a high accuracy thermometer (Omega HH 501 AT, 0.1\%). Measurements were performed in a pressure range up to $19 \mathrm{MPa}$. In order to confirm the reproducibility of the results some points were repeated resulting in maximum deviations of $0.2 \mathrm{~K}$.

\subsection{Particles from gas saturated solutions (PGSS $\left.{ }^{\circledR}\right)$}

Structured lipid particles unloaded and loaded with ketoprofen were produced through PGSS ${ }^{\circledR}$ process. The schematic representation of the equipment (FAME UNIT, Separex, France, 2010) used to produce the particles is represented in figure 1 and was previously described ${ }^{29,32}$.

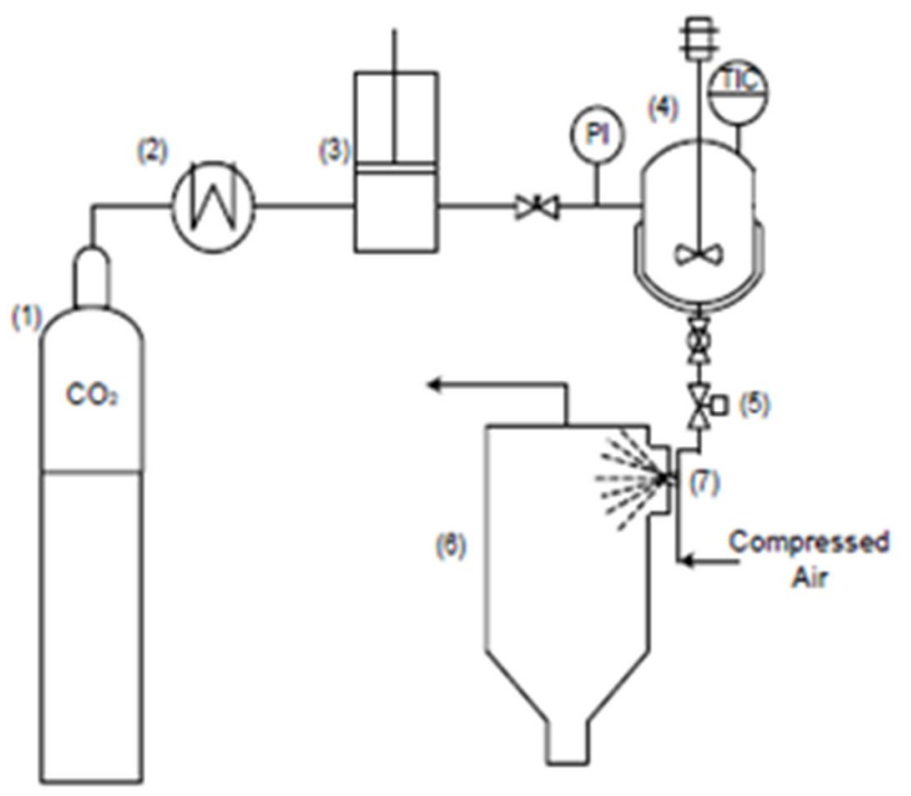

Figure 1| Experimental setup: (1) $\mathrm{CO}_{2}$ cylinder (2) cryostate (3) pneumatic piston pump (4) stirred vessel (electrically thermostated) (5) automated depressurisation valve (6) recovery vessel (7) nozzle

Carbon dioxide was fed by a pneumatic pump (29723-71, Haskel International Inc., CA, USA) to a $50 \mathrm{~cm}^{3}$ electrically thermostated high-pressure stirred vessel, 
containing the mixture of lipids with and without the drug to be processed, until the desired working pressure was reached. After 30 minutes of stirring (150 rpm), the mixture was depressurized by an automated depressurization valve and atomized through a two-fluid nozzle $(\mathrm{d}=250 \mu \mathrm{m})$ to a cyclone, where it was externally mixed with compressed air $(0.7 \mathrm{MPa})$. The particles were finally recovered into a collector vessel of $18 \mathrm{~L}$ at atmospheric pressure.

The operating conditions ( $T$ and $P$ ) were chosen according to the measurements of melting point depression of the mixtures in the presence of compressed $\mathrm{CO}_{2}$ and varied in order to see their effect on the particles' morphology and size.

\subsection{Spray Chilling}

Particles of Gelucire $43 / 01^{\mathrm{TM}}$ and GMO with mass ratios of 3:1 and 10:1 were also produced through Spray Chilling using a Büchi Mini Spray Dryer B-290 with an adequate accessory chamber to allow the melting of the mixtures. A schematic representation of the apparatus is represented in Figure 2 and was previously described in the PhD Thesis of Sampaio de Sousa ${ }^{33}$.

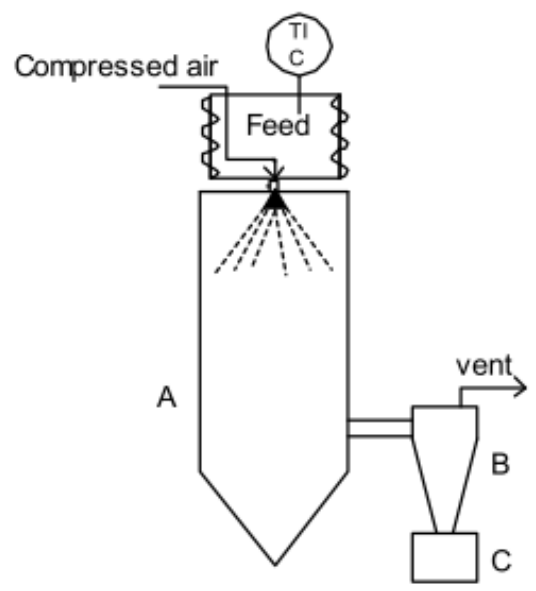

Figure 2| Scheme of the apparatus used for the Spray Chilling experiments. A - Drying chamber, B Separative cyclone, C-Particle collector. 
The temperature in the accessory chamber was set at 338.15K, using a water bath, to ensure that the mixture was liquefied. The liquid was further atomized through a two-fluid nozzle with $700 \mu \mathrm{m}$ diameter inner tip and $1400 \mu \mathrm{m}$ diameter cap-orifice, using compressed air as the drying air with a volumetric flow rate of $40 \mathrm{~m}^{3} / \mathrm{h}$.

\subsection{Particles' characterization}

\subsubsection{Particle size, particle size distribution and morphology analysis} Particle size and morphology were analyzed visually by FE-SEM (Field Emission Scanning Electron Microscopy) JEOL 7001F at 10-15kV. Before analysis, particles were covered with approximately $300 \AA$ of a gold-platinum film with a sputtercoater in argon atmosphere (Polaron). Particle size and particle size distribution (PSD) were determined by Laser Diffraction (Malvern Mastersizer 2000). Particles were dispersed in distilled water and measurement was carried out after a gentle rotation of the particles suspension container in order to obtain an even dispersion of the particles. In this work, particle size measurements are reported as volume distribution and defined as the d0.5 (maximum particle diameter below which 50\% of the sample volume exists - also known as the median particle size by volume). Each diameter value reported is the average of three suspensions of particles. The span value is also reported, that is, the ratio between d0.5 and (d0.9- d0.1); span values near to 1 represent narrow PSD.

\subsubsection{Thermal behavior}

Differential Scanning Calorimetry (DSC) measurements were carried out on a DSC TA instruments Q200 (module MDSC) with the aim of studying the melting temperature/enthalpy of the particles and bulk materials. The samples were placed in an aluminum pan and sealed; the probes were heated from 253.15 to $473.15 \mathrm{~K}$ at a rate of $10 \mathrm{~K} / \mathrm{min}$ under nitrogen atmosphere. In order to confirm the 
reproducibility of the results, some samples were repeated resulting in maximum deviations of $0.2 \mathrm{~K}$ (melting point) and $2 \mathrm{~J} / \mathrm{g}$ (melting enthalpy).

\subsubsection{Determination of encapsulation efficiency (EE)}

The quantification of ketoprofen loaded inside the particles was determined by Ultraviolet-visible spectrophotometry. A certain amount of particles was suspended in a known volume of ethanol (sink conditions) and sonicated for $30 \mathrm{~min}$. The suspensions were then filtered through $0.45 \mu \mathrm{m}$ filters, being the absorbance of the resulting solutions analyzed at $254 \mathrm{~nm}$ in a UV-Visible Spectrophotometer (Genesys10uv spectrometer; Thermo Spectronic, New York, USA). Calibration was obtained by using standard samples with concentrations between 2 and $12 \mu \mathrm{g} / \mathrm{mL}$ $\left(R^{2}=0.9992\right)$. Each analysis was performed in triplicate. The encapsulation efficiency was calculated by the following equation:

$$
E E(\%)=\frac{\text { mass of drug quantified in particles }}{\text { mass of drug initially loaded }} \times 100
$$

\subsubsection{In vitro evaluation of drug release kinetics}

A sample of particles containing approximately $6 \mathrm{mg}$ of ketoprofen were suspended in $50 \mathrm{~mL}$ of dissolution medium (phosphate buffer solution, $\mathrm{pH}=6.8$ ). Samples were stirred at $155 \mathrm{rpm}$ and maintained at a temperature of 310.15K. Aliquots $(1 \mathrm{~mL})$ were withdrawn at predetermined time intervals $(1,3,5 \mathrm{~min}, 10 \mathrm{~min}, 15 \mathrm{~min}, 30$ min, etc.) and the same volume of fresh medium was added to the suspension. The samples were filtered and the concentration of ketoprofen was determined using a UV-Visible Spectrophotometer (UV-Vis Genesys10uv spectrometer; Thermo Spectronic, $\lambda=258 \mathrm{~nm}$ ). Calibration was obtained by using standard samples with concentrations between 2 and $14 \mu \mathrm{g} / \mathrm{mL}\left(R^{2}=0.999\right)$. Each analysis was performed in triplicate. 
3.5.5. In vitro permeability studies - Franz cell diffusion Franz diffusion cell system (Permegear Inc.;Bethlehem, PA) used to evaluate the in vitro ketoprofen permeability at physiological conditions was previously described in the work of Argemí et al. ${ }^{34}$. Briefly, a weighed amount of particles was added to the donor chamber. The receptor chamber was filled with receptor solution (phosphate buffer solution, $\mathrm{pH}=6.8$ ) and was maintained under constant stirring (100rpm). Temperature of receptor solution was typically maintained at $310.15 \mathrm{~K}$. Strat-MR membrane disk (Merck Millipore) was mounted between donor and receptor chamber, and samples $(350 \mu \mathrm{l})$ were withdrawn at predetermined time intervals $(5,10,15 \mathrm{~min}, 30 \mathrm{~min}, 60 \mathrm{~min}, 90 \mathrm{~min}$, etc.). The receiver chamber was replenished with fresh buffer each time sample was withdrawn. Strat-MR membranes were previously impregnated with $2 \%(\mathrm{w} / \mathrm{v})$ mucin (PBS solution) in order to mimic the mucus present in mucosa. Concentration of ketoprofen was determined as previously described in section 3.5.4.; each analysis was performed in triplicated.

\section{Results and discussion}

\subsection{Melting point measurements}

The knowledge of the solid-liquid transitions of the lipids under pressurized $\mathrm{CO}_{2}$ is essential for their precipitation through PGSS ${ }^{\circledR}$ process $^{35}$. Thus, the melting points of the three different mixtures, Gelucire 43/01 ${ }^{\mathrm{Tm}}: \mathrm{GMO}$, Gelucire 50/13 $3^{\mathrm{TM}}: \mathrm{GMO}$ and Geleol $^{\mathrm{Tm}}: \mathrm{GMO}$ were determined. The higher solid lipid:GMO mass ratio studied was 3:1.

The experimental data obtained in this work for solid-liquid transition of solid lipid:GMO mixtures (3:1 w/w) under compressed $\mathrm{CO}_{2}$ are summarized in Table 1 and Figure 3. 
Chapter 2 | Part II

Table 1| Melting points of [solid lipids:GMO] mixtures (3:1 w/w) in the presence of $\mathrm{CO}_{2}$

\begin{tabular}{|c|c|c|c|c|c|}
\hline \multicolumn{2}{|c|}{ Gelucire $43 / 01^{m w}: G M O$} & \multicolumn{2}{|c|}{ Gelucire $50 / 13^{m}:$ :GMO } & \multicolumn{2}{|c|}{ Geleol $^{m}: G M O$} \\
\hline $\begin{array}{c}\text { Pressure } \\
\text { (MPa) }\end{array}$ & $\begin{array}{c}\text { Temperature } \\
\text { (K) }\end{array}$ & $\begin{array}{c}\text { Pressure } \\
\text { (MPa) }\end{array}$ & $\begin{array}{c}\text { Temperature } \\
\text { (K) }\end{array}$ & $\begin{array}{c}\text { Pressure } \\
\text { (MPa) }\end{array}$ & $\begin{array}{c}\text { Temperature } \\
\text { (K) }\end{array}$ \\
\hline 0.10 & 317.25 & 0.10 & 320.95 & 0.10 & 330.45 \\
\hline 1.10 & 315.85 & 1.20 & 320.25 & 0.70 & 329.35 \\
\hline 2.10 & 314.25 & 2.20 & 316.55 & 1.70 & 327.75 \\
\hline 4.20 & 311.15 & 3.25 & 314.45 & 2.50 & 326.75 \\
\hline 5.20 & 307.65 & 4.40 & 309.85 & 3.25 & 325.85 \\
\hline 7.60 & 305.45 & 5.25 & 308.85 & 3.35 & 325.35 \\
\hline 9.95 & 306.55 & 5.45 & 307.55 & 4.40 & 325.15 \\
\hline 10.70 & 306.65 & 5.95 & 307.65 & 4.65 & 324.45 \\
\hline 12.80 & 307.15 & 6.25 & 307.45 & 5.55 & 324.15 \\
\hline 13.80 & 307.35 & 6.85 & 306.65 & 5.65 & 324.45 \\
\hline 15.95 & 308.15 & 7.50 & 306.95 & 5.85 & 323.95 \\
\hline \multirow[t]{17}{*}{18.65} & 308.65 & 9.10 & 307.05 & 5.90 & 324.35 \\
\hline & & 9.70 & 307.65 & 6.00 & 323.35 \\
\hline & & 10.30 & 307.85 & 6.15 & 322.95 \\
\hline & & 10.60 & 308.75 & 7.50 & 322.85 \\
\hline & & 11.60 & 310.45 & 7.50 & 323.05 \\
\hline & & 11.70 & 309.45 & 7.70 & 322.95 \\
\hline & & 12.30 & 309.65 & 8.35 & 322.85 \\
\hline & & 13.85 & 309.85 & 10.70 & 323.05 \\
\hline & & 15.90 & 310.15 & 12.35 & 322.75 \\
\hline & & 17.70 & 310.05 & 12.65 & 323.05 \\
\hline & & 17.75 & 310.05 & 12.95 & 323.75 \\
\hline & & & & 13.15 & 323.35 \\
\hline & & & & 15.15 & 323.25 \\
\hline & & & & 15.70 & 324.15 \\
\hline & & & & 16.20 & 323.55 \\
\hline & & & & 18.15 & 324.35 \\
\hline & & & & 18.40 & 324.65 \\
\hline
\end{tabular}




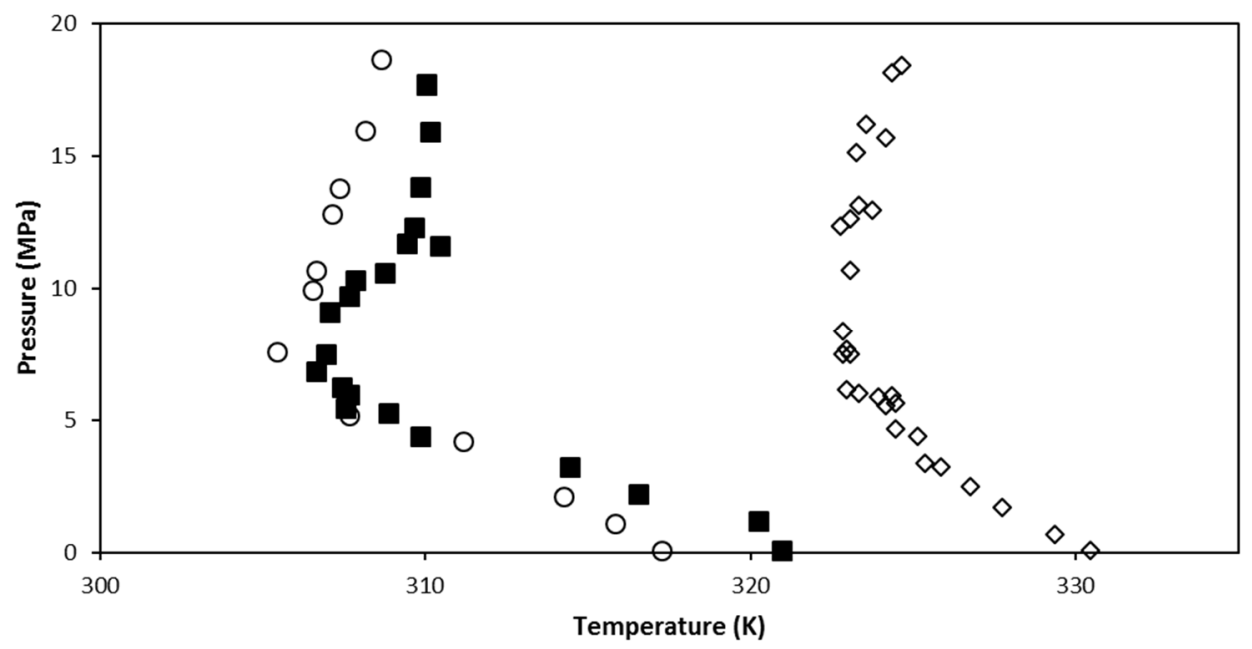

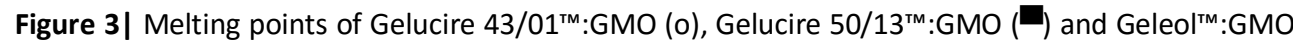
$(0)$ mixtures with mass ratio of $3: 1$ in the presence of compressed $\mathrm{CO}_{2}$

For all the evaluated mixtures of glycerolipids is possible to see an initial depression in the melting point as the pressure increased due to the incorporation of $\mathrm{CO}_{2}$ into the matrix of the lipid. The mixture containing Gelucire 50/13 ${ }^{\text {TM }}$ presents the maximum decrease in the melting temperature (reduction of $14.3 \mathrm{~K}$ at $6.85 \mathrm{MPa}$ ) while the Geleol ${ }^{\mathrm{TM}}$ containing mixture has the lowest depressure (reduction of $7.7 \mathrm{~K}$ at $12.35 \mathrm{MPa})$. Then, the effect of the hydrostatic pressure started to prevail, leading to an increase in the melting point. This general behavior is common both for lipid and polymeric substances ${ }^{28,31}$. These results are in concordance with the solid-liquid transition observed, by Sampaio de Sousa et. al., for Gelucire 43/01 ${ }^{\mathrm{m}}$, Gelucire $50 / 13^{\mathrm{TM}}$ and glycerol monostearate ${ }^{31,33}$. The blending of GMO with the solid lipids also shifted their melting point to lower temperatures, indicating the formation of an eutectic mixture ${ }^{20,36}$. 


\subsection{Development of structured lipid carriers}

4.2.1. Thermal behavior of pure compounds and physical mixtures Prior to producing the structured lipid carriers by PGSS ${ }^{\circledR}, \mathrm{DSC}$ measurements were performed on solidified samples of co-melted lipids (solid:liquid, 3:1 w/w), which were melted, mixed and rapidly solidified in ice-bath, in order to characterize the thermal behavior of the mixtures, as can be seen from Figure 4 .

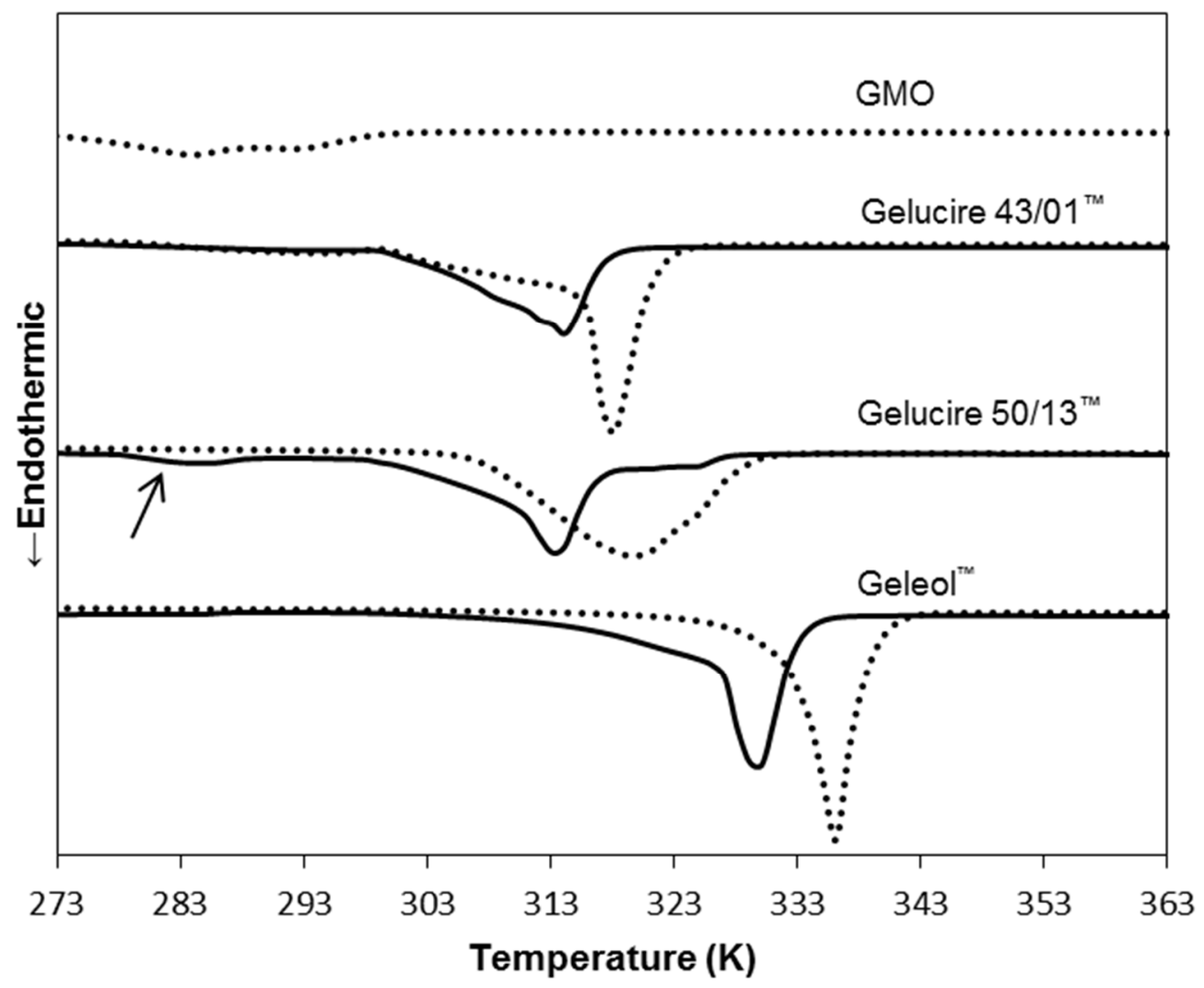

Figure 4| DSC thermograms of the three different mixtures of solid lipids:GMO (mass ratio 3:1). The dotted lines are the thermograms of pure compounds

By analyzing the thermograms is possible to verify a depression in the melting point of all the three solid lipids when mixed with GMO. The fact that the melting 
enthalpy have also decreased (data not shown) indicates the presence of lattice defects (i.e. massive crystal order disturbance) ${ }^{6,12}$. While the mixtures of Gelucire $43 / 01^{\mathrm{TM}}$ and $\mathrm{Geleol}^{\mathrm{TM}}$ with the liquid lipid present one single peak of melting in the DSC thermogram, the mixture of Gelucire $50 / 13^{\mathrm{TM}}$ with $\mathrm{GMO}$ has the presence of two separate melting peaks. This is indicative of a phase separation probably due to the saturation of the solid lipid matrix with GMO. Adding more GMO into Gelucire $50 / 13^{\mathrm{TM}}$ would most likely not result into its intercalation into the solid lipid but rather it would only increase the separate $\mathrm{GMO}$ fraction ${ }^{20}$. This occurrence may be due to the large difference in the HLB values between GMO (HLB 3) and Gelucire $50 / 13^{\mathrm{TM}}$ (HLB 13), leading to a saturation point with lower amounts of GMO in comparison with the other solid matrices.

\subsection{2. $\mathrm{PGSS}^{\circledR}$ precipitation}

As mentioned previously, Gelucire 43/01 ${ }^{\mathrm{Tm}}: \mathrm{GMO}$, Gelucire 50/13 $3^{\mathrm{Tm}}: \mathrm{GMO}$ and Geleol ${ }^{\mathrm{Tm}}: \mathrm{GMO}$ mixtures were precipitated through the PGSS${ }^{\circledR}$ technique using different temperature and pressure conditions to evaluate their impact on the size and morphology of the final structured particles. Table 2 summarizes the PGSS ${ }^{\circledR}$ precipitation experiments performed for the preparation of the structured lipid carriers together with the mass ratios between solid lipid matrices and GMO and the resulting mean particle size. 
Chapter 2 | Part II

Table 2|Summary of PGSS ${ }^{\circledR}$ co-precipitation experiments performed with [solid glycerolipids:

Glyceryl Monooleate (GMO)]; nozzle diameter $\mathrm{d}=250 \mu \mathrm{m}$

\begin{tabular}{|c|c|c|c|c|c|}
\hline System & $\begin{array}{l}\text { Mass } \\
\text { ratio }\end{array}$ & $\begin{array}{c}\text { Pressure } \\
\text { (MPa) }\end{array}$ & $\begin{array}{c}\text { Temperature } \\
\text { (K) }\end{array}$ & $\begin{array}{c}\text { Particle size } d_{0.5} \\
(\mu \mathrm{m})\end{array}$ & Span \\
\hline \multirow{6}{*}{$\begin{array}{c}\text { Gelucire } \\
43 / 01^{\mathrm{m}}: \text { GMO }\end{array}$} & $3: 1$ & 9 & 307.15 & 115.8 & 3.2 \\
\hline & $3: 1$ & 9 & 310.15 & 127.3 & 3.1 \\
\hline & $3: 1$ & 9 & 317.15 & 140.4 & 2.9 \\
\hline & $3: 1$ & 12 & 307.15 & 65.6 & 5.2 \\
\hline & $3: 1$ & 12 & 310.15 & 77.4 & 3.5 \\
\hline & $3: 1$ & 12 & 317.15 & 97.6 & 2.4 \\
\hline Gelucire & $3: 1$ & 9 & 310.15 & - & - \\
\hline $50 / 13^{\mathrm{Tm}}: \mathrm{GMO}$ & $3: 1$ & 12 & 320.15 & - & - \\
\hline \multirow{6}{*}{$\begin{array}{c}\text { Gelucire } \\
50 / 13^{\mathrm{m}}: \mathrm{GMO}\end{array}$} & $10: 1$ & 9 & 310.15 & 12.2 & 19.7 \\
\hline & $10: 1$ & 9 & 315.15 & 11.3 & 20.3 \\
\hline & $10: 1$ & 9 & 320.15 & 10.6 & 37 \\
\hline & $10: 1$ & 12 & 310.15 & 9.5 & 10.8 \\
\hline & $10: 1$ & 12 & 315.15 & 12.4 & 13.2 \\
\hline & $10: 1$ & 12 & 320.15 & 12.6 & 18.6 \\
\hline \multirow{6}{*}{ Geleol $^{\prime m}: G M O$} & $3: 1$ & 9 & 323.15 & 97.1 & 1.4 \\
\hline & $3: 1$ & 9 & 328.15 & 87.7 & 1.5 \\
\hline & $3: 1$ & 9 & 333.15 & 85.7 & 1.8 \\
\hline & $3: 1$ & 12 & 323.15 & 92.4 & 1.4 \\
\hline & $3: 1$ & 12 & 328.15 & 108.5 & 1.5 \\
\hline & $3: 1$ & 12 & 333.15 & 95.8 & 1.4 \\
\hline
\end{tabular}

Figure 5 shows the SEM micrographs of the structured lipid carriers obtained under $\mathrm{PGSS}^{\circledR}$ operating conditions that led to the production of smaller particles with each solid lipid matrix. 

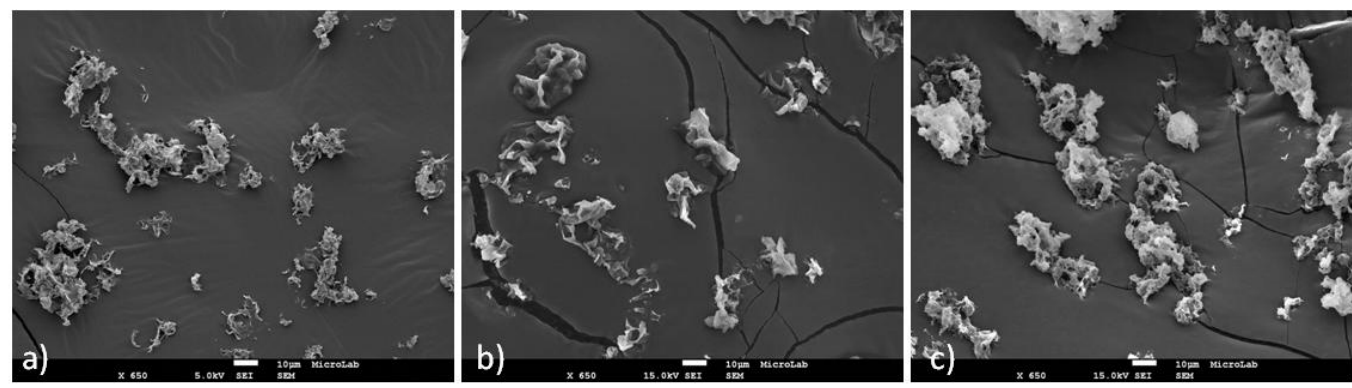

Figure 5| SEM micrographs at 650x magnification of (a) Gelucire 43/01 ${ }^{\mathrm{TM}}: \mathrm{GMO}(3: 1 \mathrm{w} / \mathrm{w})$ particles produced by $\mathrm{PGSS}^{\circledast}$ at $307.15 \mathrm{~K}$ and $12 \mathrm{MPa}$; (b) Gelucire $50 / 13^{\mathrm{TM}}: \mathrm{GMO}(10: 1 \mathrm{w} / \mathrm{w})$ particles produced by PGSS $^{\circledast}$ at $310.15 \mathrm{~K}$ and $12 \mathrm{MPa}$ and (c) Geleol ${ }^{\mathrm{TM}}: \mathrm{GMO}$ (3:1 w/w) particles produced by PGSS ${ }^{\circledR}$ at $333.15 \mathrm{~K}$ and $9 \mathrm{MPa}$

Particles of Gelucire 43/01 ${ }^{\mathrm{TM}}:$ GMO $(3: 1 \mathrm{w} / \mathrm{w})$ produced by PGSS ${ }^{\circledast}$ were in general porous, due to the release of $\mathrm{CO}_{2}$ during depressurization, having some tendency to agglomerate. In addition, the particles present branched morphology and a wide PSD. It is known that the more $\mathrm{CO}_{2}$ is solubilized in the molten lipid matrix, the less viscous the material, making it easier to break up the carrier into smaller particles during the atomization step. Since the solubility of $\mathrm{CO}_{2}$ in the lipid matrices, either in Gelucire $43 / 01^{\mathrm{TM}}$, Gelucire $50 / 13^{\mathrm{TM}}$ or in Geleol ${ }^{\mathrm{TM}}$, increases with increasing pressure and decreases with increasing temperature, it would be expected that smaller particles would be produced at higher pressure and lower temperature values $^{31,33,37}$. Also, if the working temperature is close to the melting point of the lipid matrix, it would lead to faster cooling and crystallization in the expansion chamber and thus less droplet coalescence and production of smaller particles ${ }^{38}$. This common behavior was observed for the mixture Gelucire 43/01 $1 \mathrm{~m}: \mathrm{GMO}$, being in agreement with the general behavior of molten materials while processed by PGSS $^{\circledR} 38,39$. Moreover, comparing the thermograms of the particles obtained at $307.15 \mathrm{~K}$ and $12 \mathrm{MPa}$ with the particles obtained with $307.15 \mathrm{~K}$ and $9 \mathrm{MPa}$, in the latter case it was possible to verify a peak corresponding to the melting point of GMO (data not shown). The presence of two peaks might presume that GMO was 
in excess and deposited at the surface of the solid lipid, resulting in bigger and agglomerated particles obtained with this conditions and confirmed by SEM micrographs. The mass ratio used may be near the saturation point of Gelucire $43 / 01^{\mathrm{TM}}$ when mixed with the liquid lipid, having the pressure and temperature conditions some influence in the mixture of the compounds.

Based on the previously shown DSC results regarding the thermogram of the solidified sample of co-melted Gelucire 50/13 ${ }^{\text {TM }}: G M O$, it was expected that the mass ratio of 3:1 was not suitable to produce handleable particles from these carriers, as it turned out to prove. The particles obtained were impossible to handle and too sticky, presenting two melting peaks in their thermogram (Figure 6) as in the case of the unprocessed material, exceeding the amount of GMO being dissolvable in the solid lipid matrix.

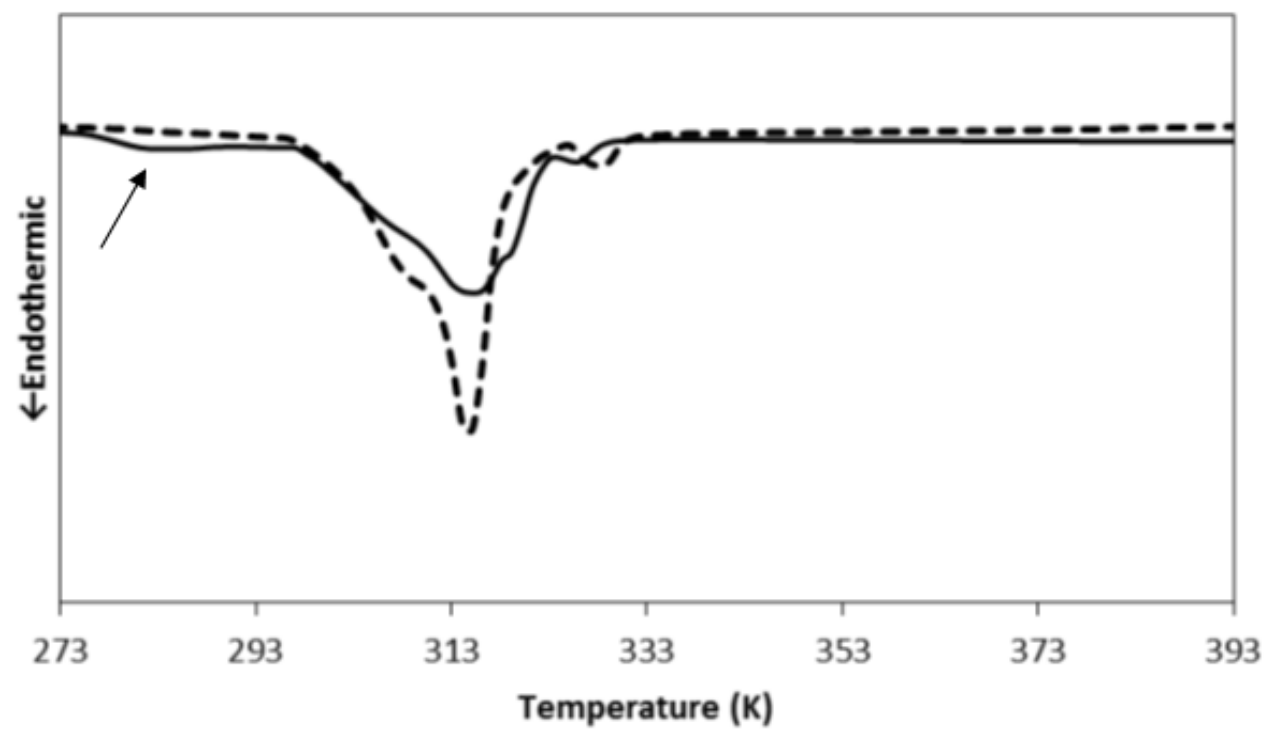

Figure 6| DSC analysis of Gelucire 50/13 ${ }^{\mathrm{TM}}:$ GMO particles with mass ratio of 3:1 (continuous line) and 10:1 (dotted line) processed at $310.15 \mathrm{~K}$ and $9 \mathrm{MPa}$

It was necessary to reduce the content of GMO to a new mass ratio of $10: 1$, so as to successfully produce viable particles with just one melting peak in their 
thermogram. From all the operating conditions tested, once again, smaller particles of Gelucire 50/13 $3^{\mathrm{TM}}: \mathrm{GMO}$ were produced at the lowest temperature and highest pressure. Nevertheless, Gelucire 50/13 ${ }^{\mathrm{TM}}: \mathrm{GMO}$ does not behave as most of the molten compounds when processed by PGSS ${ }^{\circledR}$ and thus it is not possible to see a clear trend regarding the effect of pressure or temperature on the final particle size. This could be explained by the composition of Gelucire $50 / 13^{\mathrm{TM}}$ which has not only glycerides but also PEG esters of fatty acids, having each one different properties and thus distinct behaviors. Moreover, its multicomponent matrix could also be the reason for the production of particles with widest PSD in this study. The lipids and polymers that comprise Gelucire $50 / 13^{\mathrm{TM}}$ may solidify at different rates, leading to the formation of aggregates with different sizes if the solidification step does not occur sufficiently quickly after the atomization ${ }^{40}$. These aggregates could finally be broken during the handling of the sample, leading to different particle sizes.

The structured particles obtained through the precipitation of the mixture Geleol ${ }^{\mathrm{Tm}}: \mathrm{GMO}(3: 1 \mathrm{w} / \mathrm{w})$ were less sticky in comparison with the previous ones, presenting an irregular porous shape. This fact can be due to their similar HLB value of 3 that provides a better mixture between the compounds leading to the formation of fine structured lipid carriers with the narrowest PSD of the study. Like in the case of the Gelucire $50 / 13^{\mathrm{TM}}: \mathrm{GMO}$ mixture, also in this case it is not possible to establish a clear trend regarding the effect of pressure or temperature on the final particle size, as already verified by other authors for the precipitation of glyceryl monostearate ${ }^{37}$.

\subsubsection{Stability of structured lipid carries during storage}

It is known that the lattice structure of solid lipid particles tend to be transformed into their more stable polymorphic form during storage, exhibiting progressively higher melting enthalpies upon ageing ${ }^{30}$. This occurrence can ultimately lead to 
drug leakage with possible degradation of the active compound and variations in its release profile from the drug delivery system ${ }^{1,8}$.

Table 3| Thermal characterization of the particles produced by PGSS ${ }^{\circledR}$, freshly prepared and after 6 months of storage at room temperature

\begin{tabular}{|c|c|c|c|}
\hline System & $\begin{array}{c}\text { Melting enthalpy (J g- } \\
\text { 1) at O Months }\end{array}$ & $\begin{array}{l}\text { Melting enthalpy (J g- } \\
\text { 1) at } 6 \text { Months }\end{array}$ & $\begin{array}{c}\text { Increase in melting } \\
\text { enthalpy (\%) }\end{array}$ \\
\hline Gelucire $43 / 01^{\text {m }}$ & 140.9 & 142.1 & 0.9 \\
\hline $\begin{array}{c}\text { Gelucire } 43 / 01^{\mathrm{m}}: \text { GMO } \\
(3: 1, \mathrm{w} / \mathrm{w})\end{array}$ & 94.93 & 95.26 & 0.3 \\
\hline Gelucire $50 / 13^{\text {tm }}$ & 137.3 & 157.6 & 14.8 \\
\hline $\begin{array}{c}\text { Gelucire } 50 / 13^{\mathrm{m}}: \mathrm{GMO} \\
(10: 1, \mathrm{w} / \mathrm{w})\end{array}$ & 133.9 & 136.1 & 1.6 \\
\hline Geleol $^{\text {'m }}$ & 116.6 & 197.6 & 69.5 \\
\hline $\begin{array}{c}\text { Geleol'"':GMO (3:1, } \\
\text { w/w) }\end{array}$ & 141.4 & 141.4 & 0 \\
\hline
\end{tabular}

Table 3 shows the melting enthalpy obtained from the DSC thermograms both from the solid lipid particles and from the structured solid carriers containing GMO, produced by $\mathrm{PGSS}^{\circledR}$, which had been freshly prepared, or stored in a sealed vial at room temperature, ambient pressure, non-inert conditions and not light-protected, during 6 months. Solid lipid particles composed only by the solid matrix were produced at the same operational conditions for comparison in this study. Comparing the solid lipid particles stability during storage it is possible to observe that Geleol ${ }^{\mathrm{TM}}$ particles were the less stable, presenting the highest increase in the melting enthalpy upon 6 months of storage. This could be explained due to the lattice structure of this carrier, since it presents the simplest composition of all the three glycerolipids tested, reaching a higher level of crystallinity during storage ${ }^{7}$. It is possible to verify that the glycerolipids-based particles produced without the incorporation of GMO present higher variation in melting enthalpy upon aging in 
comparison with the samples containing the liquid lipid. This fact is remarkably noticeable in the case of Geleol ${ }^{\mathrm{TM}}$ particles, whose stability with GMO was markedly increased. This reinforces the evidence that the incorporation of a liquid lipid lends stability to lipid particles during storage ${ }^{1}$.

4.3. Development of Gelucire 43/01 ${ }^{T M}: G M O$ structured lipid carriers loaded with ketoprofen

Structured lipid carriers composed of Gelucire $43 / 01^{\mathrm{TM}}: \mathrm{GMO}$ were chosen to be further studied by producing particles with different solid lipid:liquid lipid mass ratios by PGSS ${ }^{\circledR}$ and Spray Chilling, and also by the development of ketoprofenloaded structured lipid particles. This matrix was chosen due to its overall results, namely the typical behaviour while processed by PGSS ${ }^{\circledR}$, the lowest temperatures required for the precipitation of particles and their high storage stability.

\subsubsection{Thermal behavior of pure compounds and physical mixtures} DSC measurements were performed on pure compounds and on the physical mixtures with several different mass ratios of Gelucire $43 / 01^{\mathrm{TM}}: \mathrm{GMO}$, in order to characterise their thermal behaviour, as present in Figure 7 . 


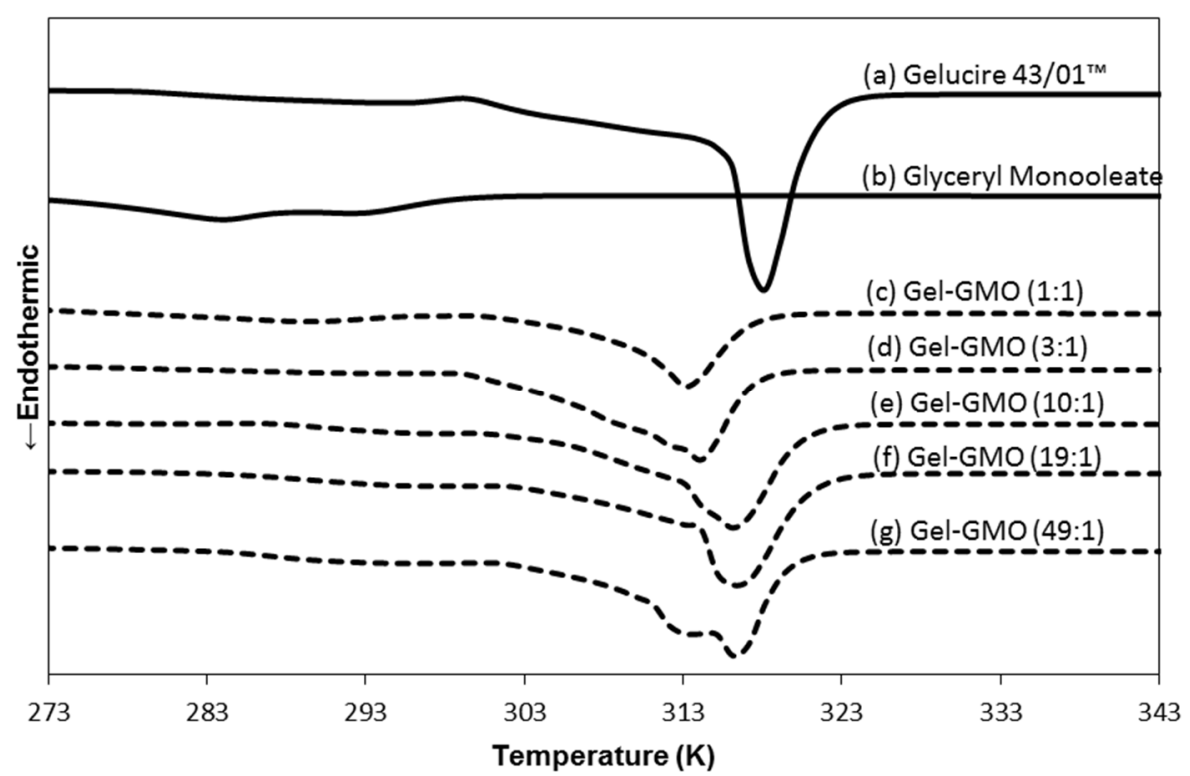

Figure 7 기 DSC thermograms of pure compounds (continuous lines; a), b)) and physical mixtures of Gelucire 43/01 ${ }^{\mathrm{TM}}$ : GMO with different mass ratios (dotted lines; c), d), e), f), g)).

Table 4 | Melting parameters of the pure compounds and physical mixtures of Gelucire $43 / 01^{\mathrm{TM}}$ : GMO with different mass ratios

\begin{tabular}{|c|c|c|c|c|c|c|c|}
\hline & GMO & $\begin{array}{l}\text { Gelucire } \\
43 / 01^{m}\end{array}$ & $\begin{array}{c}\text { Gel-GMO } \\
(1: 1)\end{array}$ & $\begin{array}{c}\text { Gel-GMO } \\
\text { (3:1) }\end{array}$ & $\begin{array}{c}\text { Gel-GMO } \\
(10: 1)\end{array}$ & $\begin{array}{c}\text { Gel-GMO } \\
(19: 1)\end{array}$ & $\begin{array}{c}\text { Gel-GMO } \\
(49: 1)\end{array}$ \\
\hline $\begin{array}{c}\text { Melting } \\
\text { point (K) }\end{array}$ & 284.0 & 318.2 & $\begin{array}{l}288.3 ; \\
313.3\end{array}$ & 314.2 & 316.2 & 316.2 & 316.5 \\
\hline $\begin{array}{c}\text { Enthalpy (J } \\
\left.\qquad \mathbf{g}^{-1}\right)\end{array}$ & 41.2 & 128.6 & $8.3 ; 53.2$ & 84.9 & 112.1 & 125.6 & 128.3 \\
\hline
\end{tabular}

Table 4 displays the related data of peaks shown in Figure 7. By analyzing the DSC thermograms, it is possible to verify a depression in the melting point of the mixture of lipids. This reduction was more significant when mixed with higher quantities of GMO, namely $1: 1$ and 3:1 mass ratio. The fact that the melting enthalpy have also decreased indicates the presence of lattice defects (i.e. massive crystal order disturbance) and the formation of structured matrices. This less ordered structure 
may allow an improvement in the total drug loading capacity of the mixtures containing liquid and solid lipids ${ }^{6,7,12}$. Furthermore, the mixture of Gelucire $43 / 01^{\mathrm{Tm}}$ : GMO $(1: 1, w / w)$ has two separate peaks in the DSC thermogram, although not distinctly visible in the figure 7, but shown in Table 4 . This could be an indication of a phase separation, mostly due to the saturation of the solid lipid matrix with GMO. Adding more GMO into Gelucire $43 / 01^{\text {TM }}$ would most likely not result into its intercalation into the solid lipid but rather it would only increase the separate GMO fraction.

\subsection{2. $\quad P G S S{ }^{\circledR}$ and Spray Chilling precipitation}

In order to verify the impact of GMO content on the size and morphology of the final structured particles, Gelucire 43/01 ${ }^{\mathrm{TM}}: \mathrm{GMO}$ mixtures were precipitated through the $\mathrm{PGSS}^{\circledR}$ technique using two additional different mass ratios (10:1 and 19:1). The temperature was varied (310.15 and 317.15K), using a fixed pressure value of $12 \mathrm{MPa}$. Table 5 presents the operating conditions used in this study, together with the resulting mean particle size.

Table 5| Summary of PGSS precipitation experiments performed with new mass ratios of Gelucire 43/01 ${ }^{\mathrm{TM}}$ and GMO, unloaded and loaded with ketoprofen

\begin{tabular}{|c|c|c|c|c|c|c|c|}
\hline System & $\begin{array}{c}\text { Co- } \\
\text { precipitation } \\
\text { with } \\
\text { ketoprofen } \\
(\% w / w)\end{array}$ & $\begin{array}{l}\text { Mass } \\
\text { Ratio }\end{array}$ & $\begin{array}{c}\text { Pressure } \\
\text { (MPa) }\end{array}$ & $\begin{array}{c}\text { Temperature } \\
\text { (K) }\end{array}$ & $\begin{array}{c}\text { Particle } \\
\text { size } d_{0.5} \\
(\mu \mathrm{m})\end{array}$ & Span & $E E(\%)$ \\
\hline & - & $10: 1$ & 12 & 310.15 & 45.1 & 1.9 & - \\
\hline & - & $10: 1$ & 12 & 317.15 & 67.0 & 1.8 & - \\
\hline Gelucire & - & $19: 1$ & 12 & 310.15 & 37.1 & 1.6 & - \\
\hline \multirow[t]{3}{*}{ 43/01 ${ }^{\mathrm{TM}}: \mathrm{GMO}$} & - & $19: 1$ & 12 & 317.15 & 51.8 & 1.5 & - \\
\hline & 10 & $3: 1$ & 12 & 310.15 & 22.6 & 2.4 & $96.8 \pm 0.6$ \\
\hline & 10 & $10: 1$ & 12 & 310.15 & 33.5 & 1.9 & $95.5 \pm 0.8$ \\
\hline
\end{tabular}




\begin{tabular}{|c|c|c|c|c|c|c|c|}
\hline & 10 & $19: 1$ & 12 & 310.15 & 43.9 & 3.0 & $95.0 \pm 0.2$ \\
\hline $\begin{array}{l}\text { Gelucire } \\
43 / 01^{\mathrm{Tm}}\end{array}$ & 10 & - & 12 & 310.15 & 42.6 & 2.1 & $90.0 \pm 0.6$ \\
\hline
\end{tabular}

As occurred in the previously tested mass ratio of $3: 1$, it is also possible to verify that in these mass ratios the resulting particle size of the structured lipid carriers produced is lower when lowest temperature is used. Moreover, we can verify that as the content of GMO decreases, the smallest the particle size distribution of the samples, that is, PSD and particle size got narrowest and smaller, respectively, as the mass ratio between solid lipid:liquid lipid increases. This result was also confirmed by SEM micrographs (data not shown), where less agglomerated particles were present when 19:1 mass ratio was used.

Spray chilling technique was also used for the production of Gelucire 43/01 ${ }^{\mathrm{TM}}$ : GMO structured particles (3:1 and 10:1 mass ratios). Figure 8 presents micrographs of the particles produced.
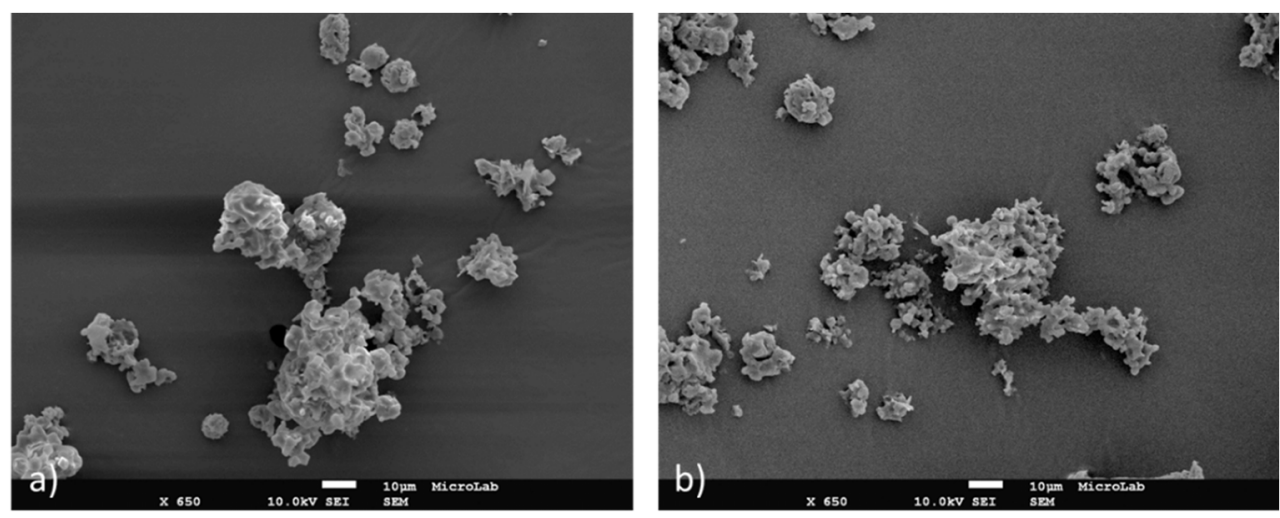

Figure 8| SEM micrographs at $650 x$ magnification of Gelucire $43 / 01^{\mathrm{TM}}+\mathrm{GMO}$ particles produced by Spray Chilling at $338.15 \mathrm{~K}$ a) with mass ratio of $3: 1, \mathrm{~b}$ ) with mass ratio of 10:1.

The particles seem to be constituted by spherical structural units that didn't have time to solidify and fused together. The mass ratio 3:1 was not suitable to produce 
handleable particles from these carriers, which were too pasty. Therefore, it was not possible to determine the particle size due to the deformations that occur during handling. On the other hand, the particles produced with 10:1 mass ratio presented a mean particle size of $96.1 \mu \mathrm{m}$ (span 2.7), being bigger than the ones produced by PGSS ${ }^{\text {тм }}$. These particles, despite being handleable, were also sticky probably due to the bad incorporation of the liquid lipid into the solid lipid. Overall, the particles produced by PGSS ${ }^{\circledR}$ with the same carrier materials and mass ratios led to non-pasty dry particles, showing that the supercritical precipitation technique is a better option for the production of structured lipid particles. Spray Chilling technique is quite similar to $\mathrm{PGSS}^{\circledR}$ since it is based in the previous fusion of the materials with the subsequent atomization and solidification of the compounds, leading to the formation of particles. Nevertheless, Spray Chilling doesn't use $\mathrm{CO}_{2}$ and therefore it is necessary to use higher temperatures to guarantee the complete melting of materials, which is a disadvantage while using thermosensitive compounds. Furthermore, during the atomization step, there is only the presence of compressed air to reduce the temperature in order to solidify the lipids, while in the case of PGSS ${ }^{\circledR}$, the expansion of $\mathrm{CO}_{2}$ and reduction of pressure conditions during the atomization step enable a faster cooling that proved to be essential for the correct solidification and formation of particles. Thus, Spray chilling technique was no longer used in this work.

Subsequently, structured lipid carriers loaded with ketoprofen $(10 \% \mathrm{w} / \mathrm{w})$ were developed by $\mathrm{PGSS}^{\circledR}$ using fixed operating conditions that previously led to the production of smaller particle sizes and narrowest PSD. Solid lipid particles of Gelucire $43 / 01^{\mathrm{TM}}$ were also produced and loaded with the NSAID at the same operating conditions, for comparison studies. It is possible to verify in Table 5 the operating conditions used in this study, together with the resulting mean particle size and encapsulation efficiency. Figure 9 shows the SEM micrographs of the ketoprofen-loaded particles. 

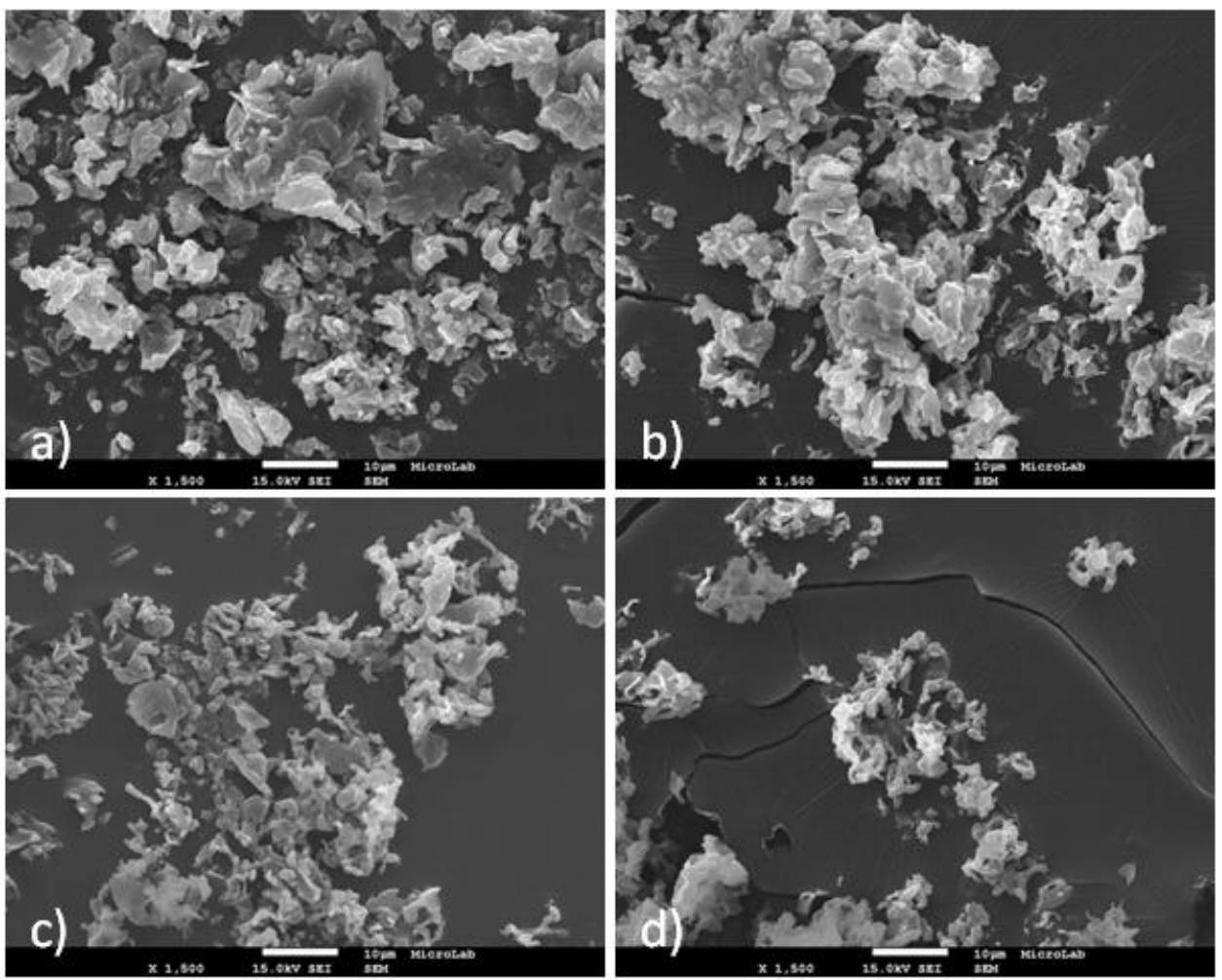

Figure 9| SEM micrographs at 1500X magnification of ketoprofen-loaded particles produced by PGSS ${ }^{\circledR}$ at $12 \mathrm{Mpa}$ and $310.15 \mathrm{~K}$ composed by a) Gelucire $43 / 01^{\mathrm{TM}}: \mathrm{GMO}(3: 1 \mathrm{w} / \mathrm{w})$, b) Gelucire $43 / 01^{\mathrm{TM}}: \mathrm{GMO}$ $(10: 1 \mathrm{w} / \mathrm{w}), \mathrm{c})$ Gelucire $43 / 01^{\mathrm{TM}}: \mathrm{GMO}(19: 1 \mathrm{w} / \mathrm{w})$ and d) Gelucire 43/01 ${ }^{\mathrm{TM}}$

In general, ketoprofen-loaded particles retained the branched-shape of the unloaded carriers, presenting a polydisperse PSD with particle sizes between 20$40 \mu \mathrm{m}$. Regarding the encapsulation efficiency, it is possible to verify that the presence of GMO increased the load capacity of the particles, being the sample with highest content of GMO (3:1 mass ratio) the one that contains the higher $\mathrm{EE}$ $(\approx 97 \%)$. On the other hand, the solid lipid particle composed of Gelucire $43 / 01^{\mathrm{TM}}$ presented the lowest EE $(\approx 90 \%)$. 
DSC measurements were performed on all ketoprofen loaded-particles, in order to characterize their thermal behaviour. Table 6 displays the data of peaks from the thermograms obtained.

Table 6| Melting parameters of ketoprofen-loaded particles of Gelucire $43 / 01^{\mathrm{TM}}$ and Gelucire $43 / 01^{\mathrm{TM}}$ : GMO with different mass ratios (freshly prepared and after 1 month of storage at ambient temperature)

\begin{tabular}{|c|c|c|c|c|c|}
\hline & & $\begin{array}{l}\text { Gelucire } \\
43 / 01^{m}\end{array}$ & $\begin{array}{c}\text { Gel-GMO } \\
\text { (3:1) }\end{array}$ & $\begin{array}{c}\text { Gel-GMO } \\
\text { (10:1) }\end{array}$ & $\begin{array}{c}\text { Gel-GMO } \\
(19: 1)\end{array}$ \\
\hline \multirow{2}{*}{$\begin{array}{l}\text { Melting point } \\
\text { (K) }\end{array}$} & $\begin{array}{l}\text { Freshly } \\
\text { prepared }\end{array}$ & 315.8 & 312.0 & 312.5 & 312.0 \\
\hline & 1 month & 315.9 & 315.0 & 315.8 & 315.4 \\
\hline \multirow{2}{*}{$\begin{array}{c}\text { Enthalpy (J g- } \\
\text { 1) }\end{array}$} & $\begin{array}{l}\text { Freshly } \\
\text { prepared }\end{array}$ & 105.2 & 80.7 & 89.7 & 95.4 \\
\hline & 1 month & 131.5 & 96.55 & 119.5 & 126.8 \\
\hline
\end{tabular}

None of the particles produced present the melting peak of the drug $(\approx 368.15 \mathrm{~K})$, revealing the possible formation of a new solid solution phase with ketoprofen, without its segregation ${ }^{28,32}$. Moreover, ketoprofen-loaded particles' melting peaks are displaced to lower temperatures than the melting points of unloaded materials (previously presented in table 4), being this effect due to the plasticizing effect of the drug in the matrix ${ }^{32,41}$. Once again it is possible to verify that lowest melting enthalpies are present when higher content of GMO was used, indicating the presence of lattice defects and the formation of structured matrices which allowed the incorporation of more drug. The melting parameters were analyzed once again one month after the preparation of the samples (storage at ambient temperature), revealing nearly maintenance of melting temperatures. Nevertheless, the carrier composed of Gelucire $43 / 01^{\mathrm{TM}}: \mathrm{GMO}$ with mass ratio of 3:1 was the one that better preserved the melting enthalpy. 


\subsubsection{Ketoprofen release and permeability studies}

In Figure 10 it is possible to verify the results obtained for the in vitro drug release experiments from the particles in phosphate buffer solution.

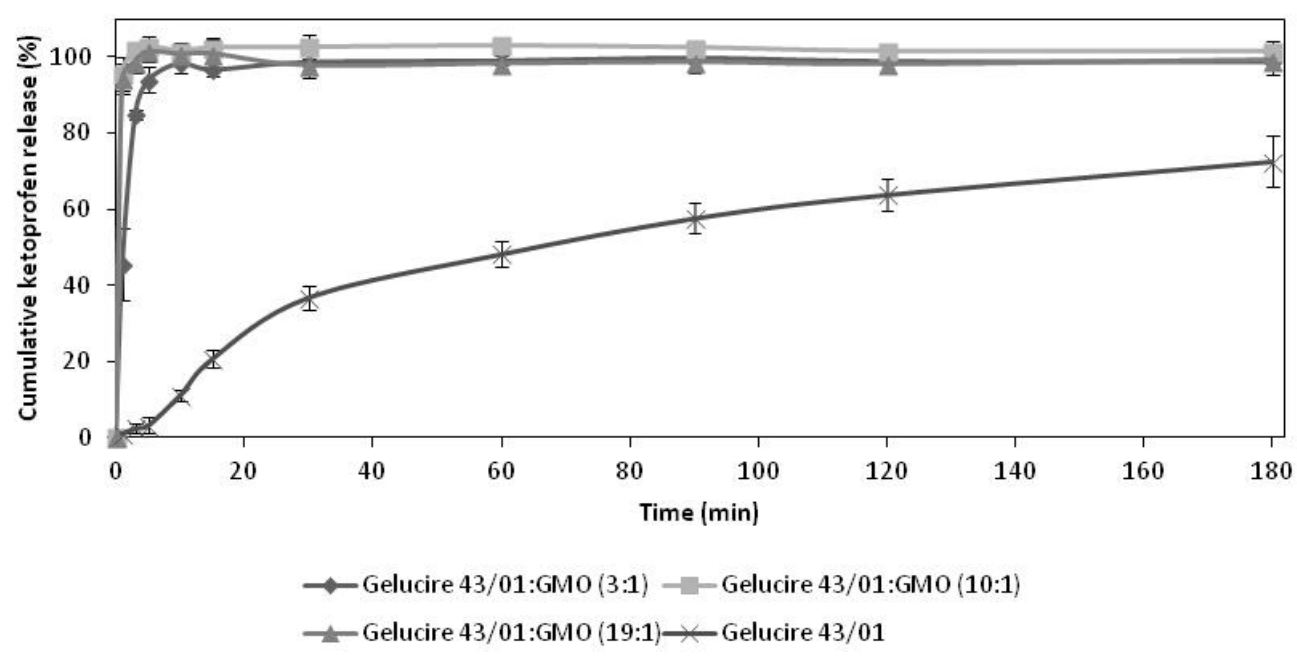

Figure 10| Drug release profiles of the ketoprofen-loaded particles produced by PGSS ${ }^{\circledR}$ (phosphate buffer solution, $\mathrm{pH}$ 6.8)

Like in the case of pure ketoprofen, all of the structured lipid carriers presented an immediate release and availability of the drug. These particles may be appropriate in situations where it is necessary to achieve fast therapeutic effect. On the other hand, the lipid particles composed of Gelucire $43 / 01^{\mathrm{TM}}$ particles present a sustained release of the drug, where after $3 \mathrm{~h}, \approx 72 \%$ of the drug was released. The higher drug release verified in structured lipid carriers could be explained by the faster drug diffusion through the liquid lipid phase than that via solid lipid phase, couple with GMO's swelling ability ${ }^{4,13}$. This behavior was also verified during the in vitro permeation studies in the Franz diffusion cell, presented in figure 11. 


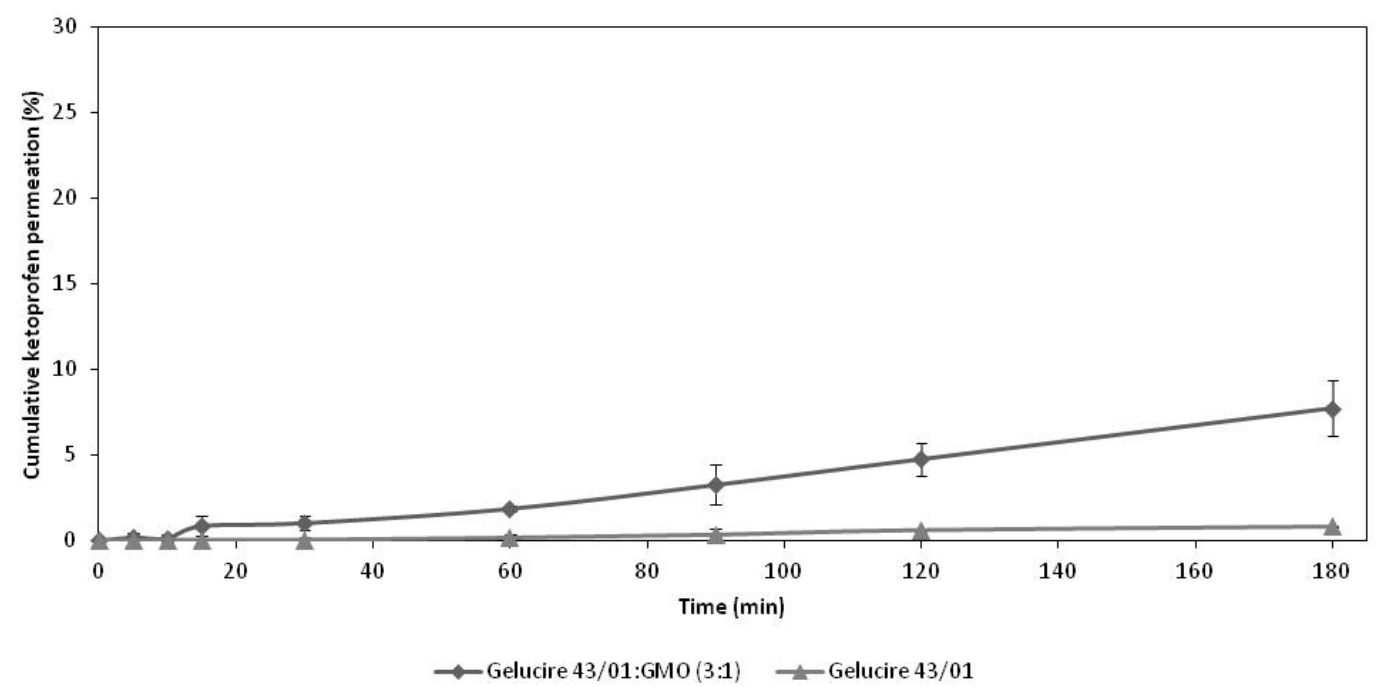

Figure 11| Permeation profiles of ketoprofen-loaded particles produced by PGSS ${ }^{\circledR}$ (phosphate buffer solution, $\mathrm{pH}$ 6.8)

The in vitro ketoprofen permeation profile across the mucous-membrane model showed much lower permeation of the solid lipid particles than the structured lipid carrier containing the highest amount of GMO. This could be related not only to the highest permeation generally attributed to structured lipid carriers but also to the GMO's mucoadhesion property ${ }^{4,42}$.

\section{Conclusions}

In this study, structured solid lipid carriers composed of glyceryl monooleate and solid glycerolipids, namely Gelucire $43 / 01^{\mathrm{TM}}$, Gelucire $50 / 13^{\mathrm{TM}}$ and Geleol ${ }^{\mathrm{TM}}$, were successfully produced by high pressure precipitation technique from gas saturated solutions, namely PGSS ${ }^{\circledR}$. This technique showed to have advantages in comparison to spray chilling technique. Regarding carrier materials, it's HLB value might be a relevant feature to be taken into account while processing mixtures of compounds. As expected, the addition of a liquid lipid in a solid lipid matrix led to increased stability of the structured solid lipid particles in comparison with solid lipid particles, 
with no significant modifications in their enthalpy of fusion after 6 months of storage. Among the binary systems studied, Gelucire $43 / 01^{\mathrm{TM}}: \mathrm{GMO}$ was selected to be loaded with ketoprofen. The mass ratio between the lipid compounds was varied and it was verified that the encapsulation efficiency correlated directly with the content in GMO. In addition, structured lipid carriers provided an immediate release of the drug with higher drug permeation through a mucous-membrane model than solid lipid particles.

\section{Acknowledgements}

This work was supported by Fundação para a Ciência e Tecnologia (FCT) through grant \# PEst-OE/EQB/LA0004/2011. V. S. S. Gonçalves is also grateful for the financial support from SFRH/BD/77350/2011 grant from FCT. S. Rodríguez-Rojo acknowledges the Ministerio de Economía y Competitividad and Universidad de Valladolid for her Juan de la Cierva fellowship (JCl- 2012-14992).

\section{References}

1 J. Pardeike, A. Hommoss and R. H. Müller, Int. J. Pharm., 2009, 366, 17084.

2 R. H. Müller, K. Mäder and S. Gohla, Eur. J. Pharm. Biopharm., 2000, 50, 161-77.

3 A. J. Almeida and E. Souto, Adv. Drug Deliv. Rev., 2007, 59, 478-90.

4 E. B. Souto, S. a Wissing, C. M. Barbosa and R. H. Müller, Int. J. Pharm., 2004, 278, 71-7.

5 M. Muchow, P. Maincent and R. H. Muller, Drug Dev. Ind. Pharm., 2008, 34, 1394-405.

6 B. Siekmann and K. Westesen, Colloids Surfaces B Biointerfaces, 1994, 3, 159-175.

7 V. Teeranachaideekul, E. B. Souto, V. B. Junyaprasert and R. H. Müller, Eur. J. Pharm. Biopharm., 2007, 67, 141-8.

8 C. Himawan, V. M. Starov and a G. F. Stapley, Adv. Colloid Interface Sci., 2006, 122, 3-33. 
9 R. H. Müller, M. Radtke and S. a Wissing, Adv. Drug Deliv. Rev., 2002, 54 Suppl 1, S131-55.

10 V. Jenning, a F. Thünemann and S. H. Gohla, Int. J. Pharm., 2000, 199, 16777.

11 F.-Q. Hu, S.-P. Jiang, Y.-Z. Du, H. Yuan, Y.-Q. Ye and S. Zeng, Int. J. Pharm., 2006, 314, 83-9.

12 V. Teeranachaideekul, P. Boonme, E. B. Souto, R. H. Müller and V. B. Junyaprasert, J. Control. Release, 2008, 128, 134-41.

13 J. Shen, M. Sun, Q. Ping, Z. Ying and W. Liu, Nanotechnology, 2010, 21, 025101.

14 a Ganem-Quintanar, D. Quintanar-Guerrero and P. Buri, Drug Dev. Ind. Pharm., 2000, 26, 809-20.

15 L. S. Nielsen, L. Schubert and J. Hansen, Eur. J. Pharm. Sci., 1998, 6, 231-9.

16 G. Garg, S. Saraf and S. Saraf, Biol. Pharm. Bull., 2007, 30, 350-3.

17 K. Moebus, J. Siepmann and R. Bodmeier, J. Control. Release, 2012, 157, 206-15.

18 D. J. Hauss, S. E. Fogal, J. V Ficorilli, C. a Price, T. Roy, a a Jayaraj and J. J. Keirns, J. Pharm. Sci., 1998, 87, 164-9.

19 T. Bansal, N. Akhtar, M. Jaggi, R. K. Khar and S. Talegaonkar, Drug Discov. Today, 2009, 14, 1067-74.

20 D. Mahlin, J. Unga, A. Ridell, G. Frenning and S. Engström, Polymer (Guildf). , 2005, 46, 12210-12217.

21 WO/1995/021688, 1995.

22 A. R. Sampaio de Sousa, A. L. Simplício, H. C. de Sousa and C. M. M. Duarte, J. Supercrit. Fluids, 2007, 43, 120-125.

23 C. A. García-González, A. Argemí, A. R. Sampaio de Sousa, C. M. M. Duarte, J. Saurina and C. Domingo, J. Supercrit. Fluids, 2010, 54, 342-347.

24 A. Pestieau, F. Krier, P. Lebrun, A. Brouwers, B. Streel and B. Evrard, Int. J. Pharm. , 2015, 485, 295-305.

25 A. V. M. Nunes and C. M. M. Duarte, Materials (Basel)., 2011, 4, 20172041.

26 Ž. Knez, E. Markočič, Z. Novak and M. K. Hrnčič, Chemie Ing. Tech., 2011, $\mathrm{n} / \mathrm{a}-\mathrm{n} / \mathrm{a}$.

27 E. Weidner, J. Supercrit. Fluids, 2009, 47, 556-565.

28 M. Fraile, Á. Martín, D. Deodato, S. Rodriguez-Rojo, I. D. Nogueira, A. L. Simplício, M. J. Cocero and C. M. M. Duarte, J. Supercrit. Fluids, 2013, 81, 226-235.

29 S. Rodríguez-Rojo, D. D. Lopes, a. M. R. C. Alexandre, H. Pereira, I. D. Nogueira and C. M. M. Duarte, J. Supercrit. Fluids, 2013.

30 Y. W. Choy, N. Khan and K. H. Yuen, Int. J. Pharm., 2005, 299, 55-64.

31 A. R. Sampaio de Sousa, M. Calderone, E. Rodier, J. Fages and C. M. M. Duarte, J. Supercrit. Fluids, 2006, 39, 13-19. 
32 V. S. S. Gonçalves, S. Rodríguez-Rojo, A. a. Matias, A. V. M. Nunes, I. D. Nogueira, D. Nunes, E. Fortunato, A. P. A. de Matos, M. J. Cocero and C. M. M. Duarte, Int. J. Pharm., 2015, 478, 9-18.

33 A. R. Sampaio de Sousa, Development of Functional Particles using Supercritical Fluid Technology, Instituto de Tecnologia Química e Biológica, Oeiras, Portugal, Ph.D. Thes., 2007.

34 A. Argemí, C. Domingo, A. R. Sampaio de Sousa, C. M. M. Duarte, C. A. García-González and J. Saurina, J. Pharm. Sci., 2011, 100, 4783-4789.

35 Ž. Knez, M. Škerget and Z. Mandžuka, J. Supercrit. Fluids, 2010, 55, 648652.

36 C. A. García-González, A. R. Sampaio da Sousa, A. Argemí, A. López Periago, J. Saurina, C. M. M. Duarte and C. Domingo, Int. J. Pharm., 2009, 382, 296304.

37 Z. Mandžuka and Ž. Knez, J. Supercrit. Fluids, 2008, 45, 102-111.

38 M. Strumendo, A. Bertucco and N. Elvassore, J. Supercrit. Fluids, 2007, 41, 115-125.

39 J. Li, H. a. Matos and E. G. de Azevedo, J. Supercrit. Fluids, 2004, 32, 275286.

40 M. Vijayaraghavan, S. Stolnik, S. M. Howdle and L. Illum, Int. J. Pharm., 2013, 441, 580-8.

41 P. Blasi, A. Schoubben, S. Giovagnoli, L. Perioli, M. Ricci and C. Rossi, AAPS PharmSciTech, 2007, 8, Article 37.

42 Y. Liu, J. Zhang, Y. Gao and J. Zhu, Int. J. Pharm., 2011, 413, 103-9.

43 S. K. Jain and A. Gupta, AAPS PharmSciTech, 2009, 10, 1128-36.

44 A. R. Sampaio de Sousa, R. Silva, F. H. Tay, A. L. Simplício, S. G. Kazarian and C. M. M. Duarte, J. Supercrit. Fluids, 2009, 48, 120-125. 
Development of structured lipid carrier systems containing glyceryl monooleate through

PGSS $\AA$ 



\section{Chapter 3}

\section{Development of multicore hybrid particles for drug delivery through the precipitation of $\mathrm{CO}_{2}$ saturated emulsions}

1. Abstract 3

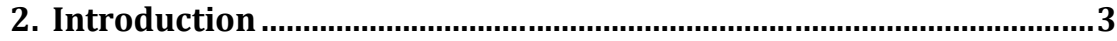

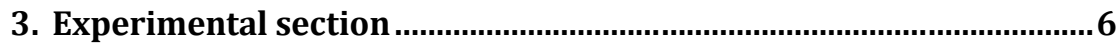

3.1. Materials....................................................................... 6

3.2. Preparation, determination of the stability and characterization of the emulsion at ambient pressure ................................................... 6

3.3. Determination of the stability of the emulsion in supercritical $\mathrm{CO}_{2} \quad 7$

3.4. Precipitation of the emulsion by particles from gas saturated solutions (PGSS $₫)$......................................................................... 8

3.5. Particles' characterization ................................................... 9

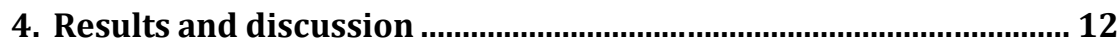

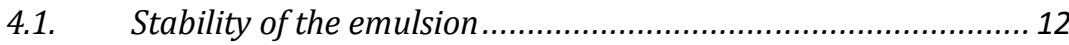

4.2. Stability of the emulsion in the presence of $\mathrm{CO}_{2} \ldots \ldots \ldots \ldots \ldots \ldots \ldots . . . . . . . . .14$

4.3. Hybrid particles from gas saturated emulsions ....................... 17

4.4. Ketoprofen-Loaded Hybrid particles from gas saturated

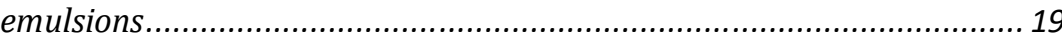

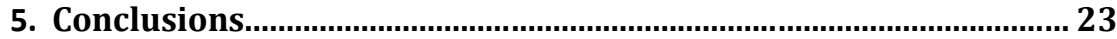

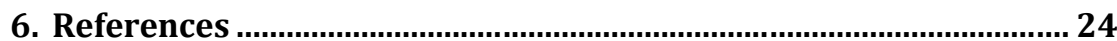


Adapted from: Gonçalves, V.S.S., Rodríguez-Rojo, S., Matias, A.A., Nunes, A.V.M., Nogueira, I.D., Nunes, D., Fortunato, E., Alves de Matos, A.P., Cocero, M.J., Duarte, C.M.M. (2015) Development of multicore hybrid particles for drug delivery through the precipitation of $\mathrm{CO} 2$ saturated emulsions. International Journal of Pharmaceutics, 478(1):9-18. doi: 10.1016/j.ijpharm.2014.11.003

The author contributed to the planning and execution of all the experiments described in this chapter. SEM analysis were performed by I.D. Nogueira, FIB measurements performed by D. Nunes and TEM done by A.P. Alves de Matos. The author was also involved on the discussion and interpretation of results, as well as on the preparation of the manuscript. 


\section{Abstract}

Hybrid lipid-polymer particles are gaining increasing interest to be applied as drug delivery systems due to their greater stability in biological fluids and enhanced cellular uptake of drugs. However, a major drawback is the fact that these particles are usually produced through techniques that use organic solvents.

This work studies the possibility of producing for the first time hybrid particles composed by lipid multicores enveloped in a polymeric layer through Particles from Gas Saturated Solutions (PGSS ${ }^{\circledR}$ ), without using organic solvents. An oil-in-water emulsion, composed by Gelucire $43 / 01^{\mathrm{TM}}$ (GEL) as the discontinuous phase and by an aqueous Polyethylene glycol 4000 (PEG) solution as the continuous phase, was successfully precipitated by PGSS ${ }^{\mathrm{TM}}$. Operating conditions that ensured the stability of the $\mathrm{CO}_{2}$ saturated emulsion were previously evaluated. The resulting PEG-GEL particles present a spherical-like morphology constituted by several lipid cores encapsulated into a polymeric shell. The applicability of these structured particles to be used as DDS was studied by using Ketoprofen, a nonsteroidal antiinflammatory drug (NSAID), as model drug. The particles provided an initial burst release of the drug due to the progressive dissolution of the external layer of PEG, followed by a controlled release of the NSAID from the GEL cores.

\section{Introduction}

Drug delivery systems (DDS) present several advantages compared to the administration of active pharmaceutical ingredients (APIs) alone, namely the controlled and sustained release of drugs, the enhanced dissolution rate of poorly water soluble drugs and the possibility of surface functionalization that allows targeted delivery 1,2. Nevertheless, during the last years, pharmaceutical technology has progressed towards the production of more complex drug delivery structures. Hence, instead of using just one carrier, hybrid particles composed of 
two or more classes of materials are being developed in an attempt to combine several functionalities in a single delivery system ${ }^{3-8}$. The most common strategy is the combination of the structural integrity and improved stability in biological fluids provided by biodegradable polymeric materials with the enhanced cellular uptake features of highly biocompatible lipid matrices. Thus, it is possible to overcome the weakness of a material using the strength of another. These robust DDS are capable to incorporate hydrophilic and/or hydrophobic drugs, and have been already used as vaccine adjuvants, for targeted cancer therapy and for the delivery of nucleic acids $^{5,6}$.

There are several conventional processes to produce hybrid DDS, like the nanoprecipitation or the solvent extraction/evaporation method, however the difficulty and cost of the purification step is a drawback that needs to be overcome $3,5,9,10$. Moreover, the current trend in every industry is the replacement of organic and toxic solvents by harmless and greener options, due to the growing concern about environmental problems and also the urgent need to develop more sustainable processes. Carbon dioxide has already proved to be a good option to replace the use of organic solvents in the production of DDS, since it is inexpensive, abundant, non-toxic and suitable for the development of environmentally friendly processes ${ }^{10-13}$. In particular, Particles from Gas Saturated Solutions (PGSS ${ }^{\circledR}$ ), patented by Weidner and co-workers ${ }^{14}$, is a method that has already been used in the production of lipid-lipid, lipid-polymer and polymer-polymer hybrid DDS without the use of organic solvents ${ }^{15-23}$. Moreover, this strategy is currently applied by Critical Pharmaceuticals Ltd (Nottingham, UK) ${ }^{24}$, to develop formulations comprising mixtures of polymers, which are able to provide a variety of drug release profiles ${ }^{21}$. Nevertheless, the possibility of obtaining structured multicore hybrid particles by PGSS ${ }^{\circledR}$ has not been investigated yet, up to the authors' knowledge. The authors previously attempted to produce lipid core- polymeric shell particles through the PGSS ${ }^{\circledast}$ technique, by simply mixing the lipid material with the polymer, 
which were immiscible with each other. Unfortunately, with this strategy it was not possible to produce core-shell particles and, therefore, the particles obtained were most likely singular structures of lipid and polymer ${ }^{25}$.

With the aim of producing structured particles composed of lipid multicores involved in a polymeric shell material, an $\mathrm{O} / \mathrm{W}$ emulsion constituted by a lipid as the discontinuous phase and by an aqueous solution containing a polymer as continuous phase was precipitated in this work through PGSS ${ }^{\circledR}$. Polyethylene glycol 4000 (PEG), a hydrophilic and biocompatible polymer (Hydrophilic-Lipophilic Balance $(\mathrm{HLB})=18)$, and Gelucire $43 / 01^{\mathrm{TM}}(\mathrm{GEL})$, a hard fat (HLB=1), were the chosen carrier materials to be formulated as an $\mathrm{O} / \mathrm{W}$ emulsion. Gelucire ${ }^{\circledR} 43 / 01$ is a release retardant that promotes the penetration and absorption of drugs into the epithelial cells ${ }^{26,27}$. On the other hand, by developing particles with the surface covered with PEG it is possible to create a stealth hydrophilic, electrically neutral shelter that reduces the levels of protein and cellular adsorption, avoiding the recognition by the immune system and thus improving particles' circulation half-life ${ }^{28-30}$. Moreover, it has been shown that particles coated with PEG (molecular weight between 2000 and $5000 \mathrm{Da}$ ) are able to perform mucus penetration, being an important feature for mucosal delivery of drugs ${ }^{31,32}$. The stability of the $\mathrm{O} / \mathrm{W}$ emulsion was studied at ambient conditions and also in the presence of pressurized $\mathrm{CO}_{2}$, to ensure its composition during $\mathrm{PGSS}^{\circledR}$ precipitation. Additionally, Ketoprofen, a nonsteroidal anti-inflammatory drug (NSAID) indicated in the treatment of musculoskeletal disorders that undergoes degradation by the effect of light, was used in this study as a model drug for the production of drug-loaded particles ${ }^{33}$. The particles obtained have been characterized considering their size, morphological and thermal properties as well as their drug release behavior. 
Chapter 3

\section{Experimental section}

\subsection{Materials}

Gelucire $43 / 01^{\text {TM }}$ was kindly supplied by Gattefossé (France). Imwitor ${ }^{\circledast} 600$ was kindly supplied by Sasol (Germany). PEG 4000 and Ketoprofen ( $\geq 98 \%$ purity) were purchased from Sigma-Aldrich (Steinheim, Germany). Dichloromethane was purchased from Fisher Scientific (Loughborough, UK). $\mathrm{CO}_{2}$ with 99.95 mol\% and 99.998 mol\% purity were delivered by Air Liquide (Portugal). All the chemicals were used without further purification.

3.2. Preparation, determination of the stability and characterization of the emulsion at ambient pressure

Oil-in-water emulsion was prepared by melting previously the oil phase constituted by Gelucire 43/01 ${ }^{\mathrm{TM}}(\mathrm{HLB}=1)$ and the emulsifier, IMWITOR ${ }^{\circledR} 600(\mathrm{HLB}=4)$, which was then gradually dispersed with continuous agitation in the heated aqueous phase containing PEG 4000 and water (ratio PEG:water $=1.82$ ). The minimal volume of water that enabled the formation of the emulsion was used. In order to confirm the formation of an $\mathrm{O} / \mathrm{W}$ emulsion, a dilution test with water was performed.

Different process variables on emulsion stability were experimentally investigated, namely the emulsifier dosage ( 0.25 to $2 \% \mathrm{w} / \mathrm{w}$ ), emulsifying temperature (328 to $353 \mathrm{~K}$ ) and mixing time (3 to 20min). The stirring intensity was fixed at 1500rpm. The emulsions were kept in a water bath at $333 \mathrm{~K}$ to avoid the precipitation of carriers. The emulsion stability was then estimated by measuring the relative volume of the emulsion after $12 \mathrm{~h}$ of its preparation ${ }^{34-36}$. The relative volume is defined as the ratio of $\mathrm{O} / \mathrm{W}$ emulsion volume to the total volume of water, oil and 
surfactant used to prepare the emulsion; the higher relative volume indicates enhanced stability.

Furthermore, the oil droplets' size of the resulting emulsion was visually determined using a Microscope Leica DM4000B (Wetzlar, Germany) and Multiple Light scattering (MLS) technique was also employed for measuring the hydrodynamic mean particle diameter of oil droplets by using TURBISCAN Classic MA 2000 with Migration Software (Formulaction, France).

\subsection{Determination of the stability of the emulsion in supercritical $\mathrm{CO}_{2}$}

The stability of PEG-GEL emulsion in a $\mathrm{CO}_{2}$ environment was studied using a high pressure view cell built by New Ways of Analytics GmbH (Germany) and previously described elsewhere ${ }^{37}$. Figure 1 shows a photograph of the equipment.

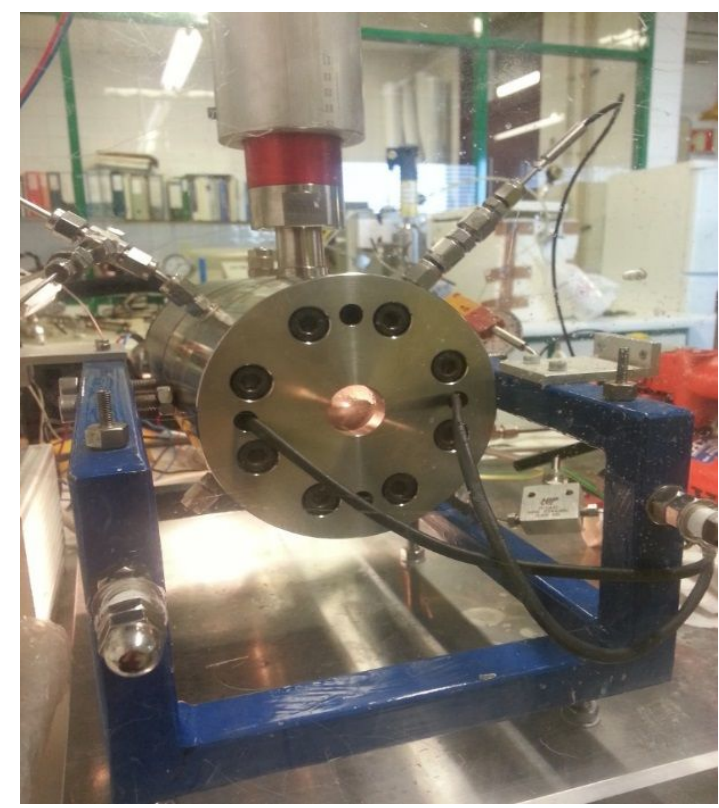

Figure 1| Photograph of the High pressure view cell (New Ways of Analytics GmbH; Germany)

Briefly, the apparatus is composed by an equilibrium cell made of a stainless steel cylinder with an internal diameter of $3.6 \mathrm{~cm}$. The cell is equipped with two sapphire 
windows positioned at the front and at the back of the cell, which permit visualizing the entire emulsion volume. The back sapphire acts also as a piston, moving inside and along the stainless steel cylinder, being possible to change the internal volume of the cell between 38 and $70 \mathrm{~cm}^{3}$. The piston is pushed by means of a hydraulic fluid pump. The equipment can operate up to $453 \mathrm{~K}$ and at pressures between atmospheric and $70 \mathrm{MPa}$. The temperature is controlled by means of a PID controller (Eurotherm 2216e), connected to a temperature sensor in direct contact with the fluid mixture inside the cell that measure temperature with an accuracy of $0.1 \mathrm{~K}$, and two electrical band heaters. Pressure is measured by an Omega DP41E230 transducer with an accuracy of $0.05 \mathrm{MPa}$. Stirring of the mixture inside the cell is performed with a magnetically coupled device.

The stability of PEG-GEL emulsion was determined at different pressure conditions and different PEG:GEL mass ratios using an initial internal volume of the cell of 38 $\mathrm{cm}^{3}$. The temperature used during the experiments was fixed, since the variation of this parameter demonstrated to have a minor effect on emulsion stability in a $\mathrm{CO}_{2}$ atmosphere ${ }^{38}$. The internal volume of the high pressure view cell was then increased to $70 \mathrm{~cm}^{3}$ in order to cause a rapid decrease of pressure and thus trying to simulate the pressure drop that occurs during PGSS ${ }^{\circledR}$ precipitation. The emulsion stability was checked through visual observation, considering that the emulsion was not stable when two phases appeared ${ }^{38,39}$.

3.4. Precipitation of the emulsion by particles from gas saturated solutions (PGSS $囚)$

PEG 4000, Gelucire 43/01 ${ }^{\mathrm{TM}}$ and PEG-GEL (3:1 w/w) particles unloaded and loaded with $9 \%(w / w)$ of Ketoprofen were produced using the PGSS ${ }^{\circledR}$ process. The schematic representation of the modified PGSS ${ }^{\circledR}$ equipment (FAME UNIT, Separex, France) used to produce the particles is shown in Figure 2. 


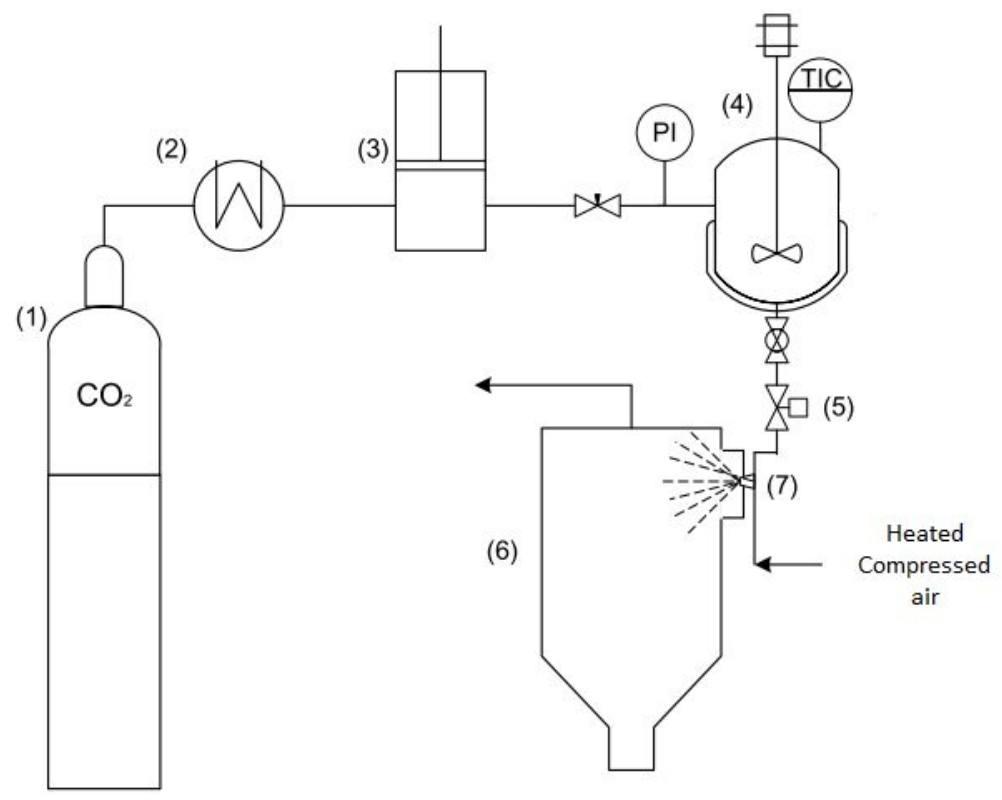

Figure 2| Experimental setup: (1) CO2 cylinder (2) cryostate (3) pneumatic piston pump (4) stirred vessel (electrically thermostated) (5) automated depressurization valve (6) recovery vessel (7) nozzle

Carbon dioxide was fed by a high-pressure piston pump to a $50 \mathrm{~cm}^{3}$ electrically thermostated high-pressure stirred vessel (323K), containing the materials to be precipitated, until the desired working pressure was reached (12MPa). After 15 minutes of stirring $(150 \mathrm{rpm})$, the mixture was depressurized by an automated depressurization valve and atomized through a two fluid nozzle $(\mathrm{d}=250 \mu \mathrm{m})$ to a cyclone, where it was mixed with heated compressed air (0.7MPa, 308K) for improved drying. Finally, the particles were recovered in an $18 \mathrm{~L}$ collector vessel.

\subsection{Particles' characterization}

3.5.1. Particle size distribution, Particle size, morphology and microstructure analysis 
Particle size distribution (PSD) was measured with a laser diffractometer (Mastersizer 2000, Malvern Instruments) equipped with a Scirocco 2000 dry disperser (Malvern Instruments). Particle size measurements are reported as volume distribution and defined as the average diameter (d0.5), being the final result the average from two measurements. The span value is also reported, that is, the ratio between $\mathrm{d} 0.5$ and (d0.9-d0.1); span values near to 1 represent narrow PSD.

Particle size and morphology were analyzed visually by FE-SEM (Field Emission Scanning Electron Microscopy) JEOL 7001F at 10-15kV. Before analysis, particles were covered with approximately $300 \AA$ of a gold-platinum film with a sputtercoater in argon atmosphere (Polaron).

The interior of the particles was analyzed through FIB (Focused ion beam) using a Carl Zeiss AURIGA CrossBeam (FIB-SEM) workstation instrument, equipped with an Oxford EDS spectrometer. The particles have been dispersed in carbon tape and afterwards covered with a conductive film ( $\mathrm{Au} / \mathrm{Pd}) . \mathrm{Ga}^{+}$ions were accelerated to 30 $\mathrm{kV}$ at $50 \mathrm{pA}$. The etching depth remained around $0.2 \mathrm{~mm}$ (micron).

The particles were imaged by transmission electron microscopy (TEM) with negative staining in order to characterise their internal structure. Briefly, the samples were suspended in $3 \%$ glutaraldehyde in $0.1 \mathrm{M}$ sodium cacodylate buffer $\mathrm{pH}$ 7.3. Following primary fixation for $2 \mathrm{~h}$ at $4{ }^{\circ} \mathrm{C}$ the samples were washed in cacodylate buffer and secondarily fixed for $2 \mathrm{~h}$ in $1 \%$ osmium tetroxide in $0.1 \mathrm{M}$ sodium cacodylate buffer $\mathrm{pH} 7.3$. Fixed samples were embedded in $2 \%$ agar for further processing. Dehydration was carried out with increasing concentrations of ethanol. After passage through propylene oxide, the samples were embedded in Epon-Araldite, using SPI-Pon as an Epon 812 substitute. Thin sections were made with glass or diamond knives and stained with $2 \%$ aqueous uranyl acetate and Reynold's lead citrate. The stained sections were studied and photographed in a JEOL 100SX electron microscope. 


\subsubsection{Thermal behavior}

Differential Scanning Calorimetry (DSC) measurements were carried out on a DSC TA instruments Q200 (module MDSC) with the aim of studying the thermal behavior of the particles. The samples were placed in an aluminium pan and sealed; the probes were heated from 253.15 to $473.15 \mathrm{~K}$ at a rate of $10 \mathrm{~K} / \mathrm{min}$ under nitrogen atmosphere.

\subsubsection{Determination of drug entrapment}

The quantification of Ketoprofen loaded inside the particles was determined by Ultraviolet-visible spectrophotometry. A certain amount of particles was dissolved in dichloromethane; the absorbance of the resulting solutions was analysed at 252 $\mathrm{nm}$ in a UV-Visible Spectrophotometer (Genesys10uv spectrometer; Thermo Spectronic, New York, USA). Calibration was obtained by using standard samples with concentrations between 1 and $12 \mu \mathrm{g} / \mathrm{mL}$. Each analysis was performed in triplicate.

\subsubsection{In vitro evaluation of drug release kinetics} A sample of particles containing approximately $3 \mathrm{mg}$ of Ketoprofen were suspended in $25 \mathrm{~mL}$ of dissolution medium (phosphate buffer solution, $\mathrm{pH}=6.8$ ). Samples were stirred at $155 \mathrm{rpm}$ and maintained at a temperature of $310.15 \mathrm{~K}$. Aliquots $(1.5 \mathrm{~mL})$ were withdrawn at predetermined time intervals $(5 \mathrm{~min}, 15 \mathrm{~min}, 30 \mathrm{~min}, 60 \mathrm{~min}$, etc.) and the same volume of fresh medium was added to the suspension. The samples were filtered and the concentration of Ketoprofen was determined using a UV-Visible Spectrophotometer (UV-Vis Genesys10uv spectrometer; Thermo Spectronic, $\lambda=260 \mathrm{~nm}$ ). Calibration was obtained by using standard samples with concentrations between 1 and $13 \mu \mathrm{g} / \mathrm{mL}$. 


\section{Results and discussion}

\subsection{Stability of the emulsion}

PEG 4000 and Gelucire 43/01 ${ }^{\text {TM }}$ have been chosen in this work for the production of multicore hybrid particles. These two carrier materials present distinct HLB values, making them completely immiscible with each other even in the presence of an emulsifier like IMWITOR ${ }^{\circledR}$ 600. Thus, it was necessary to develop an O/W macroemulsion by adding distilled water to the mixture, so as to have PEG in the continuous phase and GEL in the dispersed phase, stabilized by IMWITOR ${ }^{\circledR} 600$. Macroemulsions are by definition systems thermodynamically instable due to high levels of interfacial energy. In order to minimize this energy, the system can breakdown by coalescence, sedimentation, flocculation, creaming, Ostwald ripening and phase inversion ${ }^{40}$. The stability of each emulsion is dependent on several factors and should be studied in order to enhance its half-life. Thus, the effect of emulsifier dosage, emulsifying temperature and mixing time on the stability of PEG-GEL emulsion was experimentally evaluated through the method developed by Li and co-authors ${ }^{41}$ and previously described. Briefly, the emulsion stability was estimated by measuring the relative volume of the emulsion after $12 \mathrm{~h}$ of its preparation, which is defined as the ratio of $\mathrm{O} / \mathrm{W}$ emulsion volume to the total volume of water, oil and surfactant used to prepare the emulsion; the higher relative volume indicates enhanced stability ${ }^{41}$.

The stirring intensity was fixed at $1500 \mathrm{rpm}$; usually higher stirring intensity results in more stable emulsions ${ }^{35,36}$. The results can be seen in Figure 3. 

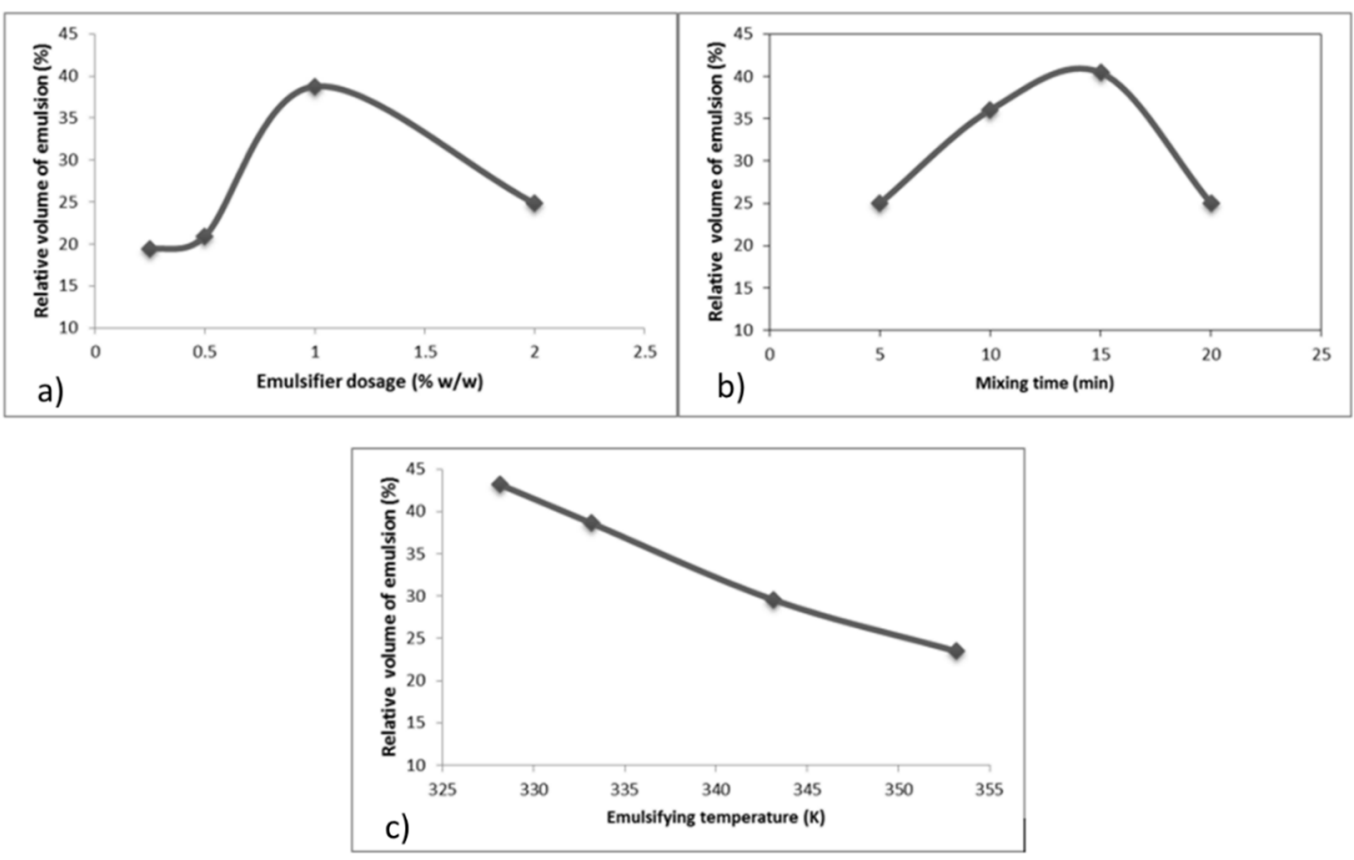

Figure 3 | Influence of different process parameters on emulsion stability using stirring intensity fixed at 1500rpm. a) Experiments performed at $338 \mathrm{~K}$ and $5 \mathrm{~min}$ of mixing time; b) Experiments performed at $338 \mathrm{~K}$ with $1 \%$ of emulsifier (w/w); c) Experiments performed with $1 \%(\mathrm{w} / \mathrm{w})$ of emulsifier and $15 \mathrm{~min}$ of mixing time

Emulsion's stability depends greatly on the concentration of the emulsifier. In this case, it is possible to verify that the relative volume of emulsion increased as IMWITOR 600 concentration increased from $0.25 \%$ to $1 \%$. When the concentration increased to $2 \%$, the emulsion stability decreased, owing to the rapid coalescence of the oil droplets ${ }^{34-36}$. The optimal surfactant concentration was found to be $1 \%$, being this emulsifier dosage fixed and used for the following experiments. Regarding the mixing time, the relative volume of emulsion increased as this parameter was changed from 5 to $15 \mathrm{~min}$, as a result of a reduction of the oil droplets' size, thus stabilizing the emulsion. Nevertheless, a decrease in the relative volume of emulsion occurred with 20min of mixing. Usually an excessive mixing time leads the surfactant to drop out from the oil-water interface, causing a 
reduction of its effectiveness and consequently a decrease in the relative volume of emulsion ${ }^{34-36}$. The optimum mixing time was fixed at $15 \mathrm{~min}$ and further used for the subsequent experiments. Afterwards, the relative volume of emulsion was measured at temperatures ranging from 328 to $353 \mathrm{~K}$. It is possible to see that emulsion stability decreased with increasing emulsifying temperature, being the most stable emulsion produced at $328 \mathrm{~K}$. Temperature is essential to the emulsification process, however an excessive temperature should be avoided because it will conduct to the coalescence of the oil phase and breakage of the emulsion ${ }^{35,36}$.

In general, the emulsions do not present high stability and are all broken after $12 \mathrm{~h}$ of preparation, presenting $45 \%$ of maximum relative volume of emulsion. Nevertheless, the objective of this work was to avoid organic solvents, so the next steps of the work progressed with this O/W emulsion, which presented oil droplets with equivalent diameter of $9 \mu \mathrm{m}$ (Figure 4).
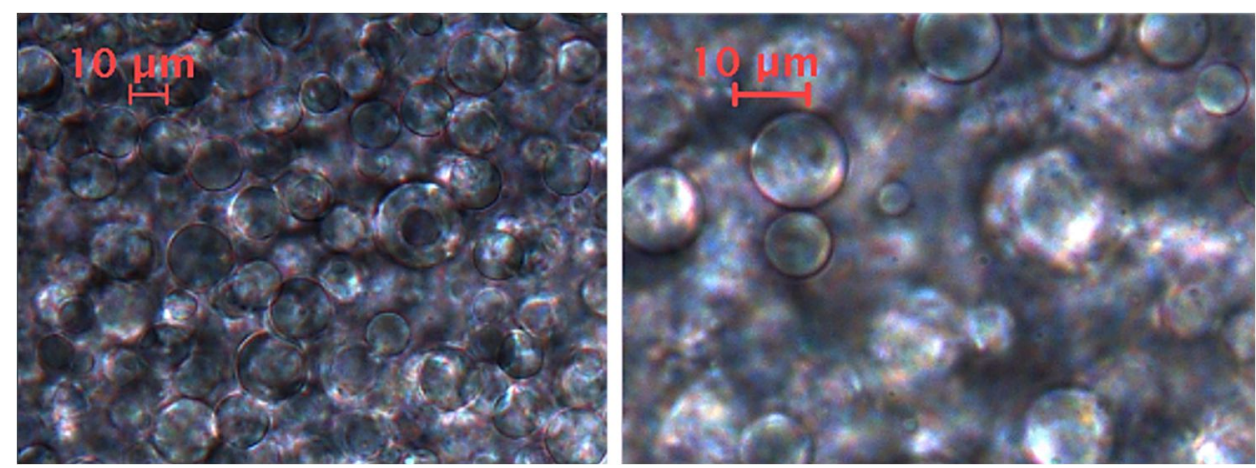

Figure 4| Microscopic pictures of emulsion droplets

\subsection{Stability of the emulsion in the presence of $\mathrm{CO}_{2}$}

The stability of PEG-GEL emulsion was also studied in the presence of $\mathrm{CO} 2$, in order to guarantee its integrity during the PGSS ${ }^{\circledR}$ process, being determined at two different pressures (12 and $18 \mathrm{MPa}$ ), at $323 \mathrm{~K}$ and three different PEG:GEL mass 
ratios $(3: 1 ; 2: 1$ and $1: 1)$. The emulsions were all prepared according to the parameters previously established and placed inside the high pressure view cell previously described. A preliminary experiment performed using the emulsion with the compounds' mass ratio of 2:1 at 12MPa revealed that it was stable for at least $15 \mathrm{~min}$ with a progressive coalescence of the internal phase. The full breakdown of the emulsion occurred after $30 \mathrm{~min}$ of stirring (Figure 5).
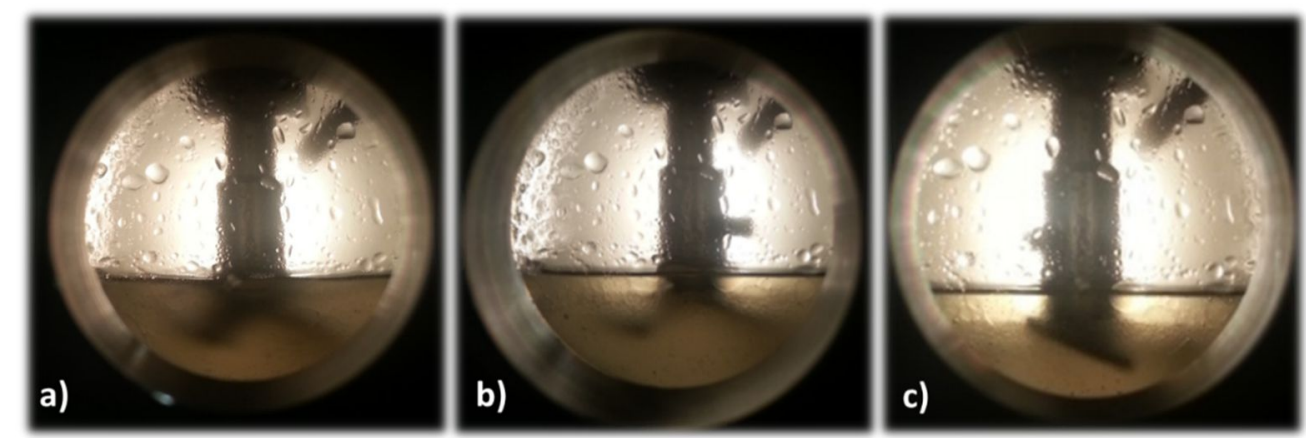

Figure 5| Pictures of the evolution of PEG:GEL emulsion in CO2 after a) $15 \mathrm{~min}$, b) $20 \mathrm{~min}$ and c) $25 \mathrm{~min}$ at $12 \mathrm{MPa}$ and $323 \mathrm{~K}$

Therefore, all the experiments were performed by studying the emulsion stability during 15min of stirring at $\mathrm{CO} 2$ atmosphere with further increase of the high pressure view cell's volume in order to simulate the rapid decrease of pressure during the $P G S S^{\circledast}$ precipitation of the emulsion $(\triangle P=3 \mathrm{Mpa}$ in experiments at $12 \mathrm{Mpa} ; \Delta \mathrm{P}=7 \mathrm{Mpa}$ in experiments at $18 \mathrm{Mpa})$. Results presented in Table 1 demonstrate that the stability of the PEG-GEL emulsion is reduced when pressure is increased from 12 to $18 \mathrm{MPa}$. 
Table 1| Stability of PEG-GEL emulsions in $\mathrm{CO} 2$ at different pressures and compounds' mass ratios.

\begin{tabular}{|c|c|c|c|c|}
\hline \multirow{2}{*}{$\begin{array}{c}\text { Mass ratio } \\
\text { PEG:GEL }\end{array}$} & \multicolumn{2}{|c|}{ Pressure $=12 \mathrm{MPa}$} & \multicolumn{2}{|c|}{ Pressure $=18 \mathrm{MPa}$} \\
\hline & $\begin{array}{c}\text { Until } 15 \mathrm{~min} \text { of } \\
\text { agitation }\end{array}$ & $\begin{array}{l}\text { After variation of } \\
\text { cell's volume } \\
(\triangle \mathrm{P}=3 \mathrm{Mpa})\end{array}$ & $\begin{array}{c}\text { Until 15min of } \\
\text { agitation }\end{array}$ & $\begin{array}{c}\text { After variation of } \\
\text { cell's volume } \\
\text { ( } \triangle \mathrm{P}=7 \mathrm{Mpa})\end{array}$ \\
\hline $3: 1$ & Stable & Stable & Stable & Coalescence \\
\hline $2: 1$ & Stable & Stable & Coalescence & 2 phases \\
\hline 1:1 & Coalescence & 2 phases & Not tested & Not tested \\
\hline
\end{tabular}

This is in agreement with the work of Varona et al. ${ }^{38}$ and justified by the diffusion of $\mathrm{CO}_{2}$ to the emulsion, preferentially to the lipid phase, increasing the oil-water interfacial tension ${ }^{42}$. Consequently, the higher content of $\mathrm{CO}_{2}$ at $18 \mathrm{MPa}$ led to higher destabilization. Thus, $12 \mathrm{MPa}$ was the chosen pressure to conduct the PGSS ${ }^{\circledR}$ experiments. Moreover, the stability of the emulsion also decreased as the PEG:GEL mass ratio varied from 3:1 to $1: 1$, due to an increase of the lipid internal phase of the emulsion. The higher content of discontinuous phase, the less stable the emulsion. This is accentuated in the presence of $\mathrm{CO}_{2}$ due to its higher solubility in the lipid ${ }^{27,43}$. The supercritical fluid will solubilize in higher extension in the discontinuous phase with an increase of its volume and consequently a higher degree of destabilization. The PEG:GEL proportion of 3:1 (w/w) demonstrated to be the most stable at the two pressures tested for at least $15 \mathrm{~min}$. Thus, this mass ratio was chosen for the $\mathrm{PGSS}^{\circledR}$ experiments, since it ensures the production of hybrid particles without a previous disruption of the emulsion structure. 


\subsection{Hybrid particles from gas saturated emulsions}

Dry PEG-GEL hybrid particles ( $d_{0.5}=226.5 \mu \mathrm{m}$; Span $=3.0$ ) were produced through the precipitation of a gas saturated o/w emulsion. As the emulsion had water in its composition, another challenge in performing precipitation by PGSS ${ }^{\circledR}$, is to dry this water content in order to collect fine dry particles. To achieve this, an adjustment was made in the PGSS ${ }^{\circledR}$ apparatus by introducing a heating system that raises the temperature of the compressed air, improving its drying capacity. The conditions used in this experiment (12MPa, 323K, 15min of mixing) were previously recognized as the most appropriate for this system, ensuring the emulsion structure and hence enabling the production of structured particles. Figure 6 shows the SEM pictures of the particles produced.
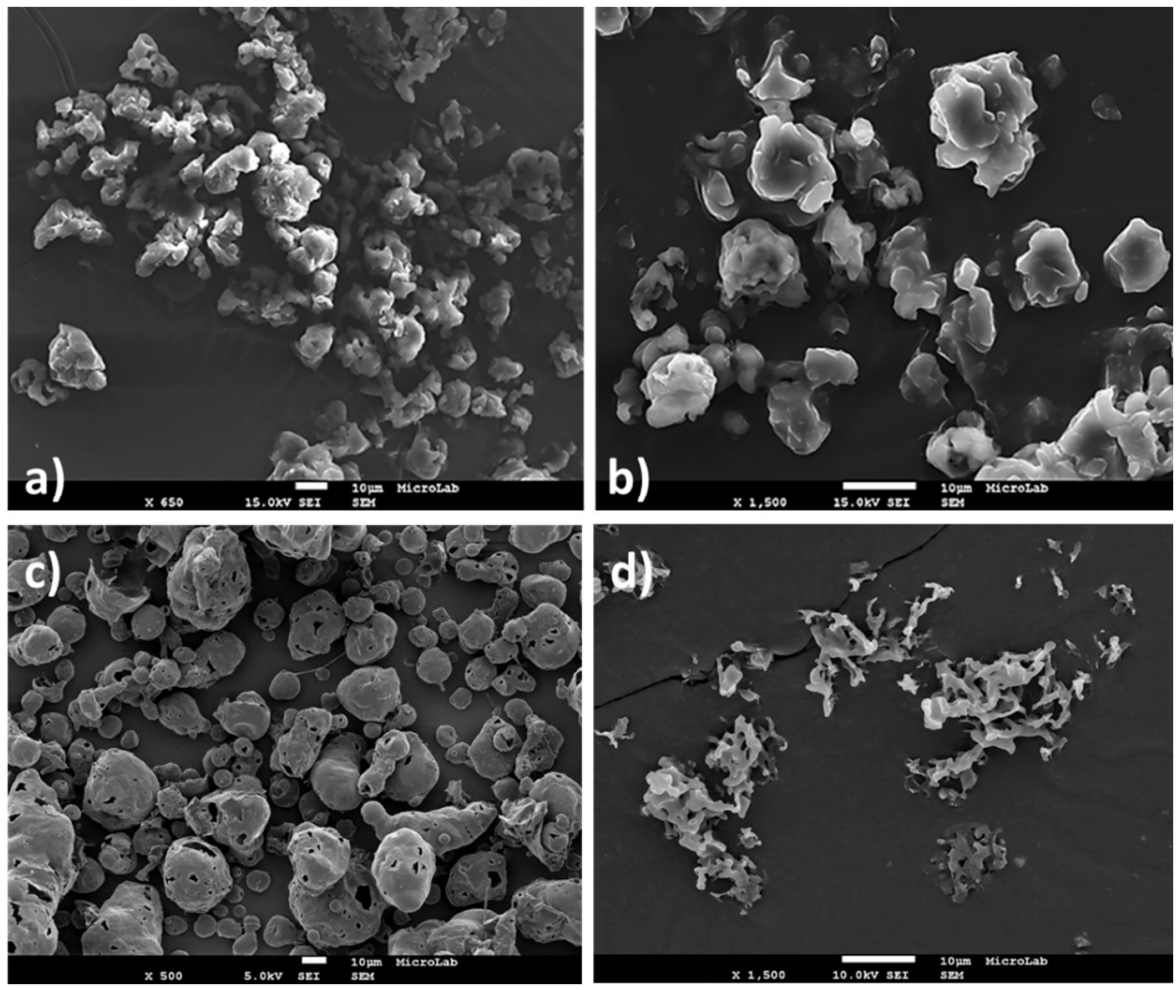

Figure 6| SEM micrographs of PEG-GEL particles at a) 650x and b) 1500x magnification; of c) PEG 4000 particles (500x magnification) and of d) Gelucire $43 / 01^{\mathrm{TM}}$ (1500x magnification). The particles were all produced by $\mathrm{PGSS}^{\circledR}$ at $12 \mathrm{MPa}$ and $323 \mathrm{~K}$. 
It is possible to verify that the PEG-GEL hybrid particles present a non-porous spherical-like structure with some tendency to aggregate. This structure is quite different compared with those from the particles composed of individually carriers processed by PGSS ${ }^{\circledR}$, since PEG 4000 particles present a porous spherical morphology while Gelucire 43/01 ${ }^{\mathrm{TM}}$ particles exhibit branched-polyp-shape. This shows that structured PEG-GEL particles were formed, instead of particles composed of individual carriers.

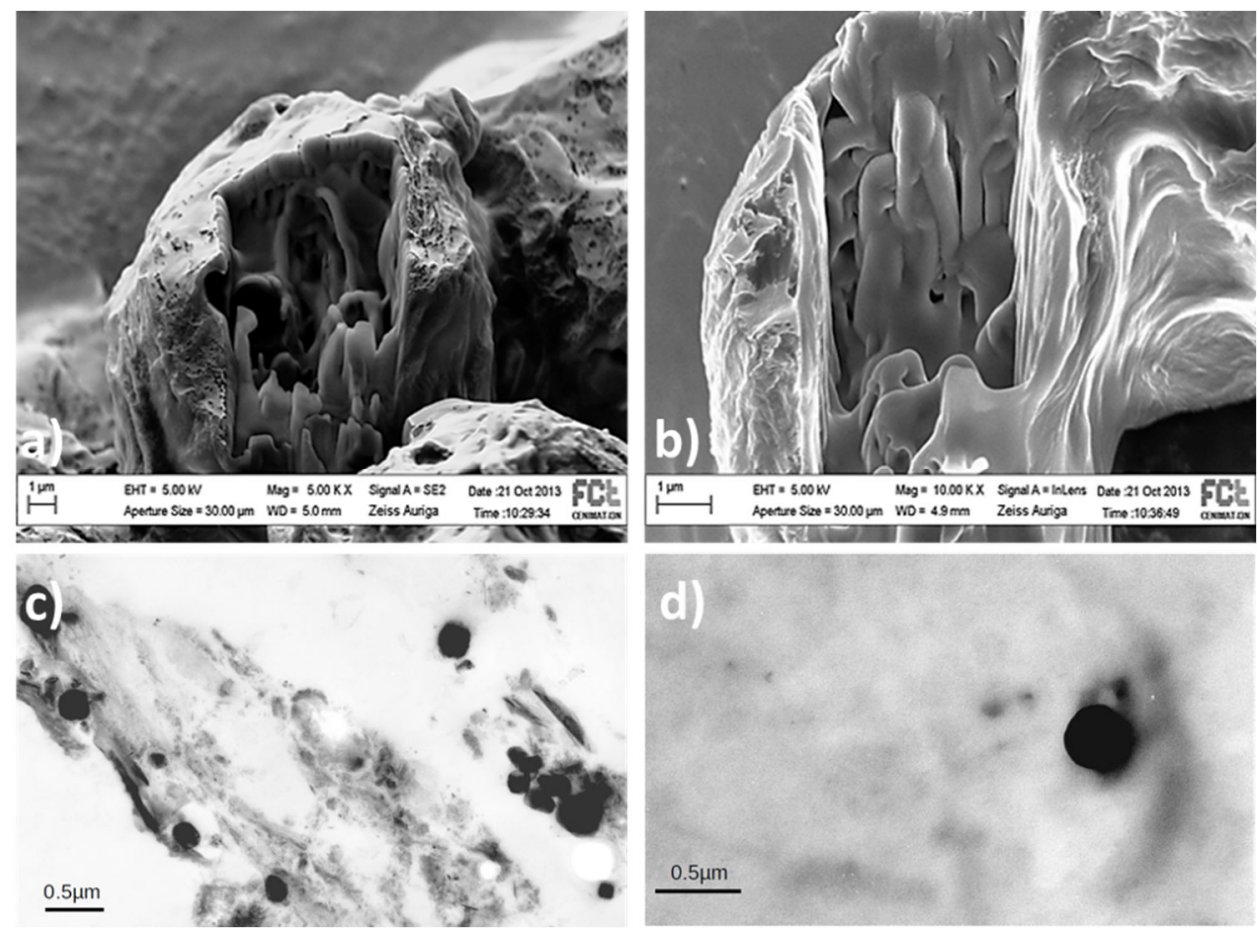

Figure 7| Microstructure of PEG-GEL hybrid particles: FIB micrographs at a) 5000x and b) 10000x magnification and c-d) TEM images

In Figure 7 the microstructure of the hybrid particles can be seen. FIB is a precise technique for ultramicrotomy that preserves pores and interfacial voids usually destroyed by conventional mechanical polishing ${ }^{44,45}$. FIB milling revealed a nonhomogenous interior of the hybrid particles with the presence of waterfalling effects, probably due to the presence of more than one carrier material. These 
effects usually appear in softer materials, where energetic gallium ion beam's degree of channeling is higher ${ }^{46}$. PEG-GEL particles are composed by internal lipid structures with a lower melting point than the external polymer. The presence of areas with distinct melting temperatures and different resistances to $\mathrm{Ga}^{+}$ions may explain this internal structure of PEG-GEL particles. Moreover, it is possible to verify the existence of sub-surface pores, most likely as a result of the expansion of $\mathrm{CO}_{2}$ during the atomization step. TEM images reveal and confirm the presence of small Gelucire $43 / 01^{\text {TM }}$ droplets $(<500 \mathrm{~nm}$ ) inside PEG 4000 material. This technique coupled with negative staining enables to contrast lipids due to their enhanced electron density ${ }^{4,47}$. Since the PEG-GEL emulsion is composed by several Gelucire $43 / 01^{\text {TM }}$ droplets dispersed in the water phase, it was expected that the particles do not present a single lipid core composed by the lipid but rather submicronmulticores of Gelucire $43 / 01^{\text {TM }}$ inside the polymer.

\subsection{Ketoprofen-Loaded Hybrid particles from gas saturated emulsions}

PEG-GEL $\left(\mathrm{d}_{0.5}=278 \mu \mathrm{m}\right.$; Span=2.1); PEG $4000\left(\mathrm{~d}_{0.5}=20 \mu \mathrm{m}\right.$; Span=2.3) and Gelucire $43 / 01^{\mathrm{TM}}\left(d_{0.5}=418 \mu \mathrm{m} ; \mathrm{Span}=1.8\right)$ particles loaded with $9 \%(\mathrm{w} / \mathrm{w})$ of Ketoprofen were also produced in this work. Ketoprofen is a drug which undergoes degradation upon exposition to light, thus it is essential to formulate this drug in a DDS so as to be protected. Figure 8 presents the SEM pictures from the pure drug and PEG-GEL drug-loaded particles. 


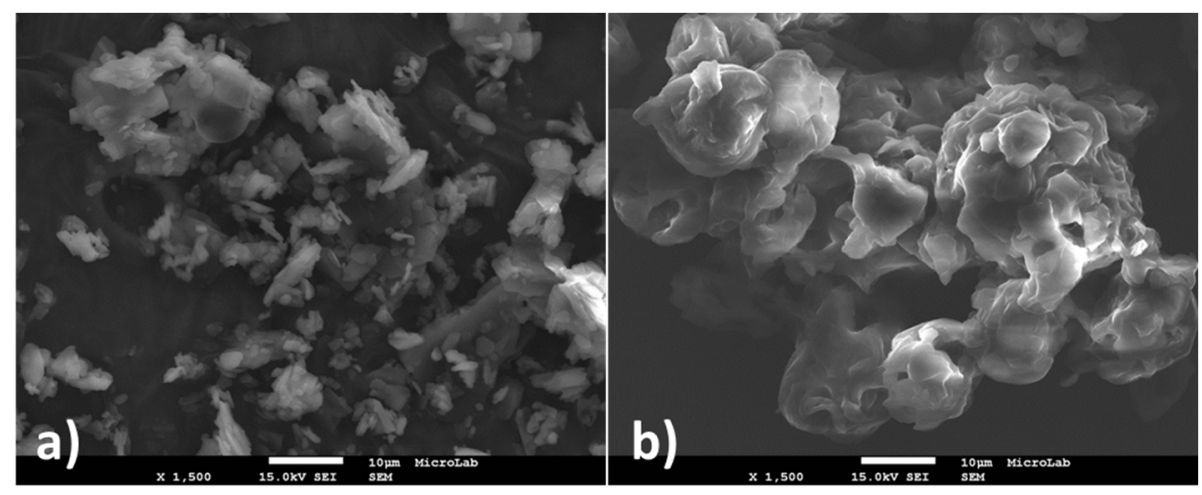

Figure 8| SEM micrographs at 1500x magnification of a) unprocessed Ketoprofen and b) Ketoprofenloaded PEG-GEL particles produced by PGSS $^{\circledR}$ at $12 \mathrm{Mpa}$ and $323 \mathrm{~K}$

In general, Ketoprofen-loaded particles present the same morphology with more tendency to aggregate in comparison with the unloaded particles. Figure 9 shows the microstructure of Ketoprofen-loaded PEG-GEL and PEG 4000 particles through FIB pictures.
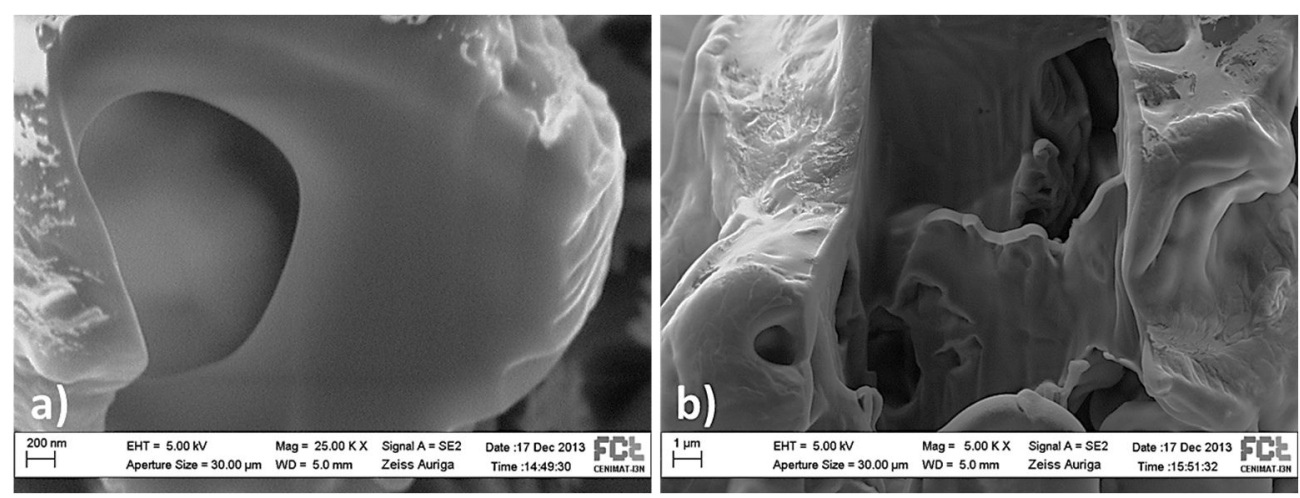

Figure 9| Micrographs of FIB cross-sections of Ketoprofen-loaded particles produced by PGSS ${ }^{\circledast}$ at $12 \mathrm{Mpa}$ and 323K composed by a) PEG 4000 (25000x magnification) and b) PEG-GEL (5000x magnification)

Both particles have inner porous due to the release of $\mathrm{CO}_{2}$. Nevertheless, while PEG 4000 particles have a homogenous structure, PEG-GEL particles feature once again 
a non-homogenous interior with waterfalling effects due to its hybrid composition, as previously explained.

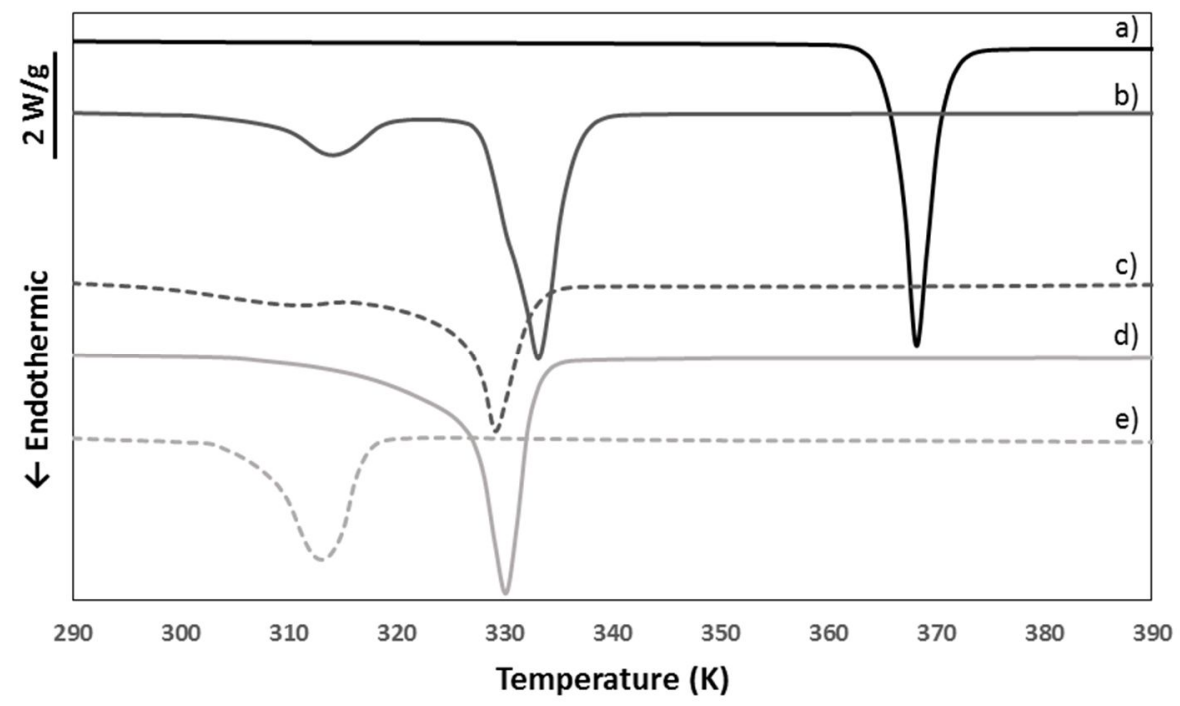

Figure 10| DSC Thermograms of a) unprocessed Ketoprofen; PEG-GEL particles b) unloaded and c) loaded with Ketoprofen; d) PEG 4000 particles loaded with Ketoprofen and e) Gelucire 43/01 ${ }^{\mathrm{TM}}$ particles loaded with Ketoprofen

By analyzing the DSC thermograms, present in figure 10 , it is possible to verify that unloaded PEG-GEL hybrid particles present two endothermic peaks of melting, being the first one of Gelucire 43/01 ${ }^{\mathrm{TM}}$ (314K) and the second one of PEG 4000 (333K). This reinforces the development of structured multicore-shell particles. Regarding the Ketoprofen-loaded particles, we can see that none of the particles (PEG, GEL, nor PEG:GEL) show the melting peak of the drug, revealing the formation of a new solid solution phase of each carrier with Ketoprofen, without its segregation ${ }^{17}$. Moreover, Ketoprofen-loaded PEG-GEL particles' melting peaks are not only diminished but also displaced to lower temperatures (308K and 329K) than the melting point of unloaded particles, being this effect due to the plasticizing effect of the drug in both lipid and polymeric phases ${ }^{48,49}$. 
With respect to Ketoprofen content determined by UV-Visible Spectrophotometer, similar results were obtained for PEG 4000 and Gelucire $43 / 01^{\mathrm{TM}}$ particles, presenting encapsulation efficiencies of $88 \%$ and $93 \%$, respectively. PEG-GEL particles presented an encapsulation efficiency of 99\%. Figure 11 presents the results obtained in in vitro drug release experiments in phosphate buffer solution.

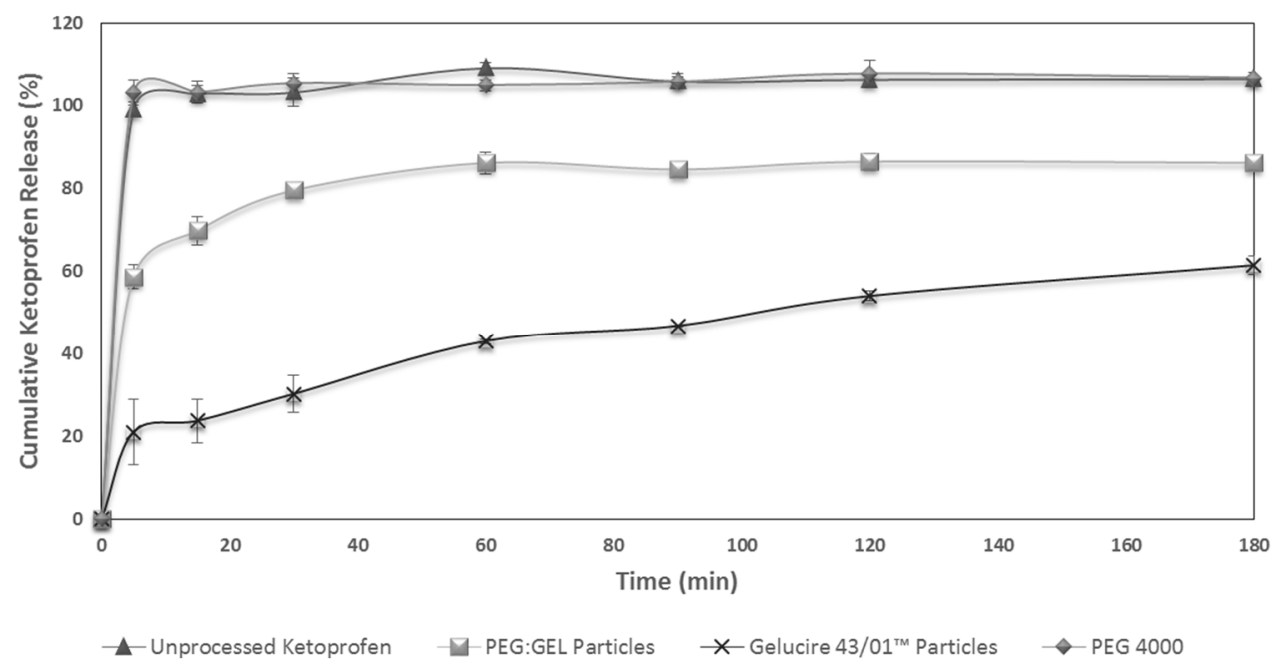

Figure 11| Drug release profiles of unprocesed Ketoprofen and of the Ketoprofen-loaded particles produced by PGSS $^{\circledR}$ (Phosphate buffer solution, $\mathrm{pH}=6.8$ )

PEG 4000 particles present a burst release of Ketoprofen, due to its hydrophilic character, with complete dissolution after $5 \mathrm{~min}$. This DDS may be appropriate in situations where it is necessary to achieve fast therapeutic effect. On the other hand, the lipophilic Gelucire $43 / 01^{\mathrm{TM}}$ particles present an initial burst release, most probably due to the dissolution of drug existing at the particles's surface, with following sustained release of the NSAID. After $3 \mathrm{~h}, 60 \%$ of the drug was released. Hybrid PEG-GEL particles are composed by two carrier materials, and thus, the release kinetics shows a profile representing a merge between the PEG 4000 and Gelucire $43 / 01^{\mathrm{TM}}$ profiles. An initial burst release can be seen, corresponding to the progressive dissolution of the outer layer of PEG 4000; thereafter, occurred a new 
increase in dissolution with a lower slope corresponding to the drug release from the lipid. During the last 2 hours of the experiment it was possible to verify the existence of a plateau at $86 \%$ of drug released. This DDS could be adequate in situations where it is necessary a loading dose with further maintenance of the therapeutic levels.

\section{Conclusions}

The potential of a green precipitation technology, namely PGSS ${ }^{\circledR}$, to produce DDS with lipid multicores and a polymeric shell was successfully demonstrated in this work through the development of hybrid particles composed by Gelucire $43 / 01^{\mathrm{Tm}}$ and PEG 4000.

Multicore hybrid particles were successfully generated from the expansion of a $\mathrm{CO}_{2}$ saturated $\mathrm{O} / \mathrm{W}$ macroemulsion at $12 \mathrm{MPa}$ and 323K, with a PEG:GEL mass ratio of 3:1. At these conditions, the emulsion proved to be stable in a $\mathrm{CO}_{2}$ environment and thus it was suitable to produce structured particles. Since the emulsion was constituted by Gelucire 43/01 ${ }^{\mathrm{TM}}$ droplets dispersed in an aqueous PEG solution, the resulting spherical-like particles were composed by several lipid cores encapsulated in a polymeric shell. The hybrid particles were also loaded with Ketoprofen, showing two sequenced profiles in the release kinetics, with an initial burst release of the drug from the polymer followed by a controlled release from the lipid cores. Further studies should be conducted in order to extend and optimize the production of multicore-shell structures with different materials. Moreover, the particle size of the particles should be reduced in order to be used in some mucosal routes such as nasal delivery. Nevertheless, these results proved that PGSS ${ }^{\circledR}$ is a versatile method and a greener alternative for the production of structured particles through the precipitation of emulsions. 


\section{Acknowledgements}

This work was supported by Fundação para a Ciência e Tecnologia (FCT) through Grant No. PEst-OE/EQB/LA0004/2011. V.S.S. Gonçalves is also grateful for the financial support from SFRH/BD/77350/2011 grant from FCT. S. Rodríguez-Rojo acknowlegdes the Ministerio de Economía y Competitividad and Universidad de Valladolid for her Juan de la Cierva fellowship.

\section{References}

1 S. Naahidi, M. Jafari, F. Edalat, K. Raymond, A. Khademhosseini and P. Chen, J. Control. Release, 2013, 166, 182-94.

2 R. Singh and J. W. Lillard, Exp. Mol. Pathol., 2009, 86, 215-23.

3 C. S. Morales, P. M. Valencia, A. B. Thakkar, E. Swanson and R. Langer, Front. Biosci., 2013, 15, 529-545.

4 L. Zhang, J. M. Chan, F. X. Gu, J.-W. Rhee, A. Z. Wang, A. F. RadovicMoreno, F. Alexis, R. Langer and O. C. Farokhzad, ACS Nano, 2008, 2, 1696702.

5 B. Mandal, H. Bhattacharjee, N. Mittal, H. Sah, P. Balabathula, L. A. Thoma and G. C. Wood, Nanomedicine, 2013, 9, 474-91.

6 W. S. Cheow and K. Hadinoto, Colloids Surf. B. Biointerfaces, 2011, 85, 21420.

7 Y. Liu, J. Pan and S.-S. Feng, Int. J. Pharm., 2010, 395, 243-50.

8 Y. Wang, K. Kho, W. S. Cheow and K. Hadinoto, Int. J. Pharm., 2012, 424, 98-106.

9 D. Sanli, S. E. Bozbag and C. Erkey, J. Mater. Sci., 2011, 47, 2995-3025.

10 E. Elizondo, J. Veciana and N. Ventosa, Nanomedicine (Lond)., 2012, 7, 1391-408.

11 A. Martín and M. J. Cocero, Adv. Drug Deliv. Rev., 2008, 60, 339-50.

12 A. Tabernero, E. M. Martín del Valle and M. A. Galán, Chem. Eng. Process. Process Intensif., 2012, 60, 9-25.

13 E. Weidner, M. Petermann and Z. Knez, Curr. Opin. Solid State Mater. Sci., 2003, 7, 385-390.

14 WO/1995/021688, 1995.

15 A. R. Sampaio de Sousa, R. Silva, F. H. Tay, A. L. Simplício, S. G. Kazarian and C. M. M. Duarte, J. Supercrit. Fluids, 2009, 48, 120-125.

16 C. A. García-González, A. R. Sampaio da Sousa, A. Argemí, A. López Periago, 
J. Saurina, C. M. M. Duarte and C. Domingo, Int. J. Pharm., 2009, 382, 296304.

17 M. Fraile, Á. Martín, D. Deodato, S. Rodriguez-Rojo, I. D. Nogueira, A. L. Simplício, M. J. Cocero and C. M. M. Duarte, J. Supercrit. Fluids, 2013, 81, 226-235.

18 S. Salmaso, S. Bersani, N. Elvassore, A. Bertucco and P. Caliceti, Int. J. Pharm. , 2009, 379, 51-8.

19 M. Vijayaraghavan, S. Stolnik, S. M. Howdle and L. Illum, Int. J. Pharm., 2013, 441, 580-8.

20 L. Casettari, E. Castagnino, S. Stolnik, A. Lewis, S. M. Howdle and L. Illum, Pharm. Res., 2011, 28, 1668-82.

21 F. Jordan, A. Naylor, C. A. Kelly, S. M. Howdle, A. Lewis and L. Illum, J. Control. Release, 2010, 141, 153-60.

22 C. A. Kelly, A. Naylor, L. Illum, K. M. Shakesheff and S. M. Howdle, Adv. Funct. Mater., 2012, 22, 1684-1691.

23 K. Vezzù, D. Borin, A. Bertucco, S. Bersani, S. Salmaso and P. Caliceti, J. Supercrit. Fluids, 2010, 54, 328-334.

24 Critical Pharmaceuticals Limited, .

25 S. Rodriguez-Rojo, D. Rego, A. V. M. Nunes, I. D. Nogueira, M. J. Cocero and C. M. M. Duarte, in 12th European Meeting on Supercritical Fluids, Graz (Austria), 2010, p. 75.

26 S. K. Jain and A. Gupta, AAPS PharmSciTech, 2009, 10, 1128-36.

27 A. R. Sampaio de Sousa, M. Calderone, E. Rodier, J. Fages and C. M. M. Duarte, J. Supercrit. Fluids, 2006, 39, 13-19.

28 L. Casettari, D. VIlasaliu, E. Castagnino, S. Stolnik, S. Howdle and L. Illum, Prog. Polym. Sci., 2012, 37, 659-685.

29 F. Alexis, E. M. Pridgen, R. Langer and O. C. Farokhzad, in Handbook of Experimental Pharmacology 197, ed. M. Schäfer-Korting, Springer Berlin Heidelberg, Berlin, Heidelberg, 2010, vol. 197, pp. 55-86.

30 I. D. Gunbas, U. Aydemir Sezer, S. Gülce İz, İ. Deliloğlu Gürhan and N. Hasirci, Ind. Eng. Chem. Res., 2012, 51, 11946-11954.

31 M. Yang, S. K. Lai, Y.-Y. Wang, W. Zhong, C. Happe, M. Zhang, J. Fu and J. Hanes, Angew. Chem. Int. Ed. Engl., 2011, 50, 2597-600.

32 Y.-Y. Wang, S. K. Lai, J. S. Suk, A. Pace, R. Cone and J. Hanes, Angew. Chem. Int. Ed. Engl., 2008, 47, 9726-9.

33 A. Argemí, C. Domingo, A. R. Sampaio de Sousa, C. M. M. Duarte, C. A. García-González and J. Saurina, J. Pharm. Sci., 2011, 100, 4783-4789.

34 S. Maiti, I. M. Mishra, S. D. Bhattacharya and J. K. Joshi, Colloids Surfaces A Physicochem. Eng. Asp., 2011, 389, 291-298.

35 H. C. Joshi, I. P. Pandey, A. Kumar and N. Garg, Adv. Pure Appl. Chem., 2012, 1, 7-11.

36 G. Chen and D. Tao, Fuel Process. Technol., 2005, 86, 499-508. 
37 A. V. M. Nunes, G. V. S. M. Carrera, V. Najdanovic-Visak and M. Nunes da Ponte, Fluid Phase Equilib., 2013, 358, 105-107.

38 S. Varona, S. Kareth, Á. Martín and M. J. Cocero, J. Supercrit. Fluids, 2010, 54, 369-377.

39 S. Varona, A. Martín and M. J. Cocero, Ind. Eng. Chem. Res., 2011, 50, 2088-2097.

40 T. F. Tadros, in Emulsion science and technology, Wiley-VCH, Weinheim, 2009, pp. 1-56.

41 X. Li, Z. Chen, H. Li and S. Han, Chinese J. Chem. Eng., 2001, 9, 200-203.

42 F. Mattea, Á. Martín, C. Schulz, P. Jaeger, R. Eggers and M. J. Cocero, AlChE J., 2009, 56, NA-NA.

43 E. Weidner, V. Wiesmet, Ž. Knez and M. Škerget, J. Supercrit. Fluids, 1997, 10, 139-147.

44 S. Yan, X. Zhang, Y. Sun, T. Wang, X. Chen and J. Yin, Colloids Surf. B. Biointerfaces, 2014, 113, 302-11.

45 B. Zhu, D. Traini, D. A. Lewis and P. Young, Colloids Surfaces A Physicochem. Eng. Asp., 2014, 443, 345-355.

46 D. Heng, P. Tang, J. M. Cairney, H.-K. Chan, D. J. Cutler, R. Salama and J. Yun, Pharm. Res., 2007, 24, 1608-17.

47 A.-L. Troutier, T. Delair, C. Pichot and C. Ladavière, Langmuir, 2005, 21, 1305-13.

48 P. Blasi, A. Schoubben, S. Giovagnoli, L. Perioli, M. Ricci and C. Rossi, AAPS PharmSciTech, 2007, 8, Article 37.

49 S. Rodríguez-Rojo, J. Kluge and M. Mazzotti, in Nanoformulation, Barcelona (Spain), 2012. 


\section{Chapter 4}

\section{Alginate-based \\ hybrid \\ aerogel \\ microparticles}

1. Abstract 3

2. Introduction ......................................................................................4

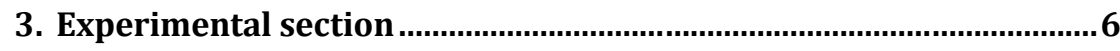

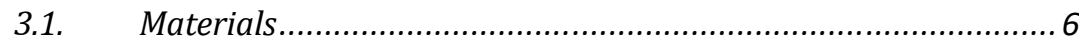

3.2. Production of hybrid alginate-based gel microparticles by emulsion gelation method................................................................. 7

3.3. Supercritical drying of gel microparticles ................................9

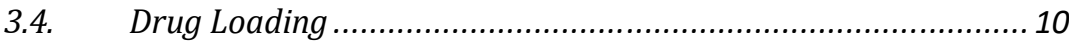

3.5. Aerogel microparticles characterization............................... 12

3.6. Statistical analysis ........................................................ 15

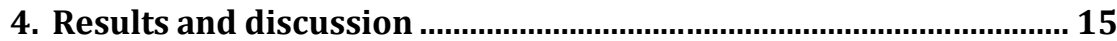

4.1. Emulsion gelation: effect of the composition and HLB.............. 15

4.2. Mucoadhesive properties................................................. 21

4.3. Drug-loaded alginate-based aerogel microparticles ................ 23

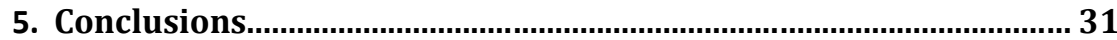

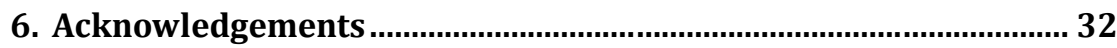

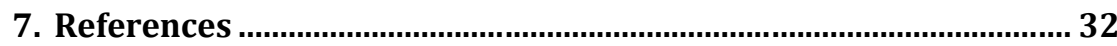


Adapted from: Gonçalves, V.S.S., Gurikov, P., Poejo, J., Matias, A.A., Heinrich, S., Duarte, C.M.M., Smirnova, I. (2016) Alginate-based hybrid aerogel microparticles for mucosal drug delivery. European Journal of Pharmaceutics and Biopharmaceutics, 107:160-170. doi: 10.1016/j.ejpb.2016.07.003

The author contributed to the planning and execution of all the experiments described in this chapter, except for SEM and BET analysis performed by $P$. Gurikov. The author was also involved on the discussion and interpretation of results, as well as on the preparation of the manuscript. 


\section{Abstract}

The application of biopolymer aerogels as drug delivery systems (DDS) has gained increased interest during the last decade since these structures have large surface area and accessible pores allowing for high drug loadings. Being biocompatible, biodegradable and presenting low toxicity, polysaccharide-based aerogels are an attractive carrier to be applied in pharmaceutical industry. Moreover, some polysaccharides (e.g. alginate and chitosan) present mucoadhesive properties, an important feature for mucosal drug delivery. This feature allows to extend the contact of DDS with biological membranes, thereby increasing the absorption of drugs through the mucosa (e.g. nasal). Alginate-based hybrid aerogels in the form of microparticles $(<50 \mu \mathrm{m})$ were investigated in this work as carriers for mucosal administration of drugs. Low methoxyl pectin and K-carrageenan were co-gelled with alginate and further dried with supercritical $\mathrm{CO}_{2} \quad\left(\mathrm{sc}-\mathrm{CO}_{2}\right)$. Spherical mesoporous aerogel microparticles were obtained for both alginate, hybrid alginate/pectin and alginate/k-carrageenan aerogels, presenting high specific surface area $\left(370-548 \mathrm{~m}^{2} \mathrm{~g}^{-1}\right)$ and mucoadhesive properties. The microparticles were loaded with ketoprofen via adsorption from its solution in $\mathrm{sc}-\mathrm{CO}_{2}$, and with quercetin via supercritical anti-solvent precipitation. Loading of ketoprofen was in the range between $17-22$ wt\% whereas quercetin demonstrated loadings of 3.1 5.4 wt\%. Both the drugs were present in amorphous state. Loading procedure allowed the preservation of antioxidant activity of quercetin. Release of both drugs from alginate/k-carrageenan aerogel was slightly faster compare to alginate/pectin. Further experiments were performed with alginate/pectin aerogels, which were loaded with neuropeptide amidated kyotorphin (78\% encapsulation efficiency). The results indicate that alginate-based aerogel microparticles can be viewed as promising matrices for mucosal applications, such as intranasal drug delivery. 


\section{Introduction}

Powder formulations have several advantages over liquid ones such as simplification of the formulation, higher chemical and microbiological stability, possibility to intimately formulate the drug with functional excipients and higher local concentrations at the absorption site of the mucosa along with improved residence time ${ }^{1}$. In present paper we focus on highly porous biopolymer aerogel microparticles as carriers for drug delivery systems (DDS). One remarkable feature of aerogels is that they are obtained by supercritical drying of wet gels yielding solid porous structures, wherein the liquid is replaced by air with minimal damage of the gel backbone ${ }^{2}$. Among various possible gels, biopolymer-based ones are of special interest due to good compatibility with human tissues ${ }^{3}$.

In the context of drug delivery, remarkable features of the biopolymer-based aerogels are: (i) high specific surface area allows to carry significant amount of the confined drug ${ }^{4}$; (ii) drug can be stabilized in the amorphous state with high stability towards recrystallization ${ }^{4-6}$; (iii) aerogel backbone is as chemically stable as original biopolymer; (iv) modulated drug release profile ${ }^{7,8}$; (v) compatibility with subsequent formulation steps such as tableting and coating 9,10. Additionally, biopolymers are ones of the most abundant renewable resources on earth representing a sustainable advantage compare to synthetic polymers ${ }^{3,8,11}$.

To the best of our knowledge, the usage of biopolymer aerogels as vehicles for mucosal targeted drug delivery remains largely unexplored. Biopolymer-based aerogels with mucoadhesive properties are of special interest for pharmaceutical applications as they can be designed for administration through various mucosal delivery routes (nasal, buccal, intestinal, vaginal). This paper presents a first attempt towards aerogel microparticles for mucosal drug delivery. Three polysaccharides, namely, alginate (with known mucoadhesive properties), pectin and $\mathrm{k}$-carrageenan are chosen for this study. 
Alginate is a natural linear anionic polysaccharide found in the cell wall of brown algae and widely used in food and pharmaceutical industries. Chemically, alginate is constituted by 1,4 -linked- $\beta$-D-mannuronic acid (M) and $\alpha$-L-guluronic acid (G) residues, generally composed by consecutive $\mathrm{G}$ residues, $\mathrm{M}$ residues or alternating MG residues. Electrostatic interactions between G-residues and polyvalent cations in aqueous media lead to formation of hydrogels ${ }^{12,13}$. Furthermore, alginate has good mucoadhesive properties, thus, if used as a part of a formulation, increases the residence time in the mucosa and therefore the absorbance of drugs ${ }^{14}$. Heat and freeze dried alginate gels lacks mesoporosity, whereas sc-dried ones (aerogels) possess large specific surface area and pore volume, up to $545 \mathrm{~m}^{2} \mathrm{~g}^{-1}$ and $7 \mathrm{~cm}^{3} \mathrm{~g}^{-}$ 1 , respectively ${ }^{15,16}$. Alginate aerogels are known in the literature in various forms such as monoliths, beads and microparticles ${ }^{8,17-19}$. We focus here on microparticulate alginate aerogels as they can be designed for administration through various mucosal delivery routes (nasal, buccal, intestinal, vaginal, etc). One conventional route towards alginate microparticles is the emulsion gelation ${ }^{17}$. The aim of the present work was two-fold. First, to further develop the emulsion gelation method and adopt it to the production of hybrid microparticles $(<50 \mu \mathrm{m})$ composed of alginate and a second biopolymer. Second, to assess mucoadhesive properties of original particles, and further load it with two model drugs, ketoprofen and quercetin, evaluating its drug load and release. Low methoxyl pectin and $\mathrm{k}$-carrageenan were chosen as second biopolymers for blending with alginate and processed into microparticles through internal gelation combined with emulsion gelation. Pectin is a cell wall structural carbohydrate present in higher plants. Similar to alginate, low methoxyl pectin forms a gel in the presence of divalent cations such as $\mathrm{Ca}^{2+11,20,21}$. Since pectin is resistant to the enzymes present in the upper gastrointestinal tract, being only degraded by colonic microflora, it is designed for colon specific drug delivery systems ${ }^{20,22}$. Moreover, pectin has many hydrogen bond forming groups allowing interaction with biological mucus ${ }^{23,24}$. K- 
Carrageenan is a natural linear sulphated carbohydrate extracted from red edible seaweeds. It is being increasingly investigated as a gelling agent/viscosity enhancing agent for controlled release DDS with prolonged retention ${ }^{11,25,26}$. K-carrageenan exhibits gelation in the presence of mono- and divalent cations and possesses antioxidant properties $12,27,28$. The best carrier system was further loaded with amidated kyotorphin (KTP-NH2; L-Tyr-L-Arg-NH2), which is a neuropeptide involved in pain regulation ${ }^{29}$.

\section{Experimental section}

\subsection{Materials}

Alginic acid sodium salt was purchased from Panreac Applichem (Germany). Low methoxyl pectin and k-carrageenan were kindly donated by Disproquima (Portugal) and FMC Biopolymer (Norway). Calcium carbonate was kindly provided by Magnesia GmbH (Germany). Sorbitan monooleate (Span 80) and polyoxyethylene sorbitan monooleate (Tween 80) were purchased from Merck (Germany). Polyglycerol polyricinoleate 4150 (PGPR) was provided by Palsgaard (Denmark). Paraffin oil, n-hexane and acetic acid ( $\geq 99.8 \%$ ) were purchased from Carl Roth GmbH (Germany). Anhydrous ethanol (99.9\%) was purchased from H. Möller GmbH \& Co.KG. Carbon dioxide (>99.9 mol\% purity) was supplied by AGA Gas GmbH (Germany). Quercetin ( $\geq 95 \%$ ) and mucin from porcine stomach (type II) were purchased from Sigma-Aldrich (Steinheim, Germany). Racemic mixture of ketoprofen was kindly provided by Chemische Fabrik Kreussler \& Co. GmbH (Germany). Amidated kyotorphin was kindly provided by Instituto de Medicina Molecular (iMM LIsboa). Chemicals used for antioxidant activity assay were 2',2'azobis (2-amidinopropane) dihydrochloride (AAPH) and 6-hydroxy-2,5,7,8tetramethylchroman-2-carboxylic acid (Trolox) from Sigma-Aldrich (St Quentin Fallavier, France) and disodium fluorescein (TCl Europe, Antwerp, Belgium). Salts 
used for phosphate buffer solution (PBS) preparation (sodium chloride, potassium chloride and monopotassium phosphate) were from Sigma-Aldrich (St Quentin Fallavier, France) and disodium hydrogen phosphate dihydrate from Riedel-deHaën (Seelze, Germany). All chemicals were used without further purification.

3.2. Production of hybrid alginate-based gel microparticles by emulsion gelation method

Alginate and hybrid alginate-based gel microparticles were prepared by the emulsion gelation combined with internal setting method (Figure 1).

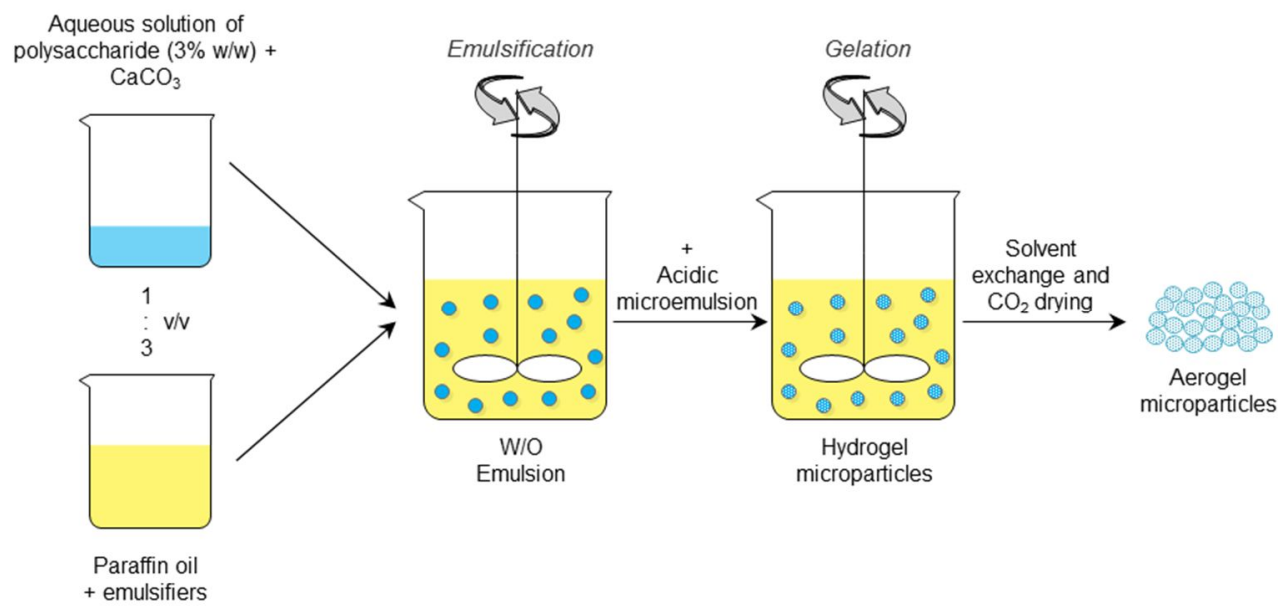

Figure 1| Process scheme used for the production of alginate-based aerogel microparticles

Calcium carbonate was mixed with aqueous solution of sodium alginate or sodium alginate/second biopolymer (pectin or K-carrageenan, 1:1 w/w, overall biopolymer concentration 3 wt\%) using an Ultra-Turrax homogenizer (Ika Werke, Germany). $\mathrm{CaCO}_{3}$ /alginate ratio of 0.365:1 (w/w) was kept throughout the study. Continuous phase was produced by mixing paraffin oil and a specific surfactant or mixture of surfactants with desirable HLB value (overall emulsifier concentration was 3 wt\%). PGPR, Span 80 and Tween 80 were chosen in this study as surfactants as they commonly used in the food industry and pharmaceutical industry ${ }^{30}$. To achieve HLB 
values between 1.5 and 4.3, a mixture of PGPR and Span 80 was used. Span 80 and Tween 80 were dissolved in paraffin oil to obtain HLB 5. The weight ratio of each surfactant was calculated according to the following equation (1):

$$
H L B_{\text {mix }}=w_{1} \times H L B_{1}+w_{2} \times H L B_{2}
$$

where $H L B_{\text {mix }}$ is the desirable HLB value, and $w_{1}, w_{2}, H L B_{1}$ and $H L B_{2}$ are mass fractions and HLB values of the individual surfactants, respectively. The continuous phase with a desired HLB was then added to the polysaccharide $/ \mathrm{CaCO}_{3}$ suspension to form a w/o emulsion (1:3, v/v). Emulsification was performed using a high speed homogenizer Ultra-Turrax for a total time of $100 \mathrm{sec}$ divided into three homogenization steps of 20 sec each with two breaks of $20 \mathrm{sec}$ in between. Then, freshly prepared microemulsion of acetic acid was added into the biopolymer/oil emulsion and stirred by a turbine stirrer $(1000 \mathrm{rpm})$ for 1 minute. The microemulsion containing acetic acid, paraffin oil and surfactants (Tween 80 and Span 80 ) was prepared following results by Porras et al. ${ }^{31}$ (Table 1 ).

Table 2| Compositions of mixtures for microparticle preparation

\begin{tabular}{cr} 
Mixture & Components and mass ratio, $\boldsymbol{w} / \boldsymbol{w}$ \\
\hline $\begin{array}{c}\text { Discontinuous phase: } \\
\text { aqueous solution of } \\
\text { polysaccharide }\end{array}$ & sodium alginate and water: $3: 97$ \\
Continuous phase: & $\begin{array}{c}\text { sodium alginate, pectin and water: } 1.5: 1.5: 97 \\
\text { paraffin oil }\end{array}$ \\
\hline sicroemulsion & Paraffin oil and surfactant mixture (eqn (1)): $97: 3$ \\
\hline
\end{tabular}

After $1 \mathrm{~h}$ of stirring (200 rpm), the suspension of gel microparticles was left on the bench overnight to complete the gelation. Oil phase was removed by decantation 
upon centrifugation (4500 rpm, $30 \mathrm{~min}$ ). Hexane was added to the suspension in order to dissolve the remaining oil and reduce its viscosity. The mixture was shaken, centrifuged (3000 rpm, $20 \mathrm{~min}$ ) and hexane was decanted. For the solvent exchange, remaining suspension was rinsed with ethanol/water mixtures $(30,60$, 90 and 100 vol.\%) followed by centrifugation (3000 rpm, $20 \mathrm{~min}$ ) and decantation of the supernatant. To ensure water removal, the last step of the solvent exchange was repeated twice or thrice to guarantee ethanol concentration higher than $98 \mathrm{wt} \%$. The ethanol concentration was measured by a densimeter DMA 4500 (Anton Paar, Austria). The resulting alcogel microparticles were placed into a filter bag soaked in pure ethanol and subjected to supercritical drying.

\subsection{Supercritical drying of gel microparticles}

The resulting gel microparticles were dried by extraction of ethanol with a continuous flow of supercritical $\mathrm{CO}_{2}$ using a high pressure autoclave described elsewhere and presented in figure $2^{32}$.

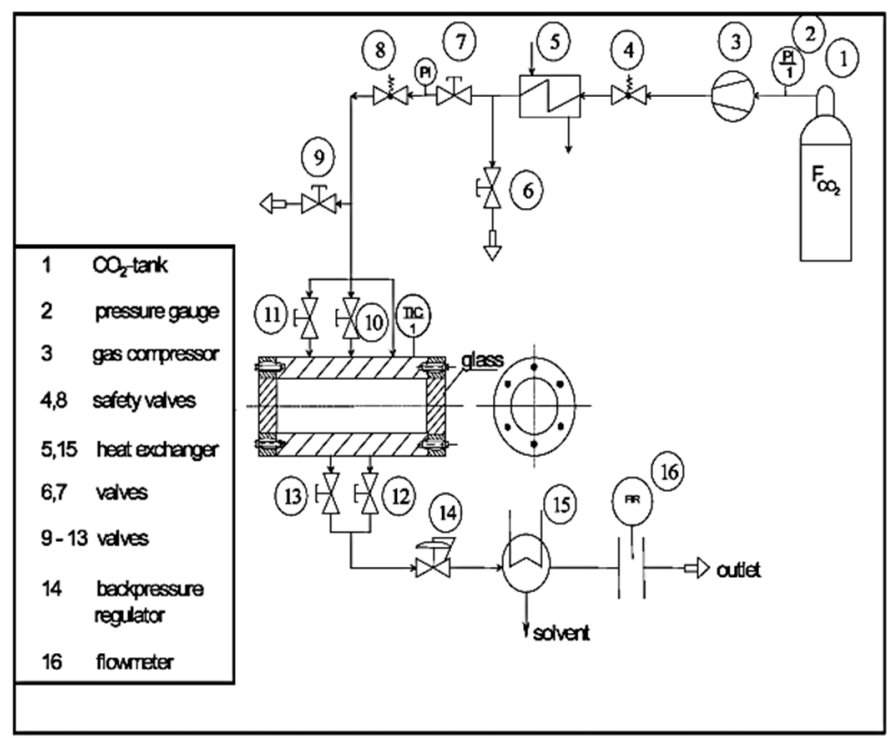

Figure 2| Flow sheet of supercritical drying apparatus 
Briefly, filter paper bags containing the samples were placed into a high pressure autoclave $(250 \mathrm{~mL})$ and covered with ethanol in order to prevent premature solvent evaporation. The autoclave was sealed and preheated to $313 \mathrm{~K}$. Preheated carbon dioxide ( $313 \mathrm{~K}$ ) was supplied into the autoclave until the desired working pressure (12 MPa) was achieved. Then, the outlet valve was adjusted to achieve carbon dioxide flow rate through the autoclave of $c a .40 \mathrm{~g} \mathrm{~min}^{-1}$. The outgoing flow was directed into a separator to split the fluid into ethanol and gaseous $\mathrm{CO}_{2}$. The drying lasted for $4 \mathrm{~h}$, then the autoclave was slowly depressurized $\left(0.5 \mathrm{MPa} \mathrm{min}{ }^{-1}\right)$ and the samples were collected.

\section{4. $\quad$ Drug Loading}

Three methods for drug loading are used in this work. Depending on the solubility of the pharmaceutical agents (ketoprofen, quercetin and amidated kyotorphin) the adsorption process took place in supercritical carbon dioxide (ketoprofen), in ethanol at the last solvent exchange step (quercetin) or in aqueous phase prior to the gelation step (amidated kyotorphin).

\subsubsection{Adsorption of ketoprofen from sc- $-\mathrm{CO}_{2}$}

Adsorption of ketoprofen was performed by exposing aerogel microparticles to the saturated solution of the drug in $\mathrm{sc}-\mathrm{CO}_{2}$. Aerogel microparticles and crystalline ketoprofen ( $0.2 \mathrm{~g}$ each) were placed into separate filter paper cartridges. This prevents contact between the parcels before heating and pressurization of the system. The cartridges were placed into two stainless steel autoclaves equipped with magnetic bars described elsewhere ${ }^{18}$. The autoclaves were heated by a heating jacket to a certain temperature $(313 \pm 1 \mathrm{~K})$ and then slowly pressurized. The system was kept at constant pressure (18 $\mathrm{MPa})$, temperature and stirring rate of $250 \mathrm{rpm}$. The pressure was monitored in-line with accuracy of $0.01 \mathrm{MPa}$. Constant 
temperature was maintained during the process. After $24 \mathrm{~h}$, depressurization of the system was carried out slowly to maintain constant temperature and to avoid the formation of a liquid phase.

\subsubsection{Quercetin adsorption from ethanolic phase and by supercritical} antisolvent precipitation

Due to the low solubility of quercetin in $\mathrm{sc}-\mathrm{CO}_{2}$, adsorption was performed during the final solvent exchange step. Gel microparticles were exposed overnight to the saturated solution of quercetin in ethanol. Subsequent drying step was performed in the same manner as described above. Upon contact with $\mathrm{sc}-\mathrm{CO}_{2}$ quercetin precipitates in the aerogel matrices due to anti-solvent properties of the sc-fluid. The low solubility of quercetin in $\mathrm{CO}_{2}$ also eliminates its leaching during the supercritical drying step ${ }^{33}$.

\subsubsection{Amidated kyotorphin adsorption from aqueous phase}

Due to the low solubility of amidated kyotorphin in ethanol and $\mathrm{sc}-\mathrm{CO}_{2}$, adsorption of peptide was performed in aqueous phase, before the gelation step occurs. Thus, the peptide was added to alginate-pectin aqueous solution (4\% KTP-NH2 loading), which was further mixed with calcium carbonate and emulsified with the oil phase (HLB 5), proceeding the protocol as mentioned before. Since neuropeptides are not only expensive but also bioactive at low concentrations, the process was scaled down so do not spend a lot of peptide. Therefore, two approaches were performed in order to start with $0.5 \mathrm{~g}$ of mixture of polysaccharides: to maintain the volume of continuous and discontinuous phases of emulsion $(100 \mathrm{~g})$ and reduce the overall biopolymer concentration to $0.5 \mathrm{wt} \%$, or to maintain overall biopolymer concentration at $3 \mathrm{wt} \%$ and reduce the final emulsion volume (16.6g). 
Chapter 4

\subsection{Aerogel microparticles characterization}

3.5.1. Particle size distribution morphology and textural properties Particle size distribution (PSD) of alcogel microparticles was measured by laser diffraction spectrometry (Beckman Coulter LS1332) using obscuration values of 9 11 vol.\%. PSD of aerogels was measured with a laser diffractometer (Mastersizer 2000, Malvern Instruments) equipped with a Scirocco 2000 dry disperser (Malvern Instruments). Particle size measurements are reported as volume distribution. Average diameter (D50) is reported as the result of two consecutive measurements. Particle morphology were analysed by SEM using a Leo 1530 microscope (Carl Zeiss, Germany) at accelerating voltage of $5 \mathrm{kV}$ and working distances in the range of 4 to $6 \mathrm{~mm}$. Before analysis, aerogel microparticles were sputtered with gold $(7 \mathrm{~nm})$. Specific surface area and pore volume were determined by low temperature nitrogen adsorption-desorption analysis (Quantachrome Nova 3000e) using Brunauer-Emmett-Teller (BET) and Barrett-Joyner-Halenda (BJH) methods, respectively. Prior to the measurements, the samples were degassed at $348 \mathrm{~K}$ for $24 \mathrm{~h}$.

\subsubsection{Mucoadhesive properties - turbidimetric measurement}

Mucoadhesive properties of the aerogels were evaluated by measuring its interaction with mucin through a turbidimetric method ${ }^{34}$. Aerogel microparticles and mucin (porcine stomach) were dispersed in distilled water $(2 \mathrm{mg} / \mathrm{mL})$ and filtered. Different ratios of mucin and microparticles aqueous solutions (3:1; 9:1, $\mathrm{v} / \mathrm{v}$ ) were mixed and incubated during $1 \mathrm{~h}$ at $310 \mathrm{~K}$. The absorbances of the mixtures mucin/aerogel $\left(\boldsymbol{A}_{\text {exp }}\right)$ were recorded at $500 \mathrm{~nm}$ with a UV-Visible spectrophotometer (UV-Vis Genesys10uv spectrometer, Thermo Spectronic). The absorbances of the individual mucin $\left(\boldsymbol{A}_{\text {mucin }}\right)$ and individual aerogel samples 
$\left(\boldsymbol{A}_{\text {aerogel }}\right)$ were also determined to calculate the theoretical absorbance $\left(\boldsymbol{A}_{\text {theor }}\right)$ for a non-interacting system using equation (2):

$$
A_{\text {theor }}=\left(A_{\text {mucin }} \times P_{\text {mucin }}\right)+\left(A_{\text {aerogel }} \times P_{\text {aerogel }}\right)
$$

where $\boldsymbol{P}_{\text {mucin }}$ and $\boldsymbol{P}_{\text {aerogel }}$ are the proportion of the compounds in the mixture. The absorbance difference $(\boldsymbol{\Delta A})$ between $\boldsymbol{A}_{\boldsymbol{e x p}}$ and $\boldsymbol{A}_{\text {theor }}$ is a measure of the mucoadhesion strength. All samples were analysed in duplicate.

\subsubsection{Determination of drug loading}

The quantification of ketoprofen and quercetin loaded in the aerogel microparticles was determined by UV spectrophotometry. Drug-loaded aerogel microparticles ( 25 $\mathrm{mg}$ ) were dispersed in a known volume of ethanol (sink conditions), sonicated for $30 \mathrm{~min}$ and additionally shaken for $10 \mathrm{~min}$ in an overhead shaker to ensure maximum dissolution of the drug. Centrifugation for $5 \mathrm{~min}$ at $3000 \mathrm{rpm}$ was applied to separate the liquid extract from the aerogel microparticles. The absorbances of the resulting solutions were analysed at 260 and $374 \mathrm{~nm}$ for ketoprofen and quercetin, respectively, in an Evolution 300 UV-Vis spectrophotometer (Thermo Fischer Scientific, USA). Calibration was obtained by using standard samples with concentrations between 2 and $14 \mu \mathrm{gL}^{-1}$ for ketoprofen and between 2 and $12 \mu \mathrm{gL}^{-1}$ for quercetin. Each analysis was performed in duplicate. Results are expressed as gram of the drug per gram of the original aerogel.

The quantification of amidated kyotorphin loaded in the aerogel microparticles was performed by reverse phase HPLC with fluorescence detection (HPLC-FLU) using an excitation wavelength of $275 \mathrm{~nm}$ and an emission wavelength of $303 \mathrm{~nm}$. The injection volume was $10 \mu \mathrm{L}$. A C18 column (Gemini, Phenomenex) $150 \mathrm{~mm}, 4.60$ $\mathrm{mm}, 5 \mu \mathrm{m}$ was used at $30^{\circ} \mathrm{C}$ with a linear gradient from (A) water/TFA (99.9:0.1, $\mathrm{V} / \mathrm{V})$, to $(\mathrm{B})$ acetonitrile/water/TFA (90:9.9:0.1, V/V) at $1 \mathrm{~mL} / \mathrm{min}$. The program 
started at $90 \% \mathrm{~A}$ and was graded to $82.5 \% \mathrm{~A}$ during three min and finally to $0 \% \mathrm{~A}$ during ten min. The retention time of KTP-NH2 was 2.6 min.

\subsubsection{Thermal behaviour}

Differential Scanning Calorimetry (DSC) measurements were carried out on a DSC TA instruments Q200 (module MDSC) with the aim of studying the thermal behaviour of the aerogel microparticles unloaded and loaded with ketoprofen and quercetin. The samples were placed in an aluminium pan and sealed; the probes were heated from 273 to $623 \mathrm{~K}$ at a rate of $10 \mathrm{~K} \mathrm{~min}^{-1}$ under nitrogen atmosphere.

3.5.5. Antioxidant activity of quercetin-loaded aerogel by ORAC method Oxygen radical absorbance capacity (ORAC) assay was carried out by a modified method for the FL800 microplate fluorescence reader (Bio-Tek Instruments, Winooski, VT, USA), as described by Serra and co-authors ${ }^{35}$.This assay measures the ability of the antioxidant species in the sample to inhibit the oxidation of disodium fluorescein (FL) catalyzed by peroxyl radicals generated from AAPH (2,2'azobis-2-methyl-propanimidamide, dihydrochloride). A suspension was prepared by adding an amount of quercetin-loaded aerogel microparticles in ethanol, sonicated for $30 \mathrm{~min}$ and additionally vortexed to ensure maximum dissolution of quercetin. Centrifugation for $5 \mathrm{~min}$ at $3000 \mathrm{rpm}$ was applied to separate the liquid extract from the aerogel microparticles, being the supernatant used for further analysis. The results were presented as Trolox equivalent (TE) per gram of quercetin. Each assay was performed in triplicated.

\subsubsection{In vitro evaluation of drug release kinetics}

A sample of aerogel microparticles was suspended in $50 \mathrm{~mL}$ of dissolution medium (PBS, pH 6.8). Samples were stirred at $155 \mathrm{rpm}$ and maintained at $310 \mathrm{~K}$ (temperature controller) ${ }^{36}$. Aliquots $(2 \mathrm{~mL})$ were withdrawn at predetermined time 
intervals $(5,15,30$ and $60 \mathrm{~min})$ and the same volume of fresh medium was added to the suspension. Quercetin-loaded samples were filtered and diluted in a mixture of phosphate buffer solution/acetone $(2: 1, v / v)$ in order to avoid possible precipitation of solubilized quercetin as a result of temperature reduction ${ }^{37}$. Samples containing ketoprofen were diluted only with PBS. Drug concentration was determined using a UV spectrophotometer (UV-Vis Genesys10uv spectrometer; Thermo Spectronic) at 258 and $376 \mathrm{~nm}$ for ketoprofen and quercetin, respectively. Calibration was obtained by using standard samples with concentrations between 2 and $14 \mu \mathrm{g} \mathrm{mL} L^{-1}$ for ketoprofen (solution in PBS) and between 0.5 and $12 \mu \mathrm{gL}^{-1}$ for quercetin (PBS/acetone, 2:1 v/v). Each analysis was performed in triplicate.

\subsection{Statistical analysis}

All data are expressed as means \pm standard errors (SD) and individual experiments were performed at least in triplicate. The statistical analysis was done using SigmaStat $3.0^{\circledR}$ software. All values were tested for normal distribution and equal variance. When homogeneous variances were confirmed, data were analyzed by One Way Analysis of Variance (ANOVA) coupled with the Tukey's post-hoc analysis to identify means with significant differences $(p<0.001$ was considered significant).

\section{Results and discussion}

\subsection{Emulsion gelation: effect of the composition and HLB}

Preparation of aerogel consists of three consecutive steps. In the first step, condensation or gelation of a precursor yields the gel. As this step often takes place in aqueous media, water has to be extracted by an organic solvent, such as ethanol, that is miscible with $\mathrm{sc}-\mathrm{CO}_{2}$. Finally, the organic solvent is extracted by $\mathrm{sc}-\mathrm{CO}_{2}$ 
leaving behind a solid structure that greatly resembles original wet gel. Preparation of aerogel microparticles requires an extra step. The most studied approach is so called emulsion gelation, wherein the precursor is first emulsified in an oil phase. Obtained macroemulsions are often thermodynamically unstable, so contentious energy input and the use of surfactants are necessary. Gelation in the emulsion droplets is triggered by adding a catalyst or heating/cooling. Once droplets turned into gel particles, the energy input should be significantly lowered in order not to damage soft gel particles. Due to this circumstance, uniform distribution of the gelation trigger within the oil phase can minimize possible agglomeration phenomena and ensure fast gelation kinetics ${ }^{38,39}$. In order to be readily available for the reaction on the droplet surface the gelation trigger should preferably be dissolved in the continuous phase but not dispersed.

To the best of our knowledge, only few works have used soluble gelation triggers for the preparation of alginate particles ${ }^{39-41}$. In a typical procedure alginate aqueous solution is mixed with a suspension of insoluble calcium salt (e.g. carbonate or citrate). The mixture is then dispersed in canola oil and homogenized. Once stable emulsion is obtained, glacial acetic acid dissolved in a small portion of canola oil is added to the emulsion with continued agitation. This liberates $\mathrm{Ca} 2+$ for gelation of the alginate polyanions. The resulting particles possess relatively large sizes of few hundred microns.

In this work we further develop this approach aiming at the preparation of microparticles (tens of microns). Preference is given paraffin oil as continuous phase due to its higher oxidative stability. However, solubility of acetic acid in mineral oil is limited ${ }^{42}$. Our preliminary experiments revealed that addition of acetic acid is a crucial step for minimizing the particle agglomeration, in agreement with above cited works ${ }^{38,39}$. To avoid formation of large droplets of acetic acid which can imbibe many finer biopolymer droplets, acetic acid was introduced in the form of microemulsion. The composition of the microemulsion was preliminarily 
optimized to obtain homogeneous and visibly clear mixture, which was added to the biopolymer emulsion (Table 1). Overall experimental procedure is shown in Fig. 1. Thereby, we suppose that the PSD of the gel is mainly determined by the PSD of the parent emulsion and thus the latter has to be stable to prevent droplet coalescence prior the reaction with acid. Among other factors, nature of surfactants plays a major role in the kinetic stability of emulsions. We studied the influence of HLB on the particle size distribution of the wet gels and dried aerogels.

\subsubsection{Particle size and particle size distribution}

Emulsion gelation at HLB 1.5 led to multimodal particle size distribution in the range of $1-1000 \mu \mathrm{m}$ for both alginate/pectin and alginate/k-carrageenan blends indicating high degree of agglomeration (Fig. 3a, c). 
a)

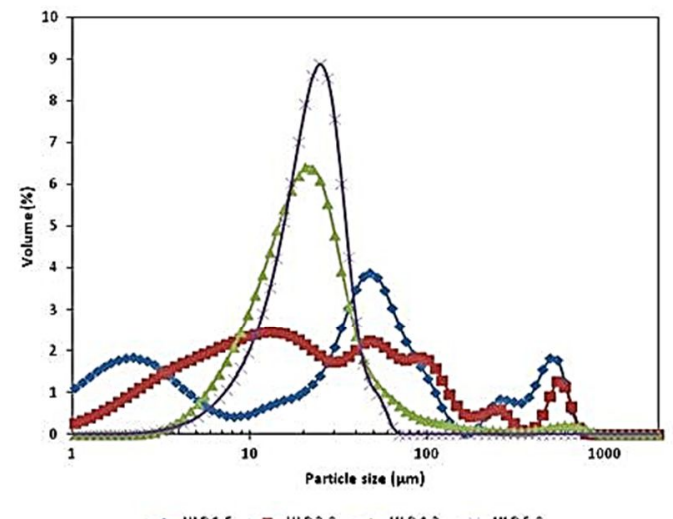

C)

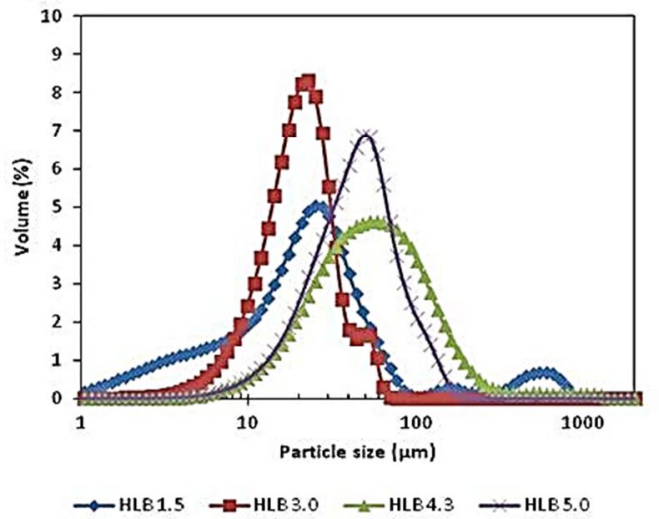

b)

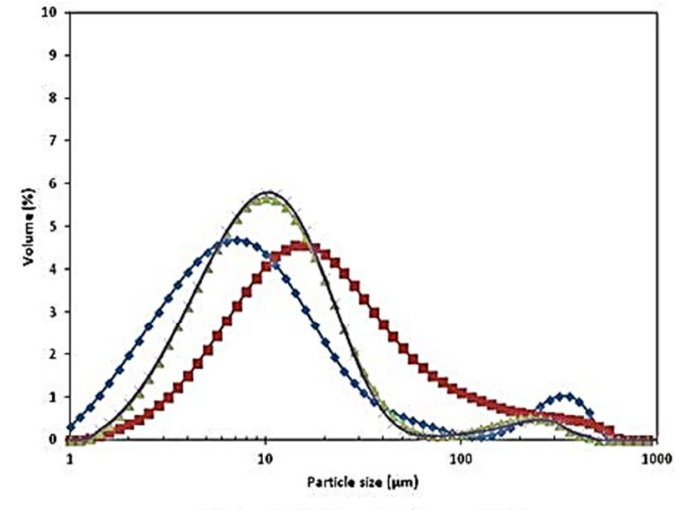

d)

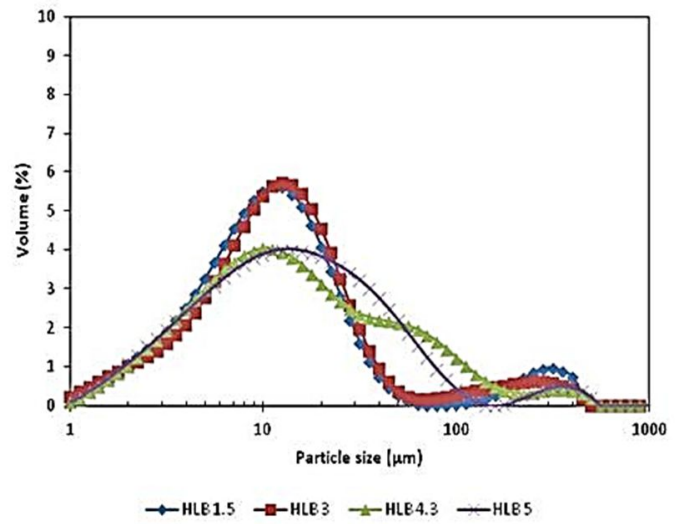

Figure 3| Particle size distribution of gel (in ethanol) and aerogel microparticles produced by emulsion gelation at different HLB values: a) alginate/pectin gel microparticles; b) alginate/pectin aerogels; c) alginate/ $\mathrm{k}$-carrageenan gel microparticles; $\mathrm{d}$ ) alginate/ $\mathrm{k}$-carrageenan aerogels

Similar phenomenon was observed for alginate/pectin at HLB 3 whereas alginate/Kcarrageenan demonstrated much narrower though bimodal distribution. For higher HLB values 4.3 and 5.0, almost no agglomeration was seen. Emulsion gelation at HLB 5.0 delivered in both cases narrower particle size distribution compared to HLB 4.3. Preliminary tests also suggested that surfactants with higher HLBs lead to much less stable emulsions with higher particle size of the discontinuous phase. This is in 
agreement with basic work by Boyd et al. ${ }^{43}$ wherein HLB range of $2.0-6.5$ is suggested for the preparation of stable water-in-paraffin oil emulsions.

Obtained gel microspheres were washed with hexane, grades of ethanol to substitute water and subjected to supercritical drying. Aerogel particles possessed smaller sizes than corresponding wet particles as can be seen in Fig. $3 b, d$. The shrinkage is most likely happened during the solvent exchange ${ }^{15}$. Alginate/pectin aerogels prepared at HLB 1.5 and 3.0 had broad PSD whereas HLB 4.3 and 5.0 gave nearly identical result with less pronounced agglomeration and $D_{50}$ of $9.2-9.4 \mu \mathrm{m}$ (Table 2).

Table 2| Properties of alginate-based aerogel microparticles

\begin{tabular}{|c|c|c|c|c|c|}
\hline Sample & $H L B$ & $\begin{array}{c}\text { Particle diameter, } \\
\qquad D_{50}, \mu \mathrm{m}\end{array}$ & $\begin{array}{l}\text { BET surface } \\
\text { area, } m^{2} g^{-1}\end{array}$ & $\begin{array}{c}\text { BJH pore } \\
\text { volume, } \mathrm{cm}^{3} \mathrm{~g}^{-1}\end{array}$ & $\begin{array}{c}C \\
\text { value }\end{array}$ \\
\hline Alginate & 5.0 & 23.0 & 330 & 1.7 & 208 \\
\hline \multirow{4}{*}{ Alginate/pectin } & 1.5 & 7.2 & 388 & 5.0 & 139 \\
\hline & 3.0 & 16.7 & 548 & 5.9 & 97 \\
\hline & 4.3 & 9.4 & 380 & 3.9 & 209 \\
\hline & 5.0 & 9.2 & 476 & 4.5 & 86 \\
\hline \multirow{4}{*}{$\begin{array}{l}\text { Alginate/K- } \\
\text { carrageenan }\end{array}$} & 1.5 & 10.1 & 415 & 3.6 & 184 \\
\hline & 3.0 & 11.1 & 383 & 3.2 & 125 \\
\hline & 4.3 & 12.4 & 370 & 3.1 & 425 \\
\hline & 5.0 & 12.7 & 406 & 3.7 & 119 \\
\hline
\end{tabular}

HLB - Hydrophilic-Lipophilic balance; BET - Brunauer-Emmett-Telle; BJH - Barrett-Joyner-Halenda

Alginate/k-carrageenan aerogel microparticles show similar $D_{50}$ values across all HLB values. In this case, oppositely to alginate/pectin, more lipophilic surfactants imparted sharper PSDs (Fig. 3d). Shrinkage seems to be more pronounced for alginate/k-carrageenan resulting in decrease of the $D_{50}$ from $45 \mu \mathrm{m}$ (alcogel) to 12.7 $\mu \mathrm{m}$ (aerogel), Table 2 (HLB 5). Higher flexibility of the $\mathrm{k}$-carrageenan chains may be a plausible explanation for this finding ${ }^{12}$. 
It is interesting to note that aerogel microparticles produced from pure alginate at HLB 5 were larger, with the $D_{50}$ of $23 \mu \mathrm{m}$. This finding highlights the influence of the biopolymer on the outcome of the emulsification process. It is of note that PSD of the wet gels and aerogels may be biased due to formation of weak aggregates. In the dry state these aggregates seem to be weakly bound and can be destroyed during the sieving through a $112 \mu \mathrm{m}$ sieve.

\subsubsection{Morphology and textural properties}

SEM images of the alginate-based hybrid aerogel microparticles showed no macroporosity (Figure 4).
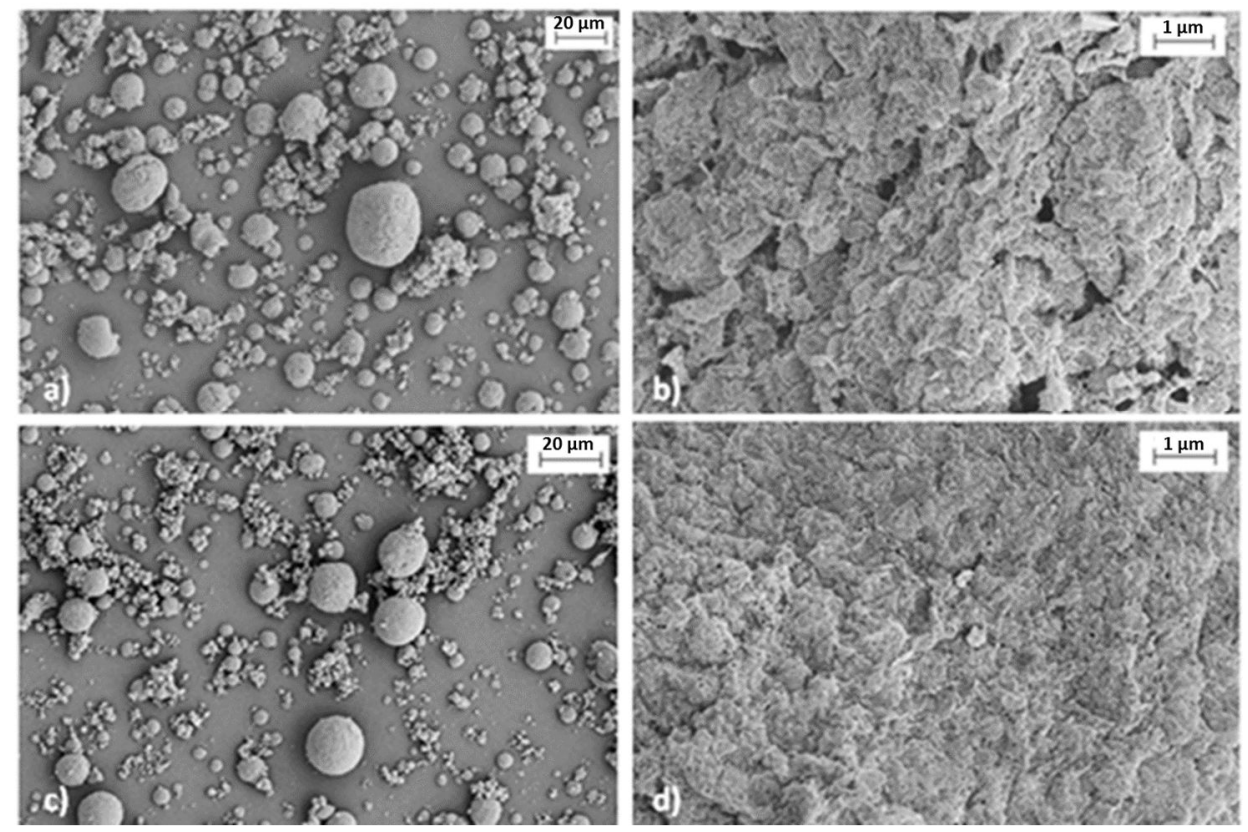

Figure $4 \mid$ SEM micrographs of aerogel microparticles prepared at HLB 5: alginate/pectin $(a, b)$; alginate/k-carrageenan (c, d)

All alginate-based aerogel microparticles present large specific surface area (330 $\left.548 \mathrm{~m}^{2} \mathrm{~g}^{-1}\right)$ and BJH pore volume $\left(1.7-5.9 \mathrm{~cm}^{3} \mathrm{~g}^{-1}\right)$, shown in Table 2 , measured by Brunauer-Emmett-Teller and Barrett-Joyner-Halenda methods, respectively. 
These values are typical for aerogels produced from other biopolymers such as chitosan, pectin, cellulose ${ }^{15}$ and comparable with alginate-based hybrids ${ }^{44-46}$. Neither surface area $\left(\mathrm{S}_{\mathrm{BET}}\right)$ nor pore volume $\left(\mathrm{V}_{\mathrm{BJH}}\right)$ demonstrate a clear dependence on HLB. More detailed study is needed to find out an interrelation between the process parameters and these quantities. An evidence that such interrelation exists is that the variability of both $\mathrm{S}_{\mathrm{BET}}$ and $\mathrm{V}_{\mathrm{BJH}}$ for each hybrid (HLB $=1.5-5.0$ ) is higher than one would expect for BET and BJH methods ${ }^{47}$. The $\mathrm{C}$ constant in Table 2 is a parameter, obtained from the adsorption branch of the BET isotherm and calculated as the ratio between the adsorption enthalpies of the first $\left(E_{1}\right)$ and second and further layers $\left(E_{2}\right)^{47}$ :

$$
\ln C=\left(E_{1}-E_{2}\right) / R T
$$

The larger the $\mathrm{C}$ constant the more hydrophilic the surface is expected to be and can be viewed as a rough measure of surface polarity. For both alginate/pectin and alginate/K-carrageenan aerogels, the $C$ values follow the same trend showing the maximum at HLB 4.3. As surfactants employed may be present to small extent in water phase, they may form inclusion complexes or disrupt inter-chain interactions ${ }^{48}$ so that the surface of the resulting gel and further aerogel is affected.

To conclude, results presented in Sections 4.1.1 and 4.1.2 show that hybrid aerogel microparticles possess higher surface area and pore volume compare to alginate aerogel. Blending with second biopolymer results in the decrease of the particle diameter $D_{50}$ approximately by a factor of 2 . Based on these results, alginate and hybrid aerogel microspheres produced at HLB 5 were chosen for further analysis.

\subsection{Mucoadhesive properties}

Mucoadhesion is the ability of materials to adhere to mucous membranes in the human body and consequently provide a temporary retention. Usually, mucoadhesive materials are hydrophilic macromolecules containing charged 
groups and/or non-ionic functional groups capable of forming hydrogen bonds with mucosal surfaces. In this work, mucoadhesion strength between aerogel and mucin was studied by a turbidimetric assay and represented as the absorbance difference $(\Delta A)$. In case $\Delta A$ is higher than zero, an interaction occurs between the polysaccharide matrix and mucin. In contrast, $\Delta \mathrm{A} \leq 0$ indicates that no interaction occurs between the microparticles and mucin ${ }^{34}$. Results of turbidimetric results are presented in Table 3.

Table 3|Turbidimetric measurement of the mucoadhesion between aerogels and mucin

\begin{tabular}{cccc}
\hline Aerogel & Alginate & Alginate/pectin & $\begin{array}{c}\text { Alginate/K- } \\
\text { carrageenan }\end{array}$ \\
\hline \multicolumn{4}{c}{ mucin/aerogel ratio 3:1 (v/v) } \\
\hline$A_{\text {exp }}$ & $0.513 \pm 0.003$ & $0.432 \pm 0.004$ & $0.482 \pm 0.002$ \\
$A_{\text {theor }}$ & 0.444 & 0.406 & 0.463 \\
$\Delta A$ & $0.069 \pm 0.003$ & $0.026 \pm 0.004$ & $0.020 \pm 0.002$ \\
\hline \multicolumn{4}{c}{ mucin/aerogel ratio 9:1 (v/v) } \\
\hline$A_{\text {exp }}$ & $0.564 \pm 0.004$ & $0.500 \pm 0.004$ & $0.523 \pm 0.003$ \\
$A_{\text {theor }}$ & 0.475 & 0.459 & 0.482 \\
$\Delta A$ & $0.089 \pm 0.004$ & $0.041 \pm 0.004$ & $0.041 \pm 0.003$ \\
\hline
\end{tabular}

Mucoadhesion properties of polyanions, especially polymers containing carboxylic groups with a high charge density, are reported in the literature ${ }^{14}$. Results suggest that all aerogel microparticles present absorbance differences higher than zero and thus demonstrate mucoadhesion properties. Aerogel microparticles containing only alginate have higher $\Delta \mathrm{A}$ compare to hybrids. Mucoadhesion strength is found to change in a similar manner with a change in the $C$ constant (Table 2). Lower $C$ constants of the hybrids may be interpreted as lower surface concentration of $\mathrm{OH}$ and free $\mathrm{COOH}$-groups that in its turn diminishes the mucoadhesion ${ }^{49}$. Despite of the decrease of $\Delta \mathrm{A}$ verified in the hybrid aerogels, mucoadhesion strength is in the range of what is reported in literature for the application as adhesive drug delivery 
systems $(\Delta \mathrm{A}>0){ }^{50,51}$. In all cases, as the mucin/aerogel ratio increased so as increased the absorbance difference and hence the mucoadhesive strength, as already reported by other authors ${ }^{34}$.

\subsection{Drug-loaded alginate-based aerogel microparticles}

Thanks to large specific surface, aerogels can be loaded with a drug by adsorption or precipitation from a solution in $\mathrm{sc}-\mathrm{CO}_{2}$ as a consecutive step of the sc-drying. For drugs practically insoluble in sc- $\mathrm{CO}_{2}$, a reverse approach can be performed ${ }^{7,15}$. The gel is first immersed in a solution with of the drug in an organic solvent. At an early stage of the sc-drying, the drug precipitates within the gel due to anti-solvent properties of $\mathrm{sc}-\mathrm{CO}_{2}{ }^{52}$.

Ketoprofen is soluble in supercritical carbon dioxide and was loaded directly by adsorption from sc- $\mathrm{CO}_{2}$. Quercetin is almost insoluble in $\mathrm{sc}-\mathrm{CO}_{2}$ and was loaded by supercritical anti-solvent process. A preliminary study was performed for the sc$\mathrm{CO}_{2}$ impregnation of ketoprofen, varying the impregnation time ( 24 or $72 \mathrm{~h}$ ). Since the final drug loading was not significantly different $(p<0.001)$, further studies were performed at $24 \mathrm{~h}$. Table 4 presents the loading achieved (gram of drug per $1 \mathrm{~g}$ of the original aerogel). For comparison reason the loading is also represented as number of molecular layers. For this, the projection area was calculated from the solvent accessible surface area of ketoprofen and quercetin (91.89 and $87.03 \AA^{2}$, respectively) and then normalized by $S_{B E T}$.

Table 4 | Drug loading capacities for alginate-based aerogel microparticles

\begin{tabular}{|c|c|c|c|c|}
\hline \multirow[b]{2}{*}{ Aerogel } & \multicolumn{2}{|c|}{ Ketoprofen } & \multicolumn{2}{|c|}{ Quercetin } \\
\hline & $\begin{array}{c}\text { Drug } \\
\text { loading \% }\end{array}$ & $\begin{array}{c}\text { Number of } \\
\text { adsorbed layers }\end{array}$ & $\begin{array}{c}\text { Drug } \\
\text { loading \% }\end{array}$ & $\begin{array}{c}\text { Number of } \\
\text { adsorbed layers }\end{array}$ \\
\hline Alginate & $22 \pm 1$ & $1.42 \pm 0.05$ & $3.1 \pm 0.5$ & $0.16 \pm 0.03$ \\
\hline Alginate/pectin & $19 \pm 1$ & $0.86 \pm 0.06$ & $5.4 \pm 0.2$ & $0.197 \pm 0.008$ \\
\hline Alginate/K-carrageenan & $17 \pm 2$ & $0.9 \pm 0.1$ & $3.8 \pm 0.1$ & $0.162 \pm 0.005$ \\
\hline
\end{tabular}


Since all aerogels were loaded with ketoprofen at identical pressure and temperature, potential differences in loading would correspond to differences in affinity between aerogel and drug. As there are no statistically significant differences in the loading across the aerogels $(p<0.001)$, it can be concluded that ketoprofen - aerogel interaction is of the same magnitude. Formation of hydrogen bonds between $\mathrm{OH}$ - and $\mathrm{COOH}$-groups of the polysaccharides and carboxylic and carbonyl group of ketoprofen may be involved in such interactions. Slight decrease in the loading of ketoprofen for hybrid aerogels compare to pure alginate supports this explanation since $\mathrm{OH}$ - and $\mathrm{COOH}$-groups from pectin and carrageenan can be coordinated by calcium cations. This decrease is also consistent with the reduction in the C constant (Table 2). The loading of ketoprofen achieved in this study is comparable with literature data for drug-loaded aerogels being in the range of 12 $-30 \mathrm{wt} \%{ }^{4,18}$. As for quercetin, the loading mechanism is essentially different in this case. The loading is determined by two factors: (i) the concentration of quercetin in the saturated ethanolic solution $\left(2.5 \mathrm{~g} \mathrm{~L}^{-1}\right)$; (ii) quercetin solubility in $\mathrm{sc}-\mathrm{CO}_{2}$ and $\mathrm{CO}_{2}$ /ethanol mixtures. In our anti-solvent experiments, the concentration of ethanol in sc- $\mathrm{CO}_{2}$ did not exceed few mol. \%. Even though the solubility of quercetin in $\mathrm{sc}-\mathrm{CO}_{2}$ at such ethanol concentration is not available in the literature, in a first approximation we can assume no loss of quercetin upon the contact with sc- $-\mathrm{CO}_{2}{ }^{33}$. Then, the loading can be calculated form the overall pore volume of the gel and saturated concentration $\left(7.9 \pm 0.2 \mathrm{mg} \mathrm{m}^{-1}\right)$. As the overall pore volume is unknown, taking the BJH pore volume instead, we arrive at the maximal possible theoretical loading of $1.4,3.6$ and $2.9 \mathrm{wt} \%$ for alginate, alginate/pectin and alginate/carrageenan aerogels, respectively. Actual loadings are $1.3-2.2$ times higher than these values. Two reasons have to be taken into account to explain this discrepancy. First, alginate aerogels may contain some macropores ${ }^{16}$. Second, gels undergo shrinkage during the sc-drying. Thereby, the BJH pore volume is not representative measure of the overall pore volume and can be used to estimate the 
lower bound of the loading. The number of adsorbed layers is equal to approximately 1.0 for ketoprofen and considerably lower for quercetin (ca. 0.2). This result is a first evidence that ketoprofen is present in the aerogel in its amorphous state. It is known that desorption and precipitation from sc- $\mathrm{CO}_{2}$ may lead to amorphous state ${ }^{5,8}$. However, as it pointed out by Gorle et al. ${ }^{6}$, strong interactions between solute and aerogel surface favour amorphous state of the drug. Results in the literature show that amorphous state can be stabilized up to 4 molecular layers on silica aerogel ${ }^{53}$. Weak interactions, however, lead to crystalline state even at low loading $\left(0.03-0.2\right.$ molecular layers) ${ }^{6}$. Figure 5 presents SEM micrographs of quercetin-loaded aerogel microparticles, where no drug crystals can be seen. The same result was observed for ketoprofen.

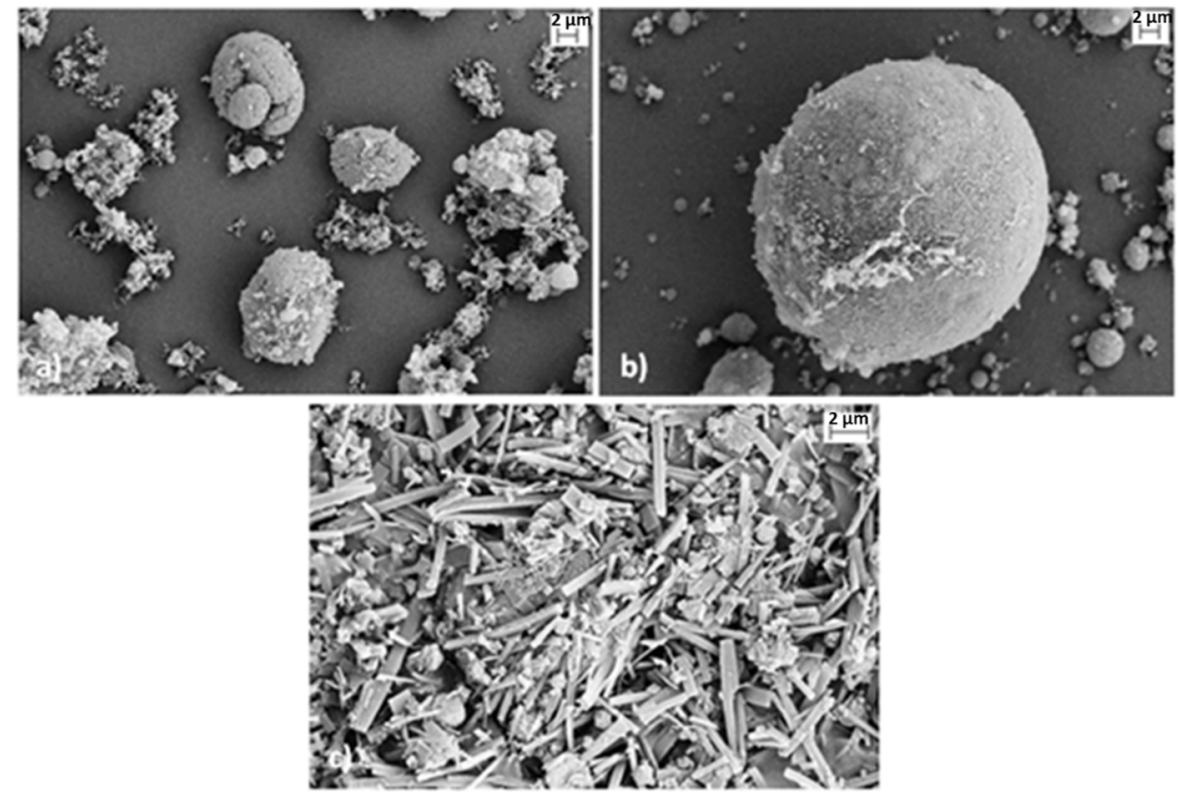

Figure 5| SEM micrographs of quercetin-loaded aerogel microparticles (HLB 5) of a) Alginate-Pectin and b) Alginate-K-Carrageenan; c) SEM micrograph of quercetin precipitated by supercritical antisolvent process.

To confirm that the drugs were loaded in amorphous state, DSC thermograms of the pure drugs, original and drug-loaded aerogels were also obtained (figure 6). 

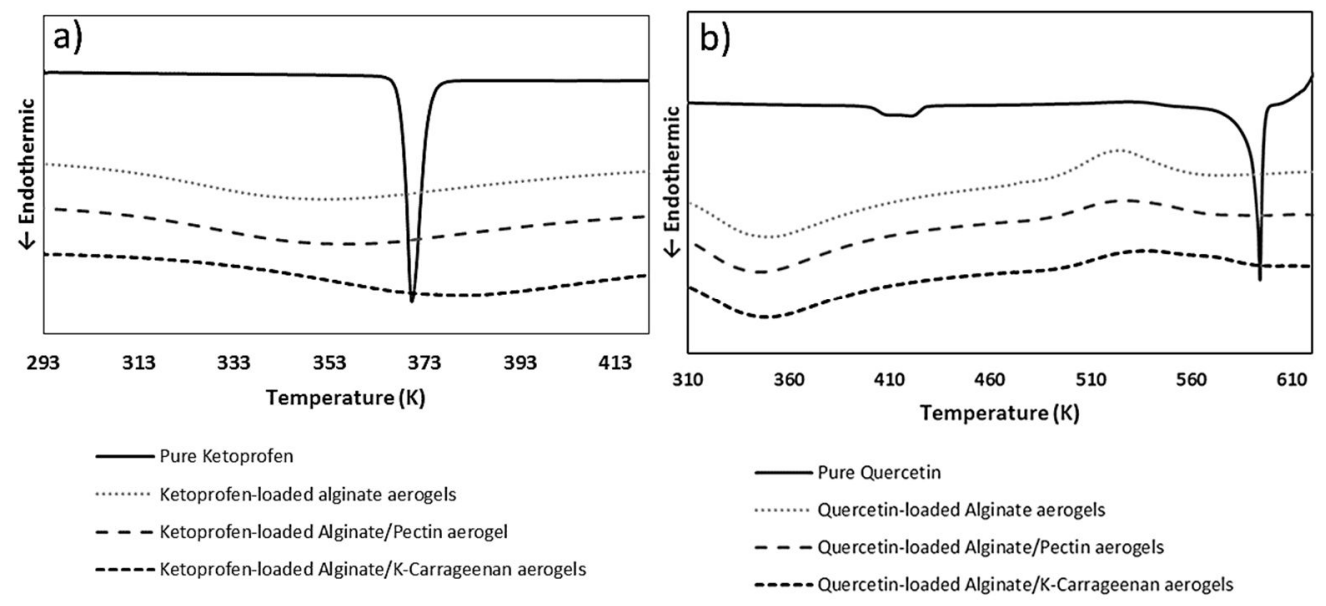

Figure 6| DSC Thermograms of a) unprocessed ketoprofen and ketoprofen-loaded aerogels; and b) of unprocessed quercetin and quercetin-loaded aerogels

As expected, pure ketoprofen presented a melting peak at $370 \mathrm{~K}$ whether pure quercetin presented two endothermic peaks, the first, at $421 \mathrm{~K}$, corresponds possibly to the loss of bound water, and the second, at $594 \mathrm{~K}$, is related to the melting point of quercetin ${ }^{36,54}$. Unloaded aerogels showed an endothermic peak $(353-361 \mathrm{~K}$ ) due to loss of water and an exothermic peak (522 - $525 \mathrm{~K}$ ), having very similar thermograms to the drug-loaded aerogels. The absence of ketoprofen and quercetin melting peaks on the thermograms of drug-loaded aerogels suggests the amorphization of the drugs. Thus, we can conclude that there is a strong interaction between all aerogels and drugs which allows to stabilize considerable amount of the drugs in the amorphous state. DSC analysis were repeated after 1.5 year storage at room conditions in a sealed protected from light container. No crystalline peaks have been detected for both ketoprofen and quercetin clearly demonstrating that the drugs loaded into aerogels are stable towards recrystallization (Figure 7). 

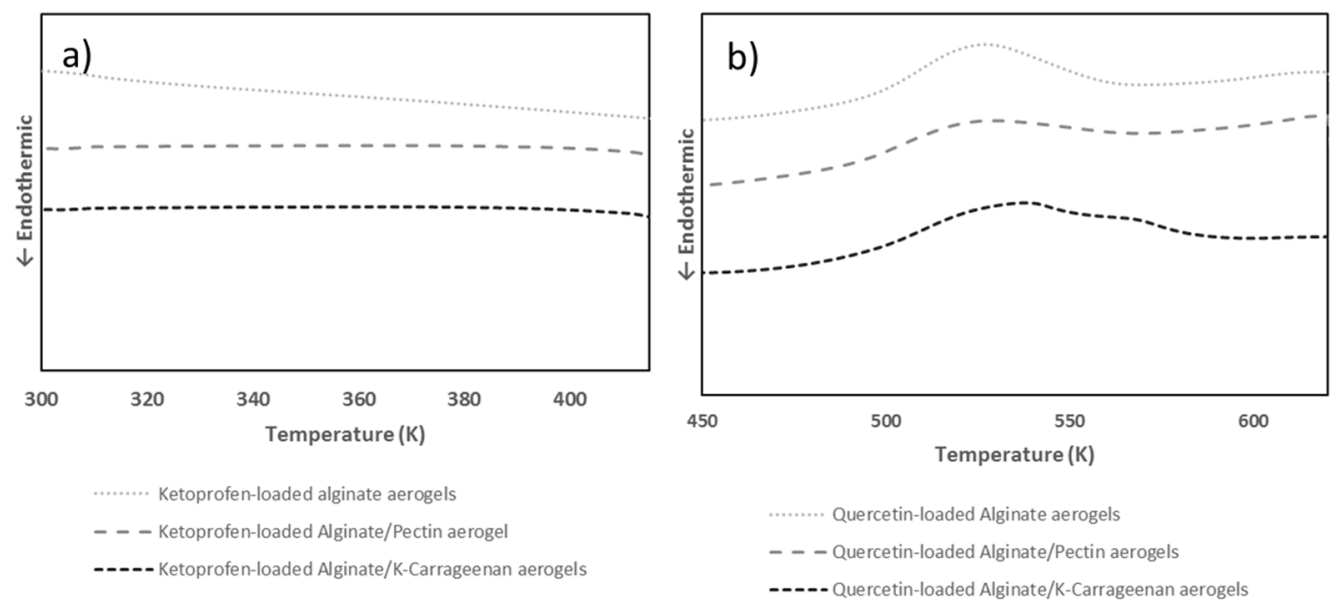

Figure 7| DSC Thermograms of a) ketoprofen-loaded aerogels after 1.5 years of storage in a sealed protected from light container (second heating cycle); and b) quercetin-loaded aerogels after 1.5 years of storage in a sealed protected from light container (second heating cycle)

The antioxidant properties of quercetin-loaded alginate-based aerogel microparticles were also assessed in this work in order to verify the preservation of the flavonoid bioactivity after its precipitation and $\mathrm{CO}_{2}$ drying of alcogels. Figure 8 presents the ORAC values for both pure quercetin and quercetin-loaded aerogel microparticles.

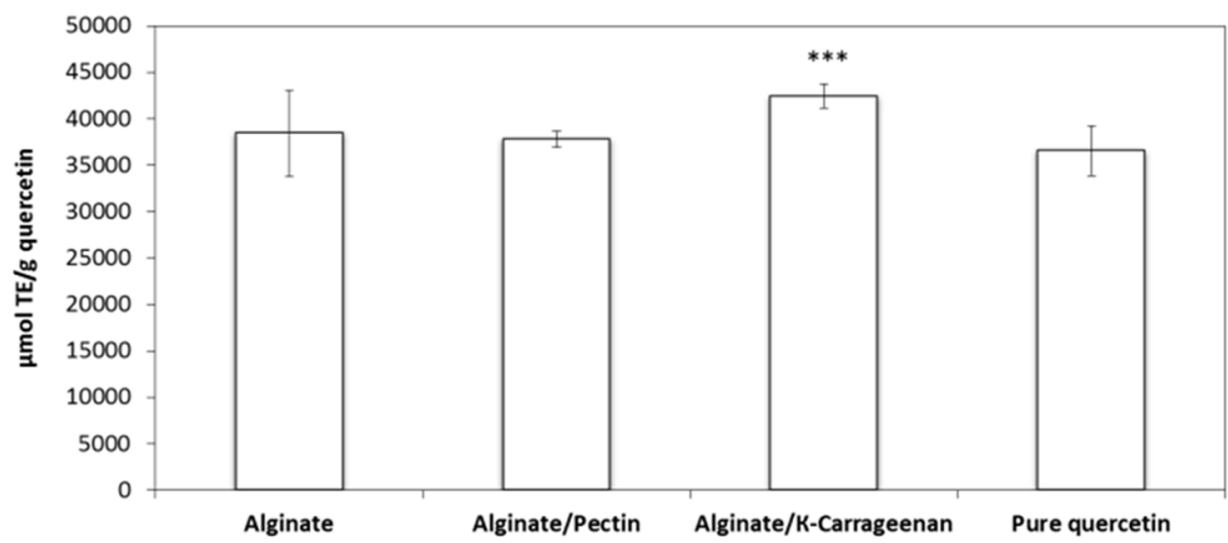

Figure 8| Results of ORAC antioxidant activity of pure quercetin and quercetin-loaded aerogels presented as antioxidant activity per unit mass of quercetin $(* * *$ refers to statistical differences in relation with pure quercetin; $p<0.001$ ) 
Pure quercetin showed an antioxidant activity of $(3.7 \pm 0.3) \times 10^{4} \mu \mathrm{mol}$ TE eq per gram of pure quercetin. This value is close to the ORAC values obtained for quercetinloaded aerogels. This demonstrates that the loading method and $\mathrm{CO}_{2}$ drying of alcogels preserved the original strong antioxidant property of quercetin. Moreover, alginate/к-carrageenan aerogel loaded with quercetin presented an antioxidant activity of $(4.2 \pm 0.1) \times 10^{4} \mu \mathrm{mol}$ TE eq, which is statistically larger $(p<0.001)$ than the value for pure quercetin. This could be explained by the fact that $\mathrm{k}$-carrageenan has some antioxidant activity by itself ${ }^{27,28}$.

The drug release of the aerogel matrices was accessed in this work. Alginate, pectin and $\mathrm{k}$-carrageenan are hydrophilic polysaccharides and, thus, it is expected that corresponding aerogels would rapidly collapse in aqueous medium leading to a fast release of the amorphous drug molecules ${ }^{18}$. Nevertheless, as can be seen in Fig. 9a, the release of ketoprofen was slightly slower from the aerogel matrices in comparison with pure ketoprofen that was completely dissolved in PBS within 15 $\min$. 

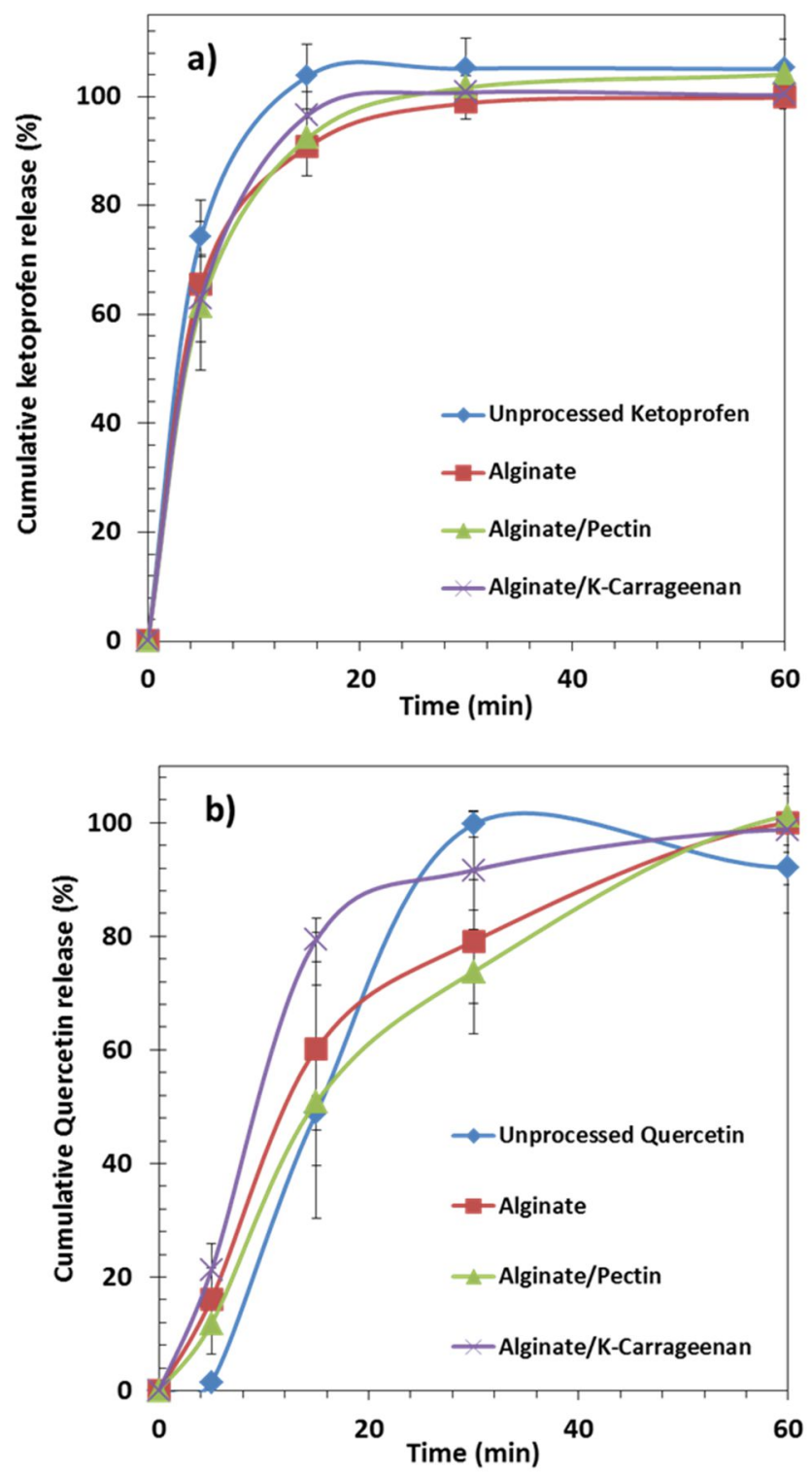

Figure 9| Drug release profiles of unprocessed ketoprofen and ketoprofen-loaded aerogel microparticles (a), and unprocessed quercetin and quercetin-loaded aerogel microparticles (b). Release media: phosphate buffer solution, $\mathrm{pH}=6.8,310 \mathrm{~K}$.

On the other hand, the release of quercetin from the aerogel matrices was initially faster than the dissolution of pure quercetin in the PBS medium (Fig. 9b). After 5 min of experiment, only $1.5 \%$ wt of pure quercetin was dissolved, while $12-21$ 
wt\% was released from the aerogel matrices during the same period of time. All unprocessed quercetin was dissolved after $30 \mathrm{~min}$, showing degradation from this point. As quercetin has low solubility in aqueous media, the presence of hydrophilic matrices coupled with amorphous state of quercetin could explain this initially faster dissolution in case of drug-loaded aerogels. This result was more pronounced in the alginate/k-carrageenan hybrid, probably due to the presence of sulphate groups, which confers higher swelling capacity of this matrix ${ }^{55}$ and smaller particle size compare to pure alginate (Table 2). Alginate/pectin showed the slowest release of quercetin most probably due to the slower swelling of the matrix. This observation is also in agreement with lower $\mathrm{C}$ constant compare to other aerogels. Moreover, all of the biopolymer-based aerogel materials seemed to have a protective effect against quercetin degradation. Althans and co-authors verified that the presence of linear or cross-linked poly-(n-isopropylacrylamide) polymers were able to provide chemical stabilization of the flavonoid in aqueous media ${ }^{56}$. Among mucosal drug delivery, and particularly in intranasal route, singular attention is paid to pharmacologically active substances with low stability in the gastrointestinal tract, low absorption in the colon, and/or an intense first pass metabolism, such as proteins, peptides, or very polar substances ${ }^{57}$. Proteins or peptides were never loaded in aerogel matrices, thus, in order to prove that it is also possible to perform it, hybrid alginate/pectin aerogel was selected to be further produced and loaded with amidated kyotorphin, a modified endogenous neuropeptide with analgesic properties ${ }^{58,59}$. Since this peptide is insoluble in sc$\mathrm{CO} 2$ or ethanol, it is loaded and added to the polysaccharide's solution, before the gelation takes place; with this approach, KTP-NH2 which is dissolved in the initial solution, is expected to be trapped in the aerogel network during the gelation. Then, it should withstand all solvents and supercritical drying ${ }^{60}$. Two types of approaches were performed in order to scale down the process, due to the cost of the peptide and its high therapeutic effect. An encapsulation efficiency (EE) of 
$78.2 \%$ was achieved by maintaining the polysaccharide concentration and reducing the emulsion volume, while only $17.0 \%$ was obtained when the polysaccharide concentration was reduced and the emulsions' volume maintained. This suggests that using higher volume of emulsion led probably to peptide loss during washes. Nevertheless, the result obtained during volume reduction $(78.2 \% \mathrm{EE})$ is very promising and proves that it is possible to load this type of drug into aerogel matrices. Nevertheless, it is just a proof of concept, and more research should be carried out, from the loading with peptides with different polarities until the peptide's stability and maintenance of therapeutic action.

\section{Conclusions}

In this work, alginate-based hybrid aerogel microparticles were prepared by emulsion gelation method and dried with supercritical $\mathrm{CO}_{2}$. Spherical hybrid microparticles with mesoporous structure presented high specific surface area $\left(>300 \mathrm{~m}^{2} \mathrm{~g}^{-1}\right)$ and mucoadhesive properties. Pectin revealed better interaction with alginate, increasing the degree of cross-linking between both polysaccharides, resulting in higher specific surface area and lower shrinkage found in the alginatepectin aerogels. Pure alginate and alginate-based hybrid aerogels were loaded with ketoprofen and quercetin using supercritical $\mathrm{CO}_{2}$ impregnation and anti-solvent process, respectively. Both drugs were confirmed to be in amorphous state. Antioxidant activity of quercetin was not affected by loading and supercritical drying. Drug release from alginate/k-carrageenan aerogel was found to be slightly faster for both model drugs compare to alginate/pectin counterpart. Moreover, amidated kyotorphin, a peptide with analgesic properties, was succefully loaded into alginate/pectin aerogel microparticles (EE 78\%). Based on the results obtained we can conclude that these novel formulations have a potential to be applied as drug delivery systems for several mucosal routes, having nasal route as an example. 


\section{Acknowledgements}

This work was supported by Fundação para a Ciência e Tecnologia (FCT) through grant PEst-OE/EQB/LA0004/2011 and by DFG (project SM 82/8-3). V. S. S. Gonçalves is grateful for the financial support from FCT through the grant SFRH/BD/77350/2011 and transnational cooperation project FCT-DAAD (57050501). iNOVA4- Health - UID/Multi/04462/2013, a program financially supported by Fundação para a Ciência e Tecnologia/Ministério da Educação e Ciência, through national funds and co-funded by FEDER under the PT2020 Partnership Agreement is acknowledged.

\section{References}

1 F. Buttini, P. Colombo, A. Rossi, F. Sonvico and G. Colombo, J. Control. Release, 2012, 161, 693-702.

2 A. C. Pierre and G. M. Pajonk, Chem. Rev., 2002, 102, 4243-4266.

3 Z. Liu, Y. Jiao, Y. Wang, C. Zhou and Z. Zhang, Adv. Drug Deliv. Rev., 2008, 60, 1650-1662.

$4 \quad$ I. Smirnova, S. Suttiruengwong and W. Arlt, KONA Powder Part. J., 2005, 23, 86-97.

5 B. S. K. Gorle, I. Smirnova, M. Dragan, S. Dragan and W. Arlt, J. Supercrit. Fluids, 2008, 44, 78-84.

$6 \quad$ B. S. K. Gorle, I. Smirnova and W. Arlt, J. Supercrit. Fluids, 2010, 52, 249257.

7 G. Tkalec, M. Pantić, Z. Novak and Ž. Knez, J. Mater. Sci., 2015, 50, 1-12.

8 T. Mehling, I. Smirnova, U. Guenther and R. H. H. Neubert, J. Non. Cryst. Solids, 2009, 355, 2472-2479.

9 C. M. M. Hentzschel, M. Alnaief, I. Smirnova, A. Sakmann and C. S. S. Leopold, Eur. J. Pharm. Biopharm., 2012, 80, 130-135.

10 S. Antonyuk, S. Heinrich, P. Gurikov, S. Raman and I. Smirnova, Powder Technol., 2015, 285, 34-43.

11 S. Doppalapudi, S. Katiyar, A. J. Domb and W. Khan, in Advanced polymers in medicine, Springer International Publishing, 2015, pp. 33-66.

12 F. Quignard, R. Valentin and F. Di Renzo, New J. Chem., 2008, 32, 1300.

13 G. R. Mahdavinia, Z. Rahmani, S. Karami and A. Pourjavadi, J. Biomater. Sci., 2014, 25, 37-41. 
14 H. H. Tønnesen and J. Karlsen, Drug Dev. Ind. Pharm., 2002, 28, 621-630.

15 C. a. García-González, M. Alnaief and I. Smirnova, Carbohydr. Polym., 2011, 86, 1425-1438.

16 P. Gurikov, S. P. Raman, D. Weinrich, M. Fricke and I. Smirnova, RSC Adv., 2015, 5, 7812-7818.

17 M. Alnaief, M. A. Alzaitoun, C. A. García-González and I. Smirnova, Carbohydr. Polym., 2011, 84, 1011-1018.

18 C. A. García-González, M. Jin, J. Gerth, C. Alvarez-Lorenzo and I. Smirnova, Carbohydr. Polym., 2015, 117, 797-806.

19 M. Robitzer, L. David, C. Rochas, F. Di Renzo and F. Quignard, in Macromolecular Symposia, 2008, vol. 273, pp. 80-84.

20 L. Liu, M. L. Fishman, J. Kost and K. B. Hicks, Biomaterials, 2003, 24, 33333343.

21 V. Brar and G. Kaur, Polym. Plast. Technol. Eng., 2014, 53, 1518-1531.

22 C. a. García-González, E. Carenza, M. Zeng, I. Smirnova and A. Roig, RSC Adv. , 2012, 2, 9816.

23 N. Thirawong, R. A. Kennedy and P. Sriamornsak, Carbohydr. Polym., 2008, 71, 170-179.

24 N. Thirawong, J. Nunthanid, S. Puttipipatkhachorn and P. Sriamornsak, Eur. J. Pharm. Biopharm., 2007, 67, 132-140.

25 L. Li, R. Ni, Y. Shao and S. Mao, Carbohydr. Polym., 2014, 103, 1-11.

26 Y. Liu, Y. Y. Zhu, G. Wei and W. Y. Lu, Eur. J. Pharm. Sci., 2009, 37, 306-312.

27 H. Yuan, J. Song, W. Zhang, X. Li, N. Li and X. Gao, Bioorg. Med. Chem. Lett., 2006, 16, 1329-1334.

28 Y. Sun, B. Yang, Y. Wu, Y. Liu, X. Gu, H. Zhang, C. Wang, H. Cao, L. Huang and Z. Wang, FOOD Chem., 2015, 178, 311-318.

29 A. Mistry, S. Stolnik and L. Illum, Int. J. Pharm., 2009, 379, 146-157.

30 F. Y. Ushikubo and R. L. Cunha, Food Hydrocoll., 2014, 34, 145-153.

31 M. Porras, C. Solans, C. González and J. M. Gutiérrez, Colloids Surfaces A Physicochem. Eng. Asp., 2008, 324, 181-188.

32 I. Smirnova, J. Mamic and W. Arlt, Langmuir, 2003, 19, 8521-8525.

33 A. Chafer, T. Fornari, A. Berna and R. P. Stateva, J. Supercrit. Fluids, 2004, 32, 89-96.

34 P. He, S. S. Davis and L. Illum, Int. J. Pharm., 1998, 166, 75-88.

35 A. T. Serra, A. a. Matias, R. F. M. Frade, R. O. Duarte, R. P. Feliciano, M. R. Bronze, M. E. Figueira, A. de Carvalho and C. M. M. Duarte, J. Funct. Foods, 2010, 2, 46-53.

36 V. S. S. Gonçalves, S. Rodríguez-Rojo, A. a. Matias, A. V. M. Nunes, I. D. Nogueira, D. Nunes, E. Fortunato, A. P. A. de Matos, M. J. Cocero and C. M. M. Duarte, Int. J. Pharm., 2015, 478, 9-18.

37 M. Fraile, R. Buratto, B. Gómez, Á. Martín and M. J. Cocero, Ind. Eng. Chem. Res., 2014, 53, 4318-4327. 
38 B. C. Thanoo, M. C. Sunny and A. Jayakrishnan, J. Pharm. Pharmacol., 1992, 44, 283-286.

39 D. Poncelet, R. Lencki, C. Beaulieu, J. P. P. Halle, R. J. J. Neufeld and A. Fournier, Appl. Microbiol. Biotechnol., 1992, 38, 39-45.

40 D. Poncelet, B. Poncelet De Smet, C. Beaulieu, M. L. Huguet, A. Fournier and R. J. Neufeld, Appl. Microbiol. Biotechnol., 1995, 43, 644-650.

41 D. Poncelet, Ann. N. Y. Acad. Sci., 2006, 944, 74-82.

42 N. Muro-Suñé, G. M. Kontogeorgis, N. Von Solms and M. L. Michelsen, Ind. Eng. Chem. Res., 2008, 47, 5660-5668.

43 J. Boyd, C. Parkinson and P. Sherman, J. Colloid Interface Sci., 1972, 41, 359-370.

44 M. Martins, A. a. Barros, S. Quraishi, P. Gurikov, S. P. Raman, I. Smirnova, A. R. C. Duarte and R. L. Reis, J. Supercrit. Fluids, 2015.

45 S. Quraishi, M. Martins, A. A. Barros, P. Gurikov, S. P. Raman, I. Smirnova, A. R. C. Duarte and R. L. Reis, J. Supercrit. Fluids, 2015, 105, 1-8.

46 S. P. Raman, P. Gurikov and I. Smirnova, J. Supercrit. Fluids, 2015, 106, $23-$ 33.

47 M. F. De Lange, T. J. H. Vlugt, J. Gascon and F. Kapteijn, Microporous Mesoporous Mater., 2014, 200, 199-215.

48 H. Bu, A.-L. Kjøniksen, K. D. Knudsen and B. Nyström, Langmuir, 2005, 21, 10923-10930.

49 J. D. SMART, Adv. Drug Deliv. Rev., 2005, 57, 1556-1568.

50 J. Varshosaz and Z. Dehghan, Eur. J. Pharm. Biopharm., 2002, 54, 135-141.

51 P. F. Builders, O. O. Kunle and M. U. Adikwu, Int. J. Pharm., 2008, 356, 174180.

52 Z. Ulker and C. Erkey, J. Supercrit. Fluids, 2015.

53 G. P. Sanganwar and R. B. Gupta, Int. J. Pharm., 2008, 360, 213-218.

54 M. Fraile, Á. Martín, D. Deodato, S. Rodriguez-Rojo, I. D. Nogueira, A. L. Simplício, M. J. Cocero and C. M. M. Duarte, J. Supercrit. Fluids, 2013, 81, 226-235.

55 Z. Mohamadnia, M. J. Zohuriaan-Mehr, K. Kabiri, A. Jamshidi and H. Mobedi, J. Biomater. Sci. Polym. Ed., 2008, 19, 47-59.

56 D. Althans, P. Schrader and S. Enders, J. Mol. Liq., 2014, 196, 86-93.

57 a. M. Privalova, N. V. Gulyaeva and T. V. Bukreeva, Neurochem. J., 2012, 6, 77-88.

58 M. Ribeiro, A. Pinto, M. Pinto, M. Heras, I. Martins, A. Correia, E. Bardaji, I. Tavares and M. Castanho, Br. J. Pharmacol., 2011, 163, 964-973.

59 M. M. B. Ribeiro, S. S. Santos, D. S. C. Sousa, M. Oliveira, S. M. Santos, M. Heras, E. Bardaji, I. Tavares and M. A. R. B. Castanho, Amino Acids, 2013, 45, 171-178.

60 Z. Ulker and C. Erkey, J. Control. Release, 2014, 177, 51-63. 


\section{Chapter 5}

\section{Application of RPMI 2650 as a cell model to evaluate solid formulations for intranasal delivery of drugs}

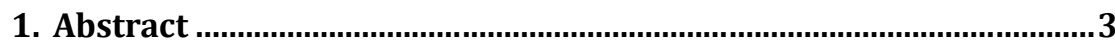

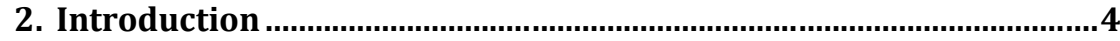

3. Experimental section ............................................................................ 7

3.1. Materials ............................................................................ 7

3.2. Production of microparticles................................................ 8

3.3. Sterilization of particles ......................................................... 9

3.4. Cell Culture ............................................................................ 9

3.5. Cytotoxicity assay - MTS .................................................... 9

3.6. RPMI 2650 permeation assay............................................... 10

3.7. Statistical Analysis ......................................................... 14

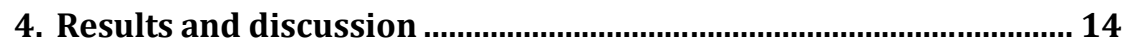

4.1. RPMI 2650 cell culture and development of cell monolayer ...... 14

4.2. Cell viability of RPMI 2650 monolayer after microparticles' exposure ................................................................................... 15

4.3. RPMI 2650 as permeation model (ALI culture) ...................... 16

4.4. Ketoprofen-loaded microparticles' permeability on RPMI 2650

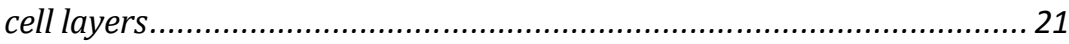

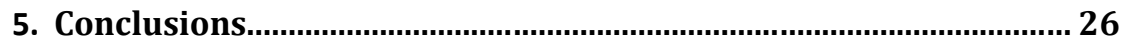

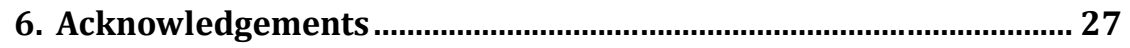

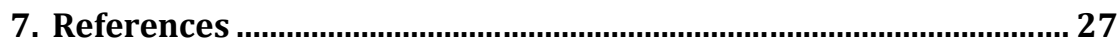


Adapted from: Gonçalves, V.S.S., XXX

The author contributed to the planning and execution of all the experiments described in this chapter. The author was also involved on the discussion and interpretation of results, as well as on the preparation of the manuscript. 


\section{Abstract}

During the development of intranasal drug delivery systems, it is necessary to assess the cytotoxicity and drug transport through nasal epithelium. In order to avoid animal experiments or the use of excised tissues, in vitro cell models, such as RPMI 2650 cells, are being preferred during recent years. Nevertheless, the deposition of solid formulations into nasal cell layers and consequently the interaction powder formulation-cells with further transepithelial transport rate of drugs have been poorly studied or reported.

Thus, the purpose of this work is to further investigate RPMI 2650 cell line as an effective alternative to animal tissues for solid drug-loaded formulations cytotoxicity and permeation studies in order to become a tool for drug discovery. RPMI 2650 cells were cultured submersed and in air-liquid interface conditions, being characterized regarding transepithelial electrical resistance and mucus production. Pure ketoprofen and five formulations loaded with same drug, namely solid lipid particles (Gelucire 43/01 ${ }^{\mathrm{TM}}$ ), structured lipid particles (Gelucire 43/01 ${ }^{\mathrm{Tm}}: \mathrm{GMO}$ ) and aerogel microparticles (Alginate, Alginate:Pectin, Alginate:Carrageenan), were evaluated with RPMI 2650 model in terms of cytotoxicity and drug permeability (applied as solution, dispersion or powder+buffer).

RPMI 2650 cells were capable to grow in monolayer and multilayer, showing the same permeability as excised human nasal mucosa for sodium fluorescein (paracellular marker), with analogous TEER values and mucus production. None of the powders showed cytotoxicity when applied to RPMI 2650 cells. Regarding drug permeation through cell layers, not only the form of application of powders but also their physical and chemical properties can affect the final drug's permeation. Aerogel microparticles administered directly to the cell layer (powder + buffer) 
exhibited the highest permeation-enhancing effect compared to the pure drug, which can be attributed to the mucoadhesive properties of the carrier materials, being an attractive formulation for nasal drug delivery.

According to these results, RPMI 2650 showed to be an appropriate and interesting alternative to ex vivo or in vivo nasal models for the evaluation of nasal drug-loaded formulations cytotoxicity and permeation.

\section{Introduction}

During the last year, the nasal administration of drugs became an interesting noninvasive route for delivery of drugs. Human nasal cavity has a surface area of 150 $\mathrm{cm}^{2}$, with a total volume of $15-20 \mathrm{~mL}$. Moreover, it presents an extensive vascularization through the mucosa with a leaky epithelium, which provides an optimal absorption area for the delivery of drugs ${ }^{1,2}$. Drugs absorbed in the nasal mucosa can have a local or systemic action or can be even targeted to the brain ${ }^{1,3,4}$. This route of administration can provide highly absorptive rate of drugs and increase its bioavailability, especially those that have higher presystemic metabolism or poor oral absorption (e.g. therapeutic peptides), due to the avoidance of first-pass effect, intestinal efflux transporters or enzymatic degradation along the gastrointestinal tract $(\mathrm{GIT})^{5-7}$. Besides, the nasal cavity offers an alternative approach to reach the brain, bypassing the blood-brain barrier (BBB), since the olfactory and trigeminal nerves are in contact with both nasal cavity and central nervous system ${ }^{8,9}$. Nevertheless, there are some limitations of this administration, such as short time of residence (10-20 $\mathrm{min}$ ) of formulation due to the mucociliary clearance, a restricted volume administration (25-200 $\mu \mathrm{L})$ and the presence of some enzymatic activity, though in less extension than in GIT, that can degrade peptide drugs ${ }^{1,10}$. Hence, the ideal nasal formulation should be capable to prolong the residence time in the nasal cavity through the use of intelligent 
responsive polymers or mucoadhesive carriers that can prolong the contact with the nasal mucosa, or increase cellular uptake of drugs using lipid based carriers ${ }^{3,11-}$ 13.

During the development of drug loaded formulations for nasal administration, preclinical studies assessing transmucosal drug transport or toxic effects of excipients can be performed using excised tissue, primary cell cultures, or immortalized cell lines ${ }^{2}$. Excised human tissue is usually hard to obtain presenting inter- and intraindividual differences. Consequently, drug permeation studies are usually performed using excised mucosa from experimental or slaughtered animals, which introduces other drawbacks, such as challenging species differences and ethical concerns ${ }^{5,14}$. It is known that transepithelial electrical resistance (TEER) of human nasal mucosa obtained from inferior turbinates ranges from $40-180 \Omega \cdot \mathrm{cm}^{2}$, which can strongly differ from other animal tissues ${ }^{2,5,15}$. As an alternative to this ethically controversial animal studies, there are in vitro human cell lines (primary and immortalized) that can be used for the evaluation of drug formulations. Primary cell culture, despite having good morphological and biochemical equivalence to human nasal mucosa, present some limitations such as heterogeneity within and between cultures, undefined reproducibility, higher number of tight junctions compared to human nasal excised tissue, which results in significantly higher TEER $\left(600-3100 \Omega \cdot \mathrm{cm}^{2}\right)^{14-16}$. On the other hand, immortalized cell lines from human origin are of great interest due to good genetic homogeneity, data reproducibility and ease of culture maintenance ${ }^{5}$. In particular, RPMI2650, an immortalized cell line derived from an anaplastic squamous cell carcinoma of the human nasal septum, are the only commercially available cells that present similar TEER values, compound's permeability and enzymatic metabolic barrier comparable to that of human excised nasal tissue ${ }^{2,17-20}$. Several scientists have investigated, optimized and tried to improve this cell line during the last years, including the optimization of culture conditions, the investigation of cell morphology, presence of tight 
junctions, improvement of barrier proprieties or expression of drug transporters $2,5,14,15,17,19,21,22$. However, not enough studies of the application of nasal formulations in this cell line have been performed so far and its suitability as a valid in vitro nasal model is still under question. Moreover, some authors studying Calu3 cell line as a tool to screen pulmonary drug delivery have demonstrated that drug's permeability depends greatly on the type of application of the tested materials into the cell layer (powder, solutions or dispersions), which has not been studied with RPMI 2650, as far as the authors know ${ }^{23-25 .}$

Thus, this work had two main objectives: to further characterize RPMI 2650 cell line as an effective alternative to animal tissues for solid drug-loaded formulations interaction (adhesion), cytotoxicity and absorption studies and to determine the extent to which the administration of drugs in particulate forms would differ in relation to the permeability of the same compounds applied as solutions. For that purpose, RPMI 2650 cells were cultured submersed and in air-liquid interface conditions, with the further characterization of transepithelial electrical resistance and mucus production. Pure ketoprofen and five formulations loaded with same drug, namely solid lipid particles (Gelucire $43 / 01^{\mathrm{TM}}$ ), structured lipid particles (Gelucire 43/01 ${ }^{\mathrm{m}}$ : GMO, $3: 1 \mathrm{w} / \mathrm{w}$ ) and aerogel microparticles (Alginate; Alginate:Pectin, Alginate:Carrageenan, 1:1 w/w) , were evaluated with RPMI 2650 model in terms of cytotoxicity and drug permeability (applied as solution, dispersion or powder+buffer). Sodium fluorescein was chosen and used in this work as paracellular transport marker. 


\section{Experimental section}

\subsection{Materials}

Nunc $^{\text {TMEasy Flask }}{ }^{\mathrm{TM}} 75 \mathrm{~cm}^{2}$ (ThermoScientific), Multiwell 24 Well BD Falcon ${ }^{\circledR}$ (Becton Dickinson) and Thincert ${ }^{\mathrm{TM}}$ Tissue culture inserts for Multiwell 12 plates (Greiner bioone, $0.4 \mu \mathrm{m}$ pore size) were used in this work. Cell culture media, supplements and other reagents, namely Minimum essential medium (MEM), fetal bovine serum (FBS), L-glutamine, Non-essential aminoacids (NEAA), PenStrep (PS), Trypsin-EDTA (0.25\%), Tryptan blue stain (0.4\%) and Formalin solution $10 \%$ neutral buffered (formaldehyde, $4 \% \mathrm{w} / \mathrm{w}$ ) were obtained from Invitrogen (Gibco, Invitrogen Corporation, Paisley, UK). PBS powder for cytotoxicity assays, CelLytic ${ }^{\mathrm{TM}} M$, Ketoprofen ( $\geq 98 \%$ ), Fluorescein sodium salt, $\beta$-Nicotinamide adenine dinucleotide, Tris(hydroxymethyl)aminomethane (99.8\%), Sodium pyruvate and Alcian Blue 8GX were obtained from Sigma-Aldrich (St. Louis, USA). CellTiter 96 AQueous One Solution Cell Proliferation Assay was obtained from Promega (Wisconsin, USA). The Krebs-Ringer buffer, pH 7.4 (KRB), which was used for permeation studies, contained the following substances in 11 of double-distilled water: $6.8 \mathrm{~g} \mathrm{NaCl}$ (Sigma-Aldrich), $0.4 \mathrm{~g} \mathrm{KCl}$ (Riedel-de Haen), $0.14 \mathrm{~g} \mathrm{NaH}_{2} \mathrm{PO}_{4} \cdot \mathrm{H}_{2} \mathrm{O}$ (Sigma-Aldrich), 2.1 $\mathrm{g} \mathrm{NaHCO}_{3}$ (Sigma-Aldrich), 3.575 g HEPES (Sigma-Aldrich), $1.0 \mathrm{~g}$ d-glucose (SigmaAldrich), $0.2 \mathrm{~g} \mathrm{MgSO}_{4} .7 \mathrm{H}_{2} \mathrm{O}$ (Fluka) and $0.26 \mathrm{~g} \mathrm{CaCl}_{2} .2 \mathrm{H}_{2} \mathrm{O}$ (Sigma-Aldrich). For sterilization experiments tryptone soya broth (TSB) and tryptone soya agar (TSA) were purchased from Oxoid (Hampshire, England). Dimethyl sulphoxide (99.9\%) was obtained from Carlo Erba Reagents and acetic acid (96\%) obtained from Riedelde-Haen.

Regarding particle production, Gelucire $43 / 01^{\mathrm{TM}}$, and Peceol ${ }^{\mathrm{TM}}(\mathrm{GMO})$ were kindly supplied by Gattefossé (France). Ketoprofen ( $\geq 98 \%$ purity) was purchased from Sigma-Aldrich (Steinheim, Germany). $\mathrm{CO}_{2}$ (99.95 and 99.998 mol\% purity) was 
delivered by Air Liquide (Portugal). Ethanol (96\%) was purchased from AGA (Portugal). Alginic acid sodium salt was purchased from Panreac Applichem (Germany). Low methoxyl pectin and K-carrageenan were kindly donated by Disproquima (Portugal) and FMC Biopolymer (Norway). Calcium carbonate was kindly provided by Magnesia GmbH (Germany). Sorbitan monooleate (Span 80) and polyoxyethylene sorbitan monooleate (Tween 80) were purchased from Merck (Germany). Paraffin oil, n-hexane and acetic acid ( $\geq 99.8 \%$ ) were purchased from Carl Roth GmbH (Germany).

\subsection{Production of microparticles}

Solid lipid particles and structured lipid particles composed by Gelucire $43 / 01^{\mathrm{TM}}$ and Gelucire 43/01 ${ }^{\mathrm{TM}}: \mathrm{GMO}(3: 1, \mathrm{w} / \mathrm{w})$, respectively, were produced and loaded with ketoprofen by PGSS ${ }^{\circledR}$ (Chapter 2, Part II). Alginate-based hybrid aerogel microparticles (with low methoxyl pectin or K-carrageenan, 1:1 w/w) were loaded with ketoprofen through supercritical $\mathrm{CO}_{2}$ impregnation (CHAPTER 4). Each microparticle's composition is listed in table 1.

Table 1| Microparticles' composition

\begin{tabular}{|c|c|c|c|}
\hline Composition & $D 0.5(\mu m)$ & $\%$ Ketoprofen (w/w) & Morphology \\
\hline Gelucire $43 / 01^{\text {TM }}$ & 42.6 & 8.1 & Branched \\
\hline Gelucire 43/01 ${ }^{\text {TM }}:$ GMO $(3: 1, w / w)$ & 22.6 & 9.1 & Branched \\
\hline Alginate & 23.0 & 24.9 & Spherical \\
\hline Alginate:Pectin $(1: 1, w / w)$ & 9.2 & 11.4 & Spherical \\
\hline Alginate:Carrageenan $(1: 1, w / w)$ & 12.7 & 10.3 & Spherical \\
\hline
\end{tabular}




\subsection{Sterilization of particles}

The sterilization of the microparticles was carried out as previously described by $\mathrm{Li}$ and co-workers with some modifications 26. Briefly, microparticles were put directly in contact with UV irradiation during $15 \mathrm{~h}$ at room temperature in a Biological Safety Cabinet (Nuaire, USA). To further confirm sterility, aerogels were incubated in tryptone soya broth at $37 \stackrel{\circ}{\circ}$. After 3 days, microparticles were plated in tryptone soya agar (during $24 \mathrm{~h}$ at $37 \stackrel{\circ}{\circ}$ ) to ensure the absence of bacterial contamination (data not shown).

\subsection{Cell Culture}

RPMI 2650 cells were purchased from the German Collection of Microorganisms and Cell Cultures (ACC 287, DSMZ, Braunschweig, Germany) and used between passages 4 and 34 for experiments. The cells were cultured (seeding 1.5×105 cells $/ \mathrm{cm} 2$ ) in $75 \mathrm{~cm} 2$ polystyrene cell-culture flasks under standard conditions, specifically, a humidified atmosphere at $37{ }^{\circ} \mathrm{C}$ and $5 \% \mathrm{CO} 2$ with medium changes three times per week. Cell counting was performed using a hemocytometer. The cells were maintained in a standard culture medium consisting of MEM, $10 \%$ heatinactivated fetal bovine serum (FBS), 1 \% I-glutamine, $1 \%$ NEAA and $1 \%$ Pen/strep solution. For cell passaging during standard cultivation, the cells were detached when confluence reached about $80 \%$ by treating the cells with trypsin-EDTA at 37 ${ }^{\circ} \mathrm{C}$. The cells were collected and viability was determined using a standard trypan blue staining procedure. The cells were seeded into new flasks at 1:4 or 1:8 split ratio.

\subsection{Cytotoxicity assay-MTS}

For cytotoxicity experiments, RPMI 2650 were assayed in MEM culture media with $0.5 \%$ FBS, $1 \%$ NEAA and $1 \%$ glutamine. Briefly, cells were seeded at a density of 
$1.5 \times 105$ cells $/ \mathrm{cm} 2$ in 24-well plate (area of each well $2 \mathrm{~cm} 2$, volume $1 \mathrm{~mL}$ ) and the medium was changed every $48 \mathrm{~h}$. After reaching confluence (4 days), 0.100 and $0.250 \mathrm{mg}$ of sterilized microparticles were added to RPMI 2650 cells and incubated at $37 \stackrel{\circ}{\circ}$ in a $5 \%$ CO2 during 1 hour. Following the incubation period, samples' dilutions were removed, cells were rinsed with PBS and $1 \mathrm{~mL}$ of a CellTiter $96^{\circledR}$ AQueous One Solution Cell Proliferation Assay reagent (containing MTS and PES) was added to each well and left to react for 2-4 hours. This solution reagent contains a tetrazolium compound (3-(4,5-dimethylthiazol-2-yl)-5-(3carboxymethoxyphenyl)-2-(4-sulfophenyl)-2H-tetrazolium, inner salt; MTS and an electron coupling reagent (phenazine ethosulfate, PES). PES has an enhanced chemical stability which allows it to be combined with MTS and leading to a stable solution. MTS is bio-reduced by cells into a colored formazan product that is soluble in tissue culture medium. The quantity of formazan produced was measured spectrophotometrically at $490 \mathrm{~nm}$ in a microplate reader (EPOCH, Bio-Tek, USA) and is directly proportional to the number of living cells in culture 27. Culture medium with DMSO ( $25 \% \mathrm{v} / \mathrm{v}$ ) was used as positive control for cytotoxicity. Results were expressed in terms of percentage of cellular viability relative to control (cells without microparticles) (\%). Experiments were performed in triplicate in at least three independent assays.

\subsection{RPMI 2650 permeation assay}

RPMI 2650 cells were seeded $\left(1.5 \times 10^{5}\right.$ cells $\left./ \mathrm{cm}^{2}\right)$ on permeable Thincert $^{\circledR}$ inserts with polyethylene terephthalate (TC-PTP, $0.4 \mathrm{~mm}, 1.13 \mathrm{~cm}^{2}$ ). The cultures were maintained in a liquid-covered culture (LCC) for 8 days, and the medium was replaced every 2-3 days. After this period, the inserts were lifted to the air-liquid interface $(A L I)$ and cultured for 2 more weeks ${ }^{2,14}$. During the cultivation, the transepithelial electrical resistance and production of mucus were determined, and 
drug permeability was evaluated at the end of this experimental period $\left(22^{\text {nd }}\right.$ day after seeding).

\subsubsection{Transepithelial Electrical Resistance (TEER) Measurements} TEER values were determined for RPMI 2650 cultures every 2-3 days with EVOM $^{\circledR}$ resistance meter and Endohm ${ }^{\circledR}$ chamber (World Precision Instruments, Sarasota, Florida, USA). $1.75 \mathrm{ml}$ culture medium was added to the Endohm ${ }^{\circledR}$ chamber, for TEER measurements. To conduct the measurements during ALI culture, standard culture medium $(0.5 \mathrm{~mL})$ was added to the apical compartment for $30 \mathrm{~min}$. Three wells (minimum) were assigned for each measurement.

\subsubsection{Alcian Blue assay}

Alcian blue was used to stain mucus secretion on the surface of mono/multilayer of RPMI 2650 cells ${ }^{28,29}$. The cultures were washed twice with $100 \mu \mathrm{L}$ PBS and fixed using $4 \%(\mathrm{v} / \mathrm{v})$ paraformaldehyde for 20 minutes. The cells were washed again with PBS and stained using $100 \mu \mathrm{L}$ alcian blue stain (1\% (w/v) alcian blue in $3 \%(\mathrm{v} / \mathrm{v})$ acetic acid/water at $\mathrm{pH}$ 2.5) for 15 minutes. The cells were rinsed multiple times with PBS and the inserts were air-dried. Images were obtained using Leica DM IRB Microscope equipped with a Leica DFC 295 camera. The images were analyzed using Image J (v1.410, NIH) with Colour Inspector 3D v2.0 (Kai Uwe Barthel; Internationale, Medieninformatik, Berlin, Germany) plug-in. A three-dimensional (3D) color space was produced representing the 8-bit red-green-blue (RGB) value of each image. The blue ratio $\left(R_{G B} B_{B}\right.$ ratio) was calculated by dividing the mean $R_{G B}$ by the sum of the $R G B$ values for each image $\left(R G B_{R}+R G B_{G}+R G B_{B}\right)$. The mean ratio of three images was used as an indication of the degree of mucus production at each time point of culture time.

\subsubsection{Drug permeation studies}




\subsubsection{Fluorescein sodium salt permeability}

Fluorescein sodium salt (NaFl) was used as a marker substance for paracellular permeation in order to validate the RPMI 2650 cell model. NaFl was dissolved in Krebs-Ringer buffer (KRB) as the donor solution (25 ppm). Before this solution was applied on filter inserts, cells were rinsed twice with KRB ( $37 \stackrel{\circ}{\circ})$ and incubated with the buffer for $60 \mathrm{~min}$. The buffer was removed and $0.5 \mathrm{~mL}$ of $\mathrm{NaFL}$ donor solution was added to the apical side of the cells, following addition of $1.5 \mathrm{~mL}$ pre-warmed KRB to acceptor chamber. The plates were kept in an incubator $\left(37 \stackrel{\circ}{\circ}, 5 \% \mathrm{CO}_{2}\right)$ for $1 \mathrm{~h}$. After incubation period, the marker molecule that permeated through the RPMI 2650 multilayer and reached the basolateral compartment was quantified by fluorescence spectroscopy using a fluorescence plate reader (FLx800, BioTek) with excitation and emission wavelengths of 485 and $528 \mathrm{~nm}$, respectively.

The apparent permeability coefficient $\left(P_{a p p}\right)$ was calculated by the following equation and expressed as $\mathrm{cm} / \mathrm{s}^{19}$ :

$$
\text { Papp }=\frac{[C b] \times V}{A \times[C 0] \times \Delta t}
$$

where $[C b](\mathrm{ppm})$ is the concentration of the molecule in the basolateral compartment at the end of the experiment, [C0] (ppm) is the initial apical concentration of the molecule, $V(\mathrm{~mL})$ is the volume of the basolateral compartment, $A$ is the surface area $\left(\mathrm{cm}^{2}\right)$ and $\Delta t$ is the duration of the experiment (s).

This analysis was performed in triplicate in at two independent experiments.

\subsubsection{Ketoprofen-loaded microparticles uptake experiments}

The permeation of pure ketoprofen and ketoprofen-loaded microparticles was evaluated in similar way as described above for $\mathrm{NaFl}$ (section 2.6.3.1.). To evaluate the effect of different administration forms of samples, ketoprofen and ketoprofen- 
loaded microparticles were tested as "solution", "dispersion" and "powder+KBR". "Solution" was prepared by previously dissolving the pure drug/drug-loaded microparticles in KRB (30 min, ultrasound bath), which was then applied as donor solution to the apical side of the cells. "Dispersion" was prepared by gently disperse the drug/drug-loaded microparticles in KRB, immediately before placing the sample in the apical side of cell layer. Finally, "powder+KBR" indicates that the samples were dissolved/dispersed in KRB after being directly dispersed onto the apical side of RPMI 2650 layer. In the last case, inserts were transferred to a separate plate to avoid possible contamination of adjacent inserts or basolateral compartments. The permeated ketoprofen was quantified with a UV-Visible Spectrophotometer (UVVis Genesys10uv spectrometer; Thermo Spectronic, $\lambda=258 \mathrm{~nm}$ ). Calibration was obtained by using standard samples with concentrations between 2 and $14 \mu \mathrm{g} / \mathrm{mL}$ $\left(R^{2}=0.9995\right)$. Each analysis was performed in duplicated or triplicate in at least three independent experiments. TEER measurements were performed immediately before the application of particles and at the end of the assay using KRB.

\subsubsection{Lactate dehydrogenase (LDH) assay}

The release of intracellular lactate dehydrogenase enzyme (LDH) into KRB buffer can be correlated with the extent of cell lysis. Hence, in order to verify possible cytotoxicity during permeation assays, LDH activity from the apical KRB samples was analyzed by observing the rate of oxidation of NADH to NAD coupled with the reduction of pyruvate to lactate at $340 \mathrm{~nm}$, as previously described by other authors 30-32. Cytotoxicity was calculated as percentage of the total LDH release from cells treated with $100 \mu$ l CelLytic M ( 5 min incubation with further centrifugation for 10 min/12000 G in Mikro 220R, Hettich, Tuttlingen, Germany). 


\subsection{Statistical Analysis}

All data are expressed as means \pm standard errors (SD) and individual experiments were performed at least in triplicate. The statistical analysis was done using SigmaStat $3.0^{\circledR}$ software. All values were tested for normal distribution and equal variance. When homogeneous variances were confirmed, data were analyzed by One Way Analysis of Variance (ANOVA) coupled with the Tukey's post-hoc analysis to identify means with significant differences.

\section{Results and discussion}

\subsection{RPMI 2650 cell culture and development of cell monolayer}

RPMI 2650 cell line was successfully cultured in MEM with $10 \%$ of serum, as reported and recomended by Reichl and co-authors ${ }^{14}$, growing rapidly and consistently. Two different seeding densities were tested, $0.4 \times 10^{5} \mathrm{cells} / \mathrm{cm}^{2}$ and 1.5 $\times 10^{5}$ cells $/ \mathrm{cm}^{2}$, the last of which with fast proliferation and $80 \%$ of confluence being reached after 3-4 days, proving to be the most efficient. By observation of monolayers under a light microscope, it was possible to verify the small size of RPMI 2650 cells and their ability to spread over the entire t-flask's surface (figure 1). Few aggregates were sometimes observed, as mentioned by Bai et al ${ }^{17}$. 


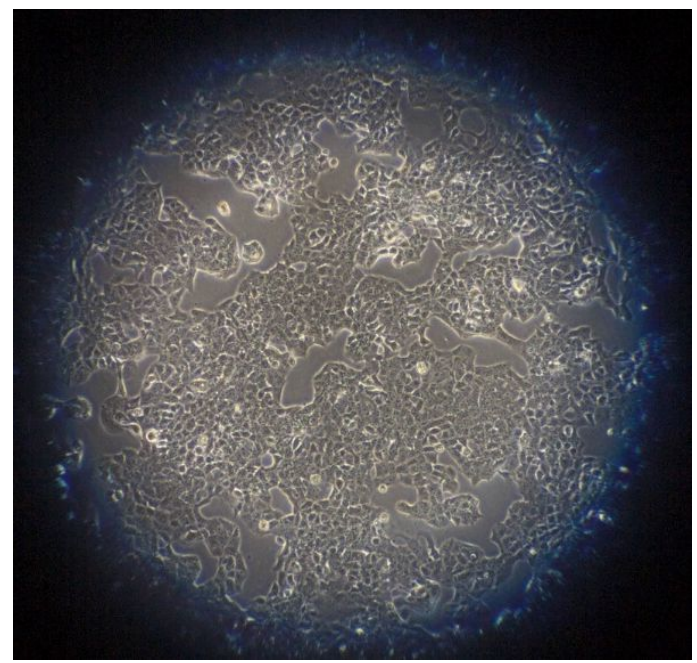

Figure 1| Eighty percent confluent RPMI 2650 monolayer grown in $75 \mathrm{~cm} 2$ T-flask under a light microscope (100x magnification)

RPMI 2650 cells were then seeded at $1.5 \times 105$ cells/cm2 density and subcultured into new flasks at 1:4 or 1:8 split ratio for the rest of experiments.

\subsection{Cell viability of RPMI 2650 monolayer after microparticles' exposure}

It is known that microparticles for intranasal administration should have mean particle size above $10 \mu \mathrm{m}$ and be mucoadhesive in order to stick to the moist surface of the nasal mucosa ${ }^{33,34}$. Additionally, it is important to assess the safety of microparticles in the nasal epithelium in order to guarantee the non-cytotoxic profile of the pharmaceutical formulations. For that purpose, and before performing the permeability studies, RPMI 2650 cell viability was studied after $1 \mathrm{~h}$ of incubation with pure ketoprofen and ketoprofen-loaded microparticles (100 and $250 \mathrm{ppm}$ ). This time of contact was chosen due to the fact that nasal mucus layer is renewed every $10-30 \min ^{35,36}$.

Prior to the assay, the incidence of UV irradiation during 15 hours directly into the drug and drug-loaded microparticles showed to be an effective sterilization 
method, as confirmed by the absence of microorganism's growth in TSA plates (data not show). This avoids the possible interference of microorganisms contamination that could lead to MTS reduction to formazan crystals contributing to overestimated absorbance ${ }^{27}$. The results of toxicity experiments revealed that the powders did not show cytotoxicity in the tested range of concentrations relatively to the control (100\% of cell viability, culture medium) after $1 \mathrm{~h}$ of incubation (Figure 2). A solution of $25 \%(\mathrm{v} / \mathrm{v})$ of DMSO in cell culture media was used as a positive cytotoxic control (final cellular viability of $35.9 \pm 3.9 \%, n=5$ ).

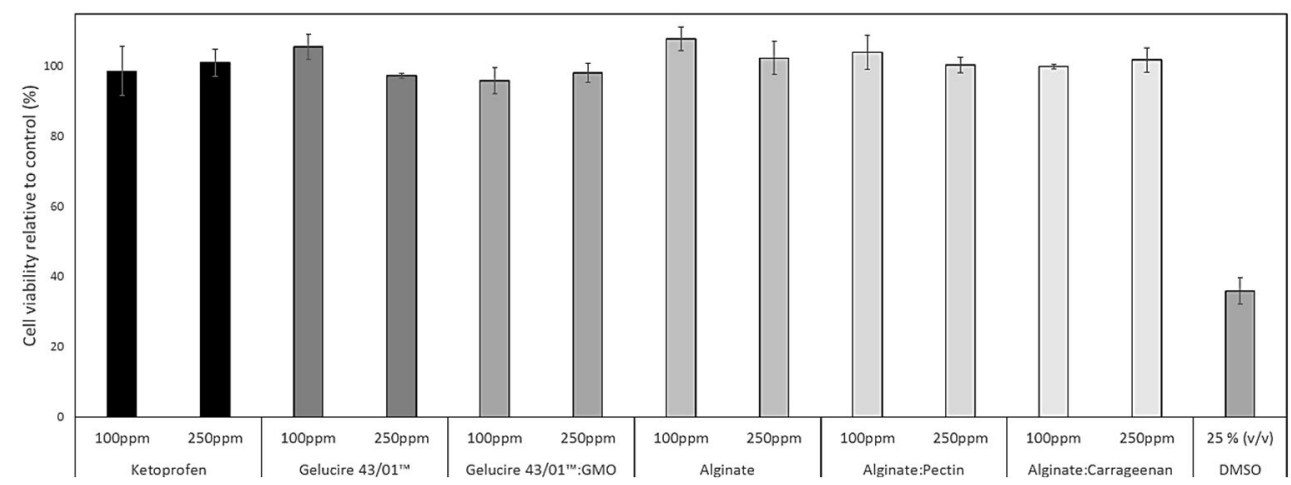

Figure 2| Cytotoxicity assay using MTS reagent: incubation of 100 and 250ppm of powders in RPMI 2650 cell line during $1 \mathrm{~h}$ at $37 \stackrel{\circ}{\circ} \mathrm{C}$ and $5 \% \mathrm{CO} 2$ humidified atmosphere (mean $\pm S D, n=3$ ). Solution of 25 $\%(v / v)$ of DMSO in cell culture media was used as a positive cytotoxic control.

These results demonstrated that pure ketoprofen and ketoprofen-loaded microparticles do not alter cell growth and thus can be recognized as non-cytotoxic and biocompatible materials to the cell culture model of the nasal barrier ${ }^{37}$. These results are similar to recent studies of alginate-based hybrids with other cell lines, such as Caco $2^{27}$ or $L 929$ cell lines ${ }^{38}$.

\section{3. $\quad$ RPMI 2650 as permeation model (ALI culture)}

In 2007, Bai and co-authors have concluded that culturing RPMI 2650 in an air-liquid interface enabled the development of tight junctions and thus is a mandatory culture condition when using this cell line as in vitro model for the evaluation of 
nasal drug delivery/permeation ${ }^{17}$. In 2012, Reichl and Becker have demonstrated that RPMI 2650 present TEER values and drug permeability similar to excised human nasal mucosa when cultured with MEM containing $10 \%$ serum on polyethylene terephthalate surface ${ }^{14}$. More recently, the expression of drug transporters was studied for the first time by Kreft et al $^{5}$. Dolberg and co-authors have studied and compared the expression and localization of P-glycoprotein in excised human nasal mucosa ${ }^{15}$. In this work, we wanted to further investigate and apply RPMI 2650 as an effective nasal epithelial model for the characterization of intranasal pharmaceutical formulations.

The TEER of RPMI 2650 cells, cultured on permeable polyethylene terephthalate filter inserts under LCC for 8 days followed by ALI condition for 2 weeks, was studied in this work, and the results are represented in figure 3.

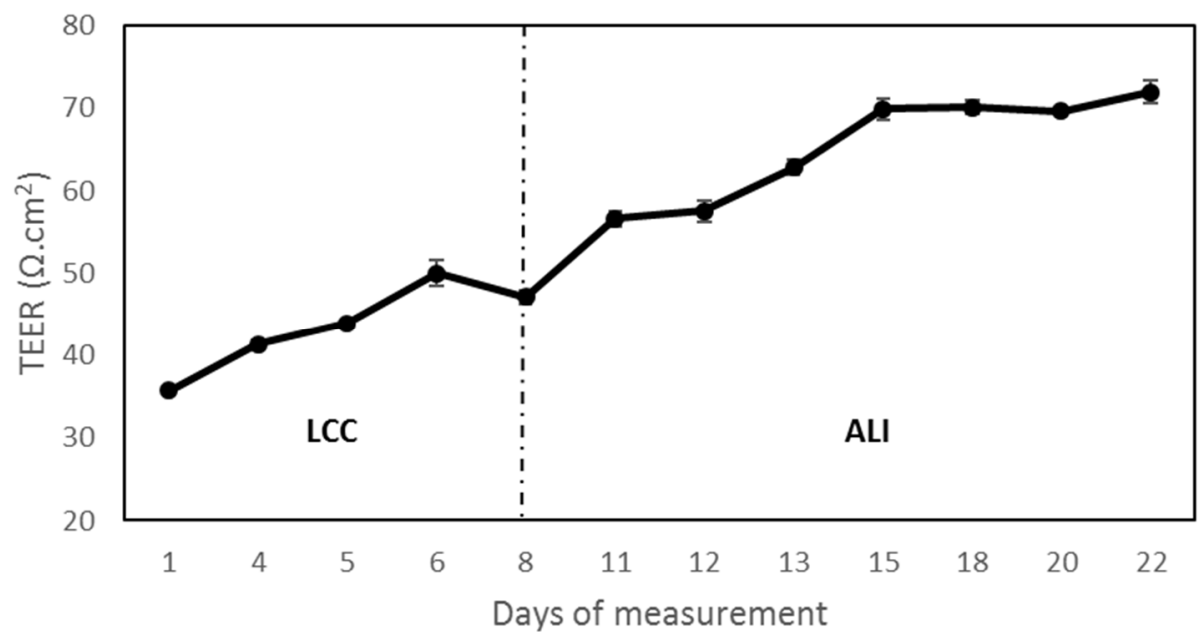

Figure 3| Transepithelial electrical resistance of RPMI 2650 cells cultured for 22 days with standard culture medium: 8 days under liquid-covered culture (LCC) plus 14 days under Air-liquid interface (ALI) (mean $\pm S D, n=3$ )

One important objective of this cell model is to mimic the barrier function of nasal epithelium tissue. Since the human nasal mucosa is a leaky epithelium, it presents 
lower TEER values (40-180 $\left.\Omega . \mathrm{cm}^{2}\right)$ compared to other epithelia, like intestinal or corneal ${ }^{2,5}$. It is possible to verify that our TEER's value increased until day 15 (about $70 \Omega . \mathrm{cm}^{2}$ ) from which has not changed substantially. Thus, these TEER results are similar to in vivo like situation, which is crucial for the validation of this model. Bai et al have reported TEER values around 140-190 $\Omega . \mathrm{cm}^{2}$, while Reichl and co-authors achieved TEER values 72-250 $\Omega . \mathrm{cm}^{2}$ 14,15,17. Kreft and co-authors obtained TEER values for air-liquid interface of $38-41 \Omega . \mathrm{cm}^{2}$, while for liquid-liquid culture the values were smaller and bellow the in vivo values, demonstrating the importance of the ALI culture for the development of tight junctions ${ }^{5}$. Therefore, RPMI 2650 cells cultured in ALI conditions presents itself as the best cell model to mimic human nasal mucosa in comparison with other available options, such as human primary nasal epithelial cells or EpiAirway ${ }^{\text {TM }}$ that present TEER valuer ranging from 200 to $3450 \Omega . \mathrm{cm}^{2}$, which are higher than in vivo situation ${ }^{14}$.

The nasal mucosa is also characterized by the presence of goblet cells responsible for the mucus secretion 7,33,35. Regarding RPMI 2650, there are still some doubts regarding the production of mucus, since some authors referred the inability of these cells to differentiate into goblet or ciliated cells and thus unable to produce mucus ${ }^{10}$. Yet, one of the key features of intranasal formulations is mucoadhesive capacity, thus it would be essential the presence of mucus in RPMI 2650 in order to mimic the in vivo situation so as to understand the interaction of formulations with the mucus layer present in the surface of nasal cells. In this work, alcian blue cell's staining was performed in order to evaluate if there was mucus production by RPMI 2650 cells ${ }^{28,29}$. From figure 4 it is possible to verify that mucus was successfully produced by RPMI 2650 since the first day of culture. 

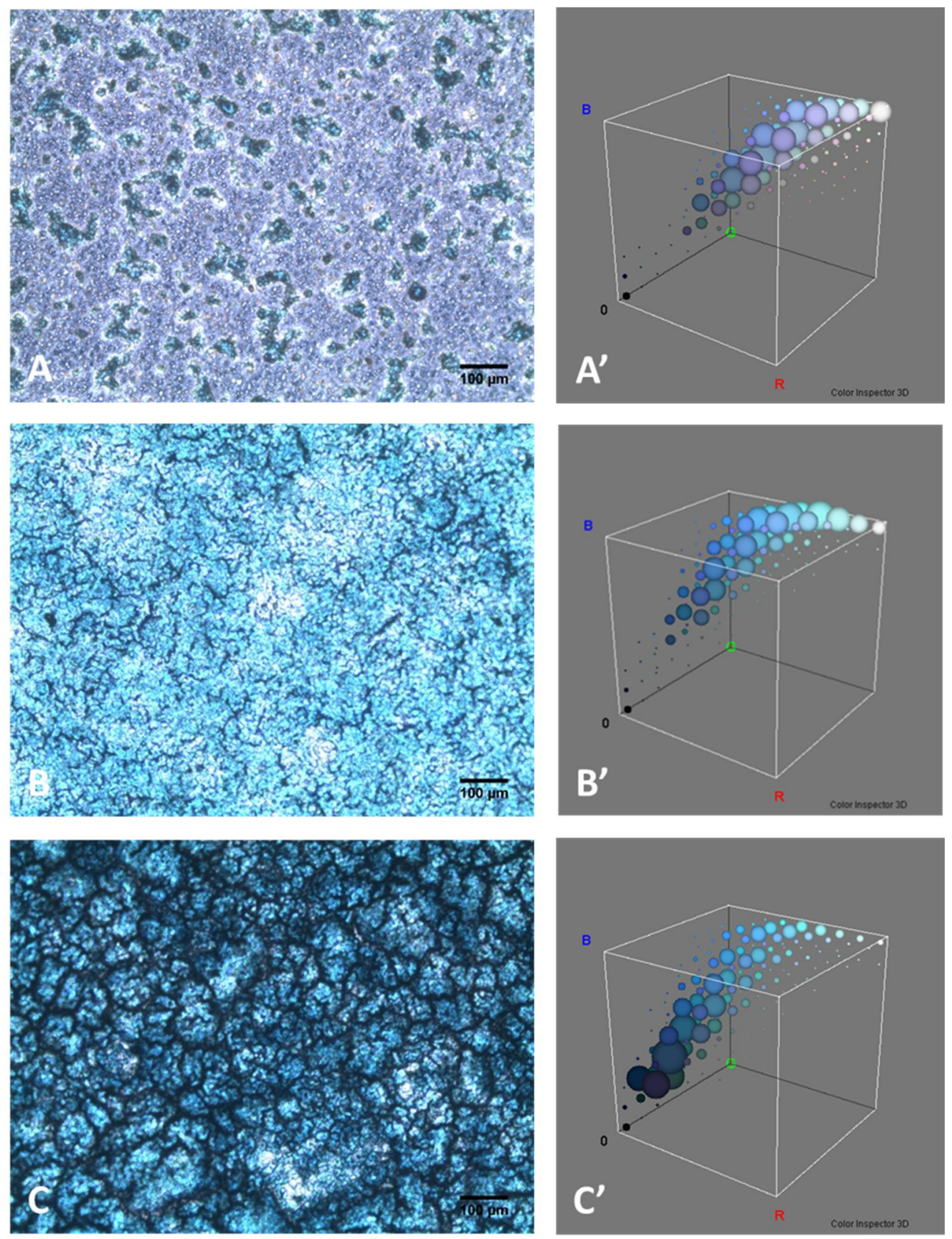

Figure 4| Mucus staining of RPMI 2650 cells at (A) day 1, (B) day 11 and (C) day 22. (A', B' and $C^{\prime}$ represent RGB color space analysis for A, B and C images 
A confluent mucus coat was observed on the apical surface of RPMI 2650 on day 8 and thereafter. Mucus secretion increased with respect to culture time until day $13-15$, and remained relatively constant from this time (measured by the $R_{G B} B_{B}$ ratio present in figure 5). This behavior is coincident with the increase in the TEER value. Nevertheless, and as already mentioned by other authors, the mucus' formation plateau could be due to a limitation of Alcian blue qualitative measurement technique ${ }^{28}$.

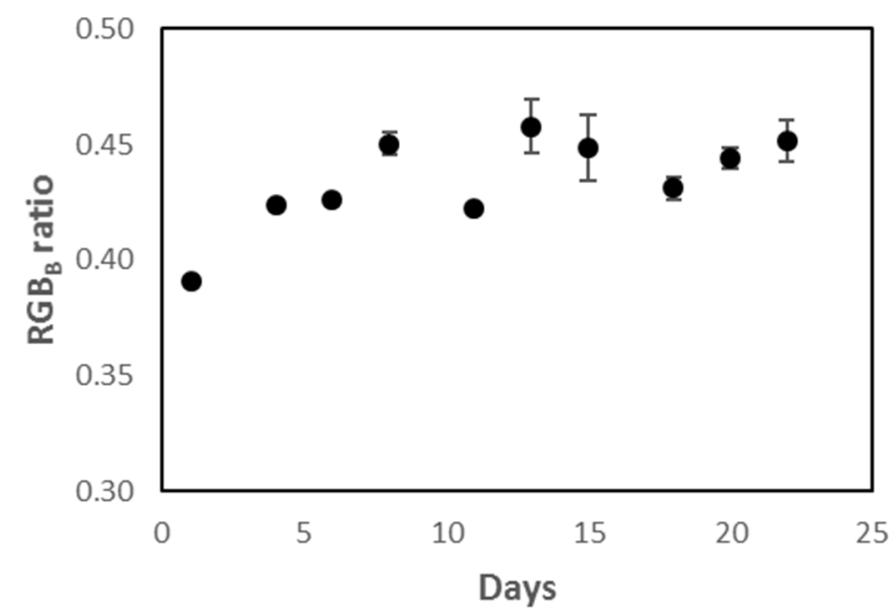

Figure 5| Plot of $R G B B$ ratio=RGBB/(RGBR + RGBG + RGBB) mucus staining as function of time in culture (mean $\pm S D, n=3$ )

These results confirm and are in agreement with authors that advocate the presence of goblet cells and mucus in this cell model ${ }^{5,17,19}$.

Finally, we studied the RPMI 2650 transepithelial permeability of sodium fluorescein (paracellular permeation marker) as the last step for the validation of this cell line as reliable model to mimic the nasal epithelium. The results are shown in table 2, where we compared our values to the ones obtained in a standard RPMI 2650 model $^{2}$, in an optimized RPMI 2650 model $^{14}$ and in human ex-vivo model ${ }^{39}$. 
Table 2| Permeation coefficients (Papp) of sodium fluorescein through RPMI 2650 model

\begin{tabular}{c|c} 
Nasal epithelial model & $\boldsymbol{P}_{\text {app }}$ Sodium fluorescein $\left(\mathbf{1 0}^{-6} \mathrm{~cm} / \mathrm{s}\right)$ \\
\hline Standard RPMI 2650 model (a) & $6.08 \pm 2.0$ \\
Optimized RPMI 2650 model (b) & $2.04 \pm 0.1$ \\
Our RPMI 2650 model & $2.4 \pm 0.2$ \\
Excised nasal mucosa (c) & $3.12 \pm 2.0$
\end{tabular}

Ref (a) Wengst and Reichl, 2010, Ref (b) Reichl and Becker, 2012 and Ref (c) Agu et al., 2001

It is possible to verify that our model led to Papp in the range as the fluorescein permeability reported for excised nasal mucosa, thus being a good alternative to ex vivo models for the evaluation of pharmaceutical formulations.

\subsection{Ketoprofen-loaded microparticles' permeability on RPMI 2650 cell layers}

Powders with mucoadhesive properties are an interesting alternative to liquid formulations for the intranasal delivery of drugs, not only due to their higher stability but also because of their ability for the attachment on the mucus layer before being dissolved and cleared ${ }^{33}$. After its administration through nasal powder devices, it is known that particle's properties can influence the delivery rate of drugs, namely particle size, shape, surface texture, contact area, hygroscopy or electrical properties ${ }^{25}$. Thus, in our study, we compare the permeability effectiveness of pure ketoprofen and ketoprofen-loaded particles, namely branched-shape lipid particles and porous spherical particles composed by biopolymers, through RPMI 2650 cell model. Moreover, some authors have shown that during in vitro investigation of respiratory epithelial drug permeability (namely, pulmonary delivery of drugs), the type of application of the test materials, such as powder, solutions or dispersions, has a great influence on the final outcome ${ }^{23-25}$. During in vivo situation, the particles are deposited in nasal mucosa, where it occurs its dissolution or release of drugs into nasal epithelial lining fluid (in the case of non- 
biodegradable or insoluble materials) followed by solute transport across the epithelium. Thus, the most accurate in vitro assay would be to deposit the particles directly into the cells. Nevertheless, the lack of solvent in the apical part would make difficult to accurately predict the administered concentration and the calculation of $\mathrm{P}_{\mathrm{app}}$ would be merely estimate. Therefore, the influence of application form of samples (ketoprofen and ketoprofen-loaded microparticles) tested as "solution", "dispersion" and "powder+KBR" was studied in this work. Higher amount of powders were used (fixed ketoprofen dose of $250 \mathrm{ppm}$ ), comparing to cytotoxicity experiments, in order to enable the detection of drug in the basolateral compartment ${ }^{40}$.

Figure 6 shows the apparent permeability coefficients of pure ketoprofen and 5 different formulations through RPMI 2650 cell multilayer after 60 min of its application as a solution, dispersion or powder+KBR. Since lipid particles (Gelucire $43 / 01^{\mathrm{TM}}$ ) and structured lipid particles (Gelucire $43 / 01^{\mathrm{TM}}: \mathrm{GMO}$ ) are not soluble in water or aqueous buffer, these formulations were only applied as dispersion or powder+KBR. 


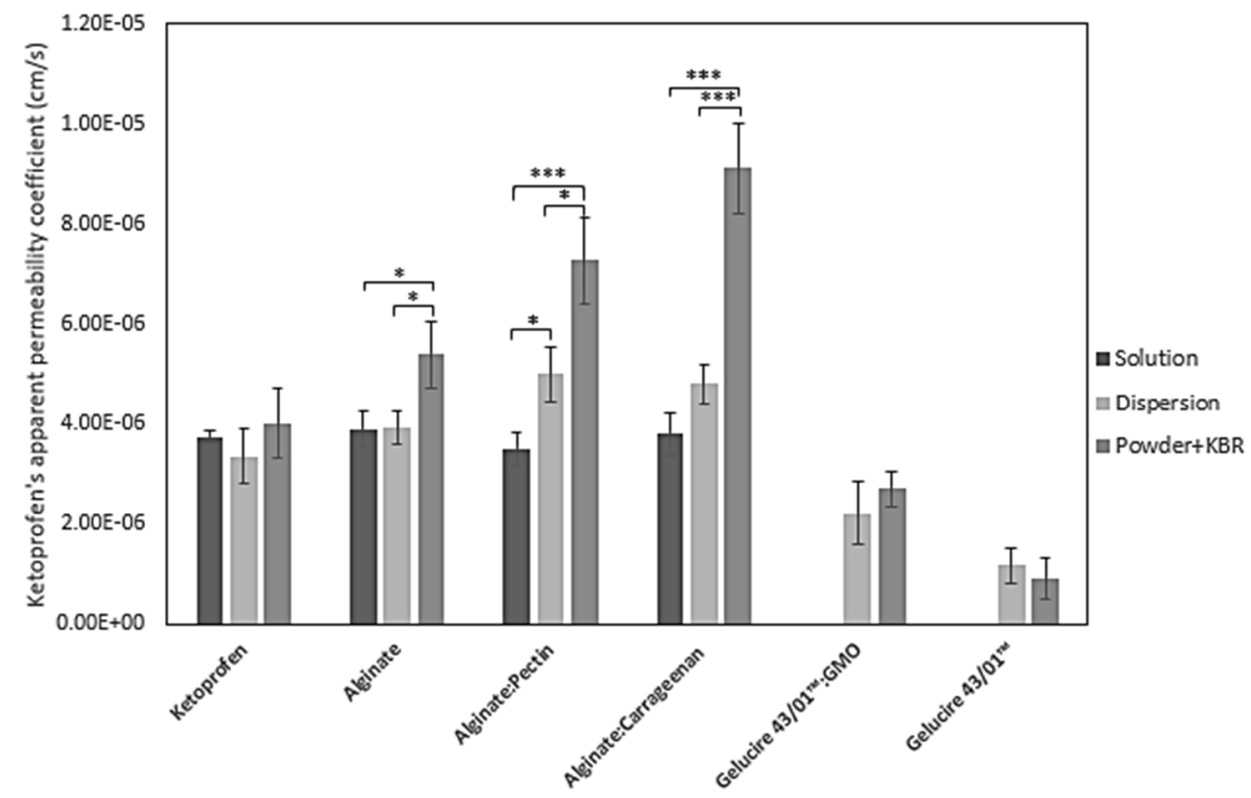

Figure 6| Effect of different administration forms (solution, dispersion or powder+KRB) on the apparent permeability coefficients of ketoprofen or ketoprofen-loaded microparticles through RPMI 2650 multilayer (mean $\pm S D, n \geq 3$ ); Statistical differences between same sample when administered in different forms are denoted as $* P<0.05 ; * * P<0.001$

It is possible to verify that in the case of aerogels, the final permeated drug strongly depended on the type of administration. The application of alginate-pectin as a dispersion was the only formulation to give different results $(p<0.05)$ in relation with the solution form. On the other hand, the application of the three alginatebased microparticles directly into the cells followed by the addition of buffer resulted in higher drug permeability compared with other types of administration with the same composition. This effect was more pronounced in case of Alginate:carrageenan, since the "powder+KRB" presented a 2.4 and 1.9 fold increase compared to "solutions" and "dispersion", respectively (statiscally difference $p<0.001$ ). Several authors have also reported the increase of drug permeation of powder formulations in comparison with solutions or dispersions when applied to pulmonary cells ${ }^{23-25,41}$. Asai and co-authors referred that the 
higher powder permeability compared to solution results in the increase in concentration-dependent passive transport through intercellular and intracellular route (that is, route-independent) due to the high drug concentration locally reached by dissolution of the powders in a small volume of mucus ${ }^{23}$. Nevertheless, in our results, it is possible to verify that the ketoprofent's $\mathrm{P}_{\mathrm{app}}$ of pure ketoprofen, Gelucire 43/01 ${ }^{\mathrm{TM}}$ and Gelucire 43/01 ${ }^{\mathrm{TM}}: \mathrm{GMO}$ was independent of the type of administration, since there is no statistically difference between different application form of samples. These results demonstrate and confirm that the properties of the powders affect the final outcome, that is, the degree of permeability of a drug. In figure 7 it is possible to see the same results but comparing the pure drug and different drug-loaded formulations when applied in the same way.

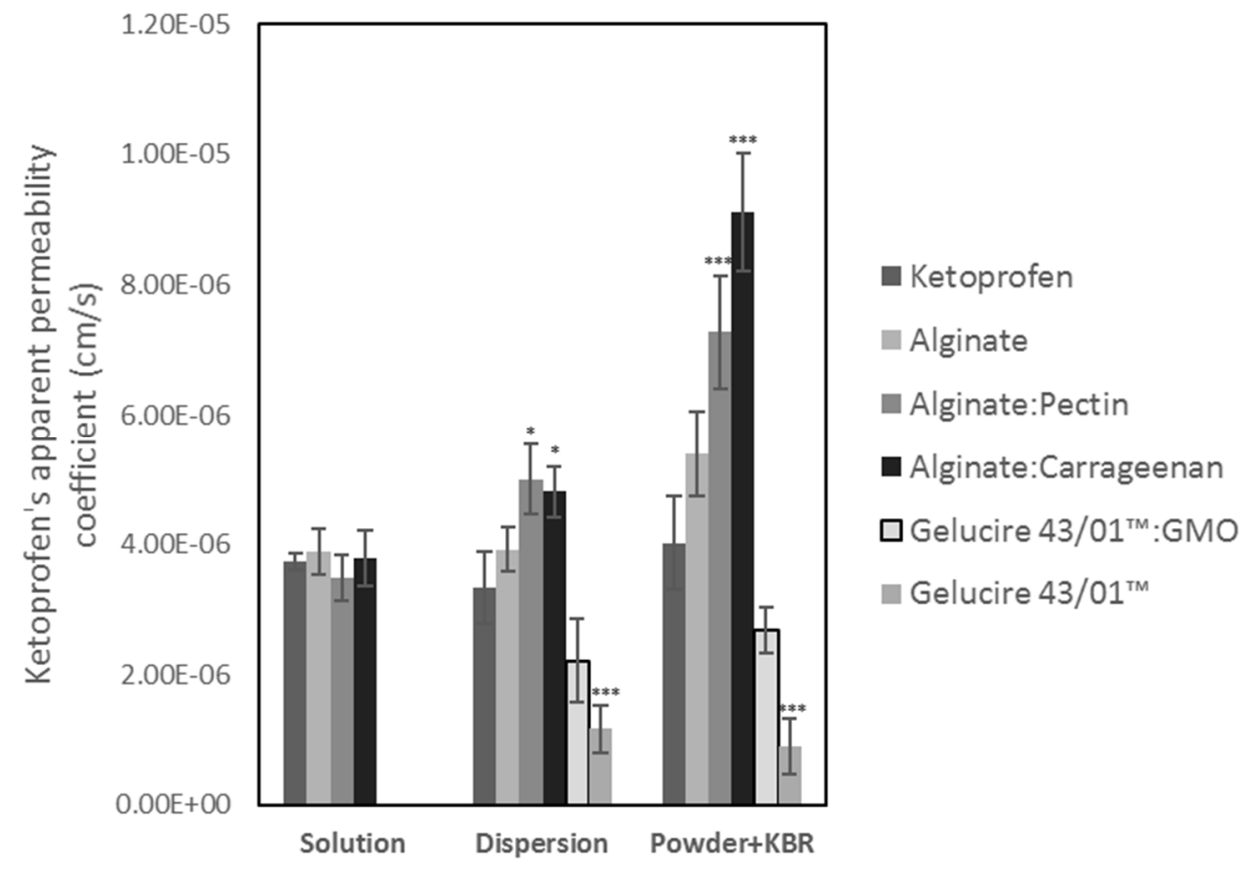

Figure 7 7 Effect of different formulations (ketoprofen or ketoprofen-loaded microparticles) on ketoprofen apparent permeability coefficients through RPMI 2650 multilayer when applied as solution, dispersion or powder+KRB (mean $\pm S D, n \geq 3$ ); Statistical differences in relation with pure ketoprofen when administered in the same form are denoted as $* \mathrm{P}<0.05 ;{ }^{* * *} \mathrm{P}<0.001$ 
When the powders were applied as a solution, there was no differences in the Papp of the drug between the samples testes. Grainger et al have mentioned that compounds in solution present a uniform concentration over the surface of the cell layer and so, the advantages of powder properties are lost, since everything is dissolved. ${ }^{24}$. Regarding the dispersion form of administration, the hybrid forms of alginate-based aerogels showed an increased permeation of ketoprofen $(p<0.05)$ while the solid lipid particle provided a reduced $\mathrm{P}_{\mathrm{app}}$ of the drug $(\mathrm{p}<0.001)$, probably due to a slower release of ketoprofen from this carrier material. The highest difference of drug permeability between samples was undoubtedly when applied as powder directly to the cells followed by the addition of buffer (powder+KRB). Once again the solid lipid particle Gelucire 43/01 ${ }^{\text {TM }}$ provided a decreased permeation of ketoprofen $(p<0.001)$. The addition of GMO to this lipid (Gelucire $43 / 01^{\mathrm{TM}}: \mathrm{GMO}$ ) increased somewhat the permeation of drug compared to solid lipid particles, probably due to the mucoadhesive properties of glyceryl monooleate, nevertheless it didn't increase ketoprofen' permeation in comparison with pure drug. Despite the swelling capacity of GMO, the structured lipid particle formulation is still a lipid formulation and thus it presents slower release of the drug. Hybrid alginate-pectin and alginate-carrageenan aerogels showed once again increased permeation of ketoprofen $(p<0.001)$ relative to pure API, with 1.8 and 2.3 increase fold respectively. Alginate and pectin are biopolymers known to have mucoadhesive properties and thus are capable to increase the time of contact with the mucosa increasing the absorbance of drugs 42,43 . Carrageenen is being increasingly investigated as a gelling agent/viscosity enhancing agent to be use as controlled release DDS prolonging the retention in the mucosa ${ }^{44}$. It would be expected that aerogels administered directly to RPMI 2650 cells would attach to the cell layer due to their mucoadhesive properties, with a saturated drug system produced immediately adjacent to the particles and increased permeation ${ }^{24}$. The fact that alginate microparticles didn't result in increase of ketoprofen's 
permeability compared to pure drug could be due to the higher drug loading in this sample in comparison with hybrid aerogels. Alginate aerogel has $24.9 \%$ of ketoprofen and thus $75.1 \%$ of pure alginate, while the hybrid microparticles have around $10 \%$ of drug and $90 \%$ of carrier material (of which $45 \%$ of alginate). Since we fixed the amount of drug, it is obvious that in the case of hybrid aerogels, the amount of carrier material would be very high in comparison with pure alginate, and probably this explains the higher permeation coefficients in the case of hybrid materials, showing that the presence of mucoadhesive agents are of extreme importance to increase the drug's permeability. Lastly, to mention that none of the formulations or types of administration affected the barrier properties of the cell multilayers, as indicated by practically the same TEER values before and after the deposition and the absence of cytotoxicity (LDH release, data not shown).

\section{Conclusions}

RPMI 2650 cells used in this work proved to be an appropriate alternative to excised nasal mucosa for the in vitro evaluation of nasal drug permeation. The cell model presented the ability to grow in monolayer and multilayer, showing the same permeability as excised mucosa for sodium fluorescein as paracellular marker, with similar TEER values and proof mucus production.

During the in vitro testing of different formulations performed in this work, it was demonstrated that not only the form of application of powders (solution, dispersion or powder) but also their physical and chemical properties can affect the final outcome of drug permeation. Pure ketoprofen and five different formulations (solid lipid particle, structured lipid particles and alginate-based aerogel microparticles) loaded with ketoprofen were tested. No differences were observed in the $\mathrm{P}_{\mathrm{app}}$ between the "solution", "dispersion" or "powder+KRB" forms of administration of pure drug or lipid particles. No differences were also seen 
between all the formulations when applied as solution. Nevertheless, the dry aerogel powders administered directly to the cell layer exhibited a permeationenhancing effect compared to the pure drug, probably due to the mucoadhesive properties of the carrier materials, without cytotoxicity, which is desirable as a useful intranasal solid formulation.

This work demonstrated that, with some possible limitations, RPMI 2650 cells in air-liquid interface culture could be used as screening tool (solid formulation-cell interaction, cytotoxicity and permeability) in the preclinical assessment of formulations for intranasal delivery of drugs.

\section{Acknowledgements}

This work was supported by Fundação para a Ciência e Tecnologia (FCT) through grant \#PEst-OE/EQB/LA0004/2011. V. S. S. Gonçalves is also grateful for the financial support from SFRH/BD/77350/2011 grant from FCT. A.A. Matias also acknowledges FCT for her FCT Investigator Starter Grant (IF/00723/2014). iNOVA4Health - UID/Multi/04462/2013, a program financially supported by FCT / Ministério da Educação e Ciência, through national funds and co-funded by FEDER under the PT2020 Partnership Agreement is acknowledged. The authors would like to thank Bárbara Cunha from iBET, Portugal, for the LDH assay protocol. V.S.S. would like to thank Dr Teresa Serra and Joana Poejo from iBET, Portugal, for the training in cell manipulation.

\section{References}

1 S. Lungare, J. Bowen and R. Badhan, J. Pharm. Sci., 2016, 105, 1209-1220.

2 A. Wengst and S. Reichl, Eur. J. Pharm. Biopharm., 2010, 74, 290-297.

3 S. K. Singh, P. Dadhania, P. R. Vuddanda, A. Jain, S. Velaga and S. Singh, RSC 
Adv., 2016, 6, 2032-2045.

4 O. Gartziandia, S. P. Egusquiaguirre, J. Bianco, J. L. Pedraz, M. Igartua, R. M. Hernandez, V. Préat and A. Beloqui, Int. J. Pharm., 2016, 499, 81-89.

5 M. E. Kreft, U. D. Jerman, E. Lasi??, T. L. Ri??ner, N. Hevir-Kene, L. Peternel and K. Kristan, Pharm. Res., 2015, 32, 665-679.

6 Y. Ozsoy, S. Gungor and E. Cevher, Molecules, 2009, 14, 3754-3779.

7 S. Grassin-Delyle, A. Buenestado, E. Naline, C. Faisy, S. Blouquit-Laye, L.-J. Couderc, M. Le Guen, M. Fischler and P. Devillier, Pharmacol. Ther., 2012, 134, 366-79.

8 L. Illum, Eur. J. Pharm. Sci., 2000, 11, 1-18.

9 C. Dufes, J.-C. Olivier, F. Gaillard, A. Gaillard, W. Couet and J.-M. Muller, Int. J. Pharm., 2003, 255, 87-97.

10 F. Sousa and P. Castro, in Concepts and Models for Drug Permeability Studies, Elsevier, 2016, pp. 83-100.

11 E. Gavini, a B. Hegge, G. Rassu, V. Sanna, C. Testa, G. Pirisino, J. Karlsen and P. Giunchedi, Int. J. Pharm., 2006, 307, 9-15.

12 A. Mistry, S. Stolnik and L. Illum, Int. J. Pharm., 2009, 379, 146-157.

13 S. Eskandari, J. Varshosaz, M. Minaiyan and M. Tabbakhian, Int. J. Nanomedicine, 2011, 6, 363-71.

14 S. Reichl and K. Becker, J. Pharm. Pharmacol., 2012, 64, 1621-1630.

15 A. M. Dolberg and S. Reichl, Int. J. Pharm., 2016.

16 J. Yoo, Y. Kim, S. Lee, M. Lee, H. Roh, B. Jhun, C. Lee and D. Kim, Pharm. Res., 2003, 20, 1690-1696.

17 S. Bai, T. Yang, T. J. Abbruscato and F. Ahsan, J. Pharm. Sci., 2008, 97, 1165-1178.

18 H. G. Peter, 1996.

19 L. Kürti, S. Veszelka, A. Bocsik, B. Ózsvári, L. G. Puskás, Á. Kittel, P. SzabóRévész and M. A. Deli, Cytotechnology, 2013, 65, 395-406.

20 R. J. Salib, L. C. Lau and P. H. Howarth, Clin. Exp. Allergy, 2005, 35, 811-9.

21 L. Kürti, S. Veszelka, A. Bocsik, N. T. K. Dung, B. Ózsvári, L. G. Puskás, Á. Kittel, P. Szabó-Révész and M. A. Deli, Toxicol. Vitr., 2012, 26, 445-454.

22 L. Kürti, R. Gáspár, Á. Márki, E. Kápolna, A. Bocsik, S. Veszelka, C. Bartos, R. Ambrus, M. Vastag, M. A. Deli and P. Szabó-Révész, Eur. J. Pharm. Sci., 2013, 50, 86-92.

23 A. Asai, T. Okuda, E. Sonoda, T. Yamauchi, S. Kato and H. Okamoto, Pharm. Res., 2016, 33, 487-497.

24 C. I. Grainger, L. L. Greenwell, G. P. Martin and B. Forbes, Eur. J. Pharm. Biopharm., 2009, 71, 318-324.

25 C. Meindl, S. Stranzinger, N. Dzidic, S. Salar-Behzadi, S. Mohr, A. Zimmer and E. Fr??hlich, PLoS One, 2015, 10, 1-19.

26 L. Li, K. Y. Y. Mak, J. Shi, C. W. W. H. C. H. Leung, C. M. M. Wong, C. W. W. H. C. H. Leung, C. S. K. S. K. Mak, K. Y. Y. Chan, N. M. M. M. M. Chan, E. X. X. 
Wu and P. W. T. W. T. Pong, Microelectron. Eng., 2013, 111, 310-313.

27 V. S. S. Gonçalves, P. Gurikov, J. Poejo, A. Matias, S. Heinrich, C. M. M. Duarte and I. Smirnova, Eur. J. Pharm. Biopharm., 2016.

28 M. Haghi, P. M. Young, D. Traini, R. Jaiswal, J. Gong and M. Bebawy, Drug Dev. Ind. Pharm., 2010, 36, 1207-14.

29 F. Pan, L. Han, Y. Zhang, Y. Yu and J. Liu, Int. J. Food Sci. Nutr., 2015, 66, 680-5.

30 B. Cunha, T. Aguiar, M. M. Silva, R. J. S. Silva, M. F. Q. Sousa, E. Pineda, C. Peixoto, M. J. T. Carrondo, M. Serra and P. M. Alves, J. Biotechnol., 2015, 213, 97-108.

31 B. Cunha, C. Peixoto, M. M. Silva, M. J. T. Carrondo, M. Serra and P. M. Alves, J. Memb. Sci., 2015, 478, 117-129.

32 G. Fotakis and J. A. Timbrell, Toxicol. Lett., 2006, 160, 171-177.

33 P. G. Djupesland, Drug Deliv. Transl. Res., 2013, 3, 42-62.

34 D. M. Vasa, L. A. O’Donnell and P. L. D. Wildfong, J. Pharm. Innov., 2015, 10, 200-210.

35 C. V. Pardeshi and V. S. Belgamwar, Expert Opin. Drug Deliv., 2013, 10, 957-72.

36 P. G. Djupesland, J. C. Messina and R. a Mahhoud, Ther. Deliv., 2014, 5, 709-733.

37 International Standard ISO 10993-5 Biological evaluation of medical devices - Part 5: Tests for cytotoxicity: in vitro methods, 2009, vol. $3 \mathrm{Ed}$.

38 M. Martins, A. a. Barros, S. Quraishi, P. Gurikov, S. P. Raman, I. Smirnova, A. R. C. Duarte and R. L. Reis, J. Supercrit. Fluids, 2015.

39 R. U. Agu, M. Jorissen, T. Willems, P. Augustijns, R. Kinget and N. Verbeke, J. Pharm. Pharmacol., 2001, 53, 1447-1456.

40 P. Artursson and J. Karlsson, in Pharmaceutical Applications of Cell and Tissue Culture to Drug Transport, Springer New York, Boston, MA, 1991, pp. 93-105.

41 S. Hein, M. Bur, U. F. Schaefer and C. M. Lehr, Eur. J. Pharm. Biopharm., 2011, 77, 132-138.

42 H. H. Tønnesen and J. Karlsen, Drug Dev. Ind. Pharm., 2002, 28, 621-630.

43 N. Thirawong, R. A. Kennedy and P. Sriamornsak, Carbohydr. Polym., 2008, 71, 170-179.

44 L. Li, R. Ni, Y. Shao and S. Mao, Carbohydr. Polym., 2014, 103, 1-11. 


\section{Chapter 6}

\section{Concluding Remarks \& Outlook}

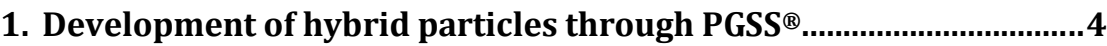

1.1. Solid and Structured lipid particles ....................................... 4

1.2. Core-shell particles............................................................... 6

2. Development of hybrid aerogel particles .......................................... 8

3. Evaluating nose-to-brain delivery systems using RPMI 2650 as in

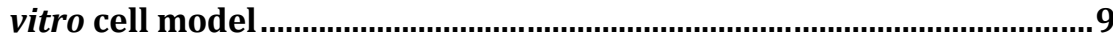

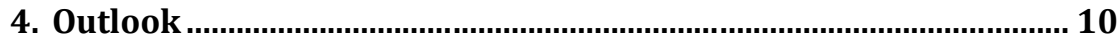

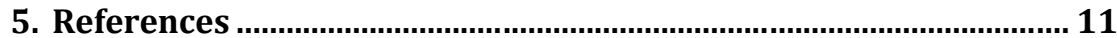


"Now this is not the end. It is not even the beginning of the end. But it is, perhaps, the end of the beginning"

Winston Churchill 
The research work described in this thesis aimed at explore and optimize supercritical fluid (SCF)-based precipitation and drying technologies to produce hybrid particulate structures with improved features for efficient nose-to-brain drug administration. For this pharmaceutical application, the hybrid drug delivery systems (DDS) produced through SCF technology would need to have specific characteristics, such as:

- particle size above $10 \mu \mathrm{m}$, so as to avoid particles' inhalation to the lungs;

- high porosity and consequently large surface area, in order to be loaded with great amount of drugs and provide the nasal mucosal with high local drug concentration; - mucoadhesive properties in order to guarantee a prolonged residence time in the nasal mucosa so as to not be quickly cleared;

- fast drug release, due to the rapid nasal mucociliary clearance;

- non cytotoxicity;

- provide highest drug permeation through nasal mucosa in comparison with pure drug.

Additional valuable knowledge regarding the production of particles using supercritical fluid technology can be gathered from the results obtained throughout the chapters of this thesis, on the subject of drug delivery systems. Novel hybrid particles have been deeply researched and specifically designed, combining different materials and taking advantage of $\mathrm{sc}-\mathrm{CO}_{2}$ based green technologies. Different physical, chemical or biological characterization was made so as to carefully analyze each delivery system which could provide insights into the structure-property relationships. This would allow a more confident design of hybrid particles for nose-to-brain delivery in the future.

The most important results obtained during this Ph.D. thesis are highlighted in this chapter. The main achievements, conclusions, as well as some challenges, are described in three sections composed by the two different approaches explored for 
the production of particles, namely, the development of hybrid particles by PGSS ${ }^{\circledR}$ and the production of aerogel hybrid microparticles, and by the final in vitro characterization of the DDS produced using a nasal cell model. Lastly, the outlook for future research is also presented.

\section{Development of hybrid particles through PGSS ${ }^{\circledR}$}

Despite all the progresses previously described in chapter 1 concerning the use of supercritical fluid-based precipitation techniques, in particular PGSS ${ }^{\circledast}$, for the production of hybrid particles as DDS, additional research was still required for the development of novel structures in order to meet the needs of the pharmaceutical industry ${ }^{1-3}$. Many researchers applied PGSS ${ }^{\circledR}$ technique for the precipitation of solutions or suspensions so as to produce polymer, lipid or hybrid particles, since it is an attractive and simple $\mathrm{CO}_{2}$-based precipitation process that eliminates the need of organic solvents ${ }^{4}$. Nevertheless, the use of this clean technique for the precipitation of mixtures of liquid and solid lipids (room and ambient temperature) in order to obtain the second generation of lipid particles (structured lipid particles) or its application for the precipitation from sc- $\mathrm{CO} 2$ saturated emulsions so as to produce core-shell particles had never been explored.

\subsection{Solid and Structured lipid particles}

In part I of Chapter 2 it was highlighted that it is mandatory to perform fundamental research for each system to be precipitated through PGSS ${ }^{\circledR}$. The effect of several operating parameters of $\mathrm{PGSS}^{\circledR}$ process on the size and morphology of single component lipid particles, namely temperature, pressure, nozzle diameter, and the co-precipitation with a model drug, were investigated. During this study it was possible to verify that as the complexity of the components of the lipid matrices 
was increased, unique thermodynamic properties were obtained during the atomization step. Thus, despite all the theories available for the general behavior of a molten compound in the presence of $\mathrm{sc}_{-} \mathrm{CO}_{2}$, and the influence of PGSS ${ }^{\circledR}$ operating conditions on the final features of the particles produced, there are always compounds whose behavior is impossible to predict. This is especially important in the case of precipitation of mixtures of substances that will lead to the production of hybrid particles.

In view of the above mentioned aspects, fundamental research was also essential to be performed before the successfully production of structured lipid particles in Chapter 2, Part II. PGSS ${ }^{\circledR}$ process proved to be a greener alternative for the production of these $2^{\text {nd }}$ generation of lipid particles in comparison with techniques that use organic solvents, or even a better alternative in comparison with spray chilling. The homogeneous mixture of a liquid mucoadhesive lipid, glyceryl monooleate (GMO), with solid glycerolipids was strongly dependent on the hydrophilic-lipophilic balance (HLB) of each component. The newly hybrid particles produced showed to have higher storage stability, higher encapsulation efficiency with immediate release of model drug (ketoprofen) from its matrix and higher permeation through a mucous-membrane model (Franz Cell) in comparison with single glycerolipid particles.

Mucoadhesive systems used in mucosal drug delivery are usually composed of polymeric materials, such as cellulose derivatives, chitosan or polyacrylates ${ }^{5}$. It is not common to find in literature lipids with mucoadhesive properties, being GMO one example of a lipid with this feature, if not the only one. Therefore, most of the mucoadhesive assays described in the literature are not targeted for lipid or structured lipid particles. In fact, during this Ph.D. project, one difficulty was to determine the mucoadhesion of the structured lipid systems produced due to the non-applicability of some well-established methods (often used for polymeric systems), with the occurrence of some interferences resulting in unreliable results. 
The mucoadhesive characteristics of glyceryl monooleate were previously investigated through "flushing" bioadhesive test and tensiometric method by Nielsen and co-authors, revealing that the mechanism of mucoadhesion is unspecific and involving dehydration of the mucosa ${ }^{6,7}$. Therefore, we assume that the addition of GMO to a lipid formulation would provide mucoadhesion to the final delivery system, which was somehow proven by the results from Franz cell assay.

\subsection{Core-shell particles}

The recent advancements in the field of pharmaceutical technology have led to the development of abundant hybrid particles, such as core-shell delivery systems. Yet, core-shell particles are usually produced by emulsion/double emulsion solvent evaporation process or other techniques involving organic solvents which have been recognized as hazardous to human health and environment. Thus, in order to introduce a sustainable and GRAS (Generally recognized as safe) alternative in line with consumer concerns and regulatory demands, we aimed at adapting PGSS ${ }^{\circledR}$ technique for production of core-shell particles.

In this Ph.D. dissertation, and referred in Chapter 3, it was possible to produce for the first time ketoprofen-loaded hybrid particles constituted by lipid Gelucire $43 / 01^{\mathrm{TM}}$ multicores involved by a polymeric shell of polyethylene glycol (PEG) 4000. The coverage of particles surface with PEG, a biocompatible, hydrophilic and biologically inert polymer, was intended to achieve rapid penetration in nasal mucus ${ }^{8}$. On the other hand, the use of Gelucire ${ }^{\circ} 43 / 01$, a lipid that acts as protective agent against light, oxidation and moisture, promotes the penetration and absorption of drugs into the epithelial cells ${ }^{9,10}$. Owing to the fact that PEG 4000 and Gelucire $43 / 01$ are carriers completely immiscible with each other due to the large difference in their HLB values, there was the concern of independent precipitation of each material. In order to avoid it, an O/W emulsion constituted by the lipid as the discontinuous phase and by an aqueous solution containing the 
polymer as continuous phase was produced and then precipitated through PGSS ${ }^{\circledast}$. During this work, it was clearly mandatory to study the stability of the emulsion in the presence of $\mathrm{sc}_{-} \mathrm{CO}_{2}$ using a high pressure view cell, in order to determine the range of temperature and pressure within which the emulsion remained stable during pressurization and depressurization.

Since the emulsion was composed by several Gelucire $43 / 01^{\mathrm{TM}}$ droplets dispersed in the water phase, particles with submicron-multicores of Gelucire $43 / 01^{\mathrm{TM}}$ inside the polymer shell were obtained. To evaluate and prove the organization of the carrier materials and particles structure, a combination of several characterization methods was applied, namely focused ion beam (FIB), transmission electron microscopy (TEM) and Differential scanning calorimetry (DSC).

$\mathrm{PGSS}^{\circledR}$ is not a typical process to produce particles from aqueous solutions, as in the case of spray dryer, and, moreover, it was never used to obtain particles from an emulsion constituted by two carriers. During this project, it was possible to produce particles from an $\mathrm{O} / \mathrm{W}$ emulsion, by modifying the process with the introduction of heated compressed air. The two fluid nozzle in the apparatus allowed an external mixing of the heated compressed air and the gas saturated solution, obtaining a better drying capacity. This new developed method to obtain particles from an emulsion could be not only a greener substitute to the conventional emulsion solvent evaporation that uses organic solvents, but also an alternative to PGSS-drying without using large quantities of $\mathrm{CO}_{2}$ to dry the particles 11-13.

Nevertheless, the particles produced in this chapter had mean particles sizes above $200 \mu \mathrm{m}$ with wide particle size distribution, and thus, despite being a proof of concept on how it is possible to produce multicore-shell particles loaded with drugs by $\mathrm{PGSS}^{\circledR}$, its use as a drug delivery system specifically for nose-to-brain administration was not further evaluated. 


\section{Development of hybrid aerogel particles}

It is known that the use of supercritical $\mathrm{CO}_{2}$ for alcogels drying enables the preservation of the gel matrix and the obtaining of extremely porous aerogels. Nevertheless, it was highlighted in Chapter 1 that there was still much to do in the field of aerogels, particularly related to its application as drug delivery systems ${ }^{14}$. Although some research has been made since the beginning of this thesis, covering some aspects of oral drug delivery or the development of hybrid aerogels as scaffolds for tissue engineering, there was no application of these structures, simple or hybrid, for intranasal administration of drugs ${ }^{15-17}$. The research work described in Chapter 4 addressed the production of alginate-based hybrid aerogel microparticles for intranasal delivery of drugs, using as second biopolymers pectin or carrageenan. With the objective to obtain microparticles in the range size of tens of microns, we further developed emulsion gelation method, by adding acetic acid in the form of a microemulsion. The HLB of the surfactants used during the emulsion gelation process proved to be one of the key parameters that influence the final particle size and porosity of the aerogels. Pectin revealed better interaction with alginate, increasing the degree of cross-linking between both polysaccharides, which resulted in higher specific surface area and lower shrinkage found in the alginate-pectin aerogels in comparison with alginate-carrageenan. The spherical hybrid microparticles produced presented mesoporous structure with high specific surface area $\left(>300 \mathrm{~m}^{2} \mathrm{~g}^{-1}\right)$ and mucoadhesive properties. It was possible to load drugs with different polarities in these structures, either in aqueous phase, ethanol phase or by supercritical $\mathrm{CO}_{2}$ impregnation, with maintenance of drug's properties and amorphous state. Moreover, hybrid aerogel produced showed fast release of drugs due to its hydrophilic nature, which makes these carriers appropriate for intranasal delivery of drugs, since nasal mucus clearance quickly removes DDS from the surface of mucosa. 


\section{Evaluating nose-to-brain delivery systems using RPMI 2650 as in vitro cell model}

Despite all the progress made concerning the use of Caco-2 cell lines as a valid model to evaluate oral dosage formulations, very little has been done in relation to RPMI 2650 cell line for nasal applications, and thus, additional research was still required. Bearing this in mind, the last goal of this Ph.D. thesis (Chapter 5) was to explore RPMI 2650 as a valid in vitro nasal model for the evaluation of the hybrid particles produced (structured lipid particles and aerogel microparticles) as effective DDS for intranasal administration. RPMI 2650 cell line showed to be an alternative to excised nasal mucosa and in vivo assays for the evaluation of nasal solid formulations cytotoxicity or drug permeation. The cell model presented same permeability as excised human nasal mucosa, with similar transepithelial electrical resistance (TEER) values and proof mucus production. During the evaluation of the solid formulations, it was demonstrated that not only the form of application (solution, dispersion or powder) but also their physical and chemical properties affected the final outcome of drug permeation. From all the formulations tested, hybrid aerogel microparticles applied as powders directly into the cells showed higher drug permeability compared with other types of formulations or forms of administration. These formulations presented the ability to attach to the cell layer, probably owing to their mucoadhesive properties, with consequently high drug concentration locally reached by dissolution of the powders in a small volume of mucus, leading to higher permeation through the nasal cell layer ${ }^{18,19}$. The presence of mucoadhesive agents showed to be of extreme importance to increase the drug's permeability, which was mainly noticed in hydrophilic DDS whose structure is rapidly solubilized in the nasal mucus. None of the particles showed cytotoxicity. 
Chapter 6

\section{Outlook}

Despite the innovative results regarding the use of supercritical fluids for the PGSS ${ }^{\circledR}$ precipitation of drug delivery systems, the development of models that could accurately predict the characteristics of the final product still constitutes the great challenge that scientists in the field have to address, so that this technique could be scaled-up and its use become widespread ${ }^{4}$.

Concerning particles' characterization, flowability should also be assessed in order to guarantee particles' aerosolization for appropriate nasal deposition, as new methods to determine mucoadhesion should be developed, especially in the case of lipid formulations.

Regarding the use of RPMI 2650 cell line to evaluate nasal formulations, despite the confirmed presence of mucus, further research should be done in order to study the mucin expression (types of mucin) and the absolute mucin content so as to better understand the type of interactions between drug delivery systems and the mucus present at the cells surface. Efforts should be done in order to have drug permeation profiles and to further understand the drug transport mechanisms. Furthermore, to note that this model does not present ciliated cells, preventing the simulation of mucociliary clearance present in vivo. Regarding the deposition of the particles into the cells surface, the use of a deposition device could guarantee an easy and uniform dispersal of powders into the cells, with the advantage to precisely control the dose administered ${ }^{19,20}$. Still, this work demonstrated that, with some possible limitations, RPMI 2650 cells in air-liquid interface culture could in fact be used as in vitro model for drug permeation in the preclinical assessment of formulations for intranasal delivery of drugs.

On the other hand, another concern is the lack of data under real in vivo conditions. The evaluation of the behavior of hybrid particles with body nasal temperature, humidity and exposed to different chemical environments (e.g. presence of 
enzymes), is crucial for their final application in nose-to-brain delivery of drugs. Moreover, it would be necessary to test and choose the most appropriate nasal drug delivery device to use in a clinical perspective ${ }^{21}$.

Still, this Ph.D. thesis shows, undoubtedly, that supercritical fluids can be a green pharmaceutical technology to be used by pharmaceutical industry in order to develop particles with tailored features for different routes of administration.

\section{References}

1 M. Vijayaraghavan, S. Stolnik, S. M. Howdle and L. Illum, Int. J. Pharm., 2013, 441, 580-8.

2 I. Espírito Santo, A. São Pedro, R. Fialho and E. Cabral-Albuquerque, Nanoscale Res. Lett., 2013, 8, 386.

3 A. Tabernero, E. M. Martín del Valle and M. A. Galán, Chem. Eng. Process. Process Intensif., 2012, 60, 9-25.

$4 \quad$ A. V. M. Nunes and C. M. M. Duarte, Materials (Basel)., 2011, 4, 20172041.

5 L. Jiang, L. Gao, X. Wang, L. Tang and J. Ma, Drug Dev. Ind. Pharm., 2010, 36, 323-336.

6 S. Milak and A. Zimmer, Int. J. Pharm., 2015, 478, 569-587.

7 L. S. Nielsen, L. Schubert and J. Hansen, Eur. J. Pharm. Sci., 1998, 6, 231-9.

8 X. Zhang, H. Zhang, Z. Wu, Z. Wang, H. Niu and C. Li, Eur. J. Pharm. Biopharm., 2008, 68, 526-34.

9 S. K. Jain and A. Gupta, AAPS PharmSciTech, 2009, 10, 1128-36.

10 A. R. Sampaio de Sousa, M. Calderone, E. Rodier, J. Fages and C. M. M. Duarte, J. Supercrit. Fluids, 2006, 39, 13-19.

11 M. J. A. M. Tobio, R. Gref, A. Sánchez, R. Langer, Pharm. Res., 1998, 15, 270-275.

12 Á. Martín and E. Weidner, J. Supercrit. Fluids, 2010, 55, 271-281.

13 Á. Martín, H. M. Pham, A. Kilzer, S. Kareth and E. Weidner, Chem. Eng. Process. Process Intensif., 2010, 49, 1259-1266.

14 Z. Ulker and C. Erkey, J. Control. Release, 2014, 177, 51-63.

15 C. A. García-González, M. Jin, J. Gerth, C. Alvarez-Lorenzo and I. Smirnova, Carbohydr. Polym., 2015, 117, 797-806.

16 S. Quraishi, M. Martins, A. A. Barros, P. Gurikov, S. P. Raman, I. Smirnova, A. R. C. Duarte and R. L. Reis, J. Supercrit. Fluids, 2015, 105, 1-8.

17 M. Martins, A. a. Barros, S. Quraishi, P. Gurikov, S. P. Raman, I. Smirnova, 
Chapter 6

A. R. C. Duarte and R. L. Reis, J. Supercrit. Fluids, 2015.

18 C. I. Grainger, L. L. Greenwell, G. P. Martin and B. Forbes, Eur. J. Pharm. Biopharm., 2009, 71, 318-324.

19 A. Asai, T. Okuda, E. Sonoda, T. Yamauchi, S. Kato and H. Okamoto, Pharm. Res., 2016, 33, 487-497.

20 S. Hein, M. Bur, U. F. Schaefer and C. M. Lehr, Eur. J. Pharm. Biopharm., 2011, 77, 132-138.

21 P. G. Djupesland, Drug Deliv. Transl. Res., 2013, 3, 42-62. 




\section{www.itqb.unl.pt}

"Everything is theoretically impossible, until it is done."

Robert A. Heinlein 